Florida International University FIU Digital Commons

$11-12-2010$

\title{
4-Hydroxy Estradiol-Induced Oxidant-Mediated Signaling Is Involved In The Development Of Breast Cancer
}

Victor Okoh

Florida International University, okoh.victor@gmail.com

DOI: $10.25148 /$ etd.FI1 1041501

Follow this and additional works at: https://digitalcommons.fiu.edu/etd

\section{Recommended Citation}

Okoh, Victor, "4-Hydroxy Estradiol-Induced Oxidant-Mediated Signaling Is Involved In The Development Of Breast Cancer" (2010). FIU Electronic Theses and Dissertations. 348.

https://digitalcommons.fiu.edu/etd/348 


\title{
FLORIDA INTERNATIONAL UNIVERSITY
}

Miami, Florida

\section{4-HYDROXY ESTRADIOL-INDUCED OXIDANT-MEDIATED SIGNALING IS INVOLVED IN THE DEVELOPMENT OF BREAST CANCER}

\author{
A dissertation submitted in partial fulfillment of the \\ requirements for the degree of \\ DOCTOR OF PHILOSOPHY \\ in \\ PUBLIC HEALTH \\ by \\ Victor Onyishi Okoh
}

2011 
To: Interim Dean Michele Ciccazzo

College of Arts and Sciences

This dissertation, written by Victor Onyishi Okoh, and entitled 4-Hydroxy EstradiolInduced Oxidant-Mediated Signaling is Involved in the development of Breast cancer, having been approved in respect to style and intellectual content, is referred to you for judgment.

We have read this dissertation and recommend that it be approved.

$\begin{array}{r}\hline \text { Alejandro Barbieri } \\ \hline \text { Jai Parkash } \\ \hline \text { Dentin Felty } \\ \hline \text { Deodutta Roy, Major Professor }\end{array}$

Date of Defense: November 12, 2010

The dissertation of Victor Onyishi Okoh is approved.

\author{
Interim Dean Michele Ciccazzo \\ R.Stempel College of Public Health and Social Work
}

Interim Dean Kevin O'Shea

University Graduate School

Florida International University, 2011 


\section{DEDICATION}

I dedicate this thesis to my family (Stella, Onyenka, Isioma and Ifeoma) for their patience and sacrifices during the course of this program. I also dedicate this thesis to my late brother Ikechukwu Okoh for being a class act in his brief time on earth. 


\section{ACKNOWLEDGMENTS}

I would like to acknowledge my mentor Dr. Roy, as well as my committee members Drs.

Barbieri and Parkash, for their technical and moral support in completion of this thesis. 


\title{
ABSTRACT OF THE DISSERTATION \\ 4-HYDROXY ESTRADIOL-INDUCED OXIDANT-MEDIATED SIGNALING IS INVOLVED IN THE DEVELOPMENT OF BREAST CANCER
}

\author{
by \\ Victor Onyishi Okoh \\ Florida International University, 2011 \\ Miami, Florida \\ Professor Deodutta Roy, Major Professor
}

Breast cancer is a disease associated with excess exposures to estrogens. While the mode of cancer causation is unknown, others have shown that oxidative stress induced by prolonged exposure to estrogens mediates renal, liver, endometrial and mammary tumorigenesis though the mechanism(s) underling this process is unknown. In this study, we show that 4-hydroxyl 17 $\beta$-estradiol (4-OHE2), a catechol metabolite of estrogen, induces mammary tumorigenesis in a redox dependent manner. We found that the mechanism of tumorigenesis involves redox activations of nuclear respiratory factor-1 (NRF1); a transcriptions factor associated with regulation of mitochondria biogenesis and oxidative phosphorylation (OXPHOS), as well as mediation of cell survival and growth of cells during periods of oxidative stress. Key findings from our study are as follows: (i) Prolonged treatments of normal mammary epithelial cells with 4-OHE2, increased the formation of intracellular reactive oxygen species (ROS). (ii) Estrogen-induced ROS activates redox sensitive transcription factors NRF1. (iii) 4-OHE2 through activation of serine-threonine kinase and histone acetyl transferase, phosphorylates and acetylate NRF1 respectively. (iv) Redox mediated epigenetic modifications of NRF1 facilitates 
mammary tumorigenesis and invasive phenotypes of breast cancer cells via modulations of genes involved in proliferation, growth and metastasis of exposed cells. (v) Animal engraftment of transformed clones formed invasive tumors. (vi) Treatment of cells or tumors with biological or chemical antioxidants, as well as silencing of NRF1 expressions, prevented 4-OHE2 induced mammary tumorigenesis and invasive phenotypes of MCF-10A cells. Based on these observations, we hypothesize that 4OHE2 induced ROS epigenetically activate NRF1 through its phosphorylation and acylation. This, in turn, through NRF1-mediated transcriptional activation of the cell cycle genes, controls 4-OHE2 induced cell transformation and tumorigenesis. 
I. INTRODUCTION

II. HYPOTHESIS, SPECIFIC AIMS AND RELEVANCE OF FINDINGS

III. LITERATURE REVIEW: ESTROGEN-INDUCED REACTIVE OXYGEN SPECIES-MEDIATED SIGNALING CONTRIBUTE TO BREAST CANCER

Abstract

Introduction

Generation of genotoxic metabolites of estrogen as a potential mechanism of breast carcinogenicity

Estrogen receptor mediated carcinogenic actions

Estrogen, mitochondria, and ROS generation

Estrogen and mitochondria

Mitochondria and generation of estrogen induced ROS

Estrogen-induced ROS-mediated oxidative DNA damages 23

Estrogen-induced ROS mediated redox signalings 25

Regulation of phosphatases by estrogen-induced ROS 26

Activation of kinases by estrogen-induced ROS 30

A-Raf

ERK

AKT

Activation of redox sensitive transcription factors by estrogeninduced oxidants signaling

NRF1

Role of estrogen-induced redox signaling in the development of breast cancer

Estrogen-induced ROS as potential mediator of cell transformation and generators of human breast cancer stem cells 
IV. REACTIVE OXYGEN SPECIES CAUSES NEOPLASTIC TRANSFORMATION AND XENOGRAFT GROWTH OF 4HYDROXY ESTRADIOL-TRANSFORMED MAMMARY EPITHELIAL CELLS VIA TRANSDUCTION OF REDOX SIGNALS TO PI3K/AKT

Abstract

Introduction 94

Materials and methods $\quad 96$

$\begin{array}{lr}\text { Results } & 104\end{array}$

Discussions 110

$\begin{array}{ll}\text { List of references } & 120\end{array}$

$\begin{array}{ll}\text { Figures and legends } & 128\end{array}$

V. ESTROGEN-INDUCED REDOX SIGNALING OF NRF1 MEDIATES IN VITRO GROWTH AND METASTASIS OF BREAST CANCER CELLS

Abstract 139

Introduction 140

Materials and methods $\quad 142$

Results $\quad 149$

Discussions 155

List of references 161

$\begin{array}{ll}\text { Figures and legends } & 170\end{array}$

VI. THE ACTIVATION OF NRF1 BY ESTROGEN IS

NECESSARY FOR BREAST CANCER SUSCEPTIBILITY TO

DEVELOP A MALIGNANT PHENOTYPE AND FOR

INVASIVE GROWTH OF BREAST TUMORS 179

$\begin{array}{ll}\text { Abstract } & 179\end{array}$

Introduction $\quad 180$

Materials and methods $\quad 183$

$\begin{array}{lr}\text { Results } & 189\end{array}$

Discussions $\quad 191$

List of references 194

$\begin{array}{ll}\text { Figures and legends } & 199\end{array}$

$\begin{array}{ll}\text { VITA } & 208\end{array}$ 


\section{LITERATURE REVIEW}

1. Scheme showing metabolism of estrogen and redox cycling of its metabolites

2. Estrogen induced cellular responses including carcinogenicity and growth of cancer cell do not correlate with the binding affinity of various estrogens to estrogen receptor (ER) and their potency both in vitro and in vivo

3. Dual Roles of ROS: High ROS levels induce oxidative damage and produce cell death, where as low physiologic ROS levels facilitate cell-to-cell communication and cell proliferation

4. Mechanism of ROS signaling in coordinated inactivation of phosphatases and activation of kinases leading to estrogenmediated changes in the expression of genes involved in growth, apoptosis, transformation or invasion of cells

REACTIVE OXYGEN SPECIES CAUSES NEOPLASTIC TRANSFORMATION AND GROWTH OF 4-HYDROXY ESTRADIOL-TRANSFORMED MAMMARY EPITHELIAL CELLS VIA TRANSDUCTION OF REDOX SIGNALA TO PI3K/AKT PATHWAY

1. $17 \beta$-estradiol and its catechol metabolites induce ROS production in MCF-10A cells in a dose dependent manner

2. E2 and 4-OHE2, but not 2-OHE2 transforms MCF-10A cells in a dose dependent manner

3. Clonogenic expansion and invasiveness of 4-OH-E2 transformed MCF-10A cells

4. Spheriod Formation in Collagen and HuBiogel

5. Phenotypic Assessment of Transformed Cells

6. 
7. The growth of E2-induced transformed clone was inhibited by both antioxidants, ebselen and $\mathrm{N}$-acetyl cysteine

8. E2-induced 3-D tumor spheroid formation was inhibited by ROS modifiers

9. Estrogen and its metabolites differentially activates PI3K/Akt signaling pathway during mammary transformation

10. 4-OHE2 Activation of PI3K/Akt Signaling Pathway is Abrogated by Chemical and Biological ROS Modifiers

11. 4-OHE2 induced Activation of Akt1 Mediates MCF-10A Neoplastic Transformation

12. 4-OHE2 induced up-regulation of cell cycle gene during neoplastic transformation of mammary cells is inhibited by ROS modulators

\section{ESTROGEN-INDUCED REDOX SIGNALING OF NRF1 MEDIATESIN VITRO GROWTH AND METASTASIS OF BREAST CANCER CELLS}

1. Estrogen induced ROS mediates in vitro proliferation of MCF-7 breast cancer Cells

2. Differential effects of ROS production on in vitro growth of MCF-7

3. ROS Scavengers inhibits E2 induced growth of MCF-7 cells

4. Estrogen induced activation of Akt is abrogated by ROS scavengers

5. Estrogen induced NRF1 activation is abrogated by ROS scavengers

6. Akt phosphorylate and activate NRF1 which mediate in vitro growth of MCF-7 cells

7. Silencing of NRF1 attenuates estrogen induced in vitro growth of MCF-7

8. NRF1 expressions modulates estrogen induced proliferation and growth of $\mathrm{MCF}-7$ cells 
THE ACTIVATION OF NRF1 BY ESTROGEN IS NECESSARY FOR BREAST CANCER CELL SUSCEPTIBILITY TO DEVELOP A MALIGNANT PHENOTYPE AND FOR INVASIVE GROWTH OF BREAST TUMORS

1. Redox expression of NRF1 modulates 4OHE2 induced mammary transformation

2. NRF1 expression mediates 4OHE2 induced mammary tumorigenesis

3. Activation of Akt phosphorylate NRF1 during mammary tumorigenesis

4. PCAF expression participates in 4OHE2 induced mammary transformation

Akt Phosphorylation of NRF1 induces its Acetylation during mammary transformation

6. Transactivation of NRF1 during mammary tranformation is redox dependent

7. NRF1 expression is involved in in vitro growth of breast cancer cells

9. NRF1 over-expression modulates invasion of MCF-7 cells 


\section{LIST OF ACRONYMS}

2-Hydroxy estradiol

2-OHE2

2-Methoxy estradiol

2-MeO-E 2

4-Hydroxy estradiol

$4-\mathrm{OHE}_{2}$

4-Methoxy estradiol

4-MeO-E2

Activator protein 1

AP-1

Adenosine-5'-triphosphate

ATP

5-Bromodeoxyuridine

BrdU

Catalase

Cata

Cell division cycle

CDC

Complementary deoxyribonucleic acid

cDNA

Chromatin immunoprecipitation

ChiP

Carbon dioxide

$\mathrm{CO} 2$

Acetyl group

$\mathrm{COCH} 3$

Catechol o methyl transferase

COMT

Copper

$\mathrm{Cu}$

Copper ion

$\mathrm{Cu} 2+$

Cytochrome p450 1beta1

CYP450 1B1

Cyclic adenosine monophosphate response element binding

CREB protein

2', 7', -dichlorofluorescein

DCF

2', 7', -dichloro-dihydrofluorescein

DCFH 
Dimethyl sulfoxide

DMSO

Deoxyribonucleic acid DNA

$17-\beta$-Estradiol E2

E2 Transcription Factor E2F

Ebselen

Ebs

Electron Transport Chain

ETC

Eukaryotic initiation factor 2

eIF2

Estrogen receptor

ER

Estrogen receptor positive

$\mathrm{ER}^{+}$

Estrogen receptor negative

$\mathrm{ER}^{-}$

Estrogen response element

ERE

External regulated kinase

ERK

Estrogen receptor knock out

ERKO

Fetal bovine serum

FBS

Growth factor receptor positive

GFR+

Growth factor receptor negative

GFR $^{-}$

Hydrogen peroxide

$\mathrm{H}_{2} \mathrm{O}_{2}$

Hank's Balanced Salt Solution

HBSS

Horse serum

HS 
Intergrin associated proteins

Knock down

Manganese

$\mathrm{Mn}$

Manganese superoxide dismutase MnSOD

Messenger ribonucleic acid mtTFA, TFAM

Mitochondrial DNA mtDNA

$N$-Acetyl-Cysteine

NAC

Nuclear respiratory factor 1

NRF1

Nuclear factor kappa beta

NFk B

Super oxide

$\mathrm{O} 2^{--}$

Super oxide dismutase

SOD

Optical density

OD

Oxidative phosphorylation

OXPHOS

Over expression

$\mathrm{Ox}$

p300/CBP-associated factor

PCAF

Proliferating Cell Nuclear Antigen

PCNA

Polyacrylamide gel electrophoresis

PAGE

Phosphate buffered saline

PBS

Polymerase chain reaction

PCR

Phosphatase and tensin homolog

PTEN

Quantitative PCR

qPCR 


\section{CHAPTER I}

\section{INTRODUCTION}

Estrogens are complete breast carcinogens in experimental models as they are capable of initiating and triggering growth and selection, resulting in palpable malignancy (1-3). Both epidemiological and animal studies indicate that estrogens are a known risk factor for breast cancer $(1,3)$. However, the mechanisms by which estrogen initiate or stimulate the progression of cancer remain the subject of a long-standing controversy, because we have been not able to resolve whether estrogen or their metabolites are procarcinogenic.

We have previously shown that estrogen-induced tumor formation is decreased in animals exposed to inhibitors of estrogen metabolism or to hormonally potent estrogens with decreased metabolic conversion to catechol metabolites compared to E2 (2). Moreover, we have shown that chronic treatment of the hamsters with vitamin $\mathrm{C}$ reduced the incidence of E2-induced renal carcinogenesis by $\sim 50 \%$ (2). Since vitamin $\mathrm{C}$ has no antiestrogenic activity, its strong inhibitory effect on estrogen-induced tumorigenesis may largely be derived from its protective effect against the oxidative damage caused by the estrogens and its metabolites. Most of the recent studies show that hydroxyestrogens and methoxy derivatives represent the majority of either urinary or intratumor estrogens in human breast cancer patients, whereas they are relatively scarce in urine or mammary glands of healthy women (4). These studies showed that 4-OH-E2 is elevated in breast tumors as compared to normal mammary tissues which implicates its role in breast cancer and strongly suggest the involvement of estrogen metabolites in the initiation and/or promotion steps of breast carcinogenesis. 
Recent studies indicate that mammary tumors can develop despite a lack of a functional ER $\alpha$ [2]. Although tamoxifen and other antiestrogens are considered to prevent cancer through competition for the ER, other mechanisms cannot be ruled out as these compounds also block metabolism and redox cycling of estrogen, and are free radical scavengers (5). The 4-OH-E2 induces an estrogenic response in the uterus of ER null mice, and this response is not inhibited by ICI182780 (6). These findings suggest that, in addition, to nuclear ER-mediated genomic signaling pathways, non-genomic pathway(s) are involved in the estrogen-dependent growth of preneoplastic and neoplastic cells. We believe that to produce cell transformation both genomic and non-genomic actions of estrogen are required and these two complementary mechanisms through which estrogens produce transformed phenotype of cells. Formation of estrogen-DNA adducts in mammary tissues have been shown by combined LS-MS-MS and LC-nano ES tandem mass spectrometry (7). In addition, 4-hydroxycatechol estrogen conjugates with glutathione or its hydrolytic products (cysteine and $\mathrm{N}$-acetylcysteine) have been detected in mammary tissues from ERKO/Wnt-1 mice (8). Although this type of DNA adduction may play a role in the generation of mutations, it appears to be a late event. In our recent studies, estrogen-induced a rapid increase of intracellular ROS formation in MCF-7 cells (9). Based on our preliminary study showing 4-OH-E2-induced ROS formation in MCF10A cells, the accumulation of 4-OH-E2 in estrogen target organ of the cancer will result in increased formation of ROS in the target cells. In addition, 4-OH-E2 is also strongly active at the estrogen receptor $(10,11)$, which would add to the growth stimulation of the ER-positive cells. Our preliminary data revealed that 4-OH-E2 may also activate an additional signal transduction pathway that is different from the classical 
ER•signaling pathway. The contribution of this signal transduction system to breast carcinogenesis is the subject of the proposed study.

In pursuing mitochondrial regulators of cell cycle progression, we discovered that intracellular ROS levels increase as cells progress through G1 and into S phase upon E2 exposure (11). High ROS levels induce oxidative damage and arrests cells in G0/G1. However, low physiologic ROS levels are utilized by cells for cell-to-cell communication and in proliferation. Inhibition of estrogen-induced ROS by antioxidants prevents early G1 gene expression. We now know that the delicate intracellular interplay between oxidizing and reducing equivalents allows ROS to function as second messengers in the control of cell proliferation and cell transformation $(11,12)$. Our preliminary study showed that MCF-10A cells treated with 4-OH-E2 rapidly produce ROS, which is preceded by an increase in the level of $\mathrm{Ca} 2+$. The accumulation of 4-OH-E2 as recently reported in the human breast tissue in cancer subjects (9) will allow increased formation of ROS and $\mathrm{Ca} 2+$ in the target organ of cancer in a sensitive subpopulation. Our preliminary study showed that the overexpression of catalase and MnSOD prevented 4OH-E2-induced anchorage-independent growth of MCF-10A cells. These studies data indicate that 4-OH-E2-induced cell transformation may be mediated, in part, by ROS and $\mathrm{Ca} 2+$ signal transduction pathways that are different from the classical nuclear ER genomic signaling pathway. Therefore, how 4-OH-E2, through ROS signalings, produces malignant phenotype is an issue of fundamental importance to this proposal. 
Recently, an NRF1 and CREB pair has been identified as a key regulator of the transcriptional program of the cell cycle in human cells because thes pair of transcription factors showed a significant co-occurrence rate on promoters of cell cycle regulated genes (13). NRF1 appears to play an important role as a regulator of cell cycle genes because NRF1 binding site has been identified by comparing genome-wide locations on genes involved in DNA replication, mitosis, and cytokinesis $(14,15)$. Some of the genes which contain NRF1 binding sites on their promoters included Cdc2, Cdc25C, PCNA, and cyclin B1. In addition to NRF1's role in controlling mitochondrial biogenesis-related genes, these observations are consistent with a role for NRF1 in regulating genes involved in growth and development. The expression of early G1 genes, c-myc, c-fos, cjun, cyclin D1, and NRF1 are regulated by ROS $(2,16)$. The mRNAs of some of these genes are induced by estrogen-induced ROS and hydrogen peroxide as well as other inducers of oxidative stress $(2,11)$. Based on these studies, we have proposed that $4-\mathrm{OH}$ E2-induced ROS through activating the transcription factor NRF1 leads to the induction of cell cycle genes that contain the binding site(s) for this transcription factor in their promoters. This, in turn, supports the growth of anchorage-dependent and -independent cells. 


\section{LIST OF REFERENCE}

[1] IARC working group. Monographs on the evaluation of hormonal contraception and postmenopausal hormonal therapy. 72, 399-530, 1999.

[2] Roy D and Singh KP. Estrogen-induced genetic alterations and breast, endometrial, testicular and prostate cancers, Current Genomics, 5, 245-257, 2004.

[3] IARC working group. Monographs on the evaluation of combined estrogenprogestogen contraceptives and menopausal therapy. 91, 2005.

[4] Castagnetta L, Granata OM, L Cocciadiferro, A Saetta, L Polito, G Bronte, S Rizzo, I Campisi, B Agostara, G Carruba: Sex steroids, carcinogenesis, and cancer progression. Ann N Y Acad Sci. 1028, 233-246, 2004.

[5] Arteaga E, Villaseca P, Bianchi M, Rojas A, Marshall G.Raloxifene is a better antioxidant of low-density lipoprotein than estradiol or tamoxifen in postmenopausal women in vitro. Menopause. 10, 142-146, 2003.

[6] Couse JF, Korach KS. Estrogen receptor null mice: what have we learned and where will they lead us Endocr Rev 20, 358-417, 1999.

[7] Embrechts J, Lemiere F, Van Dongen W, Esmans EL, Buytaert P, Van Marck E, Kockx M, Makar A.: Detection of estrogen DNA-adducts in human breast tumor tissue and healthy tissue by combined nano LC-nano ES tandem mass spectrometry. J Am Soc Mass Spectrom. 14, 482-491, 2003.

[8] Devanesan P, Santen RJ, Bocchinfuso WP, Korach KS, Rogan EG, Cavalieri E. Catechol estrogen metabolites and conjugates in mammary tumors and hyperplastic tissue from estrogen receptor-alpha knock-out (ERKO)/Wnt-1 mice: implications for initiation of mammary tumors. Carcinogenesis. 22, 1573-1576, 2001.

[9] Felty Q, Xiong WC, Sun D, Sarkar S, Singh KP, Parkash J, Roy D. Estrogen-Induced Mitochondrial Reactive Oxygen Species as Signal-Transducing Messengers. Biochemistry. 44, 6900-6909, 2005.

[10] Felty Q, Xiong WC, Sun D, Sarkar S, Singh KP, Parkash J, Roy D. EstrogenInduced Mitochondrial Reactive Oxygen Species as Signal-Transducing Messengers. Biochemistry. 44, 6900-6909, 2005

[11] Felty Q, Roy D. Estrogen, mitochondria, and growth of cancer and non-cancer cells. J Carcinog. 15, 41-51, 2005 
[12] Roy D and Cai Q: Estrogen, immunoactivation, gene damages and development of breast, endometrial, ovary, prostate and testicular tumors. Recent Adv Steroid Biochem Mol Biol 3, 1-32, 2002

[13] Cuendet M, Liu X, Pisha E, Li Y, Yao J, Yu L, Bolton JL. Equine estrogen metabolite 4-hydroxyequilenin induces anchorage-independent growth of human mammary epithelial MCF-10A cells: differential gene expression. Mutat Res 550, 10921,2002

[14] Russo J, Hasan Lareef M, Balogh G, Guo S, Russo IH. Estrogen and its metabolites are carcinogenic agents in human breast epithelial cells. J Steroid Biochem Mol Biol 87, $1-25,2003$

[15] Elkon R, Linhart C, Sharan R, Shamir R, Shiloh Y. Genome-wide In Silco identification of transcription regulators controlling the cell cycle in human cells. Genome research, 13, 773-780, 2003

[16] Cam H, Balciunaite E, Blais A, Spektor A, Scarpulla RC, Young C, Kluger Y, Dynlacht BD A common set of gene regulatory networks links metabolism and growth inhibition. Mol Cell 16, 399-411, 2004. 
CHAPTER II

HYPOTHESIS, SPECIFIC AIMS, AND RELEVANCE OF FINDINGS

Hypothesis

We hypothesize that 4-hydroxy estradiol (4-OH-E2), a catechol metabolite of $17 \beta$ estradiol (E2)-induced ROS epigenetically activate NRF1 through its phosphorylation and acylation. This, in turn, through NRF1 mediated transcriptional activation of cell cycle genes, controls 4-OH-E2-induced cell transformation and tumorigenesis.

Specific Aim 1: To determine whether estrogen-induced RO/NS are involved in estrogen-induced in vivo growth of malignant breast epithelial cells. To achieve this aim, we would determine whether: a overexpresion of mt superoxide dismutase (SOD) or catalase that detoxify ROS; or co-treatment with the chemical antioxidant scavengers, Nacetylcysteine and ebselen, prevents estrogen-induced cell transformation and in vivo growth of malignant breast epithelial cells. b: Whether Knockdown of mitochondrial biogenesis through silencing of mtTFA will lead to attenuations of RO/NS production and whether reduced ROS production prevents estrogen-induced cell transformation and in vivo growth of malignant breast epithelial cells.

Specific Aims 2: To determine that 4-OH-E2-induced ROS through activation of NRF1 signaling transform normal breast epithelial cells to malignant cells. To accomplish these goals, we will determine whether the transformation of normal breast epithelial cells by 4-OH-E2 is prevented by: a) the overexpression of ROS modifiers catalase and MnSOD, 
b) silencing of NRF1. Cell transformation will be assessed by determining colony efficiency, colony size, ductulogenic capacity, and invasiveness. We will also determine whether silencing of NRF1 and overexpression of MnSOD or catalase prevent 4-OHE2-induced tumor formation in three-dimensional culture mimicking in vivo environment. The findings of this aim will reveal a new paradigm by showing that the carcinogenic activity of 4-OH-E2 requires NRF1.

Specific Aim 3: To determine whether 4-OH-E2 induced ROS through stimulating redox sensitive AKT kinase and histone acetyltransferase of CREB binding protein associated factor (P/CAF), respectively, control phosphorylation and acylation of the NRF1. The 4OH-E2-induced epigenetic changes in turn activate NRF1. To test the postulate of this aim, we will determine that: i) NRF1 stability and transactivation are regulated by 4-OHE2-induced ROS. This mechanism involves NRF1 phosphorylation by AKT kinase and NRF1 acylation by the histone acetyltransferase CREB binding protein-associated factor (P/CAF), respectively; and (ii) the 4-OH-E2-induced epigenetic changes have an additive or synergistic effect on NRF1 activation. We will determine whether NRF1 transctivating ability is modulated by controlling its phosphorylation and/or acylation; and (iii) transcriptional activation of cell cycle genes and cell cycle progression are prevented by silencing ofAKT, P/CAF, or NRF1. These observations will reveal the new paradigm of 4-OH-E2-induced cell cycle regulation of anchorage-independent cells by NRF1 


\section{Relevance of findings}

This study addresses an important public health issue by studying whether phosphorylation and acetylation of NRF1 by 4-OH-E2-generated ROS promote malignant transformation of normal breast epithelial cells. The proposed studies are highly innovative, since they tested the novel concept that oxidants participate in 4-OHE2-induced cellular transformation and tumorigenesis. Understanding if aberrant activation of NRF1 signaling by 4-OH-E2-generated ROS contributes to development of E2-dependent breast tumors provides new insights into cancer predisposition. Moreover, it provides a novel paradigm for understanding the molecular mechanisms underlying the carcinogenic effects of natural estrogen and other medicinal and environmental estrogenic agents. This is a new line of research that may well set the stage for the design and development of new and more effective NRF1 signaling-based drugs or gene therapies for the prevention and treatment of breast cancer. 


\title{
CHAPTER III
}

\section{LITERATURE REVIEW}

\section{ESTROGEN-INDUCED REACTIVE OXYGEN SPECIES-MEDIATED SIGNALINGS CONTRIBUTE TO BREAST CANCER GROWTH \\ Victor Okoh, Alok Deoraj, Deodutta Roy \\ Department of Environmental and Occupational Health, Florida International University, Miami, FL 33199-0001 \\ (2010 - Biophysica Biochmica Acta, Received 22 September 2010; revised 12 October 2010; accepted 14 October 2010. Available online 29 October 2010, doi:10.1016/j.bbcan.2010.10.005)}

\begin{abstract}
Elevated lifetime estrogen exposure is a major risk factor for breast cancer.

Recent advances in the understanding of breast carcinogenesis clearly indicate that induction of estrogen receptor (ER) mediated signaling is not sufficient for the development of breast cancer. The underlying mechanisms of breast susceptibility to estrogen's carcinogenic effect remain elusive. Physiologically achievable concentration of estrogen or estrogen metabolites has been shown to generate reactive oxygen species (ROS). Recent data indicates that these ROS can induce DNA synthesis, increased phosphorylation of kinases, and activation of transcription factors, e.g., AP-1, NRF1, $\mathrm{E} 2 \mathrm{~F}, \mathrm{NF}_{\mathrm{k}} \mathrm{B}$ and $\mathrm{CREB}$ of non genomic pathways which are responsive to both oxidants and estrogen. Estrogen-induced ROS by increasing genomic instability and by transducing signal through influencing redox sensitive transcription factors play important role (s) in cell transformation, cell cycle, migration and invasion of the breast cancer. The present review discusses emerging data in support of the role of estrogen induced ROS-mediated signaling pathways which may contribute in the development of
\end{abstract}


breast cancer. It is envisioned that estrogen induced ROS mediated signaling is a key complementary mechanism that drives the carcinogenesis process. ROS mediated signaling however occurs in the context of other estrogen induced processes such as ERmediated signaling and estrogen reactive metabolite-associated genotoxicity. Importantly, estrogen-induced ROS can function as independent irreversible modifiers of phosphatases and activate kinases to trigger the transcription factors of downstream target genes which participate in cancer progression.

\section{INTRODUCTION}

Estrogen is a class of 18-carbon steroid. There are a total of 9 estrogens in humans of which the three major ones are $17 \beta$-Estradiol $\left(E_{2}\right)$, Estrone $\left(E_{1}\right)$, Estriol $\left(E_{3}\right)$. These estrogens are synthesized primarily in the ovaries of premenopausal women. Other organs such as brain and adipose tissues also synthesize estrogens through aromatization of testosterone [1]. Estrogens are also synthesized in male species. A relatively high concentration of estrogen is found in rete testis fluid and in testicular vein and lymph of rodents [2;3]. The level of estrogens in peripheral blood of men averages $69 \mathrm{pg} / \mathrm{ml}$ compared to $199 \mathrm{pg} / \mathrm{ml}$ in non-ovulating women [4]. $\mathrm{E}_{2}$ is the predominantly circulating and the most biologically active ovarian steroid. In addition to endogenous sources, the body burden of estrogen may increase from the intake of synthetic medicinal estrogens, such as $17 \alpha$-ethinyl estradiol (used as oral contraceptive), mestranol, premarin (used in hormone replacement therapy), and diethylstilbestrol (used in the treatment of highly advanced breast and prostate cancers). Physiological estrogens are essential for the growth and maintenance of various reproductive and non-reproductive organs in the body 
where they elicit different growth responses in tissues depending on the cell-type, type of estrogen receptor (ER) present, dose and timing of exposure.

Elevated lifetime estrogen exposure has been shown to be a major risk factor for cancer in hormone-dependent organs, particularly breast and endometrium [5-9]. This may help explain the observation that breast cancer risk increases in the women who experience early menarche (onset of menstruation) and late menopause whereas breast cancer risk is reduced in the women who experience late menarche and early menopause [10;11]. A cohort study by the European Prospective Investigation into Cancer and Nutrition found that excess serum estrogens are associated with incidence of breast cancer in premenopausal women [12]. Similarly, estrogen replacement therapy in post menopausal women has been demonstrated to be associated with breast, cervical, and endometrial carcinoma [13]. In experimental models, estrogens are established breast carcinogens, as they are capable of initiating and triggering growth and selection to generate palpable malignancy [14-18]. These findings led the International Agency for Research on Cancer and National Toxicology Program to categorize estrogens as human carcinogens $[19 ; 20]$. Post menopausal women exhibit the highest breast cancer incidence when serum estrogens are at their lowest level [6]. In contrast, the estrogen levels in mammary tissues are similar in pre and post menopausal women [21]. In addition, post-menopausal breast cancer patients have significantly higher estrogen levels in breast tissues than non disease pre or post menopausal women [22]. This finding indicates that site-specific estrogen synthesis or estrogen load may be the major source associated with breast carcinogenesis 
and growth of breast cancer cells. However, the underlying mechanisms of breast cell susceptibility to estrogen's carcinogenic effect remain elusive.

The signaling pathway plays a critical role in mammary gland development. This pathway has also been shown to be essential in promoting growth of estrogen receptor positive $(\mathrm{ER}+)$ breast cancer cells. Whether this pathway alone is sufficient to induce breast carcinogenesis is still unresolved. Mammary tumors can develop in mice lacking functional ER alpha $(\mathrm{ER} \alpha)$ [15;23]. Likewise, $\mathrm{E}_{2}$ and its catechol metabolite, 4-hydroxy estradiol $\left(4-\mathrm{OH}-\mathrm{E}_{2}\right)$ can induce an estrogenic response in the uterus of $\mathrm{ER} \alpha$ null mice, where an antiestrogen (ICI182780) fails to inhibit such response [24]. Though tamoxifen (TAM) and other antiestrogens inhibit breast cancer growth through their actions at the ER, these antiestrogens also inhibit growth of cancer cells that are estrogen receptor negative [25-27]. In addition, estrogen undergoes oxidative metabolism and generates ROS which is implicated in carcinogenic conversion and growth of cancer cells $[9 ; 18]$. TAM on the other hand can block estrogen metabolism and acts as a ROS scavenger [14]. These findings therefore suggest that other mechanism(s) independent of ER status exist that mediate estrogen induced cellsignaling leading to malignant transformation and growth of mammary epithelial cells. One such mechanism being investigated by us is the role of estrogen induced mitochondria ROS in mammary carcinogenesis. Using physiologically achievable estrogen concentrations corresponding to the estrogenic menstrual peak, we showed that estrogen induces rapid formation of mitochondrial ROS in MCF-7 cells [28]. Other reports support our observation that estrogen-induced ROS production relies on mitochondria, which are the main source of ROS in the epithelial 
cell [29]. Some of the same mitogenic pathways that are sensitive to ROS levels are regulated by carcinogenic levels of estrogen. We have recently shown that inhibitors of mitochondrial ROS production prevent $\mathrm{E}_{2}$-induced expression of cell cycle genes containing nuclear respiratory factor-1 (NRF1) binding sites (e.g., cyclin B1, PCNA, and PRC1), decrease $E_{2}$-induced NRF1 expression, and delay growth [30]. Together these studies indicate that in addition to ER mediated signaling, $\mathrm{E}_{2}$ through $\mathrm{ROS}$ signaling can support initiation and progression of breast cancer by alternative pathways.

In this review, we discuss a novel concept that estrogen-induced ROS can produce genotoxic effects as well as support the development of estrogen-dependent breast tumors. This envisioned ROS mediated mechanism most likely contributes to the process that drives carcinogenesis, while this mechanism seems to occur in the context of other ER-mediated signaling and estrogen reactive metabolite-associated genotoxicity. To highlight the ROS mediated carcinogenesis mechanism, first, estrogen metabolism and redox cycling of hydroxylated estrogens leading to the generation of genotoxic estrogen metabolites is briefly discussed. Then, we elaborate on the role of mitochondria in estrogen-induced generation of oxidants and emerging data on how estrogen-induced ROS modifies redox-sensitive signal transduction pathways that contribute in the cell transformation, cell growth and cancer progression. 
GENERATION OF GENOTOXIC METABOLITES OF ESTROGEN AS A POTENTIAL MECHANISM OF BREAST CARCINOGENICITY

Cells are protected from estrogen-mediated mitogenicity and genotoxicity through conjugation of parent estrogens to sulfate and glucuronide moieties. Estrogen metabolism and generation of genotoxic estrogen metabolites are summarized in Figure 1 and have been previously reviewed extensively [9;31-33], therefore we have limited our discussion in this area. Endogenous and synthetic estrogens, i.e. $E_{1}, E_{2}, E_{3}, 17 \alpha$ ethinyl estradiol $\left(E_{2}\right)$ and equilenin $(\mathrm{Eq})$ are converted into catechol estrogens through aromatic hydroxylation by specific cytochrome P450 isoforms/peroxidase enzymes [9;34]. The catechol estrogens are inactivated by methylation, catalyzed by catechol methyltransferases, as well as by glucuronidation and sulfation, catalyzed by glucuronosyltransferases and sulfotransferases, respectively [35]. Oxidation of the catechol estrogens moieties gives rise to estrogen semi-quinones and quinines, i.e., estrogen-2,3-semi-quinone and estrogen-3,4-semi-quinone [36;37]. Catechol estrogens, particularly 4-OH-E $E_{2}$, via nonenzymatic autoxidation, may undergo redox cycling to produce reactive semiquinone and quinone intermediates with concomitant production of ROS. However, this redox reaction of catechol estrogens is enhanced in the presence of $\mathrm{Cu}^{2+}$ or $\mathrm{Fe}^{3+}$ and by enzymatic catalysis by cytochrome $\mathrm{P} 450$ oxidases or peroxidases, which is accompanied with an increased generation of ROS. Catecholestrogens can reduce $\mathrm{Cu}^{2+}$ or $\mathrm{Fe}^{3+}$ ions to $\mathrm{Cu}^{+}$or $\mathrm{Fe}^{2+}$. The $\mathrm{Cu}^{+}$or $\mathrm{Fe}^{2+}$ ions in turn, may reduce organic or inorganic peroxides, which are capable of initiating lipid peroxidation in the presence of oxygen. Both iron and copper are now recognized as major transition metals that may facilitate the formation of ROS through redox cycling of catechol compounds as well as 
by the Fenton reaction [38]. Estrogen quinones are conjugated with glutathione both in vivo and in vitro [37;39] by glutathione transferases [40]. 4-Hydroxylated estrogen metabolites or the diethylstilbestrol metabolite diethylstilbestrol-4, 4-quinone in a microsomal cytochrome $\mathrm{P} 450$ activation system, induce 8-hydroxylation of guanine bases of DNA. In addition to oxidant-induced damage to DNA, estrogens generate lipid peroxidation and oxygen radical-mediated oxidation of amino acid residues of proteins to carbonyl-containing moieties. The oxidant-induced oxidative DNA damage in estrogentarget tissue has been taken as evidence for the generation of oxygen radicals by metabolic redox cycling of catecholestrogens or diethylstilbestrol (DES) and for their participation in the induction of estrogen-induced cancer in animals or humans. Catechol estrogen semiquinone/quinone can also directly react with DNA to form adducts [31]. These adducts can either be stable DNA adducts that remain in DNA or can form depurinating adducts that destabilizes DNA's glycosyl bond [41]. DNA adduct formation and depurination at critical sites such as tumor suppressors or oncogenes can lead to mutations which have been postulated to be the initiator of breast cancer [41]. Rodent studies demonstrate that $E_{2}$ induces tumors in those tissues only where $E_{2}$ is predominantly converted to $4-\mathrm{OH}-\mathrm{E}_{2}$ by 4 -hydroxylase enzyme [42;43]. We have previously shown that $\mathrm{E}_{2}$-induced tumor formation is decreased in animals exposed to inhibitors of estrogen metabolism [17;18] or to hormonally potent estrogens undergoing reduced metabolic conversion to catechol metabolites [44]. The rate of $4-\mathrm{OH}-\mathrm{E}_{2}$ formation is also shown to be 4 -fold higher than that of $2-\mathrm{OH}-\mathrm{E}_{2}$ in human mammary fibroadenomas and adenocarcinomas [45]. The 4-OH- $\mathrm{E}_{2}$ are the most prevalent estrogen metabolite in breast tumor tissues and have a significantly higher circulating level in 
women with breast cancer [46]. Hydroxyestrogen and methoxy estrogen derivatives account for the majority of urinary or intra-tumor estrogens in human breast cancer patients but they are relatively scarce in the urine or mammary glands of healthy women [16]. Oxidative cellular damage such as 8-hydroxylation of guanine bases of DNA and lipid peroxidation have also been demonstrated in human breast and indicate the in vivo pro-oxidant effects of the estrogen and catecholestrogen metabolites formed in this tissue (reviewed in [9;31]). For example, elevated $4-\mathrm{OH}-\mathrm{E}_{2}$ levels in breast tumors and in women with breast cancer compared to normal mammary tissues implicate $4-\mathrm{OH}-\mathrm{E}_{2}$ in breast cancer and it strongly suggests that $4-\mathrm{OH}-\mathrm{E}_{2}$ metabolite participates in development of breast carcinogenesis [47]. Our recent studies showed that $\mathrm{E}_{2}$ or 4-OH-E $\mathrm{E}_{2}$ elicited transformed phenotypes in ER $\alpha$ negative MCF-10A cells through ROS-sensitive signal transduction pathways [48-51]. When exposed to $\mathrm{E}_{2}, 4-\mathrm{OH}-\mathrm{E}_{2}, 4-$ hydroxyequilenin, equilenin or its catechol metabolite, similar transformation in MCF10F and MCF-10A were observed by other researchers [52;53]. Although neither 2-OH$\mathrm{E}_{2}$ nor $2-\mathrm{OH}-\mathrm{E}_{1}$ is carcinogenic in vitro or in vivo $[42 ; 54 ; 55]$, both $2-\mathrm{OH}-\mathrm{E}_{2}$ and $2-\mathrm{OH}-\mathrm{E}_{1}$ are capable of producing ROS and undergo metabolic redox cycling like 4-OH-E 2 . The lack of carcinogenicity of 2-hydroxylated estrogen metabolites in vivo may be due to their rapid inactivation by catechol-O-methyltransferase (COMT)-mediated Omethylation [55-57], rapid clearance [58], and weak estrogenic hormonal activity (compared with 4-OH-E ${ }_{2}$ [59]. It may also be due to $2-\mathrm{MeO}-\mathrm{E}_{2}$, the major product of COMT-mediated O-methylation of $2-\mathrm{OH}-\mathrm{E}_{2}$ that possesses unique anti-tumorigenic activity. These studies support the concept that $\mathrm{E}_{2}$ and mainly its metabolite $4-\mathrm{OH}-\mathrm{E}_{2}$ are carcinogenic in breast epithelial cells. 


\section{ESTROGEN RECEPTOR MEDIATED CARCINOGENIC ACTIONS}

The conventional paradigm of estrogen carcinogenic action is based on binding to ER $\alpha / \beta$, which has been extensively reviewed; therefore, we limited our discussion in this area. Estrogen binding to its receptors, ER $\alpha$ and $\mathrm{ER} \beta$, initiates gene transcriptions by binding to estrogen response elements (ERE) of genes involved in cell growth. Therefore, increases in estrogen activity or exogenous estrogenic exposure may lead to increased cell proliferation [60]. It is speculated that rapidly proliferating cells are error prone due to the less time accorded for DNA proof reading and repairs. Errors incorporated into critical genes such as oncogenes and/or tumor suppressors may likely lead to mutations and neoplastic growth. Nevertheless, the classical concept of estrogen receptor mediated actions in cancer does not address the fact that the majority of normal mammary epithelial cells that transform into cancerous cells are ER negative (ER') but are growth factor receptor positive $\left(\mathrm{GFR}^{+}\right)$[61;62]. On the other hand, about 7\%-15\% of normal mammary epithelial cells are ER positive (ER $\left.{ }^{+}\right)$ but lack growth factor receptors $\left(\mathrm{GFR}^{-}\right)$[63]. The predominant $\mathrm{ER}^{+}$cells in normal mammary tissues are the stromal cells. Estrogen induced proliferative responses of normal ER ${ }^{-}$mammary epithelial cells may be mediated by the induction of $\mathrm{GFR}^{+}$stromal cells [64]. Interestingly, the majority of breast cancer cells in vivo are $\mathrm{ER}^{+}$but $\mathrm{GFR}^{-}$and do proliferate upon estrogen exposure [65]. These observations therefore implie that ER positive phenotypic expressions observed in majority of breast cancer cells may be manifestation of malignant transformation.

Furthermore, discrepancies between the binding affinity of various estrogens to ER and their potency both in vitro and in vivo have been reported (Figure 2). For example, 17 $\alpha$ estradiol has a very weak affinity for ER compared to that of DES and $17 \alpha$ - 
ethinylestradiol; but its ability to stimulate the growth of Leydig cells and other cells is equivalent to that of DES [66]. Similarly, the receptor binding affinity of $4-\mathrm{OH}-\mathrm{E}_{2}$ is $50 \%$ that of DES or $\mathrm{E}_{2}$, but its ability to stimulate cell growth in the mouse uterus is greater than either of these compounds [67]. In Noble rats, $E_{1}$ is more potent than $E_{2}$ in producing growth of mammary tissues [68;69]. In addition, estrogen-induced tumor formation is decreased in animals exposed to inhibitors of estrogen metabolism [17;18] or to hormonally potent estrogens with decreased metabolic conversion to catechol metabolites [44] compared to $E_{2}$. The ectopic expression of Wnt-1, a proto-oncogene in mice induced mammary hyperplasia and tumorigenesis in the absence of ER $\alpha$ in female and male mice [15;23]. All these studies indicate that estrogen induced cellular responses including carcinogenicity and growth of cancer cell are verycomplex and the conventional paradigm as described above cannot explain all observed discrepancies.

\section{ESTROGEN, MITOCHONDRIA, AND ROS GENERATION}

Both natural and synthetic estrogenic compounds containing a phenolic structure possess pro-oxidant and/or antioxidant activities. A balance of pro- and antioxidant effects of estrogens depends on the nature (structure) of the estrogen and on its concentrations. Under physiological conditions, the parent estrogen and the metabolic profile of estrogen metabolites in a specific tissue or fluid determine its pro- or antioxidant activities. In additionto the above-described metabolic redox cycling of hydroxylated estrogens producing ROS, we present here the evidence supporting the role of mitochondria in estrogen-induced generation of oxidants. 
Estrogen and mitochondria: Mitochondria are an integral component of steroidogenesis. Key enzymes of estrogen biosynthesis (3 $\beta$-hydroxysteroid dehydrogenase and aromatase) have been identified in the mitochondria of ovarian tumor epithelial cells [70]. Exogenously added estrogen is preferentially and rapidly $>50 \%$ within a few minutes) transported to mitochondria [71]. How estrogen functions in the mitochondria remains unclear; however, presence of $\operatorname{ER} \alpha$ and ER $\beta$ in mitochondria indicates a potential role of estrogen in the regulation of mitochondrial genome transcription [72-74]. In the human mitochondrial genome, partial or ERE $1 / 2$ sites in the D-loop region, CO II, tRNA-met, $12 \mathrm{~S}$ rRNA, $7 \mathrm{~S}$ rRNA, URF1, and URF5 were identified. We recently reported that mitochondria are a major target of estrogen within the cell [28;75]. Estrogen can also affect mitochondria at the protein level. Estrogen and ER agonists have been shown to inhibit mitochondrial respiratory complexes I, II, III, IV, and mitochondrial ATP synthase ( $\mathrm{F}_{0} \mathrm{~F}_{1}$-ATPase) [76;77], but most of these studies used cytotoxic dose of estrogen and any physiologic responses by mitochondria were probably overlooked. Mitochondrial proteins are encoded in the mitochondria and nuclear genomes. Mitochondrial transcription factor A (mtTFA), which controls mtDNA copy number, is essential for mitochondrial biogenesis [78]. When translocated into the mitochondria, mtTFA initiates transcription and replication of the $\mathrm{mt}$ genome. Translation is initiated by mitochondrial translation initiation factor 2 (MTIF2), which is encoded by the mt genome and contains a consensus binding site for ER. The tissue-specific coactivators of steroid receptors (including ER), such as peroxisome proliferator-activated receptorcoactivator-1 (PGC-1), and the PGC-1-related proteins, PRC and PERC, coactivate the expression of mtTFA [79-82]. Both transcriptional activators nuclear respiratory factor 1 
and 2 (NRF1 and 2) and coactivators (PGC-1, PRC) act as important mediators in the maintenance and proliferation of mitochondria [83]. Steroid hormones, androgens and thyroxin, can induce changes in mitochndrial genome-derived mRNA and rRNA by increasing mtTFA mRNA expression from the nuclear genome [84]. At the posttranslational level, an interaction between mtTFA and ${ }_{\mathrm{p}} 53$ has been shown to control mitochondrial biogenesis [85], and ${ }_{\mathrm{p}} 53$ interacts with ER [86]. Estradiol increased phosphorylation of a $76-\mathrm{kDa}$ protein in the mitochondrial fraction of the rat corpus luteum [87]. This report, together with the presence of protein kinases within mitochondria, further suggests that estrogens regulate mitochondrial physiology at the post-translational level [77].

Mitochondria and generation of estrogen induced ROS: Several enzymatic systems and organelles produce ROS, such as NADPH oxidases at the plasma membrane, nitric oxide synthases, xanthine oxidase, peroxisomes at endoplasmic reticulum (cytochromes P450) and mitochondria. Mitochondria however, are the largest source of ROS in epithelial cells. Over $90 \%$ of oxygen is consumed by mitochondria, and up to $4 \%$ of the oxygen in the mitochondria is utilized to produce RO/NS. The respiratory chain produces superoxide radicals $\left(\mathrm{O}_{2}^{-}\right)$. The major source of $\mathrm{H}_{2} \mathrm{O}_{2}$ in cells arises from the dismutation of $\mathrm{O}_{2}{ }^{-{ }^{-}}\left(2 \mathrm{O}_{2}{ }^{--}+2 \mathrm{H}^{+}=\mathrm{H}_{2} \mathrm{O}_{2}+\mathrm{O}_{2}\right)$. At physiologic $\mathrm{pH}$, non-enzymatic dismutation is rapid $\left(\sim 10^{5} \mathrm{~mol}^{-1} \mathrm{sec}^{-1}\right)$, but dismutation is markedly accelerated by the superoxide dismutases $\left(\mathrm{SOD} ;>10^{9} \mathrm{~mol}^{-1} \mathrm{sec}^{-1}\right) . \quad \mathrm{H}_{2} \mathrm{O}_{2}$ freely diffuses through cellular membrane and is a precursor of $\mathrm{OH}^{-}$. Mitochondrial nitric oxide synthase (NOS) produces nitric oxide (NO), which combines with $\mathrm{O}_{2}^{-\cdot}$ to generate peroxinitrite $\left(\mathrm{ONOO}^{-}\right)$. All these $\mathrm{RO} / \mathrm{NS}$ may cause 
mitochondrial and cellular damage if present in excess (Figure 3). The physiologic production of RO/NS by mitochondria can have profound effects on initiation of preneoplastic foci and its promotion as well as tumor cell growth both in vivo and in vitro (Figure 3). Multiple non-mitochondrion and mitochondrion-dependent defense system regulate intracellular RO/NS formation and maintain an appropriate redox environment [88]. Glutathione, a tripeptide thiol (cysteine-glutamine-glycine), and thioredoxin (Trx), a small protein that has two cysteines in its active site, are responsible for much of the antioxidant defense of cells but are also likely mediators of oxidative signaling. These thiols are used as substrates for glutathione peroxidases, Trx peroxidases (peroxiredoxins) [75;89], and glutathione-S-transferases, enzymes that regulate the steady state concentration of hydroperoxides $(\mathrm{ROOH})$ including $\mathrm{H}_{2} \mathrm{O}_{2}$, and also used as electrophiles, such as 4-hydroxy-2,3-nonenal (4HNE), which is a lipid peroxidation product.

Earlier studies failed to identify that physiologic concentrations of estrogen stimulate mitochondrial ROS generation.That is why possibly cytotoxic doses of estrogen and isolated mitochondria were used. We and others have shown that mitochondria are significant targets of estrogen [28;30]. Recently, we reported that physiological concentrations of $\mathrm{E}_{2}$ stimulate a rapid production of intracellular ROS in epithelial cells which depends on cell adhesion, the cytoskeleton, and integrins [28]. In our studies of $\mathrm{E}_{2}$ induced ROS generation in MCF-7 and other cells, hydroxylated estrogen metabolites or adducts immediately after addition of $\mathrm{E}_{2}$ were not detected which rules out the possibility of ROS generation by redox cycling of hydroxylated estrogens. These events occur 
earlier than ER-mediated genomic actions. $E_{2}$-induced ROS production does not depend on the presence of ER on breast cancer cells as $\mathrm{ER}^{-}$cell line MDA-MB 468 produced ROS equal to or more than that of $\mathrm{ER}^{+} \mathrm{MCF} 7, \mathrm{~T} 47 \mathrm{D}$, and ZR75 cell lines [28].

The ROS molecules, $\mathrm{H}_{2} \mathrm{O}_{2}$ and $\mathrm{NO}$, also stimulate mitochondrial biogenesis, a process that depends on the flow of molecules into and out of the organelle [90;91]. It has been shown recently that oxidative stress causes an increase in mitochondrial mass in human lung cells. However, the molecular mechanism underlying the increase in mitochondrial mass and mtDNA is still unclear. Furthermore, the mitochondrial mass of mtDNA-less cells was also significantly increased by exposure to low concentrations of $\mathrm{H}_{2} \mathrm{O}_{2}$, suggesting that the increase in mitochondrial mass in replicating cells may result from an increase in ROS production. Thus, the delayed production of estrogen-induced ROS may occur via this mechanism, whereas the transient estrogen-induced increase in ROS may result from estrogen activation of the mtTFA complex leading to increased oxidative phosphorylation.

\section{ESTROGEN-INDUCED ROS-MEDIATED OXIDATIVE DNA DAMAGES}

Estrogen-induced oxidative DNA damage through ROS has been extensively reviewed [9;31-33], therefore we have limited our discussion in this area here. 8- Hydroxy-guanine (8-OHdG), an indicator of oxidative DNA damage, causes G->T and A->C substitutions in DNA templates. It has been shown that breast carcinoma DNA contains dramatically higher concentrations of base modifications, such as 8-hydroxy-guanine, 2,6-diamino-4hydroxy-5-formamidopyrimidine, and 8-hydroxyadenine [92-94]. An elevated level 
(3.35-fold higher) of 8-OHdG was observed in $\mathrm{ER}^{+}$when compared with $\mathrm{ER}^{-}$malignant tissues. 8-OHdG level in $\mathrm{ER}^{+}$MCF-7 cell line was significantly higher (9.3-fold higher) than ER ${ }^{-}$MDA-MB 231 cell line [93]. There was a higher level of 8-OHdG in the DNA of early-stage cancer tissue than that of later-stage cancer tissue, which suggests that ROS may play an important role in the early phase of carcinogenesis. The urinary 8 -OHdG level $(1,827+/-1,500 \mathrm{pmol} / \mathrm{kg} /$ day $)$ in 18 women with gynecologic cancer has been shown to be significantly higher than in 10 women $(747+/-425 \mathrm{pmol} / \mathrm{kg} /$ day $)$ without carcinoma [94]. Gene mutation induced by ROS has been observed in C-Ha-ras-1 and p53 [95;96]. Recently, it has been shown that methylation alone induced C:G-->T:A transitions in the p53 gene, whereas nitric oxide treatment produced more C:G-->A:T transversions at $\mathrm{CpG}$ sites and, thus, increased mutational yields. Alterations in the genome of breast cells is likely produced by oxidative attack of ROS generated by estrogen-induced oxidative stress in combination with receptor-mediated proliferation of oxidatively damaged cells. This view is supported by the findings of DNA damage induced in vitro or in vivo by estrogen-induced ROS, 4-OH- $\mathrm{E}_{2}$ and both natural and synthetic estrogens in the target organs of cancer [31;32]. Catecholestrogen through redox cycling produce free radicals that generate various forms of free radical-induced DNA damage [31;32]. Cotreatment with an inhibitor of IL-1 $\beta$ and TNF- $\alpha$, pentoxifylline, inhibited stilbene estrogen-induced increase in myeloperoxidase activities, 8-OHdG formation, mutations in the genome and prevented the estrogen induced testicular and uterine pre-neoplastic lesions [9]. Estrogen by stimulating nitric oxide synthase (NOS) and the subsequent generation of NO could affect methylation and expression of genes [97-99]. Thus, ROS/NO induced by estrogen may produce both gene mutations and gene 
silencing, which, in turn, can predispose an individual to the development of cancer. Therefore, estrogen-induced ROS may play multiple roles in tumor initiation and progression. Compelling evidence for the transforming capacity of ROS is the finding that overexpression of Mox1 (the catalytic subunit of NADPH oxidase) induces superoxide generation and transforms NIH 3T3 cells. Furthermore, Mox1-transfected cells produce aggressive tumors in athymic mice similar in size to those produced by Ras-transformed NIH $3 \mathrm{~T} 3$ cells [100], illustrating the critical role of this ROS regulator in vivo. These results are consistent with the concept that generation of genetic alterations is required for the initiation and progression of estrogen-induced tumors.

\section{ESTROGEN-INDUCED ROS MEDIATED REDOX SIGNALINGS}

ROS fulfill the characteristics of a second messenger since they are short-lived (rapidly generated and degraded), produced in response to a stimulus, highly diffusible (e.g., $\mathrm{H}_{2} \mathrm{O}_{2}$ ), and they are ubiquitously present in most cell types. In this section, we review the ROS-mediated signaling pathways which contribute to initiation, promotion and progression of estrogen-dependent breast tumors. Signaling proteins, including protein tyrosine phosphatases and several transcription factors, that contain critical cysteines are sensitive to redox changes and thus are potential targets of modifications by ROS (Figure 4). A common feature of redox signaling appears to be the oxidative modification of critical cysteines in protein phosphatases that act on protein kinases. Kinases in turn activate redox sensitive transcription factors that influence the expression of genes involved in cell transformation, cell growth, and cancer progression. 
Regulation of phosphatases by estrogen-induced ROS: ROS reversibly regulate cysteinebased phosphatases, which include protein tyrosine phosphatases (PTPs), dual-specificity phosphatases (such as, Cdc25s), low-molecular-weight PTPs, and the lipid phosphatase, PTEN. Oxidation of PTPs can be reversed by thiol compounds, once the catalytic cysteine forms a disulfide bond with an N-terminal cysteine. This disulfide bond can originate from same site cysteines, as is the case with low molecular weight PTPS, from "distant" cysteines such as with PTEN and Cdc25, or from a bond between the PTP and a thiol, such as with PTP1B. The important step of the disulfide bond blocks the oxidation of the thiolate to Cys-SOH by the connection to another thiolate. Oxidation and phosphorylation have the potential of influencing each other in the signaling of PTPs and protein tyrosine kinase (PTKs). We have used Cdc25 as a major focus of this section to describe the redox regulation of phosphatase by estrogen-induced ROS. The Cdc25s, dual-specificity tyrosine phosphatases, possess the necessary elements to function directly in redox control of the cell cycle. Three homologues of Cdc25s exist in humans: Cdc25s A, B, and C. All contain a nucleophilic catalytic cysteine within a conserved motif that enables these enzymes to dephosphorylate phosphoproteins. The first suggestion that $\mathrm{Cdc} 25$ phosphatases act as potential redox controllers of the cell cycle was made more than 10 years ago by Mori laboratory which showed the direct involvement of ROS in the two-cell block of the mouse embryo [101]. Embryo development past the two-cell stage occurred when they injected the ROS modifiers SOD or Trx in vitro. Trx was shown to act through the phosphorylation state of Cdc2 kinase because the injection of Trx led to dephosphorylation and activation of the Cdc2 kinase during M-phase of the second cleavage. Other studies suggested that the oxidative stress 
generated in human cells in response to UV or IR exposure degrades Cdc25s- A through its phosphorylation on serine-123 by check point kinase (chk) [102;103]. This leads to its ubiquitylation and its proteolytic degradation. In contrast, Finkel's laboratory has shown that $\mathrm{Cdc} 25 \mathrm{C}$ undergoes rapid non proteasomal degradation in response to $\mathrm{H}_{2} \mathrm{O}_{2}$ treatment in HeLa cells [104]. This response is due to a decreased half-life for Cdc25C as a result of disulfide linkage formation between its active-site and backdoor cysteines. Cdc25C's response to $\mathrm{H}_{2} \mathrm{O}_{2}$ treatment does not depend on the Chk pathway, suggesting a direct interaction between ROS and Cdc25C. The active-site cysteines of the Cdc25's are highly susceptible to oxidation [105]. The rate of thiolate conversion to the sulfenic acid by $\mathrm{H}_{2} \mathrm{O}_{2}$ for $\mathrm{Cdc} 25 \mathrm{~B}$ is 15 -fold and 400 -fold faster than that for the protein tyrosine phosphatase PTP1B and the cellular reductant glutathione, respectively [105]. Cdc25A $\left(69 \mathrm{M}^{-1} \mathrm{~S}^{-1}\right)$ and $\operatorname{Cdc} 25 \mathrm{C}\left(120 \mathrm{M}^{-1} \mathrm{~S}^{-1}\right)$, with highly homologous catalytic domains to Cdc25B ( $60 \%$ identity), are only slightly less reactive than $\operatorname{Cdc} 25 \mathrm{~B}\left(164 \mathrm{M}^{-1} \mathrm{~S}^{-1}\right)$. The sulfhydryl group on cysteine residues can be oxidized to form a disulfide bond (CysSSR), sulfenic acid (Cys-SOH), sulfinic acid $\left(\mathrm{Cys}-\mathrm{SO}_{2} \mathrm{H}\right)$ or sulfonic acid $\left(\mathrm{Cys}-\mathrm{SO}_{3} \mathrm{H}\right)$; the two latter being quite stable while disulfide bonds and protein sulfenic are relatively reactive and are often considered as the mediators in redox signaling. The active-site cysteine is protected by rapid intramolecular disulfide formation with back-door cysteines in wild-type enzymes and these intramolecular disulfides can then be rapidly and effectively reduced by $\operatorname{Trx} / \operatorname{TrxR} 2$ but not glutathione [105]. Finkel and his associates fail to show oxidation of Cdc25A, because they used very a high concentration of $\mathrm{H}_{2} \mathrm{O}_{2}$ [106]. 
Rudolph's laboratory has shown that the oxidation of Cdc 25 's catalytic site cysteine residues decrease its activity via the formation of an intramolecular disulfide bond. In addition, the catalytic cys 430 formed a disulfide bond with the invariant cys384 in some crystals suggesting that Cdc25 may be self inhibited during oxidative stress. The nucleophilic catalytic cysteines of phosphatases are known to be highly susceptible to oxidation, a property that permits redox regulation of this enzyme family. Recent studies have shown that $\mathrm{O}_{2}{ }^{-}$is a more efficient regulator of PTP1B than $\mathrm{H}_{2} \mathrm{O}_{2}$, with a calculated rate constant in vitro $\left(\sim 3 \times 10^{2} \mathrm{M}^{-1} \mathrm{sec}^{-1}\right)$ about eight times faster than for $\mathrm{H}_{2} \mathrm{O}_{2}$ [107]. Nevertheless, one can argue that the reaction rate would be more than 100 times faster with $\mathrm{H}_{2} \mathrm{O}_{2}$ than with $\mathrm{O}_{2}{ }^{-}$in cells, considering that the steady state concentration of $\mathrm{H}_{2} \mathrm{O}_{2}$ in the cytosol is approximately $10^{3}$ times more than the concentration of $\mathrm{O}_{2}{ }^{-}{ }^{-}[108]$. As described above, $\mathrm{H}_{2} \mathrm{O}_{2}$ exposure oxidized $-\mathrm{SH}$ group of $\mathrm{Cdc} 25 \mathrm{~A}$ faster than that of PTP1B [105;109]. Besides the widely believed concept that chk-mediated phosphorylation leads to $\mathrm{Cdc} 25$ proteosome-dependent degradation; its activity appears to be regulated by oxidation in the same way as oxidation regulates PTP1B activity.

A rapid decrease in Cdc25A activity was shown when MCF-7 cells were exposed to physiological concentrations of estrogen [51]. A similar decrease in Cdc25A activity was observed in $\mathrm{H}_{2} \mathrm{O}_{2}$ treated HeLa cells [110]. Further examination revealed a lower level of Cdc25A - SH residues in the estrogen treated group compared to the vehicle control [51]. In addition, cotreatment with antioxidants prevented the oxidation of $-\mathrm{SH}$ residues in estrogen treated cells [51]. These findings suggest that estrogen-induced ROS oxidatively inactivates Cdc25A. A recent study showed that the oxidation of the Cdc25 
active cysteine site leads to enzyme inactivation [111;112]. We and others have also identified an estrogen mediated protein interaction between Cdc25A and ERK in MCF-7 and hepatoma cells respectively when treated with Cdc25A inhibitor Cpd [113]. Independent of ER\&\&, estrogen activates the MAPK pathway via ROS -dependent inactivation of Cdc25A. An increase in Cdc25A mRNA has been reported after 6 hrs of $\mathrm{E}_{2}$ treatment and an increased synthesis of $\mathrm{Cdc} 25 \mathrm{~A}$ protein was detected from 10 to 12 hrs after $\mathrm{E}_{2}$ treatment $[114 ; 115]$. The level of $\mathrm{Cdc} 25 \mathrm{~A}$ protein did not change immediately after $E_{2}$ exposure, however, an increased in the level of its protein as early as $3 \mathrm{hrs}$ after $\mathrm{E}_{2}$ exposure was detected. This observation suggests that E2 treatment increases Cdc25A stability. We further looked for any post-translational modification from $\mathrm{E}_{2}$-exposure because full enzymatic activity of $\mathrm{Cdc} 25 \mathrm{~A}$ requires phosphorylation at multiple Ser and Thr residues in the amino-terminal of the protein. In contrast to UV or IR effects on Cdc25A in cells, we observed a rapid decrease in serine phosphorylation of Cdc25A in response to physiological concentrations of estrogen which paralleled the decrease in phosphatase activity. A similar decrease in the serine phosphorylation of Cdc25A and its activity was observed in response to the exposure of cells with $\mathrm{H}_{2} \mathrm{O}_{2}$. Cdc25A is also phosphorylated at tyrosine residues, and in contrast to serine phosphorylation, tyrosine phosphorylation of Cdc25A was enhanced in cells treated with estrogen or $\mathrm{H}_{2} \mathrm{O}_{2}$. Others have also shown that lower oxidant concentration increase the rate of tyrosine phosphorylation by tyrosine phosphatase [116]. These studies did not examine the oxidation of active site cysteines nor did they explain how tyrosine phosphorylation occurred and how tyrosine phosphorylation inactivated phosphatase activity. ROS activated ERK enhanced tyrosine phosphorylation of Cdc25 $\mathrm{A}_{\text {in }} \mathrm{E}_{2}$-treated 
MCF-7 cells protects Cdc25A from degradation [117]. Tyrosine phosphorylation of increased the half-life and accumulation of Cdc25A which may contribute to Cdc25A stimulated $\mathrm{Cdk} 2$ activity.

Besides the Cdc25, some of the other phophatases, such as, MKP3, PTEN, PTP1B1, PTP2A, and PP5 [118-120] are responsive to ROS and regulate estrogen-mediated signaling. For example, the activity of Ser/Thr protein phosphatase 5 (PP5) is responsive to oxidative stress and estrogen. Elevated levels of PP5 protein found in human breast cancer have been linked to the progression of human breast cancer [121]. ERK-specific phosphatase MKP3 is another ROS responsive phosphatse that may influence phosphorylation at Ser118 of ER $\alpha$ by regulation of pERK1/2 MAPK. Antioxidant treatment by increasing MKP3 phosphatase activity blocked tamoxifen resistance [122]. These phophatases are reversibly regulated by ROS. These oxidatively modified phophatases act on their corresponding kinases based on their temporal and spatial localization in the cells.

Activation of kinases by estrogen-induced ROS: Structural changes to PTPs, as well as serine/threonine and phospholipid phosphatases, are induced by ROS, and the altered protein conformation leads to signaling cascade upregulation. Included in these cascades are src/Abl kinase-dependent, MAPK-dependent, and PI3 kinase-dependent pathways, leading to activation of AP-1, NF-kB, NRF1, and other redox-regulated transcription factors.

We describe below some of the kinases which may be influenced by estrogen-induced ROS signaling via redox regulation of phosphatases. 
A-Raf: The mitochondrial localization of protein kinases A-Raf, $\mathrm{PKC} \delta$, and $\mathrm{PKC}$ is evidence that this subcellular compartment harbors redox sensors [123;124]. The role of the protein kinase A-Raf in the mitochondria is not clear, but A-Raf mRNA is highly expressed in normal murine tissue [125]. In HeLa cells, epidermal growth factor (EGF) rapidly and transiently activates A-Raf, which in turn phosphorylates the MAP kinase activator MEK1 [125]. Interestingly, $\mathrm{E}_{2}$ can stimulate the phosphorylation of A-Raf and it appears to participate in cell cycle progression in $\mathrm{ER}^{+} \mathrm{MCF}-7$ cells [126]. Thus, it appears that mitochondrial oxidants may modulate estrogen-induced cell proliferation via A-Raf pathway. In addition to A-Raf, other redox sensitive proteins associated with mitochondria, $\mathrm{PKC} \delta$ and $\mathrm{PKC} \zeta$, have been demonstrated to activate the Raf/MEK/ERK pathway or directly activate MAPKs, respectively [124;127]. As zinc finger domains of Raf and PKC are targets of oxidative stimuli and Raf and PKC are localized in mitochondria, estrogen-induced ROS may activate A-Raf and/or PKC via the MEK/ERK pathway. Signaling pathways involving JNK and p38 MAPK are very responsive to redox regulation. JNKs have been studied primarily in the context of stress responses and apoptosis; however, accumulating evidence indicates that the JNK pathway also contributes to proliferative responses. For example, JNK1 $1^{-/-}$mouse embryonic fibroblasts (MEFs), as well as JNK1-JNK2-/ MEFs, proliferate more slowly than do wild-type MEFs and reach a lower saturation density, establishing that JNK is required for normal MEF proliferation [128]. A role for JNK in cancer development is supported by recent studies. It has been shown that skin tumorigenesis is suppressed in JNK2-deficient mice [129], and expression of an inactive variant of the JNK substrate c-Jun in immortalized fibroblasts expressing v-Src and v-Fos reduces tumorigenicity in nude mice [130]. The 
oxidative enhancement of Src-family tyrosine kinases and certain PKC isoforms as well as the dissociation of the JNK/GSTp and ASK1/Trx complexes may together contribute to the redox sensitivity of these pathways. These and other data suggest that signaling through the A-Raf/JNK pathway is very responsive to redox regulation and mediates oncogenic signals and supports cell proliferation in the absence of stress.

ERK: In addition to the ability of $\mathrm{E}_{2}$ to promote ER-dependent gene transcription, it rapidly activates ERK-1 and ERK-2 [130-134]. The activation mechanism by which this rapid signaling event occurs is unclear. The activation is extremely fast and it is believed that they are initiated at the plasma membrane and do not involve ER-mediated gene transcription. Several investigators have concluded that estrogen-induced MAPK activation is promoted by membrane bound ER $\alpha$ or ER [135-137]. There are no known functional motifs within the structure of the ER that can promote second messenger signaling [138]. Most of the studies investigating rapid MAPK activation by estrogen have employed estrogen responsive cells including MCF-7 breast cancer cells [133;139], osteosarcoma cells [140], and neuroblastoma cells [141]; yet these studies have not directly addressed the roles of ER $\alpha$ an $\$$ friR promoting estrogen -induced ERK activation. There are reports which show no correlation betweenßERxporession patterns and the activation of ERK-1/-2 in estrogen treated breast cancer cell lines. Both estrogen and the pure antiestrogen ICI182780 activate ERK-1/-2 in human SKBR3 breast carcinoma cells, which lack ER $\alpha ß$ protein and m RNA [131]. Other researchers have suggested that a membrane-associated ER-like G protein is responsible for nongenomic estrogen signaling [142-144]. They showed evidence that cellular expression of the 
orphan receptor, GPR30, is sufficient for estrogen-induced activation of ERK-1/-2. Based on these observations, it is not clear which membrane protein or how the membrane proteins (ER or GPR30) activate ERK signaling in estrogen exposed normal or cancer cells.

In many cells, extracellular $\mathrm{H}_{2} \mathrm{O}_{2}$ alone activates ERK-1/-2. As discussed previously, studies have shown that estrogen exposure rapidly activates ERK and our work indicates that both estrogen and $\mathrm{H}_{2} \mathrm{O}_{2}$ rapidly inactivate $\mathrm{Cdc} 25 \mathrm{~A}$ and activate the ERKs in MCF-7 cells. Inactivation of $\mathrm{Cdc} 25 \mathrm{~A}$ by its inhibitor $\mathrm{Cpd} 5$ results in the activation of EGFR tyrosine kinase and more recently was shown to activate ERK-1/2 in hepatoma cells [113]. Both EGFR and ERK have been shown to form protein complexes with Cdc25A in hepatoma cells [145]. Since ERK can interact with and phosphorylate EGFR, Cdc25AERK interaction could be responsible for EGFR activation. Moreover, napthoquinone based inhibitors inactivate Cdc25A by covalently binding to cysteine residues at the active sites of Cdc25A [146]. Thus, it is possible that ERK may be activated by inhibiting its association with $\mathrm{Cdc} 25 \mathrm{~A}$ or inactivating Cdc25A through its redox regulation by estrogen-induced ROS.

AKT: AKT (also called PKB) is a serine-threonine protein kinase. It is a downstream target of PI3-kinase. AKT binds to the products of PI3-kinase. AKT affects numerous downstream targets either directly or indirectly, including the pro-apoptotic proteins Bad and Caspase 9, the growth-inhibitory proteins glycogen synthase kinase-3 $\beta$, the forkhead transcription factors, the kinase IKK $\alpha$, and the kinase mTOR [147;148]. AKT has 
recently been identified to control NRF1 activity [149]. Several investigators have concluded that estrogen-induced AKT activation is promoted by membrane bound ER $\alpha$ or ER $\beta[150 ; 151]$. There are no known functional motifs within the structure of the ER that can promote second messenger signaling. There are reports which show no correlation between $\mathrm{ER} \alpha / \beta$ expression patterns and the activation of AKT-1/-2 in estrogen treated breast cancer cell lines. 17 $\alpha$-estradiol, through an ER independent mechanism, activates PI3K-AKT signaling [152]. Recently Lee et.al., [151] reported that up-regulation of PI3K/AKT signaling by $\mathrm{E}_{2}$ is mediated through activation of $\mathrm{ER} \alpha$, but not ER $\beta$. In ovarian cancer cells, 4-OH- $\mathrm{E}_{2}$ induces AKT phosphorylation while 2-OH- $\mathrm{E}_{2}$ did not [153].Our study showed that 4-OH-E $E_{2}$ increased AKT poshphorylation in ER $\alpha$ lacking MCF-10 cells. Based on these observations, it is not clear which membrane protein and/or how the membrane proteins activate AKT in estrogen exposed normal cells. AKT activity depends on its phosphorylation, which is positively regulated by PI3K and negatively regulated by a class of protein phosphatases (PPs) [154]. AKT can be activated by both $\mathrm{E}_{2}$ and $\mathrm{H}_{2} \mathrm{O}_{2}$ [118;149-151]. ROS reversibly regulate cysteine-based phosphatases [119]. There are indirect evidences indicating that AKT associates with Cdc25. For example, AKT phosphorylates Cdc25s [155]. AKT activation suppresses Cdc25 inhibitor napthoquinone- and methylating agent temozolomide -induced $\mathrm{G}_{2}$ arrest and cell death $[156 ; 157]$. A recent study indicate that Cdc25A interacted with AKT [158]. The reversible inactivation of Cdc25A or PTEN by estrogen-induced ROS appears to be a potential key player in the activation of AKT. 
Activation of redox sensitive transcription factors by estrogen-induced oxidants signaling: A significant number of transcription factors, including estrogen receptor, are redox sensitive. Some of these transcription factors contain critical cysteine residues that can be affected by ROS. As described above, signaling pathways are targeted by ROS, which result in the activation of kinases through inactivation of redox sensitive phosphatases. The active kinases, in turn, regulate phosphorylation of transcription factors. Regulation of AP-1, NF-kB, and CREB by both estrogen and ROS is widely accepted and their redox regulation by ROS has been discussed [9;118]. We have focused our discussion mainly on NRF1 in this section.

ER: A large class of DNA-binding proteins such as the glucocorticoid receptor (GR), ER, and early growth response factor-1 (egr-1), contain zinc finger domains [159], which consist of at least two zinc-coordinated thiolates. Oxidation of a zinc finger converts cysteine thiol groups to disulfide releasing zinc from the protein and resulting in a change in protein conformation that may affect protein function. Interestingly, oxidative stress has been reported to modulate ER $\alpha$ and ER $\beta$ expression in various cell lines. In human breast cancer cells MCF-7 and T-47D, exposure to $2.5 \mu \mathrm{M}$ of $\mathrm{H}_{2} \mathrm{O}_{2}$ increased the protein level of ER $\alpha$ while having a minimal effect on ER $\beta$ [160]. Endogenous oxidative stress induced by PMA $(100 \mathrm{ng} / \mathrm{ml})$ in the macrophage cell line, J774A1 also increased the expression of ER $\alpha$ [75] and it was found that Ras mitogenic activity is, in part, superoxide dependent. A recent study showed that at least 75 genes out of 891 estrogen/ER-regulated genes were responsive to oxidants and ER $\alpha$ silencing. The oxidant-sensitive subset of estrogen/ER-responsive breast cancer genes are linked to cell 
growth and invasion pathways. Findings of this study suggest that oxidant sensitive signaling pathways contribute to the development of an aggressive subset of $\mathrm{ER}^{+}$breast cancers [161]. Although protein kinases are known to participate in phosphorylation signal cascades, they may also participate in redox signaling networks due to these zinc finger domains, e.g., ROS can activate PKC that triggers the release of zinc ions [162;163]. Another protein kinase, c-Raf, known to participate in the MAPK signal cascade was also demonstrated to be redox-activated at the zinc finger domain [162;164]. As zinc-finger domains within these kinases have been reported to act as oxidant sensors, a mode of cross-communication appears to exist between redox and phosphorylation networks. Like serine-thereonine phosphatases as discussed above, ROS can inhibit some of the protein tyrosine phosphatases by reversible oxidation of their cysteine residues and enhance protein kinases, such as Src, c-Jun amino-terminal kinase (JAK), Ras, PKC, and MAPK [21]. These kinases are involved in modulating ER signaling [165;166]. Thus, ROS-mediated signaling represents another means by which ER function can be modulated by oxidants, and may be responsible for the clinical phenotype of ER breast cancer. Rapid effects of estrogen have been demonstrated to mediate the DNA binding activity and phosphorylation of transcription factors. For instance, a $10 \mathrm{nM}$ estradiol treatment of rat adipocytes doubles AP-1 DNA binding in 15 min [167]. In addition, CREB protein is phosphorylated rapidly by estradiol $(10 \mathrm{nM})$ treatment within $15 \mathrm{~min}$. Given that estradiol can stimulate mitochondrial ROS generation and that the transcription factors AP-1, NF-kB, and CREB are targets of oxidative stimuli [167;168], it is possible that estrogen-specific effects at the level of the mitochondria can activate these transcription factors by above-descibed signal transduction pathways. 
Mitochondrial generation of ROS leading to the activation of transcription factors AP-1, NF-kB, and CREB has downstream consequences for apoptosis, cell cycle progression, cell transformation, cell migration and cell invasion.

$\underline{\text { AP-1 and CREB: }}$ Growth factors and TPAactivate AP-1-dependent transcriptional activation and evidence is accumulating that ROS and 4-Hydroxy-2-nonenal (4HNE) increase the DNA binding activity of AP-1 [169-174]. The initial increase is not dependent upon protein synthesis and probably involves post-translational modifications of previously existing AP-1 complexes; however, increased synthesis of Fos and Jun also occurs rapidly upon stimulation [175]. Jun transcription is controlled by TRE and MEF2 sites while Fos transcription requires SRE and CRE sites that are regulated by all three MAPK cascades [176]. Binding of AP-1 to DNA can occur without phosphorylation, but increased binding and transcriptional activation are both signaled by phosphorylation of Fos and Jun [177]. Several transcription factors, including c-Fos and Elk-1 are phosphorylated by ERK1/2. The JNK and p38MAPK are more strongly activated by stress signals and their activation occurs through similar phosphorylation cascades. The c-Jun family of transcription factors are specifically phosphorylated by the JNK at Ser 63 and Ser 73 in a two-step process that requires binding to the delta subdomain prior to efficient phosphorylation at the $\mathrm{NH}_{2}$-terminal activation domain[178]. JNK also binds and phosphorylates the Elk-1 and ATF-2 transcription factors [179;180]. The phosphorylation of Jun at the N-terminus by JNK not only is required for transcriptional activation $[181 ; 182]$ but also seems to protect Jun against degradation by ubiquitination 
[183]. This results in an increase in the half-life and accumulation of Jun that may contribute to the JNK-stimulated AP-1 transcriptional activity.

In addition to phosphorylation, the AP-1 complex is regulated by redox mechanisms. Fos and Jun have a single conserved cysteine residue located in the basic region of DNAbinding domains that must be reduced for DNA binding activity [184]. The transcription factor AP-1 is strongly responsive to redox regulation. The exact nature of the redox change is not clearly identified. Recent in vitro data indicate that reversible Sglutathiolation of the conserved cysteine may be involved [185]. Others suggest that the reversible redox regulation of AP-1 is mediated by Trx and the nuclear protein Ref1, which both increase AP-1 binding activity [186;187]. Direct association between Trx and Ref-1 has been reported [188]. Recently we have demonstrated the evidence for the involvement of redox signaling with estrogen-induced cell proliferation [28;75]. Physiological concentrations of $\mathrm{E}_{2}$ stimulate a rapid production of intracellular ROS which lead to the phosphorylation of c-jun and CREB. Although direct ER transcription factor effects are required to promote DNA synthesis, our recent data showed that MCF-7 cell growth and cyclin D1 expression are suppressed by antioxidants and mitochondrial blockers. This observation supports our novel finding that nongenomic estrogen-induced mitochondrial ROS modulate the early stage of cell cycle progression [28]. It has become evident that regulation of the cellular redox environment is critical for estrogenmediated signaling. Thus, ROS may regulate AP-1 activity through several targets. ROS can modulate effector molecules such ERK and the c-fos/c-jun heterodimer (AP-1); and these effector molecules are known to participate in growth signal transduction [28;30]. It 
is possible that JNK pathway may be involved in the AP-1 binding and transcriptional activation induced by mitochondrial oxidants produced upon exposure to estrogen. Although the ERK pathway has been shown to be involved in AP-1 activation by other agonists, we think that it may not participate in this case, based on the inability of $\mathrm{H}_{2} \mathrm{O}_{2}$ alone to stimulate the ERK pathway in MCF-7 cells [189]. JNK is activated by stress stimuli through an activation module that may include the MAP3K apoptosis-signal regulating kinase (ASK-1) [85].Interestingly, recent data suggest that ASK-1 is activated by ROS either through Trx oxidation [190] or through dimerization [191]. Thus, ROS can either activate the JNK module or induce the formation of 4HNE, which may directly activate JNK [173].

The expression of early G1 genes, c-myc, c-fos, c-jun, cyclin D1, and NRF1 are regulated by ROS [192;193]. The mRNAs of some of these genes are induced by estrogen-induced ROS and $\mathrm{H}_{2} \mathrm{O}_{2}$ as well as other inducers of oxidative stress [114;130;192;194]. As described above c-Fos and c-Jun comprise part of the transcription factors AP-1; and AP1 binding activates the expression of down-stream target genes. In this regard, the induction of c-Fos, c-Jun and cyclin D1 is an ideal paradigm for studying the role of early response genes in response to oxidative stress-induced by estrogen. The mRNAs of c-Fos and c-Jun are induced by estrogen and also by relatively small amounts of $\mathrm{H}_{2} \mathrm{O}_{2}$, superoxide, NO, and other inducers of oxidative stress [114;192]. The earliest known growth-regulatory gene activated by $\mathrm{E}_{2}$ is $\mathrm{c}-\mathrm{Myc}$. Increased transcription of myc, as measured by accumulation of mRNA, occurs within $30 \mathrm{~min}$, and peak protein levels are observed within 1-3 h of treatment with $\mathrm{E}_{2}$ of MCF-7 cells [114]. Recent studies indicate 
that Myc protein is stabilized by $\mathrm{E}_{2}$, up to $12 \mathrm{~h}$ after its addition, well past the decline in mRNA levels. Myc expression elicits active cyclin E-Cdk2 and S-phase entry in growtharrested MCF-7 cells. Although Myc is clearly implicated in $\mathrm{E}_{2}$ action, it was not found in a genetic screen for $\mathrm{E}_{2}$-responsive genes in MCF-7 cells. Myc is induced by exposure to ROS [114]. Cyclin D1 is a well-defined target of $E_{2}$ action in MCF-7 cells, and in rodent breast epithelial tissue, ovary and uterine endometrium. In MCF-7 cells, addition of $E_{2}$ to G0/G1-arrested cells results in a two- to three-fold induction of cyclin D1 mRNA within 1-3 h and a three- to five-fold increase in synthesis and steady-state levels of cyclin D1 protein within 3-6 h. Given that cyclin D1-knockout mice are fertile, the physiologic relevance of ER as a target of cyclin D1 is uncertain. Cyclin D has a half ERE. Planas-Silva et. al., demonstrated that $\mathrm{E}_{2}$ transiently upregulates synthesis of c-Fos and c-Jun in MCF-7 cells, but not in hER-transfected HaCa T nontransformed human keratinocytes [195]. Earlier studies indicated, however, that $E_{2}$ increases AP-1 activity without increased synthesis of c-Jun or c-Fos and without the synthesis of any new proteins. Foster and Wimalasena demonstrated that ligand-activated ER is fully active at 8-10 h after $\mathrm{E}_{2}$ treatment [114]. The products of at least two $\mathrm{E}_{2}$ target genes, c-Myc and cyclin D1, can independently promote G1/S transition in MCF-7 cells and activate cyclin E-Cdk2 coincident with formation of high molecular mass cyclin E-Cdk2-p130 complexes depleted in p21CIP1 and p27KIP1. The expression of c-fos and c-myc did not depend on the presence of growth factors, suggesting that integrins alone through ROS could regulate the Go/G1 transition. Furthermore, integrin clustering in the absence of cell spreading was sufficient to induce expression of early genes (jun B and ras) involved in the $\mathrm{Go} / \mathrm{G} 1$ transition and were able to trigger $\mathrm{G} 1 / \mathrm{S}$ transition through modulating 
cyclin D1 expression [196;197]. Integrins, through ROS, control the expression of these cell cycle genes, and it is now obvious that cell adhesion and integrin ligation are obligatory processes for regulation of cdks and cyclins. JNK and p38 also have been shown to cooperate with ERK in pp60(v-src)-induced cyclin D1 expression in breast cancer cells [114]. However, an unresolved issue regarding $\mathrm{E}_{2}$-mediated signaling is whether $E_{2}$ receptors themselves actually initiate signal that can intervene in the Go/G1 and G1/S transitions. The expression of early G1 genes, c-myc, c-fos, c-jun , cyclin D1 are regulated by ROS [192]. Low and intermediate levels of RO/NS regulate cellular signaling and play an important role in normal cell proliferation [9;196]. Constant activation of AP-1 transcription factor appears to be one functional role of elevated ROS levels during tumor progression [198]. Based on these data, estrogen-induced ROS may control the expression of genes involved in cell cycle progression.

NF-kB: Activation of NF-kB is another well-studied model of redox regulation. The oxidation of a conserved cysteine residue in the DNA-binding region adjacent to the leucine zipper in AP-1 abolishes its binding to DNA [185]. The DNA binding activity of AP-1 is restored by Trx and the nuclear signaling protein redox factor-1 (Ref-1) [188] and enhanced by transient overexpression of Trx in vivo. Compared with NF-kB, AP-1 is less sensitive to oxidative inhibition by glutathione disulfide in vitro but more sensitive to oxidized Trx. Thus, in intact cells, the elevation of intracellular oxidized glutathione (GSSG) levels by inhibition of glutathione reductase inhibits selectively the DNAbinding activity of NF-kB and not that of AP-1 [199]. The protein NF-kB is regulated by its interactions with the inhibitory co-factor, which sequesters NF-kB to the cytoplasm. 
AKT is known to phosphorylate an upstream kinase, IKK $\beta$, which stimulates the degradation of Ik-B [130]. As AKT can participate in the activation of IKK $\beta$, it may be possible for estrogen-induced mitochondrial ROS to stimulate the transcription activity of NF-kB via the AKT pathway.

NRF1: The human alpha-palindromic nuclear respiratory factor -1 binding protein (NRF1) is a 503 amino acid (aa) transcription factor [200;201], located on chromosome $7 q 32.2$ [202] and codes for $68 \mathrm{kDa}$ nuclear proteins [200;203]. Several compounds that induce cellular oxidative stress have been shown to increase NRF1 expression and increase in mitochondria proliferation. For example, the bacterial lipopolysaccharide and tertiary butyl hydroperoxide have both been demonstrated to induce cellular oxidative stress which upregulates NRF1 expression and mitochondria biogenesis in rat liver cells [149;193]. Likewise, rat liver cells overexpressing NRF1 have been shown to induce ROS production and increase in mitochondria proliferation [149]. Similarly, exposures of human lung fibroblast cell line, MRC-5, with $\mathrm{H}_{2} \mathrm{O}_{2}$ at concentrations of 90-360 $\mu \mathrm{M}$ induced increases in mtDNA and mitochondria biogenesis in exposed cells [204]. The role of oxidative stress and NRF1 expression were further corroborated by works done by Miranda et. al., which revealed that HeLa cells depleted of mtDNA were under oxidative stress which induced expression of NRF1 and mitochondrial biogenesis [205]. Lastly, estrogen exposure has been reported to increase NRF1 overexpression which increased mitochondria biogenesis in MCF-7 malignant mammary epithelial cells, and human bronchial epithelial cells from female patients [206;207]. 
Oxidants modulate NRF1 expression and mitochondria biogenesis; antioxidants conversely inhibit intracellular ROS and NRF1 expressions. For example, oral administration of vitamin $\mathrm{C}$ has been demonstrated to inhibit NRF1 expressions with reduction in mitochondria biogenesis and diminished endurance training capacity [208]. In addition, catalase overexpressions have been shown to reduce NRF1 expressions and mitochondria content in heart muscles of aged mice which attenuated age related diseases observed in mice [209]. These studies imply that cellular oxidative status modulates NRF1 expression. Activated NRF1 expressions in response to ROS can lead to enhanced mitochondria biogenesis and increased bioenergetics, as well as regulation of genes involved in apoptosis and cell cycle progression.

NRF1 expression in MCF-7 (or any $\mathrm{ER}^{+}$cell types) may not be entirely due to cell's ER status. Estrogens concentration of $10 \mathrm{nM}$ has been reported to induce oxidative stress in MCF-7 cells [210;211]. In a similar manner, the pro-oxidative compound sodium butyrate [212;213] has also been shown to induce NRF1 expression in MCF-7 cells [214]. Sodium butyrate lacks estrogenic property. In addition, oxidative stress has been reported to induce NRF1 expressions in $\mathrm{ER}^{-}$breast cancer cell line such as MDA-MB468 as well as in ER ${ }^{-}$human bone osteosarcoma (U2OS) cells [215]. Likewise, SERMs such as TAM, RAL and Fulvestrant which are also pro-oxidant upon chronic exposures [216], also increase NRF1 expressions in SERM resistant MCF-7 cells [217]. These studies suggest that estrogen inductions of NRF1 in estrogen responsive breast cancer cells are not exclusive to ER status. It implies that perhaps estrogen induced oxidants also mediate NRF1 expressions in breast cancer cells irrespective of ER status. This point is 
important when considering mechanisms by which estrogen induce mammary carcinogenesis and growth of breast cancer cells.

This observation is supported by several findings. For example it has been reported that exposures of rat cardiomyocytes and liver cells to sublethal levels of pro-oxidative compounds such as LPS or t-BOOH induced oxidative stress, NRF1 expressions, mitochondria biogenesis, and promoted cell's survival and growth [193;218]. Conversely, silencing of complex II, one of the primary genes regulated by NRF1, inhibited OXPHOS, ROS production and augmented cell growth [219]. In similar manner, exogenous addition of oxidants to hepatoma cells depleted of mitochondria induced NRF1 expressions and cell proliferation [149]. These findings imply that oxidant induced NRF1 regulation promotes cell growth by coupling mitochondria bioenergetic with cell proliferation. This is further supported by findings in our laboratory that chronic exposures of non-tumorigenic, ER ${ }^{-}$mammary cells (MCF-10A) with $100 \mathrm{ng} / \mathrm{ml}$ estradiol or its catechol derivatives, $4-\mathrm{OH}-\mathrm{E}_{2}$ but not $2-\mathrm{OH}-\mathrm{E}_{2}$, induced oxidative stress, mammary transformations as well as up-regulations of NRF1. However silencing of NRF1 inhibited estrogen induced oxidative stress and inhibition of cell's transformation [49;50]. Similar observations were also reported in pre-malignant primary fibroblast cells. In these cell lines, it was observed that NRF1 and other mitochondria genes were among the transcription factors over-expressed during malignant transformation [220]. However in this study, high NRF1 expressions were likewise linked to oxidative stress and energy demand by proliferating cells. These studies imply that for cells to survive in elevated oxidative environment, they must be able to up-regulate NRF1 expression, which in turn 
increases mitochondria biosynthesis and OXPHOS. However, it is counterintuitive to upregulate pro-oxidative mechanisms during periods of oxidative stress. It is therefore speculated that high ROS levels serve other purposes such as clonal selection of neoplastic cells, and induction of apoptosis in non-neoplastic cells [221;222]. Similar mechanism might be in play during estrogen induced mammary carcinogenesis. In population of initiated cells, oxidative stress and NRF1 expression may serve to provide a pro-tumorigenic selective environment as well as the energy necessary for these cells to proliferate and grow, irrespective of ER status.

Though estrogens have been reported to modulate NRF1 expressions via $\mathrm{E}_{2} / \mathrm{ER}$ binding to ERE on NRF1 promoter regions in a number of cell lines [206;207], we demonstrated that prolonged treatment of MCF-7 cells with estrogen also induced NRF1 expression, increased cell proliferation and colony formation in soft agar assays (Okoh et al, unpublished data). Interestingly, the silencing of NRF1 or pretreatment of cells with NAC significantly reduced NRF1 expression and inhibited estrogen induced cell proliferation and anchorage independent growth (Okoh et al, unpublished data). Conversely, overexpression of NRF1 in the same cell line increased cell proliferation independently of estrogen action. These findings from our laboratory therefore imply that NRF1 expression observed in MCF-7 cells treated with estrogen is redox based as antioxidants abolish NRF1 expressions. It also suggests that redox expressions of NRF1 due to estrogen exposure may contribute to breast cancer cell growth independent of $\mathrm{E}_{2} / \mathrm{ER} / \mathrm{ERE}$ mechanisms. If this is the case, it can be surmised that estrogen induced ROS contributes in part to growth of malignant cells in a manner unrelated to ER activations. This 
assertion may therefore explain why oxidative stress is positively correlated with tumorigenesis [223;224], aggressive breast cancer phenotypes [225], and therapeutic resistance of breast cancer patients [226].

\section{ROLE OF ESTROGEN-INDUCED REDOX SIGNALING IN THE DEVELOPMENT OF BREAST CANCER}

ROS affects generation of new phenotypes of cells during the development of breast cancer through its influence on the regulation of protein kinases and signal transduction pathways. Here we describe how estrogen-induced ROS may contribute in the generation of different cell phenotypes required for the development of breast cancer.

Estrogen-induced ROS as potential mediator of cell transformation and generators of

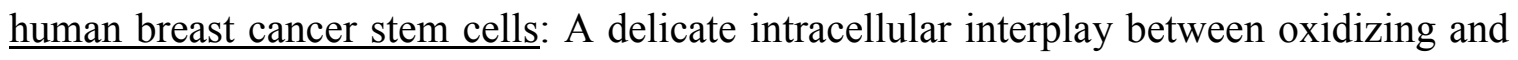
reducing equivalents allows ROS to function as second messengers in the control of cell proliferation and cell transformation [227;228]. Many studies implicate ROS in cell transformation and in the uncontrolled growth potential of tumor cells [224;229-233]. We also find that estrogen stimulates the growth of TM3 and HEK 293 cells in an ERindependent manner [9;30]. In another study estradiol-induced kidney tumor incidence in Syrian hamsters treated with antioxidants was effectively reduced by ebselen, sodium 2mercaptoethanesulfonate (Mesna, a cytoprotective thiol-containing agent), NAC and vitamin-C administration $[17 ; 18]$. Also, cotreatment with pentoxifylline, an inhibitor of IL-1 $\beta$ and Tumor necrosis factor (TNF $\alpha$ ) synthesis, prevents estrogen-induced testicular and uterine cancers [9]. Superoxide dismutases (SODs) are the first and the most 
important line of antioxidant enzyme defense against ROS and particularly superoxide $\left(\mathrm{O}_{2}{ }^{-}\right)$radical. Overexpression of the enzyme responsible for mitochondrial superoxide detoxification, manganese superoxide dismutase (MnSOD), inhibits the malignant phenotype [234-236]. MnSOD knockout mice exhibit increased oxidative DNA damage [237]. Soini et al.,2001 reported that MnSOD expression is less frequent in the tumor cells of invasive breast carcinomas than in in situ carcinomas or non-neoplastic breast epithelial cells. Several epidemiologic studies have shown an increased risk of breast cancer in the MnSOD Ala-Val polymorphic populations [238;239]. In a recent study it was shown that genetic polymorphism in the MnSOD gene may be associated with increased risk of breast cancer among Chinese women with high levels of oxidative stress or low intake of antioxidants [240]. Studies also show that there is no positive relation between genetic variation in MnSOD and breast cancer [241]. Our preliminary study showed that MCF-10A cells treated with 4-OH-E $E_{2}$ rapidly produce ROS, which is preceded by an increase in the level of $\mathrm{Ca}^{2+}$. The accumulation of $4-\mathrm{OH}-\mathrm{E}_{2}$ as recently reported in the human breast tissue in cancer subjects [46;242] will allow increased ROS and $\mathrm{Ca}^{2+}$ levels in the target organ of cancer in a sensitive subpopulation. Later, overexpression of catalase and $\mathrm{MnSOD}$ prevented 4-OH- $\mathrm{E}_{2}$-induced anchorageindependent growth of MCF-10A cells. These data together indicate that 4-OH- $\mathrm{E}_{2}$ induced cell transformation may be mediated, in part, by ROS signal transduction pathways that are different from the classical nuclear ER genomic signaling pathway (Fig. 4). 
Estrogen-induced ROS as mediators of cell cycle progression: As shown in Figure 3, high ROS levels induce oxidative damage and arrests cells in G0/G1. However, low physiologic ROS levels are utilized by cells for cell-to-cell communication and in proliferation [28]. The rapid stimulation of intracellular ROS by PDGF, EGF, and NGF suggests that this underlying mechanism of cell growth may be shared by other growth factors or mitogens, including estrogen [243]. Exogenous addition of low concentrations of $\mathrm{H}_{2} \mathrm{O}_{2}$ and/or $\mathrm{O}_{2}{ }^{-}$has been demonstrated to stimulate cell growth in a variety of cell types including fibroblasts and prostate cancer cells [159]. Although these phenomena have been overshadowed by studies concentrating on the role of ROS in the pathology of various diseases and apoptosis, they suggest that outcomes other than apoptosis may be coupled to the signaling event represented by the estrogen-induced generation of ROS. Cell cycle progression is regulated by an intricate web of signaling pathways mostly requiring growth factor stimulation and ultimately involving cyclins, cyclin-dependent kinases (cdks), and cell cycle inhibitors. Constant activation of redox sensitive transcription factors appears to be one functional role of elevated ROS levels during tumor progression [198]. The results of our more recent studies show that ebselen (a substance with glutathione peroxidase-like activity), and inhibitors of mitochondrial replication and protein synthesis prevent estrogen-induced G1 to S transition. Low and intermediate levels of ROS regulate cellular signaling and play an important role in normal cell proliferation [196]. These data suggest that redox signaling supports cell proliferation in the presence of estrogen-induced ROS. 
Several lines of indirect evidence support a role for mitochondrial oxidants in estrogeninduced cell proliferation. Isoforms of Trx, Trx-2 and thioredoxin reductase (TrxR2), which regenerates the reductant form of Trx, have been detected in mitochondria [89;244]. Dominant-negative inhibition of TrxR2 causes an increase in $\mathrm{H}_{2} \mathrm{O}_{2}$ accumulation, which activates cell proliferation [245] and increased expression of cell cycle genes involved in the $G_{1}$ and $S$ phases of the cell cycle [244-247]. In vitro treatments of primary human endometrial stromal cells with estrogen at different concentrations (10nM-100nM) result in an increase in Trx protein and mRNA expression which implicates Trx in cell growth and differentiation of estrogen responsive tissue [247]. Alterations in the cellular redox status due to increased expression of TrxR2 have been suggested to play a role in the growth of hepatocellular carcinomas [248]. Whether estrogen can specifically increase the expression or activity of Trx 2 and/or TrxR2 is not known, but these findings suggest that estrogen may modulate signal transduction of mitochondrial derived ROS via the thioredoxin system. Indirect evidence is also provided by the overexpression of the MnSOD enzyme responsible for mitochondrial ROS detoxification, which inhibits breast tumor growth [235]. As $\mathrm{H}_{2} \mathrm{O}_{2}$ is a highly diffusible signaling molecule and both MnSOD and NOS are modulated by estrogen [249;250], it is plausible that estrogen-induced ROS signaling at the level of mitochondria contributes to cell proliferation.

Many of the genes associated with high-risk breast tumors appeared to be involved in cell-cycle regulation, including Cdc2 and PRC1 [251]. Integrins through ROS control the expression of cell cycle genes; and cell adhesion and integrin ligation are obligatory 
processes for regulation of cdks and cyclins [182-184]. Recently, an NRF1 and CREB pair has been identified as a key regulator of the transcriptional program of the cell cycle in human cells because this pair of transcription factors show a significant co-occurrence rate on promoters of cell cycle regulated genes [252;253]. NRF1 appears to play an important role as a regulator of cell cycle genes because NRF1 binding site has been identified by comparing genome-wide locations on genes involved in DNA replication, mitosis, and cytokinesis. Some of the genes which contain NRF1 binding sites on their promoters include Cdc2 [254], guanine-nucleotide exchange factor, RCC1, DNA polymerase- $\alpha$, ornithine decarboxylase, GADD153, growth-arrest and DNA-damageinducible protein 153 [252]. Mammary carcinogenesis is characterized by an increased expression of NRF1, which may be linked, with increased energy demand by rapidly proliferating cells [255;256]. However, NRF1's role in mammary carcinogenesis may be more than mere energy modulators. NRF1 has been reported to be over-expressed in a number of malignant tissues including breast cancer tissues where its levels are higher in disease regions compared to adjacent normal regions suggesting that NRF1 may play a role in mammary carcinogenesis [256]. For example microarray study of genes expressed during mammary tumorigenesis in MMTV-neu mouse model reveals that NRF1 were among the transcription factors over-expressed in tumor tissues compared to adjacent normal tissue [257]. Similarly, another microarray analysis of NRF1 expression in human tissues reveals that while normal mammary tissue had more NRF1 expression than most normal tissues analyzed, (except for lung tissues), the levels of this transcription factor were highest in breast cancer tissues compared to other cancer types [256]. Lastly, NRF1 is amongst a few sets of transcription factors whose overexpression is correlated with 
progression of mammary carcinogenesis [255]. While these findings were attributable to increased energy demand, other evidence exist that suggest that these transcription factors may directly or indirectly regulate genes involved in cell proliferation in manners unrelated to mitochondria biogenesis. Whether NRF1's role in these malignant cells is indicative of metabolically active cells or whether it also regulates growth related genes that promotes malignancy is yet to be investigated. NRF1 may also play major roles in modulating cell proliferation in a manner not related to mitochondria biogenesis.

NRF1 regulates many other genes that may be involved in the development of breast cancer than that described above. For instance, there is a striking overlap in target genes between E2F4 and NRF1 [252;255]. E2Fs are target of both estrogen and oxidative stress [258;259]. There is a functional interaction of E2Fs with other transcription factors, such as FOXO1, hypoxia-inducible factor 1 (HIF-1), nuclear factor B (NFB), and peroxisome proliferator-activated receptor (PPAR), including NRF1, during oxidative responses in cells. NRF1 has been reported to transcriptionally regulate the expression of E2F1 [260] and E2F6 [215] genes. Both genes belong to E2F family of transcription factors which functions in cell cycle controls. While E2F1 is generally considered as a transcription factor activator and E2F6 as a transcription factor repressor, the coordinated activities of these genes are essential in regulating cell cycle control and to have a major role during carcinogenic process [261]. Overexpression of E2F1 in mammalian cells has been reported to induce neoplastic transformation of rat embryo fibroblasts, induce colony formation in soft agar assay and induce tumor in nude mice [262;263]. Conversely, under-expression of these same genes has likewise been shown to induce broad range of 
mice tumors as well [264;265]. This seemingly contradictory observation of E2F1 expressions highlights the tight regulations NRF1 must undertake to keep E2F1 gene expression at 'normal' physiological levels. E2F6 is a member of the E2F family of transcription factor involved in regulation of cell proliferation and differentiation via target genes involved in DNA replication, DNA repair, cell cycle control and apoptosis [261;266;267]. E2F6 expressions in cells induces growth by inhibiting cell's exit from the S phase, and delays re-entry into the cell cycle in quiescent cells [268;269]. Growth arrested cells due to delayed cell cycle could accumulate pre-malignant genetic lesions and cell transformations potentials as DNA repairs and proof reading also ceases during quiescence.

Findings that the proliferative growth of breast cancer cells exposed to estrogens activate E2F1 expressions an ER independent manner provide further support to the above concept [270]. Of interest in this study is the finding that overexpression of ER in ER breast cancer cells (MDA-MB-231) did not induce cell proliferation upon estrogen treatment even though E2F1 was mildly activated [270]. Similarly, it was shown in $\mathrm{ER}^{+}$ ZR-75 cells that ER/Sp1/NFY interactions are not necessary for estrogen-induced transactivation [259]. These findings indicate that ER status is not the sole determinant of breast cancer progression and growth due to estrogen exposures. It should be noted also that another study with similar conditions had observed that MCF-7 cells exposed to estrogen increased NRF1 and mitochondrial expressions via ER activation [206]. Both of these in vitro studies with MCF-7 cells may therefore serve to elucidate the mechanism by which estrogen induces growth of breast cancer cells, i.e. estrogens induced oxidants 
mediate NRF1 expression which may regulate E2F1 expression and promote breast cancer cell growth.

Other than binding to promoter regions of target genes involved in mitochondria biogenesis and OXPHOS, NRF1 also modulates genes involved in mitochondria regulations. For example, Nrf-2 (NFE2L2), a redox sensitive gene known to regulate antioxidants responses, has been reported to bind to antioxidant response elements on NRF1 promoter region to regulate ROS production as well as induction of antioxidant responses in cardiomyocytes overexpressing heme oxygenase (HO)-1 [271]. Likewise, cMyc overexpressions and induction of apoptosis in NIH $3 \mathrm{~T} 3$ cells depleted of serum is also reported to be mediated by NRF1 activations [272]. Hormones such as Thyroid hormone $\left(\mathrm{T}_{3}\right)$ and estrogens $\left(\mathrm{E}_{2}\right)$ have also been reported to upregulate NRF1 expressions and mitochondria biogenesis through binding to responsive elements in NRF1 promoter regions $[273 ; 274]$. NRF1 has also been reported to transcriptionally regulate expression of myocyte enhancer factor 2A (MEF2A) which is a muscle specific gene [275]. MEF2A is a DNA-binding transcription factor that activates muscle-specific, growth factorinduced, and stress-induced genes such as the cytochrome c oxidase (COX) subunits 6A (COX6A). Interestingly, MEF2A also functions in skeletal and cardiac muscle development as well as in neuronal cell differentiation and survival. They also play diverse roles in the control of cell growth, survival and apoptosis via p38 MAPK signaling pathway in muscle cells [276]. Dysregulation of MEF2A is implicated in Chinese patients with coronary artery disease [277;278] and in hepatocellular carcinoma [279]. Our recent study showed that co-exposure of inhibitors of mitochondria shown to 
control mitochondrial oxidant production prevents $E_{2}$-induced expression of cell cycle genes, cyclin B1, PCNA, and PRC1 containing NRF1 binding sites, and caused loss of NRF1 expression and growth delay. The $E_{2}$-induced stimulation of the expression of NRF1 and these cell cycle genes, and growth were restored by removing exogenous mitochondrial inhibitors that diminished oxidant exposure indicating that oxidative stress stimulates these cell cycle genes in part via NRF1 activation. Cyclin D1 has recently been reported to inhibit NRF1 expression which leads to reduced mitochondria biogenesis in mouse embryo fibroblasts (MEFs) [280]. Overexpression of cyclin D1 is usually associated with cancer cell growth [281]. While it is counter intuitive that rapidly proliferating cell such as MEF would inhibit mitochondria biogenesis which is a major source of energy production, proliferating cells do generate excess ROS because they are metabolically active. Excess cellular ROS are known to have adverse effects of cell's fate ranging from apoptosis to growth retardation [228]. Therefore it is plausible that cyclin D1 expression that drives cell cycle progression could also function to reduce mitochondria activity during periods of excess ROS. Hence the inhibition of NRF1 expression by cyclin D1 may be a negative feedback mechanism that protects the cell from harmful effect of mitochondrial derived ROS. This assertion is supported by the fact that cyclin D1 expression is likewise upregulated by mitogenic $\mathrm{E}_{2}[282 ; 283]$ as well as by ROS [284].

Estrogen-induced ROS as a mediators of breast cancer progression: E2F1 is overexpressed in breast tumors when compared with normal mammary tissue, and that patients with high E2F1-expressing tumors have significantly reduced disease-free status 
and overall survival compared with patients with low-expressing E2F1 tumors [285-289]. It should be also noted that NRF1 expressions are positively correlated with oxidative stress and progressions of mouse or human mammary carcinogenesis [255-257]. E2F6 on the other hand are transcription factor repressors and function mainly in growth inhibition [261;268]. Interestingly, one of the target gene of E2F6 is the breast cancer gene BRCA1 [290]. BRCA1 regulates cell cycle progression, apoptosis, and DNA repair, and loss of BRCA1 expression is linked to cell proliferation and transformation [291]. While BRCA1 overexpression has been reported to confer therapeutic resistance, BRCA1 deficiency confers sensitivity to oxidative stress [292]. In addition, BRCA1 mutations are associated with breast cancer progression [290]. Therefore, NRF1 dysregulation of E2F6 can lead to BRCA1 dysfunctions with adverse consequences ranging from apoptotic cell death to malignant transformation of breast epithelial cells.

In addition to regulation of E2F family of transcription factors, NRF1 is also known to regulate genes that favor breast growth and metastasis. For example NRF1 tightly regulates the expression of calpain proteases in normal cells [293]. Overexpression of this protolytic enzyme mediates tumorigenesis, metastasis and angiogenesis in breast cancer and other cancer types [294;295]. NRF1 also regulates expression of integrin-associated protein [296]. Integrins are essential for a cell's adhesion during normal development. Dysregulation of intergrin has been shown to promote carcinogenesis in mammary cells as well as other cells types [297]. Lastly, NRF1 has also been reported to regulate proliferation and growth of breast cancer in response to estrogen via activations of $\mathrm{p} 115$, membrane tethering protein involved in mammary development [298]. 
The DNA binding domain of redox sensitive NRF1 protein has been found in the regulatory regions of over 600 human genes [254]. Interestingly, while NRF1 expression is usually associated with modulating energy demand in proliferating cells, it is equally expressed in quiescence cells albeit by different mechanisms [254]. NRF1 is ubiquitously expressed in skeletal muscles, heart muscle, brown adipose fat, kidney and liver cells, and all cells with high energy demand [82;299;300]. NRF1 has been implicated in regulating genes unrelated to mitochondria biogenesis as well. For example, NRF1 transcriptionally regulates expression of CXCR4, a co-receptor for human immunodeficiency virus infection [301], GluR2, a neural subunit that controls $\mathrm{Ca}^{2+}$ permeability of AMPA receptors [302], CD155, a human polio virus receptor that functions in cell adhesion [201], the X gene of hepatitis B virus (HPV) which functions in HBV replication in vivo [303], integrin-associated protein which plays significant role in neurite outgrowth [296], GalNAc-T3 genes that function in glycosylation of mucin proteins in epithelial derived tumors [214], fragile X mental retardation 1 (FMR1) genes [304], and visinin-like protein-1 (VSNL1), a neuronal $\mathrm{Ca}^{2+}$ sensor protein [305] whose dysregulation is implicated in Alzheimer disease and schizophrenia [306], as well as cancer promotion and metastasis [307] .

These findings suggest that redox sensitive NRF1 directly or indirectly participates in the processes that favor tumorigenic conversion and aberrant cell growth either by modulating energy demand and/or modulating expressions of genes involved in cell cycle controls. While NRF1's actions on these genes are associated with normal physiological function, their dysregulation may lead to increased apoptosis or cell growth. In situations 
where NRF1 expressions or functions are dysregulated by estrogen or estrogen induced oxidative stress, downstream genes likewise can be modulated and manifest adverse effects on cell's fate. These effects may range from induction of apoptosis, to malignant transformation and growth of cancer cells. In mammary cells where aberrant cell growth or apoptosis that have been pre-initiated during estrogen metabolism and are under oxidative stress, oxidant induced NRF1 expression could further enhance excess growth in subsets of initiated cells.

Estrogen induced ROS, NRF1 and therapeutic resistance: Redox sensitive NRF1 may play an important role in therapeutic resistance of breast cancer cells. Drug resistance of a number of cancer cells are characterized by oxidative stress and metastasis [224;308;309]. Tumors contain a subset of cells that both self renew and give rise to differentiated progeny. The self renewal properties of these cells are the real driving force behind tumor growth, metastasis and recurrence as they are responsible for tumor escape from conventional therapies resulting in disease relapse. Oxidative stress induces apoptosis in a number of cells but in drug resistant cancer cell, the opposite is true; oxidative stress facilitates malignant growth and metastasis of breast cancer cells by activating MMPs such as collagenases (MMP-2) and inhibiting antiproteases such as tissue inhibitory metalloproteases TIMP [310;311]. Interestingly high mitochondria content and oxidative stress are not only associated with breast cancer risk, they are also reported to be positively correlated with stages of cancer and therapeutic resistance [308;312;313]. Whether excess NRF1 expression mediates chemoresistance and malignant growth of cancer cells or whether increased oxidative state observed in cancer 
cells are the manifestation of metabolically active cells is unknown. For example, treatment of several cancer cells lines with natural or synthetic flavonoids have been shown to restore chemo-sensitivity of these cells to cancer drugs [314;315]. Similarly, antioxidants have also been demonstrated to improve efficacies of chemo and radiotherapies in several types of human cancers [316-320]. While some epidemiological studies confirm the effectiveness of antioxidant supplementation [321], many studies see no effect [322]. Similarly several in vitro and in vivo studies have shown that antioxidants can improve drug efficacies [323]. Antioxidants when enhance the anti cancer drug effects in vitro and in animal models, implies that lowering cancer redox status may be pertinent to its therapeutic response. If that is the case, then NRF1 modulation of cellular redox status via mitochondria regulation may be central in oxidant mediated chemoresistance and malignant growth of cancer cells.

The MDR1 gene (multidrug resistance gene 1) is a membrane glycoprotein that functions in effluxing drugs from within cells in a number of malignant cell types [324]. This gene is expressed in $42 \%$ of breast cancer cases and patients with tumors expressing MDR1 gene are three times more likely to experience chemotherapy failures than patients whose tumors were MDR1 negative [325]. TAM, one of the most popular drugs used to treat breast cancer and which have a high failure rate after prolong usage has been reported to up regulate MDR1 gene expression in breast cancer cells [326]. TAM exposures have been shown to increase NRF1 expression in MCF-7 breast cancer cells as well [327]. Interestingly, NRF1 is a transcriptional regulator of MDR1 gene expression in resistant oral cancer cells and in acute lymphoblastic leukemia (ALL) [328;329]. This could be a 
mechanism that integrates drug induced oxidative stress, NRF1 expression and chemotherapeutic resistance in a number of cancers including breast cancer. While evidence of such association has not been reported in drug resistant human breast cancer cases, the rationales for such investigations are merited. There are indications that NRF1 expression may correlate with different stages of breast cancer causing possible therapeutic failures $[255 ; 330]$.

\section{SUMMARY}

Until recently, it has been argued that hydroxylated metabolites of estrogen (catechol estrogens) participate in redox cycling in the endoplasmic reticula of cells and during this redox cycling of hyroxylated estrogens, ROS are generated. These redox reactions may occur in vivo, if free hydroxylated metabolites are in close proximity of activating enzymes within the target cells. Studies recently showed that estrogens or estrogen metabolites directly acting on mitochondria of epithelial or immune cells generate ROS. Based on the dose and time of induction, the ROS, seem to play dual functions in epithelial cells. While higher doses of ROS induce oxidative damage in the genome of cells leading to cell apoptosis, exposure of low levels of ROS produce genomic instability as well as transduce signals for cell growth, cell transformation and cell invasion. This view is consistent with findings that (i) estrogen-induced ROS can lead to increased phosphorylation of kinases, such as ERK, AKT, with this effect being attributed to the redox regulation of redox-sensitive phosphatses. Some of the nongenomic pathways by which estrogen activates MAPK and AKT pathways can be explained based on estrogeninduced ROS transducing signal to their respective specific phosphatses. (ii) The 
transcription factors AP-1, NRF1, E2F, NFkB and CREB are responsive to both oxidants and estrogen. It is possible that estrogen-induced ROS transduce signals to the nucleus for the activation of transcription factors such as AP-1, CREB, E2F, NF-kB, and NRF1 to regulate their downstream target genes involved in cell transformation, cell cycle, migration and invasion (Figure 4). (iii) There is growing evidence that estrogen-induced regulation of breast cancer cell cycle is coupled to rates of cellular metabolism, ROS levels and mitochondrial mass. (iv) Inhibition of cell transformation, growth of breast cancer cells and tumor formation by overexpression of ROS detoxifying genes and cotreatment with antioxidants supports the role of ROS in estrogen-dependent breast cancer. (v) Estrogen-induced ROS by increasing genomic instability and by transducing signal through influencing redox sensitive transcription factors contribute to initiation as well as progression of breast cancer. It is envisioned that this is an important mechanism that drives the carcinogenesis process, but that it occurs in the context of other processes such as ER-mediated signaling and estrogen reactive metabolite-associated genotoxicity under investigations that may also contribute to the process. Taken together, estrogen-induced ROS mediated redox signaling seems to be complementary to the process of ER mediated cell transformation, growth and carcinogenesis. On the other hand, estrogen-induced ROS can function as independently reversible modifiers of phosphatases and activate kinases to trigger the transcription factors of target genes which participate in cancer progression. Further elaboration however, points to a convergence of both ER mediated signaling and $\mathrm{E}_{2}$ induced ROS signaling effects on the transcription factors which possibly act in synergy and contribute to the growth and cancer progression. 


\section{LIST OF REFERENCES}

1. Simpson,E.R. (2003) Sources of estrogen and their importance. J.Steroid Biochem.Mol.Biol., 86, 225-230.

2. Boukari,K., Ciampi,M.L., Guiochon-Mantel,A., Young,J., Lombes,M., and Meduri,G. (2007) Human fetal testis: source of estrogen and target of estrogen action. Hum.Reprod., 22, 1885-1892.

3. Hess,R.A., Bunick,D., and Bahr,J. (2001) Oestrogen, its receptors and function in the male reproductive tract - a review. Mol.Cell Endocrinol., 178, 29-38.

4. Jiang,N.S., Ryan,R.J., and Albert,A. (1973) Radioimmunoassay of serum estrogen. Clin.Chem., 19, 740-747.

5. Clemons,M. and Goss,P. (2001) Estrogen and the risk of breast cancer. N.Engl.J.Med., 344, 276-285.

6. Henderson,B.E., Ross,R., and Bernstein,L. (1988) Estrogens as a cause of human cancer: the Richard and Hinda Rosenthal Foundation award lecture. Cancer Res., $48,246-253$.

7. Roy,D. and bul-Hajj,Y.J. (1997) Estrogen-nucleic acid adducts: guanine is major site for interaction between 3,4-estrone quinone and COIII gene. Carcinogenesis, $18,1247-1249$.

8. Roy,D., Colerangle,J.B., and Singh,K.P. (1998) Is exposure to environmental or industrial endocrine disrupting estrogen-like chemicals able to cause genomic instability? Front Biosci., 3, d913-d921.

9. Roy,D., Cai,Q., Felty,Q., and Narayan,S. (2007) Estrogen-induced generation of reactive oxygen and nitrogen species, gene damage, and estrogen-dependent cancers. J.Toxicol.Environ.Health B Crit Rev., 10, 235-257.

10. Bernstein,L. and Ross,R.K. (1993) Endogenous hormones and breast cancer risk. Epidemiol.Rev., 15, 48-65.

11. Xu,W.H., Xiang,Y.B., Ruan,Z.X., Zheng,W., Cheng,J.R., Dai,Q., Gao,Y.T., and Shu,X.O. (2004) Menstrual and reproductive factors and endometrial cancer risk: Results from a population-based case-control study in urban Shanghai. Int.J.Cancer, 108, 613-619.

12. Kaaks,R., Berrino,F., Key,T., Rinaldi,S., Dossus,L., Biessy,C., Secreto,G., Amiano,P., Bingham,S., Boeing,H., Bueno de Mesquita,H.B., Chang-Claude,J., Clavel-Chapelon,F., Fournier,A., van Gils,C.H., Gonzalez,C.A., Gurrea,A.B., Critselis,E., Khaw,K.T., Krogh,V., Lahmann,P.H., Nagel,G., Olsen,A., Onland- 
Moret,N.C., Overvad,K., Palli,D., Panico,S., Peeters,P., Quiros,J.R., Roddam,A., Thiebaut,A., Tjonneland,A., Chirlaque,M.D., Trichopoulou,A., Trichopoulos,D., Tumino,R., Vineis,P., Norat,T., Ferrari,P., Slimani,N., and Riboli,E. (2005) Serum sex steroids in premenopausal women and breast cancer risk within the European Prospective Investigation into Cancer and Nutrition (EPIC). J.Natl.Cancer Inst., 97, 755-765.

13. Zucchetto,A., Serraino,D., Polesel,J., Negri,E., De,P.A., Dal,M.L., Montella,M., La,V.C., Franceschi,S., and Talamini,R. (2009) Hormone-related factors and gynecological conditions in relation to endometrial cancer risk. Eur.J.Cancer Prev., 18, 316-321.

14. Arteaga,E., Villaseca,P., Bianchi,M., Rojas,A., and Marshall,G. (2003) Raloxifene is a better antioxidant of low-density lipoprotein than estradiol or tamoxifen in postmenopausal women in vitro. Menopause., 10, 142-146.

15. Bocchinfuso,W.P. and Korach,K.S. (1997) Mammary gland development and tumorigenesis in estrogen receptor knockout mice. J.Mammary.Gland.Biol.Neoplasia., 2, 323-334.

16. Castagnetta,L., Granata,O.M., Cocciadiferro,L., Saetta,A., Polito,L., Bronte,G., Rizzo,S., Campisi,I., Agostara,B., and Carruba,G. (2004) Sex steroids, carcinogenesis, and cancer progression. Ann.N.Y.Acad.Sci., 1028, 233-246.

17. Liehr,J.G., Roy,D., and Gladek,A. (1989) Mechanism of inhibition of estrogeninduced renal carcinogenesis in male Syrian hamsters by vitamin C. Carcinogenesis, 10, 1983-1988.

18. Roy,D. and Liehr,J.G. (1990) Inhibition of estrogen-induced kidney carcinogenesis in Syrian hamsters by modulators of estrogen metabolism. Carcinogenesis, 11, 567-570.

19. IARC Monographs on the Evaluation of Carcinogenic Risks to Humans. Monographs on the evaluation of hormonal contraception and postmenopausal hormonal therapy 72, 399-530. 1999. WHO. Hormonal Contraception and PostMenopausal Hormonal

Therapy.

Ref Type: Conference Proceeding

20. Federal report on carcinogens. National Toxicology Program (NTP). 67 (242), 177283-77285. 2002. National Toxicology Program (NTP). Ref Type: Conference Proceeding

21. Pasqualini,J.R., Chetrite,G., Blacker,C., Feinstein,M.C., Delalonde,L., Talbi,M., and Maloche,C. (1996) Concentrations of estrone, estradiol, and estrone sulfate and evaluation of sulfatase and aromatase activities in pre- and postmenopausal breast cancer patients. J.Clin.Endocrinol.Metab, 81, 1460-1464. 
22. Vermeulen,A., Deslypere,J.P., Paridaens,R., Leclercq,G., Roy,F., and Heuson,J.C. (1986) Aromatase, 17 beta-hydroxysteroid dehydrogenase and intratissular sex hormone concentrations in cancerous and normal glandular breast tissue in postmenopausal women. Eur.J.Cancer Clin.Oncol., 22, 515-525.

23. Bocchinfuso,W.P., Hively,W.P., Couse,J.F., Varmus,H.E., and Korach,K.S. (1999) A mouse mammary tumor virus-Wnt-1 transgene induces mammary gland hyperplasia and tumorigenesis in mice lacking estrogen receptor-alpha. Cancer Res., 59, 1869-1876.

24. Couse,J.F. and Korach,K.S. (1999) Estrogen receptor null mice: what have we learned and where will they lead us? Endocr.Rev., 20, 358-417.

25. Colletta,A.A., Wakefield,L.M., Howell,F.V., van Roozendaal,K.E., Danielpour,D., Ebbs,S.R., Sporn,M.B., and Baum,M. (1990) Anti-oestrogens induce the secretion of active transforming growth factor beta from human fetal fibroblasts. Br.J.Cancer, 62, 405-409.

26. Jordan,V.C. (1994) Molecular mechanisms of antiestrogen action in breast cancer. Breast Cancer Res.Treat., 31, 41-52.

27. Charlier,C., Colin,C., Merville,M.P., Gielen,J., Lambotte,R., Plomteux,G., and Castronovo,V. (1994) [Tamoxifen in the treatment of breast cancer]. J.Gynecol.Obstet.Biol.Reprod.(Paris), 23, 751-756.

28. Felty,Q., Xiong,W.C., Sun,D., Sarkar,S., Singh,K.P., Parkash,J., and Roy,D. (2005) Estrogen-induced mitochondrial reactive oxygen species as signaltransducing messengers. Biochemistry, 44, 6900-6909.

29. Sastre-Serra,J., Valle,A., Company MM, Garau,I., Oliver,J., and Roca,P. (2010) Estrogen down-regulates uncoupling proteins and increases oxidative stress in breast cancer. Free Radic.Biol.Med., 48, 506-512.

30. Felty,Q., Singh,K.P., and Roy,D. (2005) Estrogen-induced G1/S transition of G0arrested estrogen-dependent breast cancer cells is regulated by mitochondrial oxidant signaling. Oncogene, 24, 4883-4893.

31. Cavalieri,E., Frenkel,K., Liehr,J.G., Rogan,E., and Roy,D. (2000) Estrogens as endogenous genotoxic agents--DNA adducts and mutations. J.Natl.Cancer Inst.Monogr,75-93.

32. Roy,D. and Liehr,J.G. (1999) Estrogen, DNA damage and mutations. Mutat.Res., 424, 107-115.

33. Roy,D. and Singh,K.P. (2004) Estrogen-induced genetic alterations and breast, endometrial, testicular and prostate cancers. Current Genomics, 5, 245-253. 
34. Sarabia,S.F., Zhu,B.T., Kurosawa,T., Tohma,M., and Liehr,J.G. (1997) Mechanism of cytochrome P450-catalyzed aromatic hydroxylation of estrogens. Chem.Res.Toxicol., 10, 767-771.

35. Raftogianis,R., Creveling,C., Weinshilboum,R., and Weisz,J. (2000) Estrogen metabolism by conjugation. J.Natl.Cancer Inst.Monogr,113-124.

36. Roy,D., Bernhardt,A., Strobel,H.W., and Liehr,J.G. (1992) Catalysis of the oxidation of steroid and stilbene estrogens to estrogen quinone metabolites by the beta-naphthoflavone-inducible cytochrome P450 IA family. Arch.Biochem.Biophys., 296, 450-456.

37. Zhang,F. and Bolton,J.L. (1999) Synthesis of the equine estrogen metabolites 2hydroxyequilin and 2-hydroxyequilenin. Chem.Res.Toxicol., 12, 200-203.

38. Markides,C.S., Roy,D., and Liehr,J.G. (1998) Concentration dependence of prooxidant and antioxidant properties of catecholestrogens. Arch.Biochem.Biophys., 360, 105-112.

39. Chang,M., Zhang,F., Shen,L., Pauss,N., Alam,I., van Breemen,R.B., Blond,S.Y., and Bolton,J.L. (1998) Inhibition of glutathione S-transferase activity by the quinoid metabolites of equine estrogens. Chem.Res.Toxicol., 11, 758-765.

40. Hachey,D.L., Dawling,S., Roodi,N., and Parl,F.F. (2003) Sequential action of phase I and II enzymes cytochrome p450 1B1 and glutathione S-transferase P1 in mammary estrogen metabolism. Cancer Res., 63, 8492-8499.

41. Cavalieri,E., Chakravarti,D., Guttenplan,J., Hart,E., Ingle,J., Jankowiak,R., Muti,P., Rogan,E., Russo,J., Santen,R., and Sutter,T. (2006) Catechol estrogen quinones as initiators of breast and other human cancers: implications for biomarkers of susceptibility and cancer prevention. Biochim.Biophys.Acta, 1766, 63-78.

42. Li,J.J. and Li,S.A. (1987) Estrogen carcinogenesis in Syrian hamster tissues: role of metabolism. Fed.Proc., 46, 1858-1863.

43. Liehr,J.G., Fang,W.F., Sirbasku,D.A., and ri-Ulubelen,A. (1986) Carcinogenicity of catechol estrogens in Syrian hamsters. J.Steroid Biochem., 24, 353-356.

44. Zhu,B.T., Roy,D., and Liehr,J.G. (1993) The carcinogenic activity of ethinyl estrogens is determined by both their hormonal characteristics and their conversion to catechol metabolites. Endocrinology, 132, 577-583.

45. Liehr,J.G. and Ricci,M.J. (1996) 4-Hydroxylation of estrogens as marker of human mammary tumors. Proc.Natl.Acad.Sci.U.S.A, 93, 3294-3296. 
46. Rogan,E.G., Badawi,A.F., Devanesan,P.D., Meza,J.L., Edney,J.A., West,W.W., Higginbotham,S.M., and Cavalieri,E.L. (2003) Relative imbalances in estrogen metabolism and conjugation in breast tissue of women with carcinoma: potential biomarkers of susceptibility to cancer. Carcinogenesis, 24, 697-702.

47. Malins,D.C., Holmes,E.H., Polissar,N.L., and Gunselman,S.J. (1993) The etiology of breast cancer. Characteristic alteration in hydroxyl radical-induced DNA base lesions during oncogenesis with potential for evaluating incidence risk. Cancer, 71, 3036-3043.

48. Okoh, V, Felty, Q, and Roy, D. Activation of PI3K/AKT signaling pathway is involved in 4-hydroxyestradiol-induced cell transformation. 2007. The Toxicologist, 96, p. 381, Abstract Nr. 1844. Ref Type: Conference Proceeding

49. Okoh, V., Garba, N. A., Felty, Q., and Roy, D. Inhibition of estrogen-induced growth of breast cancer cells by modulating in situ oxidant levels. 576. 6-252008. [abstract] In: Proceeding of Era of Hope, Abstract nr BC051097, June 2528 , baltimore

MD.

Ref Type: Conference Proceeding

50. Okoh, V, Garba, N. A, Felty, Q, and Roy, D. NRF1 signaling participates in the estrogen-mediated growth of breast cancer cells. 4-18-2009. [abstract] In: Proceedings of the 100th Annual Meeting of the American Association for Cancer Research (AACR); Abstract nr 3360, Apr 18-22, Denver, CO. Philadelphia (PA). Ref Type: Conference Proceeding

51. Roy, D, Felty, Q, Slingerland, J. M., Garba, N. A, Penny, R, and koh, V. Reversible inactivation of CDC25A by estrogen and antiestrogens-induced reactive oxygen species may be involved in the phosphorylatopn of p27. Era of Hope 1075. 2008. Ref Type: Conference Proceeding

52. Russo,J., Tahin,Q., Lareef,M.H., Hu,Y.F., and Russo,I.H. (2002) Neoplastic transformation of human breast epithelial cells by estrogens and chemical carcinogens. Environ.Mol.Mutagen., 39, 254-263.

53. Cuendet,M., Liu,X., Pisha,E., Li,Y., Yao,J., Yu,L., and Bolton,J.L. (2004) Equine estrogen metabolite 4-hydroxyequilenin induces anchorage-independent growth of human mammary epithelial MCF-10A cells: differential gene expression. Mutat.Res., 550, 109-121.

54. Li,J.J., Li,S.A., Oberley,T.D., and Parsons,J.A. (1995) Carcinogenic activities of various steroidal and nonsteroidal estrogens in the hamster kidney: relation to hormonal activity and cell proliferation. Cancer Res., 55, 4347-4351. 
55. Liu,S. and Lin,Y.C. (2004) Transformation of MCF-10A human breast epithelial cells by zeranol and estradiol-17beta. Breast J., 10, 514-521.

56. Fishman,J. and Martucci,C. (1980) Biological properties of 16 alphahydroxyestrone: implications in estrogen physiology and pathophysiology. J.Clin.Endocrinol.Metab, 51, 611-615.

57. Zhu,B.T. and Liehr,J.G. (1996) Inhibition of catechol O-methyltransferasecatalyzed O-methylation of 2- and 4-hydroxyestradiol by quercetin. Possible role in estradiol-induced tumorigenesis. J.Biol.Chem., 271, 1357-1363.

58. Emons,G., Merriam,G.R., Pfeiffer,D., Loriaux,D.L., Ball,P., and Knuppen,R. (1987) Metabolism of exogenous 4- and 2-hydroxyestradiol in the human male. J.Steroid Biochem., 28, 499-504.

59. Banerjee,M.R. (1976) Responses of mammary cells to hormones. Int.Rev.Cytol., 47, 1-97.

60. Pike,M.C., Spicer,D.V., Dahmoush,L., and Press,M.F. (1993) Estrogens, progestogens, normal breast cell proliferation, and breast cancer risk. Epidemiol.Rev., 15, 17-35.

61. Andersen,T.I., Heimdal,K.R., Skrede,M., Tveit,K., Berg,K., and Borresen,A.L. (1994) Oestrogen receptor (ESR) polymorphisms and breast cancer susceptibility. Hum.Genet., 94, 665-670.

62. Zeps,N., Bentel,J.M., Papadimitriou,J.M., D'Antuono,M.F., and Dawkins,H.J. (1998) Estrogen receptor-negative epithelial cells in mouse mammary gland development and growth. Differentiation, 62, 221-226.

63. Wiesen,J.F., Young,P., Werb,Z., and Cunha,G.R. (1999) Signaling through the stromal epidermal growth factor receptor is necessary for mammary ductal development. Development, 126, 335-344.

64. Cunha,G.R., Young,P., Hom,Y.K., Cooke,P.S., Taylor,J.A., and Lubahn,D.B. (1997) Elucidation of a role for stromal steroid hormone receptors in mammary gland growth and development using tissue recombinants. J.Mammary.Gland.Biol.Neoplasia., 2, 393-402.

65. Sainsbury,J.R., Farndon,J.R., Sherbet,G.V., and Harris,A.L. (1985) Epidermalgrowth-factor receptors and oestrogen receptors in human breast cancer. Lancet, 1, 364-366.

66. DuMond,J.W., Jr., Singh,K.P., and Roy,D. (2001) Regulation of the growth of mouse Leydig cells by the inactive stereoisomer, 17alpha-estradiol: Lack of correlation between the elevated expression of ERalpha and difference in sensitivity to estradiol isomers. Oncol.Rep., 8, 899-902. 
67. Newbold,R.R. and Liehr,J.G. (2000) Induction of uterine adenocarcinoma in CD1 mice by catechol estrogens. Cancer Res., 60, 235-237.

68. Colerangle,J.B. and Roy,D. (1997) Profound effects of the weak environmental estrogen-like chemical bisphenol A on the growth of the mammary gland of Noble rats. J.Steroid Biochem.Mol.Biol., 60, 153-160.

69. Holland,M.B. and Roy,D. (1995) Estrone-induced cell proliferation and differentiation in the mammary gland of the female Noble rat. Carcinogenesis, 16, 1955-1961.

70. Matsumoto,Y. (1992) Study on the estrogen production in parenchymatous cells of epithelial ovarian tumor. Osaka City Med.J., 38, 27-43.

71. Moats,R.K. and Ramirez,V.D. (1998) Rapid uptake and binding of estradiol17beta-6-(O-carboxymethyl)oxime:125I-labeled BSA by female rat liver. Biol.Reprod., 58, 531-538.

72. Monje,P. and Boland,R. (2001) Subcellular distribution of native estrogen receptor alpha and beta isoforms in rabbit uterus and ovary. J.Cell Biochem., 82, 467-479.

73. Chen,J.Q., Delannoy,M., Cooke,C., and Yager,J.D. (2004) Mitochondrial localization of ERalpha and ERbeta in human MCF7 cells. Am.J.Physiol Endocrinol.Metab, 286, E1011-E1022.

74. Chen,J.Q., Eshete,M., Alworth,W.L., and Yager,J.D. (2004) Binding of MCF-7 cell mitochondrial proteins and recombinant human estrogen receptors alpha and beta to human mitochondrial DNA estrogen response elements. J.Cell Biochem., 93, 358-373.

75. Felty,Q. and Roy,D. (2005) Mitochondrial signals to nucleus regulate estrogeninduced cell growth. Med.Hypotheses, 64, 133-141.

76. Garcia,M.V., Cabezas,J.A., and Perez-Gonzalez,M.N. (1985) Effects of oestradiol, testosterone and medroxyprogesterone on subcellular fraction marker enzyme activities from rat liver and brain. Comp Biochem.Physiol B, 80, 347354.

77. Kipp,J.L. and Ramirez,V.D. (2001) Effect of estradiol, diethylstilbestrol, and resveratrol on F0F1-ATPase activity from mitochondrial preparations of rat heart, liver, and brain. Endocrine., 15, 165-175.

78. Larsson,N.G., Wang,J., Wilhelmsson,H., Oldfors,A., Rustin,P., Lewandoski,M., Barsh,G.S., and Clayton,D.A. (1998) Mitochondrial transcription factor A is necessary for mtDNA maintenance and embryogenesis in mice. Nat.Genet., 18, 231-236. 
79. Scarpulla,R.C. (2002) Transcriptional activators and coactivators in the nuclear control of mitochondrial function in mammalian cells. Gene, 286, 81-89.

80. Wu,Z., Puigserver,P., Andersson,U., Zhang,C., Adelmant,G., Mootha,V., Troy,A., Cinti,S., Lowell,B., Scarpulla,R.C., and Spiegelman,B.M. (1999) Mechanisms controlling mitochondrial biogenesis and respiration through the thermogenic coactivator PGC-1. Cell, 98, 115-124.

81. Kressler,D., Schreiber,S.N., Knutti,D., and Kralli,A. (2002) The PGC-1-related protein PERC is a selective coactivator of estrogen receptor alpha. J.Biol.Chem., 277, 13918-13925.

82. Knutti,D., Kaul,A., and Kralli,A. (2000) A tissue-specific coactivator of steroid receptors, identified in a functional genetic screen. Mol.Cell Biol., 20, 2411-2422.

83. Kain,K.H., Popov,V.L., and Herzog,N.K. (2000) Alterations in mitochondria and mtTFA in response to LPS-induced differentiation of B-cells. Biochim.Biophys.Acta, 1494, 91-103.

84. Casas,F., Daury,L., Grandemange,S., Busson,M., Seyer,P., Hatier,R., Carazo,A., Cabello,G., and Wrutniak-Cabello,C. (2003) Endocrine regulation of mitochondrial activity: involvement of truncated RXRalpha and c-Erb Aalpha1 proteins. FASEB J., 17, 426-436.

85. Donahue,R.J., Razmara,M., Hoek,J.B., and Knudsen,T.B. (2001) Direct influence of the p53 tumor suppressor on mitochondrial biogenesis and function. FASEB J., $15,635-644$.

86. Liu,G., Schwartz,J.A., and Brooks,S.C. (1999) p53 down-regulates ER-responsive genes by interfering with the binding of ER to ERE. Biochem.Biophys.Res.Commun., 264, 359-364.

87. Steinschneider,A., Rao,M.C., Khan,I., McLean,M.P., and Gibori,G. (1991) Calcium-calmodulin and calcium-phospholipid dependent phosphorylation of membranous fraction proteins related to the tropic regulation by estradiol in the corpus luteum. Endocrinology, 128, 263-272.

88. Miranda-Vizuete,A., Damdimopoulos,A.E., and Spyrou,G. (2000) The mitochondrial thioredoxin system. Antioxid.Redox.Signal., 2, 801-810.

89. Woo,H.A., Kang,S.W., Kim,H.K., Yang,K.S., Chae,H.Z., and Rhee,S.G. (2003) Reversible oxidation of the active site cysteine of peroxiredoxins to cysteine sulfinic acid. Immunoblot detection with antibodies specific for the hyperoxidized cysteine-containing sequence. J.Biol.Chem., 278, 47361-47364. 
90. Lee,H.C., Yin,P.H., Chi,C.W., and Wei,Y.H. (2002) Increase in mitochondrial mass in human fibroblasts under oxidative stress and during replicative cell senescence. J.Biomed.Sci., 9, 517-526.

91. Nisoli,E., Clementi,E., Paolucci,C., Cozzi,V., Tonello,C., Sciorati,C., Bracale,R., Valerio,A., Francolini,M., Moncada,S., and Carruba,M.O. (2003) Mitochondrial biogenesis in mammals: the role of endogenous nitric oxide. Science, 299, 896899.

92. Malins,D.C. and Haimanot,R. (1991) Major alterations in the nucleotide structure of DNA in cancer of the female breast. Cancer Res., 51, 5430-5432.

93. Musarrat,J., rezina-Wilson,J., and Wani,A.A. (1996) Prognostic and aetiological relevance of 8-hydroxyguanosine in human breast carcinogenesis. Eur.J.Cancer, 32A, 1209-1214.

94. Yamamoto,T., Hosokawa,K., Tamura,T., Kanno,H., Urabe,M., and Honjo,H. (1996) Urinary 8-hydroxy-2'-deoxyguanosine (8-OHdG) levels in women with or without gynecologic cancer. J.Obstet.Gynaecol.Res., 22, 359-363.

95. Du,M.Q., Carmichael,P.L., and Phillips,D.H. (1994) Induction of activating mutations in the human c-Ha-ras-1 proto-oncogene by oxygen free radicals. Mol.Carcinog., 11, 170-175.

96. Hussain,S.P., Hofseth,L.J., and Harris,C.C. (2001) Tumor suppressor genes: at the crossroads of molecular carcinogenesis, molecular epidemiology and human risk assessment. Lung Cancer, 34 Suppl 2, S7-15.

97. Alworth,L.C., Howdeshell,K.L., Ruhlen,R.L., Day,J.K., Lubahn,D.B., Huang,T.H., Besch-Williford,C.L., and vom Saal,F.S. (2002) Uterine responsiveness to estradiol and DNA methylation are altered by fetal exposure to diethylstilbestrol and methoxychlor in CD-1 mice: effects of low versus high doses. Toxicol.Appl.Pharmacol., 183, 10-22.

98. Hmadcha,A., Bedoya,F.J., Sobrino,F., and Pintado,E. (1999) Methylationdependent gene silencing induced by interleukin lbeta via nitric oxide production. J.Exp.Med., 190, 1595-1604.

99. Zhu,W. and Smart,E.J. (2003) Caveolae, estrogen and nitric oxide. Trends Endocrinol.Metab, 14, 114-117.

100. Suh,Y.A., Arnold,R.S., Lassegue,B., Shi,J., Xu,X., Sorescu,D., Chung,A.B., Griendling,K.K., and Lambeth,J.D. (1999) Cell transformation by the superoxidegenerating oxidase Mox1. Nature, 401, 79-82. 
101. Aoki,F., Choi,T., Mori,M., Yamashita,M., Nagahama,Y., and Kohmoto,K. (1992) A deficiency in the mechanism for $\mathrm{p} 34 \mathrm{cdc} 2$ protein kinase activation in mouse embryos arrested at 2-cell stage. Dev.Biol., 154, 66-72.

102. Mailand,N., Falck,J., Lukas,C., Syljuasen,R.G., Welcker,M., Bartek,J., and Lukas,J. (2000) Rapid destruction of human Cdc25A in response to DNA damage. Science, 288, 1425-1429.

103. Falck,J., Mailand,N., Syljuasen,R.G., Bartek,J., and Lukas,J. (2001) The ATMChk2-Cdc25A checkpoint pathway guards against radioresistant DNA synthesis. Nature, 410, 842-847.

104. Finkel,T. (2001) Reactive oxygen species and signal transduction. IUBMB.Life, $52,3-6$.

105. Sohn,J. and Rudolph,J. (2003) Catalytic and chemical competence of regulation of cdc25 phosphatase by oxidation/reduction. Biochemistry, 42, 10060-10070.

106. Savitsky,P.A. and Finkel,T. (2002) Redox regulation of Cdc25C. J.Biol.Chem., 277, 20535-20540.

107. Barrett,W.C., DeGnore,J.P., Keng,Y.F., Zhang,Z.Y., Yim,M.B., and Chock,P.B. (1999) Roles of superoxide radical anion in signal transduction mediated by reversible regulation of protein-tyrosine phosphatase 1B. J.Biol.Chem., 274, 34543-34546.

108. Boveris A and Cadenas E (1997) Lung Biology in Health and Disease. Marcel Dekker, New York.

109. Tomko,R.J., Jr. and Lazo,J.S. (2008) Multimodal control of Cdc25A by nitrosative stress. Cancer Res., 68, 7457-7465.

110. Barre,B., Vigneron,A., and Coqueret,O. (2005) The STAT3 transcription factor is a target for the Myc and riboblastoma proteins on the Cdc25A promoter. J.Biol.Chem., 280, 15673-15681.

111. Melchheier,I., von,M.C., Stuhlmann,D., Sies,H., and Klotz,L.O. (2005) Quinoneinduced Cdc25A inhibition causes ERK-dependent connexin phosphorylation. Biochem.Biophys.Res.Commun., 327, 1016-1023.

112. Rudolph,J. (2005) Redox regulation of the Cdc25 phosphatases. Antioxid.Redox.Signal., 7, 761-767.

113. Wang,Z., Zhang,B., Wang,M., and Carr,B.I. (2005) Cdc25A and ERK interaction: EGFR-independent ERK activation by a protein phosphatase Cdc25A inhibitor, compound 5. J.Cell Physiol, 204, 437-444. 
114. Foster,J.S., Henley,D.C., Ahamed,S., and Wimalasena,J. (2001) Estrogens and cell-cycle regulation in breast cancer. Trends Endocrinol.Metab, 12, 320-327.

115. Foster,J.S., Henley,D.C., Bukovsky,A., Seth,P., and Wimalasena,J. (2001) Multifaceted regulation of cell cycle progression by estrogen: regulation of Cdk inhibitors and Cdc25A independent of cyclin D1-Cdk4 function. Mol.Cell Biol., $21,794-810$.

116. Lou,Y.W., Chen,Y.Y., Hsu,S.F., Chen,R.K., Lee,C.L., Khoo,K.H., Tonks,N.K., and Meng,T.C. (2008) Redox regulation of the protein tyrosine phosphatase PTP1B in cancer cells. FEBS J., 275, 69-88.

117. Isoda,M., Kanemori,Y., Nakajo,N., Uchida,S., Yamashita,K., Ueno,H., and Sagata,N. (2009) The extracellular signal-regulated kinase-mitogen-activated protein kinase pathway phosphorylates and targets Cdc25A for SCF beta-TrCPdependent degradation for cell cycle arrest. Mol.Biol.Cell, 20, 2186-2195.

118. Niwa,K., Inanami,O., Yamamori,T., Ohta,T., Hamasu,T., and Kuwabara,M. (2003) Redox regulation of PI3K/Akt and p53 in bovine aortic endothelial cells exposed to hydrogen peroxide. Antioxid.Redox.Signal., 5, 713-722.

119. Salmeen,A. and Barford,D. (2005) Functions and mechanisms of redox regulation of cysteine-based phosphatases. Antioxid.Redox.Signal., 7, 560-577.

120. Meng,T.C., Lou,Y.W., Chen,Y.Y., Hsu,S.F., and Huang,Y.F. (2006) CysOxidation of Protein Tyrosine Phosphatases: Its Role in Regulation of Signal Transduction and Its Involvement in Human Cancers. Journal of Cancer Molecule, 2, 9-16.

121. Golden,T., Aragon,I.V., Rutland,B., Tucker,J.A., Shevde,L.A., Samant,R.S., Zhou,G., Amable,L., Skarra,D., and Honkanen,R.E. (2008) Elevated levels of $\mathrm{Ser} / \mathrm{Thr}$ protein phosphatase 5 (PP5) in human breast cancer. Biochim.Biophys.Acta, 1782, 259-270.

122. Cui,Y., Parra,I., Zhang,M., Hilsenbeck,S.G., Tsimelzon,A., Furukawa,T., Horii,A., Zhang,Z.Y., Nicholson,R.I., and Fuqua,S.A. (2006) Elevated expression of mitogen-activated protein kinase phosphatase 3 in breast tumors: a mechanism of tamoxifen resistance. Cancer Res., 66, 5950-5959.

123. Thomson,M. (2002) Evidence of undiscovered cell regulatory mechanisms: phosphoproteins and protein kinases in mitochondria. Cell Mol.Life Sci., 59, 213219.

124. Baines,C.P., Song,C.X., Zheng,Y.T., Wang,G.W., Zhang,J., Wang,O.L., Guo,Y., Bolli,R., Cardwell,E.M., and Ping,P. (2003) Protein kinase Cepsilon interacts with 
and inhibits the permeability transition pore in cardiac mitochondria. Circ.Res., 92, 873-880.

125. Wu,X., Noh,S.J., Zhou,G., Dixon,J.E., and Guan,K.L. (1996) Selective activation of MEK1 but not MEK2 by A-Raf from epidermal growth factor-stimulated Hela cells. J.Biol.Chem., 271, 3265-3271.

126. Weinstein-Oppenheimer,C.R., Burrows,C., Steelman,L.S., and McCubrey,J.A. (2002) The effects of beta-estradiol on Raf activity, cell cycle progression and growth factor synthesis in the MCF-7 breast cancer cell line. Cancer Biol.Ther., 1, 256-262.

127. Li,L., Lorenzo,P.S., Bogi,K., Blumberg,P.M., and Yuspa,S.H. (1999) Protein kinase Cdelta targets mitochondria, alters mitochondrial membrane potential, and induces apoptosis in normal and neoplastic keratinocytes when overexpressed by an adenoviral vector. Mol.Cell Biol., 19, 8547-8558.

128. Tournier,C., Hess,P., Yang,D.D., Xu,J., Turner,T.K., Nimnual,A., Bar-Sagi,D., Jones,S.N., Flavell,R.A., and Davis,R.J. (2000) Requirement of JNK for stressinduced activation of the cytochrome c-mediated death pathway. Science, 288, 870-874.

129. Chen,N., Nomura,M., She,Q.B., Ma,W.Y., Bode,A.M., Wang,L., Flavell,R.A., and Dong,Z. (2001) Suppression of skin tumorigenesis in c-Jun NH(2)-terminal kinase-2-deficient mice. Cancer Res., 61, 3908-3912.

130. Benhar,M., Engelberg,D., and Levitzki,A. (2002) ROS, stress-activated kinases and stress signaling in cancer. EMBO Rep., 3, 420-425.

131. Filardo,E.J., Quinn,J.A., Bland,K.I., and Frackelton,A.R., Jr. (2000) Estrogeninduced activation of Erk-1 and Erk-2 requires the $\mathrm{G}$ protein-coupled receptor homolog, GPR30, and occurs via trans-activation of the epidermal growth factor receptor through release of HB-EGF. Mol.Endocrinol., 14, 1649-1660.

132. Filardo,E.J., Quinn,J.A., Frackelton,A.R., Jr., and Bland,K.I. (2002) Estrogen action via the G protein-coupled receptor, GPR30: stimulation of adenylyl cyclase and cAMP-mediated attenuation of the epidermal growth factor receptor-toMAPK signaling axis. Mol.Endocrinol., 16, 70-84.

133. Improta-Brears,T., Whorton,A.R., Codazzi,F., York,J.D., Meyer,T., and McDonnell,D.P. (1999) Estrogen-induced activation of mitogen-activated protein kinase requires mobilization of intracellular calcium. Proc.Natl.Acad.Sci.U.S.A, 96, 4686-4691.

134. Kleuser,B., Malek,D., Gust,R., Pertz,H.H., and Potteck,H. (2008) 17-Betaestradiol inhibits transforming growth factor-beta signaling and function in breast 
cancer cells via activation of extracellular signal-regulated kinase through the $\mathrm{G}$ protein-coupled receptor 30. Mol.Pharmacol., 74, 1533-1543.

135. Bulayeva,N.N., Gametchu,B., and Watson,C.S. (2004) Quantitative measurement of estrogen-induced ERK 1 and 2 activation via multiple membrane-initiated signaling pathways. Steroids, 69, 181-192.

136. Levin,E.R. (2009) Plasma membrane estrogen receptors. Trends Endocrinol.Metab, 20, 477-482.

137. Levin,E.R. (2008) Rapid signaling by steroid receptors. Am.J.Physiol Regul.Integr.Comp Physiol, 295, R1425-R1430.

138. Dechering,K., Boersma,C., and Mosselman,S. (2000) Estrogen receptors alpha and beta: two receptors of a kind? Curr.Med.Chem., 7, 561-576.

139. Migliaccio,A., Di,D.M., Castoria,G., de,F.A., Bontempo,P., Nola,E., and Auricchio,F. (1996) Tyrosine kinase/p21ras/MAP-kinase pathway activation by estradiol-receptor complex in MCF-7 cells. EMBO J., 15, 1292-1300.

140. Endoh,H., Sasaki,H., Maruyama,K., Takeyama,K., Waga,I., Shimizu,T., Kato,S., and Kawashima,H. (1997) Rapid activation of MAP kinase by estrogen in the bone cell line. Biochem.Biophys.Res.Commun., 235, 99-102.

141. Watters,J.J., Campbell,J.S., Cunningham,M.J., Krebs,E.G., and Dorsa,D.M. (1997) Rapid membrane effects of steroids in neuroblastoma cells: effects of estrogen on mitogen activated protein kinase signalling cascade and c-fos immediate early gene transcription. Endocrinology, 138, 4030-4033.

142. Lieberherr,M., Grosse,B., Kachkache,M., and Balsan,S. (1993) Cell signaling and estrogens in female rat osteoblasts: a possible involvement of unconventional nonnuclear receptors. J.Bone Miner.Res., 8, 1365-1376.

143. Razandi,M., Pedram,A., Greene,G.L., and Levin,E.R. (1999) Cell membrane and nuclear estrogen receptors (ERs) originate from a single transcript: studies of ERalpha and ERbeta expressed in Chinese hamster ovary cells. Mol.Endocrinol., $13,307-319$.

144. Loomis,A.K. and Thomas,P. (2000) Effects of estrogens and xenoestrogens on androgen production by Atlantic croaker testes in vitro: evidence for a nongenomic action mediated by an estrogen membrane receptor. Biol.Reprod., 62, 995-1004.

145. Kar,S., Wang,M., Yao,W., Michejda,C.J., and Carr,B.I. (2006) PM-20, a novel inhibitor of Cdc25A, induces extracellular signal-regulated kinase $1 / 2$ phosphorylation and inhibits hepatocellular carcinoma growth in vitro and in vivo. Mol.Cancer Ther., 5, 1511-1519. 
146. Wu,F.Y. and Sun,T.P. (1999) Vitamin K3 induces cell cycle arrest and cell death by inhibiting Cdc25 phosphatase. Eur.J.Cancer, 35, 1388-1393.

147. Stauffer,F., Holzer,P., and Garcia-Echeverria,C. (2005) Blocking the PI3K/PKB pathway in tumor cells. Curr.Med.Chem.Anticancer Agents, 5, 449-462.

148. Barnett,S.F., Bilodeau,M.T., and Lindsley,C.W. (2005) The Akt/PKB family of protein kinases: a review of small molecule inhibitors and progress towards target validation. Curr.Top.Med.Chem., 5, 109-125.

149. Piantadosi,C.A. and Suliman,H.B. (2006) Mitochondrial transcription factor A induction by redox activation of nuclear respiratory factor 1. J.Biol.Chem., 281, 324-333.

150. Sun,M., Paciga,J.E., Feldman,R.I., Yuan,Z., Coppola,D., Lu,Y.Y., Shelley,S.A., Nicosia,S.V., and Cheng,J.Q. (2001) Phosphatidylinositol-3-OH Kinase $(\mathrm{PI} 3 \mathrm{~K}) / \mathrm{AKT} 2$, activated in breast cancer, regulates and is induced by estrogen receptor alpha (ERalpha) via interaction between ERalpha and PI3K. Cancer Res., 61, 5985-5991.

151. Lee,Y.R., Park,J., Yu,H.N., Kim,J.S., Youn,H.J., and Jung,S.H. (2005) Upregulation of PI3K/Akt signaling by 17beta-estradiol through activation of estrogen receptor-alpha, but not estrogen receptor-beta, and stimulates cell growth in breast cancer cells. Biochem.Biophys.Res.Commun., 336, 1221-1226.

152. Banerjee,S., Saxena,N., Sengupta,K., and Banerjee,S.K. (2003) 17alpha-estradiolinduced VEGF-A expression in rat pituitary tumor cells is mediated through ER independent but PI3K-Akt dependent signaling pathway. Biochem.Biophys.Res.Commun., 300, 209-215.

153. Gao,N., Nester,R.A., and Sarkar,M.A. (2004) 4-Hydroxy estradiol but not 2hydroxy estradiol induces expression of hypoxia-inducible factor lalpha and vascular endothelial growth factor A through phosphatidylinositol 3kinase/Akt/FRAP pathway in OVCAR-3 and A2780-CP70 human ovarian carcinoma cells. Toxicol.Appl.Pharmacol., 196, 124-135.

154. Millward,T.A., Zolnierowicz,S., and Hemmings,B.A. (1999) Regulation of protein kinase cascades by protein phosphatase 2A. Trends Biochem.Sci., 24, 186-191.

155. Baldin,V., Theis-Febvre,N., Benne,C., Froment,C., Cazales,M., Burlet-Schiltz,O., and Ducommun,B. (2003) PKB/Akt phosphorylates the CDC25B phosphatase and regulates its intracellular localisation. Biol.Cell, 95, 547-554. 
156. Kim,H.J., Kang,S.K., Mun,J.Y., Chun,Y.J., Choi,K.H., and Kim,M.Y. (2003) Involvement of Akt in mitochondria-dependent apoptosis induced by a cdc25 phosphatase inhibitor naphthoquinone analog. FEBS Lett., 555, 217-222.

157. Hirose,Y., Katayama,M., Mirzoeva,O.K., Berger,M.S., and Pieper,R.O. (2005) Akt activation suppresses Chk2-mediated, methylating agent-induced G2 arrest and protects from temozolomide-induced mitotic catastrophe and cellular senescence. Cancer Res., 65, 4861-4869.

158. Fuhrmann,G., Leisser,C., Rosenberger,G., Grusch,M., Huettenbrenner,S., Halama,T., Mosberger,I., Sasgary,S., Cerni,C., and Krupitza,G. (2001) Cdc25A phosphatase suppresses apoptosis induced by serum deprivation. Oncogene, 20, 4542-4553.

159. Sauer,H., Wartenberg,M., and Hescheler,J. (2001) Reactive oxygen species as intracellular messengers during cell growth and differentiation. Cell Physiol Biochem., 11, 173-186.

160. Tamir,S., Izrael,S., and Vaya,J. (2002) The effect of oxidative stress on ERalpha and ERbeta expression. J.Steroid Biochem.Mol.Biol., 81, 327-332.

161. Yau,C. and Benz,C.C. (2008) Genes responsive to both oxidant stress and loss of estrogen receptor function identify a poor prognosis group of estrogen receptor positive primary breast cancers. Breast Cancer Res., 10, R61.

162. Korichneva,I., Hoyos,B., Chua,R., Levi,E., and Hammerling,U. (2002) Zinc release from protein kinase $\mathrm{C}$ as the common event during activation by lipid second messenger or reactive oxygen. J.Biol.Chem., 277, 44327-44331.

163. Korichneva,I. (2005) Redox regulation of cardiac protein kinase C. Exp.Clin.Cardiol., 10, 256-261.

164. Kim,S.K., Woodcroft,K.J., Oh,S.J., Abdelmegeed,M.A., and Novak,R.F. (2005) Role of mechanical and redox stress in activation of mitogen-activated protein kinases in primary cultured rat hepatocytes. Biochem.Pharmacol., 70, 1785-1795.

165. Valko,M., Rhodes,C.J., Moncol,J., Izakovic,M., and Mazur,M. (2006) Free radicals, metals and antioxidants in oxidative stress-induced cancer. Chem.Biol.Interact., 160, 1-40.

166. Levin,E.R. (2003) Bidirectional signaling between the estrogen receptor and the epidermal growth factor receptor. Mol.Endocrinol., 17, 309-317.

167. Dos Santos,E.G., Dieudonne,M.N., Pecquery,R., Le,M., V, Giudicelli,Y., and Lacasa,D. (2002) Rapid nongenomic E2 effects on p42/p44 MAPK, activator protein-1, and cAMP response element binding protein in rat white adipocytes. Endocrinology, 143, 930-940. 
168. Bozinovski,S., Jones,J.E., Vlahos,R., Hamilton,J.A., and Anderson,G.P. (2002) Granulocyte/macrophage-colony-stimulating factor (GM-CSF) regulates lung innate immunity to lipopolysaccharide through Akt/Erk activation of NFkappa B and AP-1 in vivo. J.Biol.Chem., 277, 42808-42814.

169. Manna,S.K., Zhang,H.J., Yan,T., Oberley,L.W., and Aggarwal,B.B. (1998) Overexpression of manganese superoxide dismutase suppresses tumor necrosis factor-induced apoptosis and activation of nuclear transcription factor-kappaB and activated protein-1. J.Biol.Chem., 273, 13245-13254.

170. Pinkus,R., Weiner,L.M., and Daniel,V. (1996) Role of oxidants and antioxidants in the induction of AP-1, NF-kappaB, and glutathione S-transferase gene expression. J.Biol.Chem., 271, 13422-13429.

171. Li,W.C., Wang,G.M., Wang,R.R., and Spector,A. (1994) The redox active components $\mathrm{H} 2 \mathrm{O} 2$ and $\mathrm{N}$-acetyl-L-cysteine regulate expression of c-jun and c-fos in lens systems. Exp.Eye Res., 59, 179-190.

172. Stauble,B., Boscoboinik,D., Tasinato,A., and Azzi,A. (1994) Modulation of activator protein-1 (AP-1) transcription factor and protein kinase $\mathrm{C}$ by hydrogen peroxide and D-alpha-tocopherol in vascular smooth muscle cells. Eur.J.Biochem., 226, 393-402.

173. Uchida,K., Shiraishi,M., Naito,Y., Torii,Y., Nakamura,Y., and Osawa,T. (1999) Activation of stress signaling pathways by the end product of lipid peroxidation. 4-hydroxy-2-nonenal is a potential inducer of intracellular peroxide production. J.Biol.Chem., 274, 2234-2242.

174. Parola,M., Robino,G., Marra,F., Pinzani,M., Bellomo,G., Leonarduzzi,G., Chiarugi,P., Camandola,S., Poli,G., Waeg,G., Gentilini,P., and Dianzani,M.U. (1998) HNE interacts directly with JNK isoforms in human hepatic stellate cells. J.Clin.Invest, 102, 1942-1950.

175. Wisdom,R. (1999) AP-1: one switch for many signals. Exp.Cell Res., 253, 180185.

176. Minden,A. and Karin,M. (1997) Regulation and function of the JNK subgroup of MAP kinases. Biochim.Biophys.Acta, 1333, F85-104.

177. Okazaki,K. and Sagata,N. (1995) The Mos/MAP kinase pathway stabilizes c-Fos by phosphorylation and augments its transforming activity in NIH $3 \mathrm{~T} 3$ cells. EMBO J., 14, 5048-5059.

178. Ichijo,H. (1999) From receptors to stress-activated MAP kinases. Oncogene, 18, 6087-6093. 
179. Whitmarsh,A.J. and Davis,R.J. (1996) Transcription factor AP-1 regulation by mitogen-activated protein kinase signal transduction pathways. J.Mol.Med., 74, 589-607.

180. Karin,M., Liu,Z., and Zandi,E. (1997) AP-1 function and regulation. Curr.Opin.Cell Biol., 9, 240-246.

181. Karin,M. (1996) The regulation of AP-1 activity by mitogen-activated protein kinases. Philos.Trans.R.Soc.Lond B Biol.Sci., 351, 127-134.

182. Karin,M. and Smeal,T. (1992) Control of transcription factors by signal transduction pathways: the beginning of the end. Trends Biochem.Sci., 17, 418422.

183. Fuchs,S.Y., Dolan,L., Davis,R.J., and Ronai,Z. (1996) Phosphorylation-dependent targeting of c-Jun ubiquitination by Jun N-kinase. Oncogene, 13, 1531-1535.

184. Abate,C., Patel,L., Rauscher,F.J., III, and Curran,T. (1990) Redox regulation of fos and jun DNA-binding activity in vitro. Science, 249, 1157-1161.

185. Klatt,P., Molina,E.P., De Lacoba,M.G., Padilla,C.A., Martinez-Galesteo,E., Barcena,J.A., and Lamas,S. (1999) Redox regulation of c-Jun DNA binding by reversible S-glutathiolation. FASEB J., 13, 1481-1490.

186. Xanthoudakis,S. and Curran,T. (1992) Identification and characterization of Ref1, a nuclear protein that facilitates AP-1 DNA-binding activity. EMBO J., 11, 653-665.

187. Schenk,H., Klein,M., Erdbrugger,W., Droge,W., and Schulze-Osthoff,K. (1994) Distinct effects of thioredoxin and antioxidants on the activation of transcription factors NF-kappa B and AP-1. Proc.Natl.Acad.Sci.U.S.A, 91, 1672-1676.

188. Hirota,K., Matsui,M., Iwata,S., Nishiyama,A., Mori,K., and Yodoi,J. (1997) AP-1 transcriptional activity is regulated by a direct association between thioredoxin and Ref-1. Proc.Natl.Acad.Sci.U.S.A, 94, 3633-3638.

189. Zhang,P., Wang,Y.Z., Kagan,E., and Bonner,J.C. (2000) Peroxynitrite targets the epidermal growth factor receptor, Raf-1, and MEK independently to activate MAPK. J.Biol.Chem., 275, 22479-22486.

190. Saitoh,M., Nishitoh,H., Fujii,M., Takeda,K., Tobiume,K., Sawada,Y., Kawabata,M., Miyazono,K., and Ichijo,H. (1998) Mammalian thioredoxin is a direct inhibitor of apoptosis signal-regulating kinase (ASK) 1. EMBO J., 17, 2596-2606. 
191. Gotoh,Y. and Cooper,J.A. (1998) Reactive oxygen species- and dimerizationinduced activation of apoptosis signal-regulating kinase 1 in tumor necrosis factor-alpha signal transduction. J.Biol.Chem., 273, 17477-17482.

192. Janssen,Y.M., Matalon,S., and Mossman,B.T. (1997) Differential induction of cfos, c-jun, and apoptosis in lung epithelial cells exposed to ROS or RNS. Am.J.Physiol, 273, L789-L796.

193. Suliman,H.B., Carraway,M.S., Welty-Wolf,K.E., Whorton,A.R., and Piantadosi,C.A. (2003) Lipopolysaccharide stimulates mitochondrial biogenesis via activation of nuclear respiratory factor-1. J.Biol.Chem., 278, 41510-41518.

194. Adler,V., Yin,Z., Tew,K.D., and Ronai,Z. (1999) Role of redox potential and reactive oxygen species in stress signaling. Oncogene, 18, 6104-6111.

195. Planas-Silva,M.D., Donaher,J.L., and Weinberg,R.A. (1999) Functional activity of ectopically expressed estrogen receptor is not sufficient for estrogen-mediated cyclin D1 expression. Cancer Res., 59, 4788-4792.

196. Burdon,R.H. (1995) Superoxide and hydrogen peroxide in relation to mammalian cell proliferation. Free Radic.Biol.Med., 18, 775-794.

197. Honore,S., Kovacic,H., Pichard,V., Briand,C., and Rognoni,J.B. (2003) Alpha2beta1-integrin signaling by itself controls G1/S transition in a human adenocarcinoma cell line (Caco-2): implication of NADPH oxidase-dependent production of ROS. Exp.Cell Res., 285, 59-71.

198. Gupta,A., Rosenberger,S.F., and Bowden,G.T. (1999) Increased ROS levels contribute to elevated transcription factor and MAP kinase activities in malignantly progressed mouse keratinocyte cell lines. Carcinogenesis, 20, 20632073.

199. Turpaev,K.T. (2002) Reactive oxygen species and regulation of gene expression. Biochemistry (Mosc.), 67, 281-292.

200. Virbasius,C.A., Virbasius,J.V., and Scarpulla,R.C. (1993) NRF1, an activator involved in nuclear-mitochondrial interactions, utilizes a new DNA-binding domain conserved in a family of developmental regulators. Genes Dev., 7, 24312445 .

201. Solecki,D., Bernhardt,G., Lipp,M., and Wimmer,E. (2000) Identification of a nuclear respiratory factor-1 binding site within the core promoter of the human polio virus receptor/CD155 gene. J.Biol.Chem., 275, 12453-12462.

202. Liu,Y., Niu,N., Zhu,X., Du,T., Wang,X., Chen,D., Wu,X., Gu,H.F., and Liu,Y. (2008) Genetic variation and association analyses of the nuclear respiratory factor 1 (nRF1) gene in Chinese patients with type 2 diabetes. Diabetes, 57, 777-782. 
203. Chau,C.M., Evans,M.J., and Scarpulla,R.C. (1992) Nuclear respiratory factor 1 activation sites in genes encoding the gamma-subunit of ATP synthase, eukaryotic initiation factor 2 alpha, and tyrosine aminotransferase. Specific interaction of purified NRF1 with multiple target genes. J.Biol.Chem., 267, 69997006.

204. Lee,H.C., Yin,P.H., Lu,C.Y., Chi,C.W., and Wei,Y.H. (2000) Increase of mitochondria and mitochondrial DNA in response to oxidative stress in human cells. Biochem.J., 348 Pt 2, 425-432.

205. Miranda,S., Foncea,R., Guerrero,J., and Leighton,F. (1999) Oxidative stress and upregulation of mitochondrial biogenesis genes in mitochondrial DNA-depleted HeLa cells. Biochem.Biophys.Res.Commun., 258, 44-49.

206. Mattingly,K.A., Ivanova,M.M., Riggs,K.A., Wickramasinghe,N.S., Barch,M.J., and Klinge,C.M. (2008) Estradiol stimulates transcription of nuclear respiratory factor-1 and increases mitochondrial biogenesis. Mol.Endocrinol., 22, 609-622.

207. Ivanova,M.M., Mazhawidza,W., Dougherty,S.M., Minna,J.D., and Klinge,C.M. (2009) Activity and intracellular location of estrogen receptors alpha and beta in human bronchial epithelial cells. Mol.Cell Endocrinol., 305, 12-21.

208. Gomez-Cabrera,M.C., Domenech,E., Romagnoli,M., Arduini,A., Borras,C., Pallardo,F.V., Sastre,J., and Vina,J. (2008) Oral administration of vitamin C decreases muscle mitochondrial biogenesis and hampers training-induced adaptations in endurance performance. Am.J.Clin.Nutr., 87, 142-149.

209. Dai,D.F., Santana,L.F., Vermulst,M., Tomazela,D.M., Emond,M.J., MacCoss,M.J., Gollahon,K., Martin,G.M., Loeb,L.A., Ladiges,W.C., and Rabinovitch,P.S. (2009) Overexpression of catalase targeted to mitochondria attenuates murine cardiac aging. Circulation, 119, 2789-2797.

210. Mobley,J.A. and Brueggemeier,R.W. (2004) Estrogen receptor-mediated regulation of oxidative stress and DNA damage in breast cancer. Carcinogenesis, $25,3-9$.

211. Patel,M.M. and Bhat,H.K. (2004) Differential oxidant potential of carcinogenic and weakly carcinogenic estrogens: Involvement of metabolic activation and cytochrome P450. J.Biochem.Mol.Toxicol., 18, 37-42.

212. Jeng,J.H., Kuo,M.Y., Lee,P.H., Wang,Y.J., Lee,M.Y., Lee,J.J., Lin,B.R., Tai,T.F., and Chang,M.C. (2006) Toxic and metabolic effect of sodium butyrate on SAS tongue cancer cells: role of cell cycle deregulation and redox changes. Toxicology, 223, 235-247. 
213. Liu,Q., Shimoyama,T., Suzuki,K., Umeda,T., Nakaji,S., and Sugawara,K. (2001) Effect of sodium butyrate on reactive oxygen species generation by human neutrophils. Scand.J.Gastroenterol., 36, 744-750.

214. Izumi,H., Ohta,R., Nagatani,G., Ise,T., Nakayama,Y., Nomoto,M., and Kohno,K. (2003) p300/CBP-associated factor (P/CAF) interacts with nuclear respiratory factor-1 to regulate the UDP-N-acetyl-alpha-d-galactosamine: polypeptide Nacetylgalactosaminyltransferase-3 gene. Biochem.J., 373, 713-722.

215. Kherrouche,Z., De Launoit,Y., and Monte,D. (2004) The NRF1/alpha-PAL transcription factor regulates human E2F6 promoter activity. Biochem.J., 383, 529-536.

216. Fernando,R.I. and Wimalasena,J. (2004) Estradiol abrogates apoptosis in breast cancer cells through inactivation of BAD: Ras-dependent nongenomic pathways requiring signaling through ERK and Akt. Mol.Biol.Cell, 15, 3266-3284.

217. Fan,M., Yan,P.S., Hartman-Frey,C., Chen,L., Paik,H., Oyer,S.L., Salisbury,J.D., Cheng,A.S., Li,L., Abbosh,P.H., Huang,T.H., and Nephew,K.P. (2006) Diverse gene expression and DNA methylation profiles correlate with differential adaptation of breast cancer cells to the antiestrogens tamoxifen and fulvestrant. Cancer Res., 66, 11954-11966.

218. Suliman,H.B., Carraway,M.S., Tatro,L.G., and Piantadosi,C.A. (2007) A new activating role for $\mathrm{CO}$ in cardiac mitochondrial biogenesis. J.Cell Sci., 120, 299308.

219. Byun,H.O., Kim,H.Y., Lim,J.J., Seo,Y.H., and Yoon,G. (2008) Mitochondrial dysfunction by complex II inhibition delays overall cell cycle progression via reactive oxygen species production. J.Cell Biochem., 104, 1747-1759.

220. Ramanathan,A., Wang,C., and Schreiber,S.L. (2005) Perturbational profiling of a cell-line model of tumorigenesis by using metabolic measurements. Proc.Natl.Acad.Sci.U.S.A, 102, 5992-5997.

221. Knowles,H.J. and Harris,A.L. (2001) Hypoxia and oxidative stress in breast cancer. Hypoxia and tumourigenesis. Breast Cancer Res., 3, 318-322.

222. Duran,H.A. and de Rey,B.M. (1991) Differential oxidative stress induced by two different types of skin tumor promoters, benzoyl peroxide and 12-Otetradecanoylphorbol-13-acetate. Carcinogenesis, 12, 2047-2052.

223. Yano,T., Ishikawa,G., and Ichikawa,T. (1993) Oxidative stress as a modulating factor of pulmonary tumorigenesis in mice; comparative study on two different strains. Comp Biochem.Physiol C., 104, 407-410. 
224. Tas,F., Hansel,H., Belce,A., Ilvan,S., Argon,A., Camlica,H., and Topuz,E. (2005) Oxidative stress in breast cancer. Med.Oncol., 22, 11-15.

225. Lieberthal,J.G., Kaminsky,M., Parkhurst,C.N., and Tanese,N. (2009) The role of YY1 in reduced HP1alpha gene expression in invasive human breast cancer cells. Breast Cancer Res., 11, R42.

226. Schiff,R., Reddy,P., Ahotupa,M., Coronado-Heinsohn,E., Grim,M., Hilsenbeck,S.G., Lawrence,R., Deneke,S., Herrera,R., Chamness,G.C., Fuqua,S.A., Brown,P.H., and Osborne,C.K. (2000) Oxidative stress and AP-1 activity in tamoxifen-resistant breast tumors in vivo. J.Natl.Cancer Inst., 92, 19261934.

227. Behrend,L., Henderson,G., and Zwacka,R.M. (2003) Reactive oxygen species in oncogenic transformation. Biochem.Soc.Trans., 31, 1441-1444.

228. Finkel,T. (2003) Oxidant signals and oxidative stress. Curr.Opin.Cell Biol., 15, 247-254.

229. Guyton,K.Z. and Kensler,T.W. (1993) Oxidative mechanisms in carcinogenesis. Br.Med.Bull., 49, 523-544.

230. Klaunig,J.E., Xu,Y., Bachowski,S., Ketcham,C.A., Isenberg,J.S., Kolaja,K.L., Baker,T.K., Walborg,E.F., Jr., and Stevenson,D.E. (1995) Oxidative stress in nongenotoxic carcinogenesis. Toxicol.Lett., 82-83, 683-691.

231. Kang,D.H. (2002) Oxidative stress, DNA damage, and breast cancer. AACN.Clin.Issues, 13, 540-549.

232. Xia,C., Meng,Q., Liu,L.Z., Rojanasakul,Y., Wang,X.R., and Jiang,B.H. (2007) Reactive oxygen species regulate angiogenesis and tumor growth through vascular endothelial growth factor. Cancer Res., 67, 10823-10830.

233. Klaunig,J.E. and Kamendulis,L.M. (2004) The role of oxidative stress in carcinogenesis. Annu.Rev.Pharmacol.Toxicol., 44, 239-267.

234. Yan,T., Oberley,L.W., Zhong,W., and St Clair,D.K. (1996) Manganesecontaining superoxide dismutase overexpression causes phenotypic reversion in SV40-transformed human lung fibroblasts. Cancer Res., 56, 2864-2871.

235. Li,J.J., Oberley,L.W., St Clair,D.K., Ridnour,L.A., and Oberley,T.D. (1995) Phenotypic changes induced in human breast cancer cells by overexpression of manganese-containing superoxide dismutase. Oncogene, 10, 1989-2000.

236. Church,S.L., Grant,J.W., Ridnour,L.A., Oberley,L.W., Swanson,P.E., Meltzer,P.S., and Trent,J.M. (1993) Increased manganese superoxide dismutase 
expression suppresses the malignant phenotype of human melanoma cells. Proc.Natl.Acad.Sci.U.S.A, 90, 3113-3117.

237. Melov,S., Coskun,P., Patel,M., Tuinstra,R., Cottrell,B., Jun,A.S., Zastawny,T.H., Dizdaroglu,M., Goodman,S.I., Huang,T.T., Miziorko,H., Epstein,C.J., and Wallace,D.C. (1999) Mitochondrial disease in superoxide dismutase 2 mutant mice. Proc.Natl.Acad.Sci.U.S.A, 96, 846-851.

238. Slanger,T.E., Chang-Claude,J., and Wang-Gohrke,S. (2006) Manganese superoxide dismutase Ala-9Val polymorphism, environmental modifiers, and risk of breast cancer in a German population. Cancer Causes Control, 17, 1025-1031.

239. Wang,S., Wang,F., Shi,X., Dai,J., Peng,Y., Guo,X., Wang,X., Shen,H., and Hu,Z. (2009) Association between manganese superoxide dismutase (MnSOD) Val9Ala polymorphism and cancer risk - A meta-analysis. Eur.J.Cancer, 45, 28742881.

240. Cai,Q., Shu,X.O., Wen,W., Cheng,J.R., Dai,Q., Gao,Y.T., and Zheng,W. (2004) Genetic polymorphism in the manganese superoxide dismutase gene, antioxidant intake, and breast cancer risk: results from the Shanghai Breast Cancer Study. Breast Cancer Res., 6, R647-R655.

241. Egan,K.M., Thompson,P.A., Titus-Ernstoff,L., Moore,J.H., and Ambrosone,C.B. (2003) MnSOD polymorphism and breast cancer in a population-based casecontrol study. Cancer Lett., 199, 27-33.

242. Liehr,J.G. and Ricci,M.J. (1996) 4-Hydroxylation of estrogens as marker of human mammary tumors. Proc.Natl.Acad.Sci.U.S.A, 93, 3294-3296.

243. Droge,W. (2002) Free radicals in the physiological control of cell function. Physiol Rev., 82, 47-95.

244. Nordberg,J. and Arner,E.S. (2001) Reactive oxygen species, antioxidants, and the mammalian thioredoxin system. Free Radic.Biol.Med., 31, 1287-1312.

245. Kim,M.R., Chang,H.S., Kim,B.H., Kim,S., Baek,S.H., Kim,J.H., Lee,S.R., and Kim,J.R. (2003) Involvements of mitochondrial thioredoxin reductase (TrxR2) in cell proliferation. Biochem.Biophys.Res.Commun., 304, 119-124.

246. Maruyama,T., Sachi,Y., Furuke,K., Kitaoka,Y., Kanzaki,H., Yoshimura,Y., and Yodoi,J. (1999) Induction of thioredoxin, a redox-active protein, by ovarian steroid hormones during growth and differentiation of endometrial stromal cells in vitro. Endocrinology, 140, 365-372.

247. Serviddio,G., Loverro,G., Vicino,M., Prigigallo,F., Grattagliano,I., Altomare,E., and Vendemiale,G. (2002) Modulation of endometrial redox balance during the 
menstrual cycle: relation with sex hormones. J.Clin.Endocrinol.Metab, 87, 28432848.

248. Choi,J.H., Kim,T.N., Kim,S., Baek,S.H., Kim,J.H., Lee,S.R., and Kim,J.R. (2002) Overexpression of mitochondrial thioredoxin reductase and peroxiredoxin III in hepatocellular carcinomas. Anticancer Res., 22, 3331-3335.

249. Lee,S.Y., Andoh,T., Murphy,D.L., and Chiueh,C.C. (2003) 17beta-estradiol activates ICI 182,780-sensitive estrogen receptors and cyclic GMP-dependent thioredoxin expression for neuroprotection. FASEB J., 17, 947-948.

250. Strehlow,K., Rotter,S., Wassmann,S., Adam,O., Grohe,C., Laufs,K., Bohm,M., and Nickenig,G. (2003) Modulation of antioxidant enzyme expression and function by estrogen. Circ.Res., 93, 170-177.

251. Pawitan,Y., Bjohle,J., Amler,L., Borg,A.L., Egyhazi,S., Hall,P., Han,X., Holmberg,L., Huang,F., Klaar,S., Liu,E.T., Miller,L., Nordgren,H., Ploner,A., Sandelin,K., Shaw,P.M., Smeds,J., Skoog,L., Wedren,S., and Bergh,J. (2005) Gene expression profiling spares early breast cancer patients from adjuvant therapy: derived and validated in two population-based cohorts. Breast Cancer Res., 7, R953-R964.

252. Elkon,R., Linhart,C., Sharan,R., Shamir,R., and Shiloh,Y. (2003) Genome-wide in silico identification of transcriptional regulators controlling the cell cycle in human cells. Genome Res., 13, 773-780.

253. Blum,R., Elkon,R., Yaari,S., Zundelevich,A., Jacob-Hirsch,J., Rechavi,G., Shamir,R., and Kloog,Y. (2007) Gene expression signature of human cancer cell lines treated with the ras inhibitor salirasib (S-farnesylthiosalicylic acid). Cancer Res., 67, 3320-3328.

254. Cam,H., Balciunaite,E., Blais,A., Spektor,A., Scarpulla,R.C., Young,R., Kluger,Y., and Dynlacht,B.D. (2004) A common set of gene regulatory networks links metabolism and growth inhibition. Mol.Cell, 16, 399-411.

255. Niida,A., Smith,A.D., Imoto,S., Tsutsumi,S., Aburatani,H., Zhang,M.Q., and Akiyama,T. (2008) Integrative bioinformatics analysis of transcriptional regulatory programs in breast cancer cells. BMC.Bioinformatics., 9, 404.

256. Ramaswamy,S., Tamayo,P., Rifkin,R., Mukherjee,S., Yeang,C.H., Angelo,M., Ladd,C., Reich,M., Latulippe,E., Mesirov,J.P., Poggio,T., Gerald,W., Loda,M., Lander,E.S., and Golub,T.R. (2001) Multiclass cancer diagnosis using tumor gene expression signatures. Proc.Natl.Acad.Sci.U.S.A, 98, 15149-15154.

257. Landis,M.D., Seachrist,D.D., Montanez-Wiscovich,M.E., Danielpour,D., and Keri,R.A. (2005) Gene expression profiling of cancer progression reveals intrinsic 
regulation of transforming growth factor-beta signaling in ErbB2/Neu-induced tumors from transgenic mice. Oncogene, 24, 5173-5190.

258. Macleod,K.F. (2008) The role of the RB tumour suppressor pathway in oxidative stress responses in the haematopoietic system. Nat.Rev.Cancer, 8, 769-781.

259. Ngwenya,S. and Safe,S. (2003) Cell context-dependent differences in the induction of E2F-1 gene expression by 17 beta-estradiol in MCF-7 and ZR-75 cells. Endocrinology, 144, 1675-1685.

260. Efiok,B.J. and Safer,B. (2000) Transcriptional regulation of E2F-1 and eIF-2 genes by alpha-pal: a potential mechanism for coordinated regulation of protein synthesis, growth, and the cell cycle. Biochim.Biophys.Acta, 1495, 51-68.

261. Muller,H., Bracken,A.P., Vernell,R., Moroni,M.C., Christians,F., Grassilli,E., Prosperini,E., Vigo,E., Oliner,J.D., and Helin,K. (2001) E2Fs regulate the expression of genes involved in differentiation, development, proliferation, and apoptosis. Genes Dev., 15, 267-285.

262. Johnson,D.G., Cress,W.D., Jakoi,L., and Nevins,J.R. (1994) Oncogenic capacity of the E2F1 gene. Proc.Natl.Acad.Sci.U.S.A, 91, 12823-12827.

263. Tsantoulis,P.K. and Gorgoulis,V.G. (2005) Involvement of E2F transcription factor family in cancer. Eur.J.Cancer, 41, 2403-2414.

264. Yamasaki,L., Jacks,T., Bronson,R., Goillot,E., Harlow,E., and Dyson,N.J. (1996) Tumor induction and tissue atrophy in mice lacking E2F-1. Cell, 85, 537-548.

265. Pierce,A.M., Schneider-Broussard,R., Gimenez-Conti,I.B., $\quad$ Russell,J.L., Conti,C.J., and Johnson,D.G. (1999) E2F1 has both oncogenic and tumorsuppressive properties in a transgenic model. Mol.Cell Biol., 19, 6408-6414.

266. Ren,B., Cam,H., Takahashi,Y., Volkert,T., Terragni,J., Young,R.A., and Dynlacht,B.D. (2002) E2F integrates cell cycle progression with DNA repair, replication, and $\mathrm{G}(2) / \mathrm{M}$ checkpoints. Genes Dev., 16, 245-256.

267. Ishida,S., Huang,E., Zuzan,H., Spang,R., Leone,G., West,M., and Nevins,J.R. (2001) Role for E2F in control of both DNA replication and mitotic functions as revealed from DNA microarray analysis. Mol.Cell Biol., 21, 4684-4699.

268. Gaubatz,S., Wood,J.G., and Livingston,D.M. (1998) Unusual proliferation arrest and transcriptional control properties of a newly discovered E2F family member, E2F-6. Proc.Natl.Acad.Sci.U.S.A, 95, 9190-9195.

269. Chen,C. and Wells,A.D. (2007) Comparative analysis of E2F family member oncogenic activity. PLoS.One., 2, e912. 
270. Stender,J.D., Frasor,J., Komm,B., Chang,K.C., Kraus,W.L., and Katzenellenbogen,B.S. (2007) Estrogen-regulated gene networks in human breast cancer cells: involvement of E2F1 in the regulation of cell proliferation. Mol.Endocrinol., 21, 2112-2123.

271. Piantadosi,C.A., Carraway,M.S., Babiker,A., and Suliman,H.B. (2008) Heme oxygenase-1 regulates cardiac mitochondrial biogenesis via Nrf2-mediated transcriptional control of nuclear respiratory factor-1. Circ.Res., 103, 1232-1240.

272. Morrish,F., Giedt,C., and Hockenbery,D. (2003) c-MYC apoptotic function is mediated by NRF1 target genes. Genes Dev., 17, 240-255.

273. Rodriguez-Pena,A., Escriva,H., Handler,A.C., and Vallejo,C.G. (2002) Thyroid hormone increases transcription of GA-binding protein/nuclear respiratory factor2 alpha-subunit in rat liver. FEBS Lett., 514, 309-314.

274. Klinge,C.M. (2008) Estrogenic control of mitochondrial function and biogenesis. J.Cell Biochem., 105, 1342-1351.

275. Ramachandran,B., Yu,G., and Gulick,T. (2008) Nuclear respiratory factor 1 controls myocyte enhancer factor $2 \mathrm{~A}$ transcription to provide a mechanism for coordinate expression of respiratory chain subunits. J.Biol.Chem., 283, 1193511946.

276. Cox,D.M., Du,M., Marback,M., Yang,E.C., Chan,J., Siu,K.W., and McDermott,J.C. (2003) Phosphorylation motifs regulating the stability and function of myocyte enhancer factor 2A. J.Biol.Chem., 278, 15297-15303.

277. Li,J., Yang,J.G., Li,W., Du,R., Gui,L., Tian,L., and Guo,Q.H. (2006) [Study on novel mutations of MEF2A gene in Chinese patients with coronary artery disease]. Zhonghua Yi.Xue.Yi.Chuan Xue.Za Zhi., 23, 265-268.

278. Yuan,H., Lu,H.W., Hu,J., Chen,S.H., Yang,G.P., and Huang,Z.J. (2006) MEF2A gene and susceptibility to coronary artery disease in the Chinese people. Zhong.Nan.Da.Xue.Xue.Bao.Yi.Xue.Ban., 31, 453-457.

279. Bai,X., Wu,L., Liang,T., Liu,Z., Li,J., Li,D., Xie,H., Yin,S., Yu,J., Lin,Q., and Zheng,S. (2008) Overexpression of myocyte enhancer factor 2 and histone hyperacetylation in hepatocellular carcinoma. J.Cancer Res.Clin.Oncol., 134, 8391.

280. Wang,C., Li,Z., Lu,Y., Du,R., Katiyar,S., Yang,J., Fu,M., Leader,J.E., Quong,A., Novikoff,P.M., and Pestell,R.G. (2006) Cyclin D1 repression of nuclear respiratory factor 1 integrates nuclear DNA synthesis and mitochondrial function. Proc.Natl.Acad.Sci.U.S.A, 103, 11567-11572. 
281. Sakamaki,T., Casimiro,M.C., Ju,X., Quong,A.A., Katiyar,S., Liu,M., Jiao,X., Li,A., Zhang,X., Lu,Y., Wang,C., Byers,S., Nicholson,R., Link,T., Shemluck,M., Yang,J., Fricke,S.T., Novikoff,P.M., Papanikolaou,A., Arnold,A., Albanese,C., and Pestell,R. (2006) Cyclin D1 determines mitochondrial function in vivo. Mol.Cell Biol., 26, 5449-5469.

282. Castro-Rivera,E., Samudio,I., and Safe,S. (2001) Estrogen regulation of cyclin D1 gene expression in ZR-75 breast cancer cells involves multiple enhancer elements. J.Biol.Chem., 276, 30853-30861.

283. Sabbah,M., Courilleau,D., Mester,J., and Redeuilh,G. (1999) Estrogen induction of the cyclin D1 promoter: involvement of a cAMP response-like element. Proc.Natl.Acad.Sci.U.S.A, 96, 11217-11222.

284. Martinez,M.C., Post,J.A., Verkleij,A.J., Verrips,C.T., and Boonstra,J. (2001) The effect of hydrogen peroxide on the cyclin D expression in fibroblasts. Cell Mol.Life Sci., 58, 990-996.

285. Han,S., Park,K., Bae,B.N., Kim,K.H., Kim,H.J., Kim,Y.D., and Kim,H.Y. (2003) E2F1 expression is related with the poor survival of lymph node-positive breast cancer patients treated with fluorouracil, doxorubicin and cyclophosphamide. Breast Cancer Res.Treat., 82, 11-16.

286. Kouvaraki,M., Gorgoulis,V.G., Rassidakis,G.Z., Liodis,P., Koutroumbi,E., Markopoulos,C., Gogas,J., and Kittas,C. (2001) Alterations of the 16q22.1 and $16 q 24.3$ chromosomal loci in sporadic invasive breast carcinomas: correlation with proliferative activity, ploidy and hormonal status of the tumors. Anticancer Res., 21, 991-999.

287. Kouvaraki,M., Gorgoulis,V.G., Rassidakis,G.Z., Liodis,P., Markopoulos,C., Gogas,J., and Kittas,C. (2002) High expression levels of p27 correlate with lymph node status in a subset of advanced invasive breast carcinomas: relation to Ecadherin alterations, proliferative activity, and ploidy of the tumors. Cancer, 94, 2454-2465.

288. Zacharatos,P., Kotsinas,A., Evangelou,K., Karakaidos,P., Vassiliou,L.V., Rezaei,N., Kyroudi,A., Kittas,C., Patsouris,E., Papavassiliou,A.G., and Gorgoulis,V.G. (2004) Distinct expression patterns of the transcription factor E2F-1 in relation to tumour growth parameters in common human carcinomas. J.Pathol., 203, 744-753.

289. Zhang,S.Y., Liu,S.C., Al-Saleem,L.F., Holloran,D., Babb,J., Guo,X., and KleinSzanto,A.J. (2000) E2F-1: a proliferative marker of breast neoplasia. Cancer Epidemiol.Biomarkers Prev., 9, 395-401. 
290. Oberley,M.J., Inman,D.R., and Farnham,P.J. (2003) E2F6 negatively regulates BRCA1 in human cancer cells without methylation of histone H3 on lysine 9. J.Biol.Chem., 278, 42466-42476.

291. Scully,R. and Xie,A. (2004) BRCA1 and BRCA2 in breast cancer predisposition and recombination control. J.Mammary.Gland.Biol.Neoplasia., 9, 237-246.

292. Bae,I., Fan,S., Meng,Q., Rih,J.K., Kim,H.J., Kang,H.J., Xu,J., Goldberg,I.D., Jaiswal,A.K., and Rosen,E.M. (2004) BRCA1 induces antioxidant gene expression and resistance to oxidative stress. Cancer Res., 64, 7893-7909.

293. Asangani,I.A., Rasheed,S.A., Leupold,J.H., Post,S., and Allgayer,H. (2008) NRF1, and AP-1 regulate the promoter of the human calpain small subunit 1 (CAPNS1) gene. Gene, 410, 197-206.

294. Carragher,N.O., Fonseca,B.D., and Frame,M.C. (2004) Calpain activity is generally elevated during transformation but has oncogene-specific biological functions. Neoplasia., 6, 53-73.

295. Demarchi,F. and Schneider,C. (2007) The calpain system as a modulator of stress/damage response. Cell Cycle, 6, 136-138.

296. Chang,W.T. and Huang,A.M. (2004) Alpha-Pal/NRF1 regulates the promoter of the human integrin-associated protein/CD47 gene. J.Biol.Chem., 279, 1454214550 .

297. Guo,W., Pylayeva,Y., Pepe,A., Yoshioka,T., Muller,W.J., Inghirami,G., and Giancotti,F.G. (2006) Beta 4 integrin amplifies ErbB2 signaling to promote mammary tumorigenesis. Cell, 126, 489-502.

298. Watanabe,A. (2003) Cloning and characterization of the promoter region of the bovine membrane tethering protein p115 gene and its regulation in mammary epithelial cells. Biochim.Biophys.Acta, 1629, 60-72.

299. Baar,K., Song,Z., Semenkovich,C.F., Jones,T.E., Han,D.H., Nolte,L.A., Ojuka,E.O., Chen,M., and Holloszy,J.O. (2003) Skeletal muscle overexpression of nuclear respiratory factor 1 increases glucose transport capacity. FASEB J., 17, 1666-1673.

300. Puigserver,P., Wu,Z., Park,C.W., Graves,R., Wright,M., and Spiegelman,B.M. (1998) A cold-inducible coactivator of nuclear receptors linked to adaptive thermogenesis. Cell, 92, 829-839.

301. Wegner,S.A., Ehrenberg,P.K., Chang,G., Dayhoff,D.E., Sleeker,A.L., and Michael,N.L. (1998) Genomic organization and functional characterization of the chemokine receptor CXCR4, a major entry co-receptor for human immunodeficiency virus type 1. J.Biol.Chem., 273, 4754-4760. 
302. Myers,S.J., Peters,J., Huang,Y., Comer,M.B., Barthel,F., and Dingledine,R. (1998) Transcriptional regulation of the GluR2 gene: neural-specific expression, multiple promoters, and regulatory elements. J.Neurosci., 18, 6723-6739.

303. Izumi,H., Ohta,R., Nagatani,G., Ise,T., Nakayama,Y., Nomoto,M., and Kohno,K. (2003) p300/CBP-associated factor (P/CAF) interacts with nuclear respiratory factor-1 to regulate the UDP-N-acetyl-alpha-d-galactosamine: polypeptide Nacetylgalactosaminyltransferase-3 gene. Biochem.J., 373, 713-722.

304. Kumari,D., Gabrielian,A., Wheeler,D., and Usdin,K. (2005) The roles of Sp1, Sp3, USF1/USF2 and NRF1 in the regulation and three-dimensional structure of the Fragile X mental retardation gene promoter. Biochem.J., 386, 297-303.

305. Fu,J., Zhang,J., Jin,F., Patchefsky,J., Braunewell,K.H., and Klein-Szanto,A.J. (2009) Promoter regulation of the visinin-like subfamily of neuronal calcium sensor proteins by nuclear respiratory factor-1. J.Biol.Chem., 284, 27577-27586.

306. Braunewell,K.H. (2005) The darker side of $\mathrm{Ca} 2+$ signaling by neuronal $\mathrm{Ca} 2+-$ sensor proteins: from Alzheimer's disease to cancer. Trends Pharmacol.Sci., 26, 345-351.

307. Gonzalez Guerrico,A.M., Jaffer,Z.M., Page,R.E., Braunewell,K.H., Chernoff,J., and Klein-Szanto,A.J. (2005) Visinin-like protein-1 is a potent inhibitor of cell adhesion and migration in squamous carcinoma cells. Oncogene, 24, 2307-2316.

308. Brown,N.S. and Bicknell,R. (2001) Hypoxia and oxidative stress in breast cancer. Oxidative stress: its effects on the growth, metastatic potential and response to therapy of breast cancer. Breast Cancer Res., 3, 323-327.

309. Pelicano,H., Carney,D., and Huang,P. (2004) ROS stress in cancer cells and therapeutic implications. Drug Resist.Updat., 7, 97-110.

310. Duffy,M.J., Maguire,T.M., Hill,A., McDermott,E., and O'Higgins,N. (2000) Metalloproteinases: role in breast carcinogenesis, invasion and metastasis. Breast Cancer Res., 2, 252-257.

311. Rajagopalan,S., Meng,X.P., Ramasamy,S., Harrison,D.G., and Galis,Z.S. (1996) Reactive oxygen species produced by macrophage-derived foam cells regulate the activity of vascular matrix metalloproteinases in vitro. Implications for atherosclerotic plaque stability. J.Clin.Invest, 98, 2572-2579.

312. Shen,J., Platek,M., Mahasneh,A., Ambrosone,C.B., and Zhao,H. (2010) Mitochondrial copy number and risk of breast cancer: a pilot study. Mitochondrion., 10, 62-68.

313. Tesarova,P., Kalousova,M., Trnkova,B., Soukupova,J., Argalasova,S., Mestek,O., Petruzelka,L., and Zima,T. (2007) Carbonyl and oxidative stress in patients with 
breast cancer--is there a relation to the stage of the disease? Neoplasma, 54, 219224.

314. Zhang,S., Yang,X., and Morris,M.E. (2004) Flavonoids are inhibitors of breast cancer resistance protein (ABCG2)-mediated transport. Mol.Pharmacol., 65, 1208-1216.

315. Alvero,A.B., O'Malley,D., Brown,D., Kelly,G., Garg,M., Chen,W., Rutherford,T., and Mor,G. (2006) Molecular mechanism of phenoxodiol-induced apoptosis in ovarian carcinoma cells. Cancer, 106, 599-608.

316. Chiao,T.B. and Lee,A.J. (2005) Role of pentoxifylline and vitamin $\mathrm{E}$ in attenuation of radiation-induced fibrosis. Ann.Pharmacother., 39, 516-522.

317. Sanchiz,F., Milla,A., Artola,N., Julia,J.C., Moya,L.M., Pedro,A., and Vila,A. (1996) Prevention of radioinduced cystitis by orgotein: a randomized study. Anticancer Res., 16, 2025-2028.

318. Drisko,J.A., Chapman,J., and Hunter,V.J. (2003) The use of antioxidant therapies during chemotherapy. Gynecol.Oncol., 88, 434-439.

319. Camphausen,K., Citrin,D., Krishna,M.C., and Mitchell,J.B. (2005) Implications for tumor control during protection of normal tissues with antioxidants. J.Clin.Oncol., 23, 5455-5457.

320. Conklin,K.A. (2000) Dietary antioxidants during cancer chemotherapy: impact on chemotherapeutic effectiveness and development of side effects. Nutr.Cancer, 37, $1-18$.

321. Paiva,S.A. and Russell,R.M. (1999) Beta-carotene and other carotenoids as antioxidants. J.Am.Coll.Nutr., 18, 426-433.

322. D'Andrea,G.M. (2005) Use of antioxidants during chemotherapy and radiotherapy should be avoided. CA Cancer J.Clin., 55, 319-321.

323. Youk,H.J., Lee,E., Choi,M.K., Lee,Y.J., Chung,J.H., Kim,S.H., Lee,C.H., and Lim,S.J. (2005) Enhanced anticancer efficacy of alpha-tocopheryl succinate by conjugation with polyethylene glycol. J.Control Release, 107, 43-52.

324. Roninson,I.B. (1992) The role of the MDR1 (P-glycoprotein) gene in multidrug resistance in vitro and in vivo. Biochem.Pharmacol., 43, 95-102.

325. Trock,B.J., Leonessa,F., and Clarke,R. (1997) Multidrug resistance in breast cancer: a meta-analysis of MDR1/gp170 expression and its possible functional significance. J.Natl.Cancer Inst., 89, 917-931. 
326. Nagaoka,R., Iwasaki,T., Rokutanda,N., Takeshita,A., Koibuchi,Y., Horiguchi,J., Shimokawa,N., Iino,Y., Morishita,Y., and Koibuchi,N. (2006) Tamoxifen activates CYP3A4 and MDR1 genes through steroid and xenobiotic receptor in breast cancer cells. Endocrine., 30, 261-268.

327. Klinge,C.M., Riggs,K.A., Wickramasinghe,N.S., Emberts,C.G., McConda,D.B., Barry,P.N., and Magnusen,J.E. (2010) Estrogen receptor alpha 46 is reduced in tamoxifen resistant breast cancer cells and re-expression inhibits cell proliferation and estrogen receptor alpha 66-regulated target gene transcription. Mol.Cell Endocrinol., 323, 268-276.

328. Shareef,M.M., Brown,B., Shajahan,S., Sathishkumar,S., Arnold,S.M., Mohiuddin,M., Ahmed,M.M., and Spring,P.M. (2008) Lack of P-glycoprotein expression by low-dose fractionated radiation results from loss of nuclear factorkappaB and NF-Y activation in oral carcinoma cells. Mol.Cancer Res., 6, 89-98.

329. Knutsen,T., Mickley,L.A., Ried,T., Green,E.D., du,M.S., Schrock,E., Macville,M., Ning,Y., Robey,R., Polymeropoulos,M., Torres,R., and Fojo,T. (1998) Cytogenetic and molecular characterization of random chromosomal rearrangements activating the drug resistance gene, MDR1/P-glycoprotein, in drug-selected cell lines and patients with drug refractory ALL. Genes Chromosomes.Cancer, 23, 44-54.

330. van,'., V, Dai,H., van,d., V, He,Y.D., Hart,A.A., Mao,M., Peterse,H.L., van der,K.K., Marton,M.J., Witteveen,A.T., Schreiber,G.J., Kerkhoven,R.M., Roberts,C., Linsley,P.S., Bernards,R., and Friend,S.H. (2002) Gene expression profiling predicts clinical outcome of breast cancer. Nature, 415, 530-536. 


\section{FIGURES AND LEGENDS}

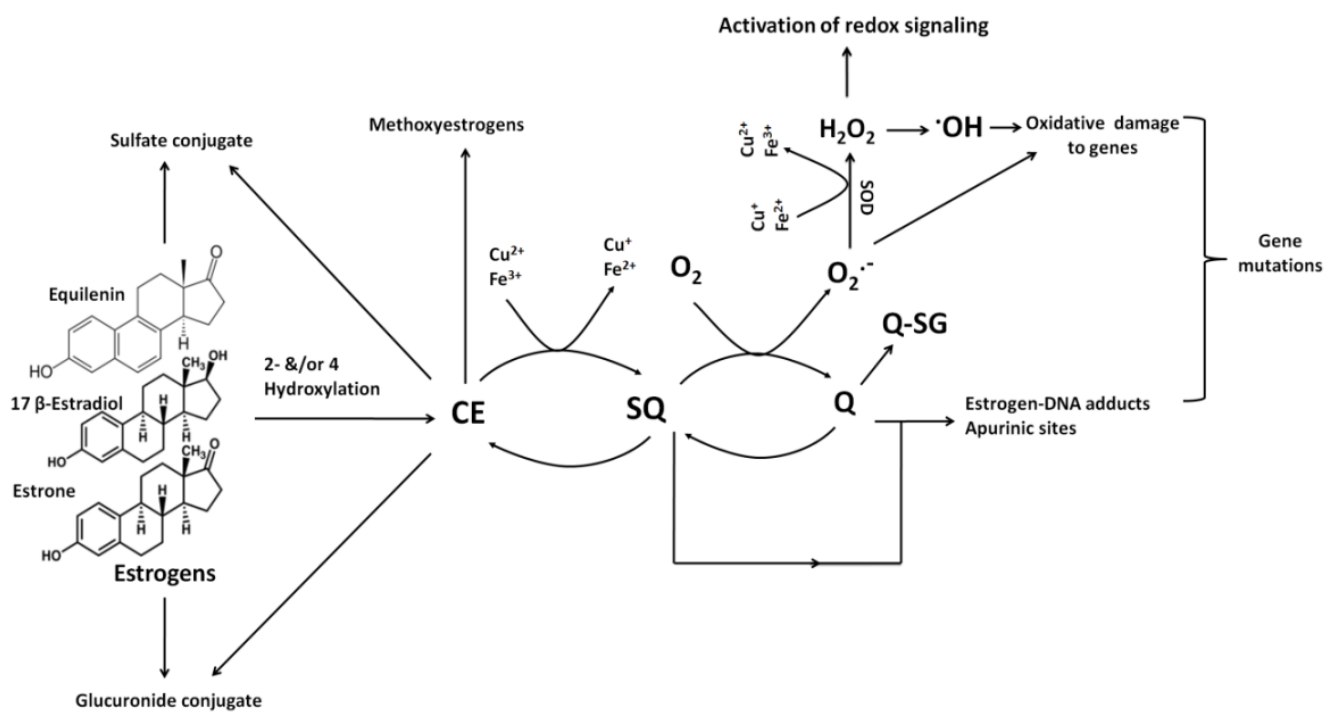

Figure 1. Scheme showing metabolism of estrogen and redox cycling of its metabolites. $\mathrm{CE}=$ Catechol estrogen, $\mathrm{SQ}=$ Semi quinone, $\mathrm{Q}=$ Quinone, $\mathrm{Q}-\mathrm{SG}=$ Quinone-glutathione conjugate.

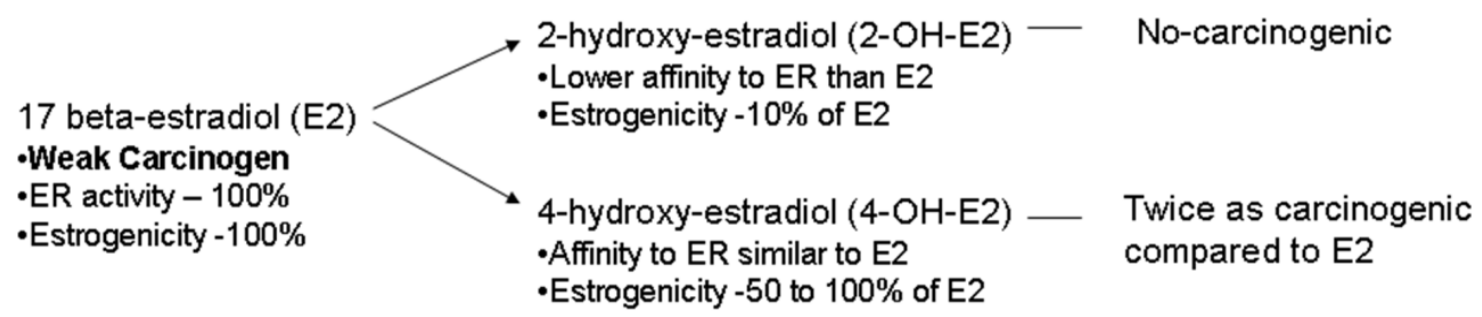

Figure 2. Estrogen induced cellular responses including carcinogenicity and growth of cancer cell do not correlate with the binding affinity of various estrogens to estrogen receptor (ER) and their potency both in vitro and in vivo 


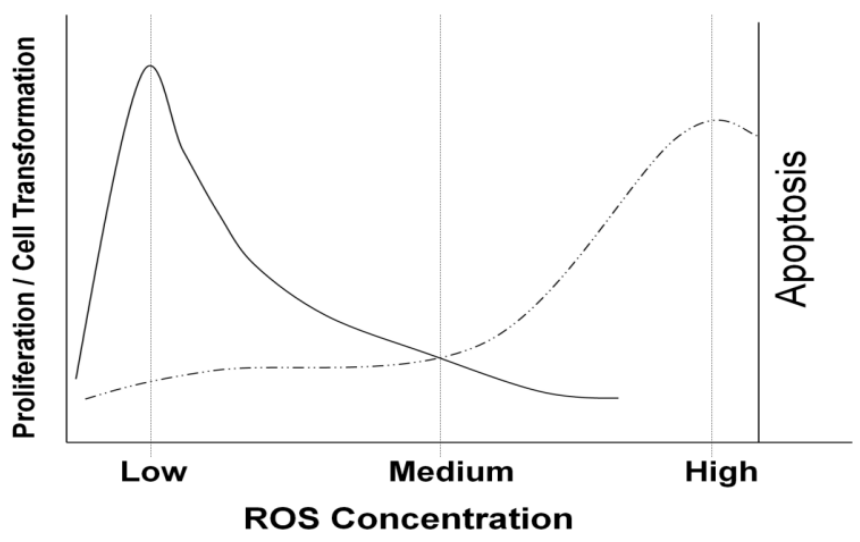

Figure 3. Dual Roles of ROS: High ROS levels induce oxidative damage and produce cell death, where as low physiologic ROS levels facilitate cell-to-cell communication and cell proliferation

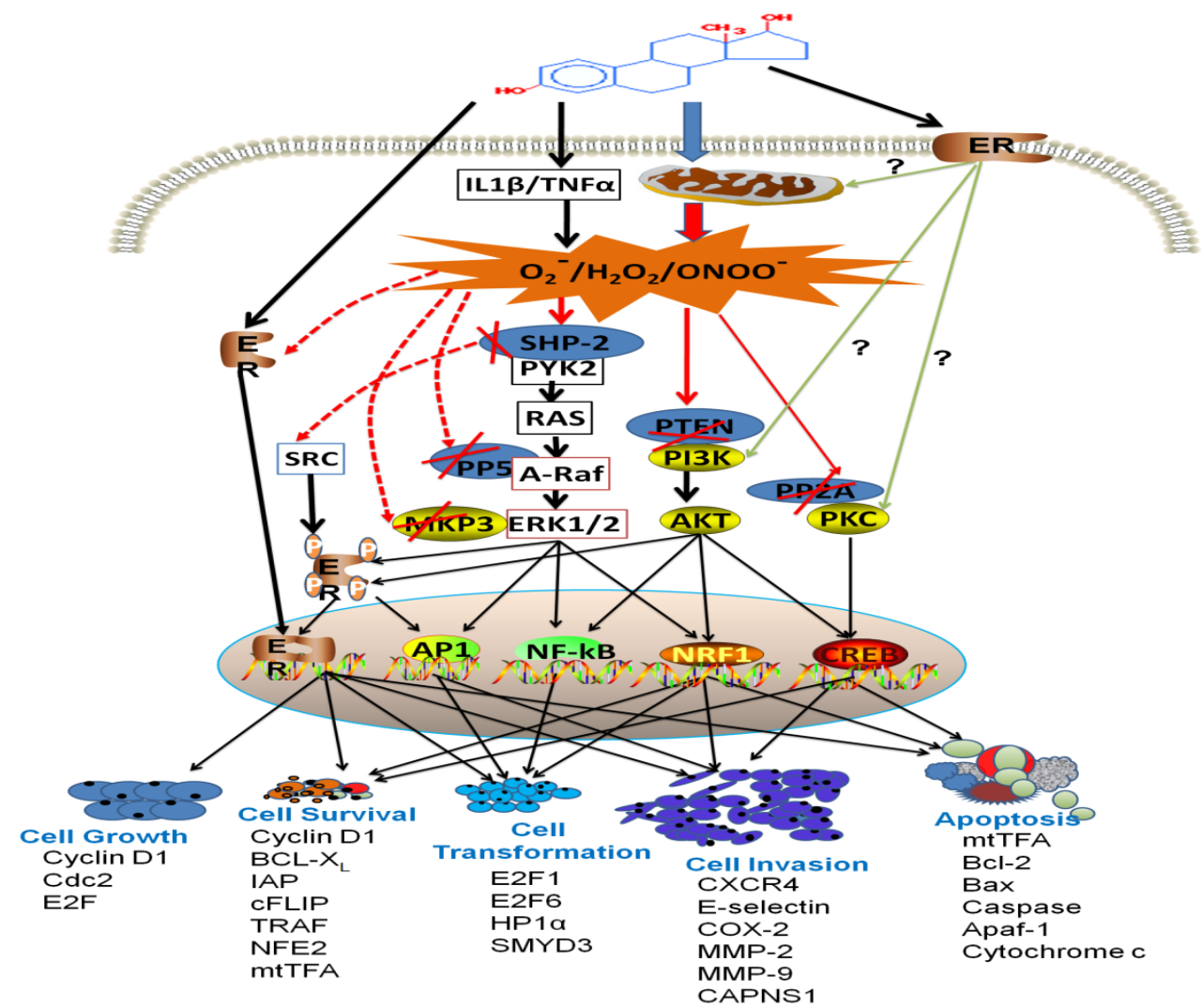

Figure 4. Mechanism of ROS signaling in coordinated inactivation of phosphatases and activation of kinases leading to estrogen-mediated changes in the expression of genes involved in growth, apoptosis, transformation or invasion of cells 


\title{
CHAPTER IV
}

\section{REACTIVE OXYGEN SPECIES CAUSES NEOPLASTIC TRANSFORMATION AND XENOGRAFT GROWTH OF 4-HYDROXY ESTRADIOL-TRANSFORMED MAMMARY EPITHELIAL CELLS VIA TRANSDUCTION OF REDOX SIGNALS TO PI3K/AKT PATHWAY}

\section{Victor O. Okoh, Deodutta Roy}

Department of Environmental and Occupational Health, Florida International University, Miami, FL 33199-0001

\begin{abstract}
Unopposed free estrogen (estrogen without progesterone) is a major risk factor for breast tumors. The mechanism by which estrogen is involved in the development of malignant breast lesions is not clear. We found that reactive oxygen species (ROS)- induced by repeated exposures to 4-hydroxy-estradiol, a predominant catechol metabolite of $17 \beta$ estradiol, caused transformation of immortalized human mammary epithelial cells. This was evident from inhibition of growth of tumors by overexpression of catalase as well as co-treatment with ebselen. Assessment of 4-hydroxy-estradiol transformed clones in 2-D and 3-D cell cultures showed that they formed spheroid structures in various matrices as well acquired invasive properties. During 4-OH-E2-mediated malignant transformation process increased AKT phosphorylation through PI3K activation was observed. This PI3K-mediated phosphorylation of AKT in 4-OH-E2-induced malignant cells was inhibited by ROS modifiers as well as by silencing of AKT expression. RNA interference of AKT markedly inhibited 4-OH-E2-induced in vitro tumor formation. Among the genes being significantly up-regulated during the 4-OH-E2-mediated malignant transformation process well known proliferating cell nuclear antigen (PCNA) as well as the cell cycle genes cyclinB1 and $\mathrm{Cdc} 25 \mathrm{c} 9$ were identified. The expression of these genes was
\end{abstract}


inhibited by ROS modifiers as well as by silencing of AKT expression and NRF1, a transcription factor that controls mitochondrial biogenesis (a major source of ROS). These studies demonstrate that: (i) 4-hyroxy-estradiol is one of the main estrogen metabolites that induce mammary tumorigenesis and (ii) ROS-mediated redox signaling leading to the activation of PI3K/AKT signaling plays an important role in 4-hydroxyestradiol-induced malignant phenotype of breast epithelial cells. In conclusion, ROS are important signaling molecules in the development of estrogen-induced malignant breast lesions that may be useful as therapeutic targets for prevention and treatment of breast cancer.

\section{INTRODUCTION}

Elevated lifetime estrogen exposure is a well-known major risk factor for breast cancer. A large body of epidemiological and experimental evidence points to a role for estrogen in the etiology of human breast cancer (1-9). In experimental models, estrogens are complete breast carcinogens, as they are capable of initiating and triggering growth and selection to generate palpable malignancy $(8-14)$. However, the signaling mechanisms by which estrogen contributes in the initiation of breast cancer remain the subject of a long-standing controversy. This is due, in part, to the inability to resolve whether estrogen or estrogen metabolites are procarcinogenic. 17ß-estradiol (E2) is metabolized to 2- and 4-hydroxy-estradiols by cytochrome p450s. We have previously shown that E2-induced renal tumor formation is decreased in animals exposed to inhibitors of estrogen metabolism or to hormonally potent estrogens undergoing reduced metabolic 
conversion to catechol metabolites compared to E2 $(10-12,15)$. Russo and others have shown that E2 or 4-OH-E2 transform normal ER $\alpha$ negative breast epithelial MCF-10F cells (17-20). 17ß-estradiol-induced transformed MCF10F cells formed tumors in SCID mice. 4-OH-E2 is twice as capable of producing anchorage-independent growth as E2 in MCF10F cells $(18,20)$. In contrast, neither 2-OH-E2 nor 2-OH-E1 are carcinogenic in vitro or in vivo (15). Similar results have been reported in MCF-10A cells exposed to 17 beta-estradiol, equilenin or its catechol metabolite, 4-hydroxyequilenin $(21,22)$. Recently, Parks et al (2009) demonstrated that treatment of MCF-10A cells with 4-OHE2 induced in vitro transformation of cells (23). However, these studies in MCF-10A failed to show in vivo tumorigenicity, invasiveness or display other salient neoplastic properties. In the present study we have established that repeated exposure of 4-OH-E2 to MCF-10A produced tumors both in vitro and in vivo.

Induction of estrogen receptor (ER) upon estrogen exposure is not sufficient for the development of breast cancer. Recent studies indicate that mammary tumors can develop in the absence of a functional ER $\alpha$ (24). Although tamoxifen and other antiestrogens are thought to prevent cancer through their actions at the ER, other mechanisms cannot be ruled out as these compounds also block metabolism and redox cycling of estrogen and are free radical scavengers (25). 4-OH-E2 induces an estrogenic response in the uterus of $\mathrm{ER} \alpha$ null mice, and this response is not inhibited by the antiestrogen ICI182780 (26). These findings suggest that estrogen-dependent growth of cells is regulated not only by nuclear ER-mediated genomic signaling pathways, but also by non-ER pathway(s). We believe that genomic and non-genomic actions of estrogen produce complementary 
effects that are required for cellular transformation. Physiologically achievable concentrations of estrogen or estrogen metabolites directly acting on mitochondria of mammary epithelial or immune cells generate reactive oxygen species (ROS) (27). We previously showed that $17-\beta$ estradiol (E2)-induced DNA synthesis in breast cancer MCF-7 cells depends on mitochondrial oxidant signaling (28). In this study, we have extended our efforts on understanding how an E2 metabolite, 4-OH-E2 produces malignant phenotype through ROS signaling. We investigated whether the susceptibility of normal breast epithelial MCF-10A cells to neoplastic transformation by estrogens depends on ROS-mediated redox signalings. We present here for the first time that oxidants induced by E2 and 4-OH-E2 but not 2-OH-E2 exposures mediate in vitro transformation of MCF-10A cells. 4-OH-E2 transformed cells are not only tumorigenic in mice but also display invasive properties as well as proliferate independent of growth factors. Co-treatments of 4-OH-E2 transformed cells with biological or chemical ROS scavengers, or silencing of Akt1 prevented tumorigenic conversion of MCF-10A cells. We propose a mechanism of tumorigenic conversion that involves oxidant-mediated activation of redox sensitive $\mathrm{PI} 3 \mathrm{~K} / \mathrm{AKT}$ signaling.

\section{MATERIALS AND METHODS}

\section{Reagents}

17ß-Estradiol (E2), 2-hydroxyestradiol (2-OH-E2), 4-hydroxyestradiol (4-OH-E2), Ebselen, N-acetyl-cysteine (NAC), and dimethylsulfoxide (DMSO) were all purchased from Sigma (St Louis, MO, USA). All antibodies; PI3K (p110), phospho PI3K (p85), 
phospho-AKT (ser 473) and total AKT antibodies were purchased from Cell Signaling Technology Inc. (Boston, MA). All tissue cultures reagents were purchased from Invitrogen Corporation (CA) unless otherwise specified.

Culture of MCF-10A cells and Adenovirus gene transfer Human mammary epithelial cells (MCF-10A) were obtained from American Type Culture Collection (ATCC) and were routinely cultured in phenol red-free DMEM-F12 media (1:1) supplemented with $5 \%$ horse serum, hydrocortisone $(0.5 \mu \mathrm{g} / \mathrm{ml})$, insulin $(10$ $\mu \mathrm{g} / \mathrm{ml})$, epidermal growth factor $(20 \mathrm{ng} / \mathrm{ml}), 100 \mathrm{ng} / \mathrm{ml}$ cholera toxin and penicillinstreptomycin $(100 \mu \mathrm{g} / \mathrm{ml}$ each $)$ and incubated at $37^{\circ} \mathrm{C}$ in a humidified atmosphere containing 5\% $\mathrm{CO}_{2}$. The cell culture media, serum, antibiotics, and growth supplements except cholera toxin (Calbiochem, La Jolla, CA) were purchased from Invitrogen Corp CA). For experimental purposes, culture media were changed to starvation media (serum free media + antibiotics) and allowed to incubate for 48 hrs prior to commencement of most experiments, unless otherwise indicated. Serum deprivation synchronizes cells in the $\mathrm{G}_{0} / \mathrm{G}_{1}$ phase of the cell cycle.

The Adenovirus-CMV (empty vector), Adenovirus-MnSOD (AdCMVMnSOD), and Adenovirus-Catalase (AdCMVCat) constructs were purchased from ViraQuest, Inc. (North Liberty, IA, USA). The adenovirus constructs used were replication-defective, E1- and E3-deleted recombinant adenovirus (29). Inserted into the E1 region of the adenovirus genome was either the human MnSOD or catalase gene, both of which are driven by a cytomegalovirus promoter. Cells were seeded in plates at $15 \%-70 \%$ 
confluence. The following day, cells were infected with adenoviruses over-expressing MnSOD or catalase or vector at $100 \mathrm{MOI}$ in serum free media. Control cells were treated with $100 \mathrm{MOI}$ of the adenovirus-CMV construct. This viral load was determined to achieve greater than $50 \%$ growth arrests of MCF-10A cells without significant cell death for the duration of experiment. Infected cells were cultured for $48 \mathrm{hrs}$ after which cells were used for experiments.

\section{$\mathrm{Akt}_{1}$ RNAi transfections}

Pre-designed and verified human shRNA for $\mathrm{Akt}_{1}$ and corresponding null vectors were purchased from OriGene (OriGene Technologies, Inc. Rockville, MD). Transfections of cells were carried out in a sub-confluent cell population using FuGENE 6 (Roche) transfection reagents according to the manufacturer's protocol. Briefly, MCF10A cells were seeded in 6 well plates with growth factor supplemented media (SM) overnight. Post seeding, cells were transfected with $2 \mu 1$ of Fugene-6 (Roche) preincubated for $20 \mathrm{~min}$ at room temperature with $0.5 \mu \mathrm{g}$ plasmid RNAi or its null controls (sham). Forty eight hrs post transfection, media were changed to serum-free (starvation media) media and incubated for an additional $48 \mathrm{hrs,}$, after which cells were used for various experiments. Transfection efficiencies ranged between $60-80 \%$ as quantified by decreased protein expression levels.

Cell viability assay

CellTiter-Fluor ${ }^{\mathrm{TM}}$ Cell Viability kit was purchased from the Promega Corporation and used according to manufacturer's instructions. Briefly, cells were seeded in 96 well plate 
at a density of $1.0 \times 10^{4}$ cells/well, serum starved for $48 \mathrm{hrs}$ and treated with estrogens or ROS modifiers. At the end of treatment procedure, substrate reagents (GF-AFC) were mixed with substrate buffer and dispensed into wells. This assay measures protease activity in live cells as opposed to MTT or MTS assay kits that measure formation of formazon crystals by mitochondrial enzymes. Plates were read on a fluorescence plate reader at 380-400 nm excitation and $505 \mathrm{~nm}$ emission and data is expressed as mean of three experiments $+/-$ SD.

\section{Cell transformation}

The cell transformation was carried out by a modified protocol of Russo's group (18). Briefly, MCF-10A cells were seeded at $30 \%$ density in a $10 \mathrm{~cm}$ dish. After $24 \mathrm{hrs}$ of seeding, media were replaced with stavation media and allowed to culture for $48 \mathrm{hrs,} \mathrm{and}$ then cells were subjected to two treatment cycles with E2 or its catechol metabolites. A treatment cycle includes a $48 \mathrm{hr}$ starvation period, $48 \mathrm{hr}$ treatment period $(100 \mathrm{ng} / \mathrm{ml}$ of either E2, 2-OHE2, and 4-OHE2), and $48 \mathrm{hr}$ recovery period in growth media containing $10 \%$ horse serum (HS) and no growth supplements. At the end of two treatment cycles, cells that would be used for immunoprecipitation and Western blot analysis were treated for an additional 30 mins with estrogens, lysed with RIPA buffer, immunoprecipitated and processed for western analysis. For anchorage independent growth assay 5000 cells/well were used for colony formation assays in soft agar. 
Anchorage independent growth

Anchorage independent growth, an indicator of neoplastic transformation of cells, was assessed as previously described by Zhou et al (30). Briefly, base support agar were made fresh by diluting $1.0 \%$ molten agarose mixed with 1:1 2x culture media (2x DMEM/F12 media, 20\% HS, 2x Penicillin-Streptomycin and $200 \mathrm{pg} / \mathrm{ml}$ estrogens) to a final $0.5 \%$. Molten agar was left at $42{ }^{\circ} \mathrm{C}$ in a water bath until dispensed at $200 \mathrm{ul} /$ well in 48 well plates, then allowed to solidify for 4 hrs at room temperature. Top agarose overlay was made fresh by mixing $0.7 \%$ molten agarose with $2 \mathrm{x}$ culture media containing appropriate 5000 cells/well, then gently overlaid over base agar. Cells were incubated for a minimum of 21 days in a $37^{\circ} \mathrm{C}$ incubator with $5 \% \mathrm{CO}_{2}$. Cultures were fed every week with top agar layer and colony formation was assumed when cell masses were 100 micron or greater as measured on a Nikon TE2000U inverted microscope (Nikon Corp., USA) with Metamorph software (Universal Imaging, USA). Images were acquired by using an Olympus C-5060 digital camera attached to the Nikon TE2000U inverted microscope with a $4 \mathrm{x}$ objective. Four wells were enumerated for each group and data expressed as mean of five wells $+/$ - SD.

Invasion and ductulogenic assays

In order to determine invasiveness of transformed cells, several colonies were aseptically picked, dissociated with trypsin and cultured for 20-30 passages in a low growth factor media (DMEM F12, 5\% FCS, 4 ng/ml EGF, $2.0 \mathrm{ng} / \mathrm{ml}$ insulin, $100 \mathrm{ng} / \mathrm{ml}$ hydrocortisone, 1x Penicillin-Streptomycin) and eventually DMEM/F12 with 5\% HS media, and 1x Penicillin-Streptomycin. Cells $\left(5.0 \times 10^{3}\right.$ cells $\left./ \mathrm{ml}\right)$ for invasion assays were seeded over 
$8 \mu \mathrm{m}$ pore transwell filter insert (Transwell, Coastar Cambridge, MA) precoated with Matrigel (Collaborative Research, Bedford, MA). Chemoattractants used were reduced growth factor supplemented media or media with 10\% FBS media positive control cells MDA MB 231. Matrix invasion was allowed for $16 \mathrm{hrs}$ at $37^{\circ} \mathrm{C}$ in a $\mathrm{CO}_{2}$ incubator. The non-invaded cells inside chambers were wiped off with a cotton swab, and the filters were fixed, stained by Diff Quick (Sigma, St. Louis, MO), cut out and mounted onto glass slides. The total number of cells that crossed the membrane were counted under a light microscope, enumerated and expressed as fold increase compared to parent cell line. The experiments were repeated five times and results are expressed as the mean \pm S.D.

For ductulogenesis, $1.0 \times 10^{3}$ cells/ml of transformed cells (p121 and screened from $3 \mathrm{x}$ Matrigel), MDA MB 231 and parental MCF-10A cells were mixed with collagen (Collagen Co., Palo Alto, CA, USA) and seeded in chamber slides precoated also with collagen. Cells were incubated for three weeks with bi-weekly feeding with 5\% HS media. To confirm spheroid formation from collagen matrix, we diluted HuBiogel, a human matrix mimetic (VIVO Biosciences Inc.), 1:3 with media and coated 0.22 micron pore transwell filter inserts for $6 \mathrm{hrs}$ at $37^{\circ} \mathrm{C}$ incubator. Cells $\left(1.0 \times 10^{3}\right)$ were seeded into each insert and chemoattractant media (DMEM/F12, 5\% HS, 1x Penicillin-Streptomycin) were added at bottom of insert. Cells were cultured for 14 days with media changed twice weekly. Images were acquired with a Olympus C-5060 digital camera under an inverted microscope with 4x objective as described above. 


\section{Chemical antioxidant treatments}

The treatment procedure for Ebselen (a glutathione peroxidase mimetic which also removes both $\mathrm{H}_{2} \mathrm{O}_{2}$ and peroxynitrite) or NAC (a precursor of glutathione and scavenger of $\operatorname{ROS})(31,32)$ varies according to the experiments design. For all experiments, $40 \mu \mathrm{M}$ Ebselen and 1.0 mM NAC were used for cell treatments. For example, in DCF assays, antioxidants were pre-loaded onto cells for 2-4 hrs before ROS measurement commences. For BrdU assays, cells were cultured with the chemical antioxidants throughout the experimental procedure. For transformation regimen, antioxidants were applied to cells each time cells were treated with estrogens. For anchorage independent growth assays, antioxidants were added to soft agar matrix media and during weekly feeding of colonies.

Measurement of reactive oxygen species (ROS)

Cellular ROS were measured on a 96 well plate reader and confocal fluorescence microscopy as previously described by Felty et al (27). Briefly MCF-10A cells were seeded at a concentration of $1.0 \times 10^{4}$ cells per well in black 96-well flat bottom plates (ThermoFisher Scientific Inc. USA) and allowed to adhere overnight. Post seeding, cells were serum starved for 48 hrs after which they were pretreated for 4 hrs with chemical antioxidants Ebselen or NAC (Sigma USA) diluted in Hank's balanced salt solution (HBSS) followed by incubation with $10 \mu \mathrm{M}$ 2',7'-dichlorofluorescin diacetate (DCFHDA) (Invitrogen Corp) for 20 min. Cells were rinsed with HBSS followed by various estrogen treatments as described in the figure legends. DCFH-DA is a non-fluorescent cell-permeable compound, which is acted upon by endogenous esterase that removes the acetate groups generating DCFH. In the presence of intracellular ROS, DCFH is rapidly 
oxidized to the highly fluorescent $2^{\prime}, 7^{\prime}$-dichlorofluorescein (DCF). The oxidative products were measured with a Tecan Genios 96 well microplate reader using 485 and $535 \mathrm{~nm}$ as excitation and emission filters respectively or fluorescence images were acquired on a Nikon TE2000U inverted fluorescence microscope equipped with a Nikon D-Eclipse C1 laser scanning confocal microscope system (Nikon Corp., USA). The built-in Nikon EZC1 software was used for confocal image acquisition and analyses. DCFH-DA stock solutions were diluted at a 1:1 ratio with Pluronic F-127 (20\% w/v). Data are expressed as mean of three experiments $+/-\mathrm{SD}$.

Immunoprecipitation and Western Blot Analysis

After the respective treatments, cells were rinsed twice with ice cold phosphate buffered saline (PBS), harvested with lysis buffer $(150 \mathrm{mM} \mathrm{NaCl}, 0.5 \%$ deoxycholate, $0.1 \%$ Nonidet P-40, 0.1\% SDS, $50 \mathrm{mM}$ Tris) containing protease and phosphatase inhibitors (Roche). Samples were diluted to $500 \mu \mathrm{g}$ of protein in $1 \mathrm{ml}$ of lysis buffer, and precleared for $1 \mathrm{hr}$ at $4{ }^{\circ} \mathrm{C}$ with $10 \mu \mathrm{l}$ of 1:1 slurry of protein A-agarose beads (Invitrogen Corp) in lysis buffer. After a brief centrifugation to remove pre-cleared beads, $2 \mu \mathrm{g}$ of desired capture antibodies were added to each supernatant and incubated on a rocking platform at $4{ }^{\circ} \mathrm{C}$ overnight and captured proteins were precipitated with $40 \mu 1$ of protein A-agarose beads for $2 \mathrm{hr}$. The beads were washed five times with lysis buffer and resuspended in $40 \mu \mathrm{L}$ sample loading buffer, subjected to electrophoresis and electroblotted onto a PVDF nylon membrane. Primary antibodies used for Western blots were diluted 1:1000 in phosphate buffered saline Tween-20, PBST and horseradish peroxidase-conjugated secondary antibodies were diluted 1:50,000 in PBST. Blots were 
treated with ECL reagents (Amersham Biotech), and proteins were detected by autoradiography. Band intensity was quantified with Bio-Rad Gel Doc Imaging System.

Immunofluorescence labeling

MCF-10A cells were seeded and treated in chamber slides as indicated in legends to the figures. Post treatment, cells were fixed with ice cold methanol for $15 \mathrm{mins}$, and permeabilized with $0.5 \%$ Triton X-100 for 30 mins. Cells were blocked with $1 \%$ normal goat sera for $1 \mathrm{hr}$ after which they were probed with antibodies diluted 1:500 for Akt and 1:500 for phospho AKT. Alexa Fluor labeled secondary antibody directed against AKT antibody was diluted 1:1000. The confocal fluorescence images were scanned on a Nikon TE2000U inverted fluorescence microscope equipped with a Nikon D-Eclipse C1 laser scanning confocal microscope system (Nikon Corp., USA). The z-series scanning was done at every $1 \mu \mathrm{m}$ up to a z-depth of $10 \mu \mathrm{m}$ by using a Nikon $40 \times 1.30$ NA DIC H/N2 Plan Fluor oil immersion objective. The built-in Nikon EZ-C1 software was used for confocal image acquisition and analyses.

\section{RESULTS}

Exposure of MCF-10A cells to $17 \beta$-estradiol (E2) and its metabolites produces a rapid increase in ROS levels: Before carrying out cell transformation, we characterized normal human mammary epithelial cells for their ability to produce ROS in response to 17 betaestradiol (E2) exposure. These cells respond to E2 in terms of producing ROS very similar to breast cancer cells. ROS production by E2 and its metabolites, 2-OH-E2 and 4- 
OH-E2 in normal human mammary epithelial MCF-10A cells was dose-dependent (Fig. 1 A,B). 4-OH-E2 induced significantly more ROS in these cells compared to E2 and 2OHE2. The abilities of these estrogens to produce ROS were inhibited by overexpression of catalase or treatment with Ebselen or NAC (Fig. 1C). When MnSOD were overexpressed in these cells, ROS levels increased significantly compared to cells treated with estrogen alone (Fig. 1C). We also measured the cellular protease activities to rule out the possibility that the differential ROS levels were not as a result of differential cell densities or viability. Our results indicate that 4-OH-E2 is the most effective in generating intracellular ROS in MCF-10A cells. Mitochondria may be the major source of estrogen induced intracellular ROS, because overexpression of MnSOD, a mitochondria superoxide dismutase that converts super oxides to hydrogen peroxide, increased the ROS content maximally.

Exposure of MCF-10A cells to $17 \beta$-estradiol (E2) and its catechol metabolites induced dose-dependent colony formation: Both MCF-10F and MCF-10A cells are spontaneously immortalized, ER negative normal human breast epithelial cell lines that are non tumorigenic in vivo. We used the anchorage independent growth (AIG) assay to examine cell transforming ability of E2 by detecting AIG positive colony formation. E2 exposure to MCF-10A cells produced dose dependent increase in colony formation. We found that repeated treatments of MCF-10A cells with various doses of E2 or its catechol metabolites induced in vitro transformation of MCF-10A cells in a dose dependent manner (Fig 2). 4-OH-E2 is more potent in transforming normal mammary epithelial 
cells compared to E2, while 2-OHE2 is a weakly transforming metabolite of MCF-10A cells (Fig 2).

Clonogenic expansion and invasiveness of 4-OH-E2 transformed MCF-10A cells: Since 4-OH-E2 induced the highest transforming frequency, we further examined whether 4OH-E2 induced colonies are clonogenic. We picked several colonies from each soft agar at the end of 21 days and cultured them in media with 10\% FBS (designated as a regular media -RM). Several of these clones did not survive beyond the 10th passage in RM. However, of the 5 that survived up to the 21st passage, we determined whether these cells have acquired anchorage independent growth properties, a hallmark for transformed cells and whether these clones also respond to estrogens. Cells were fed twice per week and cultured for 21days. Colonies were counted from quadruplicate wells, ( \pm SD). One of our clones was highly clonogenic (P21) and responsive to E2. We labelled this clone as MCF-10T15 (Figure 3A). Analysis of the invasive property of this clone MCF-10T15 by invasion assay showed that it is highly invasive (Fig. 3B).

3-D Spheroid formation of 4-OH-E2 transformed clone: To assess whether 4-OHE2 transformed MCF-10A cells are neoplastic, we picked few colonies from anchorage independent growth assay and cultured them repeatedly in growth factor reduced media, then assessed cells periodically for their ability to form spheroid structures in collagen coated $0.22 \mu \mathrm{m}$ transwell inserts, or in a rotary vessel using HuBiogel, a memetic of human stromal matrix. We found that over progressive passages, the clones in collagen 
matrix assumed a more heterogeneous population with small masses (p0) as opposed to homogenous population with aggressive phenotype (p200) (Fig. 4).

The tumorigenic conversion ability of 4-OH-E2-transformed MCF-10A cells was further investigated by 3-D culture using HuBiogel ${ }^{\mathrm{TM}}$. For 3-D culture, anchorage-independent MCF-10A human mammary gland epithelial cells transformed by 4-OH-E2 treatment were mixed with 3D HuBiogel ${ }^{\mathrm{TM}}$ matrix containing DMEM-F12, seeded into $55 \mathrm{ml}$ rotating-wall vessels and incubated at $37^{\circ} \mathrm{C}$ for 16 days. These conditions allow for the spontaneous formation of tissue-like spheroids (Fig 4).

Loss of ductulogenicity in 4-OH-E2 transformed cells: The ability to form ductile structures are characteristic of normal mammary epithelial in collagen matrix. Loss of this ability is a hallmark of transformed cells. Assessment of transformed cells in a collagen matrix indicates that these cells have indeed lost their ability to form ductile structures upon repeated treatment with 4-OHE2 (Fig 5A). This phenotypic change was evident right from $\mathrm{p} 0$ cell population and continued even at $\mathrm{p} 121$.

Aggressive phenotype enrichment: Initial invasion assessment of fifteen colonies from soft agar assay indicates that three colonies have acquired the ability to invade Matrigel matrix. These clones were subsequently cultured in growth factor reduced media over several generations and assessed periodically for invasive phenotype. We observed that successive passage of these clones increased their ability to invade Matrigel matrix. One of the clones termed clone c (MCF-10Ac) had actually acquired invasion capability that 
is about $30 \%$ that of MDA MB 231 cell line at passage (Fig 5B). The other clones had lesser invasive abilities compared to MCF-10Ac (data not shown).

4-OH-E2 treatment causes epithelial to mesenchymal transition (EMT) in MCF10A cells: We found that the 4-OH-E2 transformed clones looked very different from WT both in morphology, size and time it takes to form a sheet upon seeding. Figs. 5C, 1,2 shows that transformed clones were bigger than their WT counterpart in monolayer culture just after seeding ( $3 \mathrm{hrs}$ ). In addition, transformed cells displayed an abnormal differentiation pattern and loss of cell polarity, all phenotypes of cancer cells (Fig. 5C 3,4). The majority of clones exhibited morphological changes that resembled epithelial to mesenchymal transition. As shown in Figure 8b, MCF10A cells showed highly organized cell-cell adhesion and cell contact, whereas 4-OH-E2 transformed-MCF10A cells had an elongated and refractive appearance with cell scattering and loss of cell-cell contacts. The cobblestone-like morphology of MCF10A cells at confluency was replaced in 4-OH-E2 transformed-MCF10A cells by a spindle-like fibroblastic morphology.

Inhibition of 4-OH-E2-induced cell transformation by ROS modifiers: In cells overexpressed with adenovirus construct containing catalase and MnSOD that lowers oxidant production as well as in mtTFA silenced cells, E2 produced fewer colonies compared to E2 alone (Fig 6). Treatment of cells with chemical ROS scavenger (Ebselen or NAC) significantly inhibited the abilities of E2 or 4-OHE2 to induce neoplastic transformation of MCF-10A cells as assessed by inability to form colonies and grow in soft agar assays (Fig 6). This implies that oxidants induced by E2 and 4-OHE2 are 
necessary for tumorigenic transformation of MCF-10A cells and when oxidant levels were scavenged by biological and chemical antioxidants, estrogen induced transformation of mammary cells was inhibited.

The growth of the E2-induced transformed clone was highly responsive to E2 and was inhibited by Ebselen and $\mathrm{N}$-acetyl cysteine. Antioxidants reduce E2-induced DNA synthesis in MCF-10A transformed cells (Figure 7). As shown in Figure 8, treatment with E2 produced spheroids (Left Upper Panel). Overexpression of catalase and Ebselen inhibited E2-induced tumor spheroid formation. Cells were labeled with CFSE using the Vybrant kit for checking viability. All spheroids showing the green fluorophore (Fig. 8 Right Upper Panel) indicate that cells in tumor spheroids are alive.

4-OHE2 induced ROS activates PI3K/AKT signaling pathway: Consequences of elevated ROS in cells are apoptotic cell death, quiescence or cell transformation and neoplastic growth $(33,34)$ The signaling pathway associated with survival of cells under oxidative stress is attributed in part to activation of PI3K and AKT signaling pathways $(34,35)$. Therefore, we determined whether estrogen induced oxidants in normal mammary epithelial cells activate PI3K and AKT signaling pathways during neoplastic transformations of MCF-10A. We found that repeated treatments of MCF-10A cells with E2 and 4-OHE2 increased phosphorylation of both PI3K and AKT in cells treated with regimen of estrogen which produced cell transformation (Fig 9). Phosphorylation of both PI3K and AKT was attenuated by co-treatment with either biological or chemical ROS modifiers (Fig 5). The activation of PI3K and AKT activation by 4-OHE2 were about $30 \%$ and $120 \%$ higher than E2 or 2-OHE2 respectively (Fig 10). Interestingly, we also 
observed that silencing of $\mathrm{Akt}_{1}$ (Fig 11A), the downstream recipient of PI3K activation and Akt1 regulates proliferation and growth of mammalian cells significantly diminished 4-OHE2 induced neoplastic transformations of MCF-10A cells (Fig 11B). These data support that intracellular ROS induced by 4-OHE2 may activate AKT signaling pathway which favors survival and proliferation of cells, both required for malignant transformation.

4-OH-E2-induced ROS modulates cell cycle genes through a nongenomic, ER independent signaling pathway: We investigated whether 4-OH-E2-induced ROS signaling is involved in the modulation of cell cycle genes in the conversion of normal breast epithelial cells to malignant cells. Using a normal cell line (MCF-10A) that develop transformed clones in response to 4-OH-E2 or E2, the expression of cell cycle genes, cyclin D and pcna were measured by real time RT-PCR (Fig. 12). After exposure of $8 \mathrm{~h}$ following two $48 \mathrm{hr}$ treatments with 4-OH-E2; we observed an approximately 1.34, and 1.54- fold increase in the mRNA expression of pcna and cyclin D1. Overexpression of MnSOD and catalase as well as co-treatment with Ebselen and NAC markedly decreased 4-OH-E2 induced pcna and cyclin D1 expression compared to E2 treated cells.

\section{DISCUSSIONS}

Our results showed that E2 and its metabolite, 4-OH-E2, elicited transformed phenotypes in MCF-10A cells, which are estrogen receptor- $\alpha(E R \alpha)$ negative. Similar results have been reported in MCF-10A cells exposed to E2 or its catechol metabolite and 4hydroxyequilenin (21-23). Russo and others have shown that E2 or 4-OH-E2 transformed 
MCF-10F cells were also ER $\alpha$ negative (17-20). Our results are in agreement with

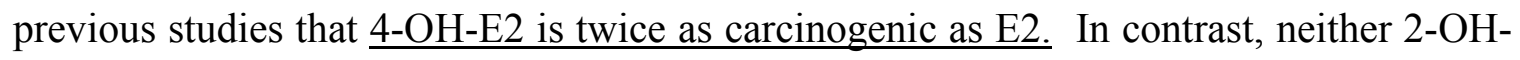
E2 is carcinogenic in vitro or in vivo (15). Interestingly, both 2-OH-E2 and 2-OH-E1 are capable of producing ROS and undergo metabolic redox cycling like 4-OH-E2. The lack of carcinogenicity of 2-hydroxylated estrogen metabolites in vivo may be due to their rapid inactivation by COMT-mediated O-methylation, rapid clearance, and weak estrogenic hormonal activity as compared with 4-OH-E2 (10-12, 36,37). Most importantly, it may be due to 2-MeO-E2, the major product of COMT-mediated Omethylation of 2-OH-E2 that possesses unique anti-tumorigenic activity. These studies support the concept that E2 and its main metabolite 4-OH-E2 are carcinogenic in breast epithelial cells.

Recent studies indicate that mammary tumors can develop in the absence of a functional ER $\alpha$ (24). Although tamoxifen and other antiestrogens are thought to prevent cancer through their actions at the ER, other mechanisms cannot be ruled out as these compounds also block metabolism and redox cycling of estrogen and are free radical scavengers (25). 4-OH-E2 induces an estrogenic response in the uterus of ER $\alpha$ null mice, and this response is not inhibited by the antiestrogen ICI182780 (26). These findings suggest that estrogen-dependent growth of cells is regulated not only by nuclear ER-mediated genomic signaling pathways, but also by non-genomic pathway(s). Genomic and non-genomic actions of estrogen may produce complementary effects that are required for cellular transformation. Estrogen is genotoxic, as seen by the presence of DNA adducts in mammary tissues from ERKO/Wnt-1 mice $(38,39)$. Although the 
formation of DNA adducts may lead to gene mutation, this type of DNA damage appears to be a late event arising from E2 metabolism. We have recently shown that estrogen induces rapid formation of ROS in MCF-7 cells $(27,40)$. 4-OH-E2 has been implicated in transforming MCF-10A cells via ROS formation based on inhibition of anchorage independent growth of MCF-10A cells (23). This study did not show in vivo tumor formation of transformed cells. The main difference between of our work and previous reports is that our transformed clones are tumorigenic in mice and ROS modifiers. The overexpression of catalase that converts hydrogen peroxide to water and Ebselen, a gluthione peroxidase mimic, inhibited cell transformation and tumor formation. This is important because MCF-10A cells are easily transformed in an in vitro system, even by mild stress such as reduced growth factor media or hypoxic conditions (41).

Both E2 and 4-OH-E2 treatment of MCF-10A cells, increased the formation of ROS as compared to untreated cells, whereas 2-OHE2 induced the minimum increase in ROS formation in MCF-10A cells. Over-expression of biological ROS modifiers and chemical scavengers of ROS prevented 4-OH-E2-induced anchorage independent growth of MCF10A cells. We observed similar results with 3-D culture of transformed cells using HuBiogel and xenograft tumor growth. These findings suggest that ROS induced by repeated exposures to 4-OH-E2, a predominant catechol metabolite of E2, cause transformation of immortalized human mammary epithelial cells with malignant growth in nude mice. Since 4-OH-E2 induces more ROS formation compared to E2 in MCF10A cells, the accumulation of 4-OH-E2 in the breast is expected to augment ROS formation here as well. 4-OH-E2 strongly binds to ER $(42,43)$ and it takes longer to dissociate from the ER than E2 (44). The greater ROS production, ER action, and breast tissue 
accumulation of 4-OH-E2 compared to E2 may account for its greater carcinogenicity in MCF-10A cells.

We and others have shown that mitochondria are significant targets of estrogen $(27,40)$. Recently, we reported that physiological concentrations of E2 stimulate a rapid production of intracellular ROS in epithelial cells which depends on cell adhesion, the cytoskeleton, and integrins $(27,40)$. These events occur earlier than ER-mediated genomic actions. E2-induced ROS production does not depend on the presence of ER on breast cancer cells as ER'cell lines MDA-MB 468 produced ROS equal to or more than that of $\mathrm{ER}^{+} \mathrm{MCF} 7, \mathrm{~T} 47 \mathrm{D}$, and ZR75cell lines (27).

It has been wrongly concluded by Parks et al (23) that redox cycling of catechol estrogen is the source of ROS. Catechol estrogens, particularly 4-OH-E2, via nonenzymatic autoxidation, may undergo redox cycling to produce reactive semiquinone and quinone intermediates with concomitant production of ROS (10-12). However, this redox reaction of catechol estrogens is enhanced in the presence of $\mathrm{Cu}^{2+}$ or $\mathrm{Fe}^{3+}$ ions and by enzymatic catalysis by cytochrome P450 oxidases or peroxidases, which is accompanied with an increased generation of ROS. Furthermore, Parks et al (23) implied the contribution of redox cycling of catechol estrogen generating ROS based on indirect evidence using a non-specific inhibitor of cytochromes P450, SKF525A and dicumarol, an inhibitor of quinine reductase. Dicumarol can also inhibit mitochondrial diaphorase, which is involved in reduction of Coenzyme Q10 in the mitochondria (45). Similarly, SKF-525A inhibits mitochondrial oxidative metabolism in intact cells and isolated mitochondria 
(46). Lower ROS formation observed in the presence of SKF525A and dicumarol may be as a result of inhibition of the mitochondrial electron transport chain. Increased ROS formation is observed within 30 seconds of E2 treatment (40). Due to the speed of ROS production as observed in our study, it is unlikely that redox cycling of 4-OHE2 is the source of these oxidants. Furthermore, in our studies of E2-induced ROS generation in MCF-7 and other cells, hydroxylated estrogen metabolites or adducts immediately after addition of E2 were not detected which also rules out the possibility of ROS generation by redox cycling of hydroxylated estrogens.

Little is known about the potential direct involvement of ROS signaling in breast cancer development. However, we and others have recently discovered that estrogen-induced oxidative bursts occur exclusively in perinuclear regions. This surge in ROS production may target inducible promoters, signaling transcription-initiation complex assembly and subsequently, driving estrogen-induced gene expression (28). While studying mitochondrial regulators of cell cycle progression, we discovered that E2-induced G1 to $\mathrm{S}$ phase transition is associated with an increase in intracellular ROS levels (28). These findings strongly support the idea that both E2-induced ROS and ER activity are required for breast cancer cell proliferation (28). When produced at high levels, ROS levels induce oxidative damage and G0/G1 arrest. However, when present at physiologic levels, ROS mediate essential cellular functions such as cell-to-cell communication and proliferation. For example, estrogen-generated ROS mediate early G1 gene expression, as seen by the ability of antioxidants to block this effect (28). We now know that the delicate intracellular interplay between oxidizing and reducing equivalents allows ROS to 
function as second messengers in signaling pathways controlling cellular proliferation and transformation $(47,48)$. Recent studies implicate a role for ROS in cell transformation and several lines of indirect evidence support a role for ROS in the development of breast cancer $(49,50)$, We recently found that, in Syrian hamsters, estradiol-induced kidney tumor formation was reduced by the antioxidants $\mathrm{N}$ acetylcysteine, vitamin $\mathrm{C}$, sodium 2-mercaptoethanesulfonate (cytoprotective thiolcontaining agent), and Ebselen (51,52). Consistent with this finding, estrogen-induced testicular and uterine cancers are prevented by pentoxifylline, a compound with antioxidant effects stemming from its ability to block synthesis of the inflammatory mediators, IL-1 $\beta$ and TNF $\alpha$ (49). Overexpression of manganese superoxide dismutase (MnSOD), the mitochondrial enzyme responsible for superoxide detoxification, blocks the appearance of malignant phenotypes (53), and the loss of this enzyme partly contributes to malignant phenotypes $(54,55)$. Not surprisingly, MnSOD knockout mice exhibit increased oxidative DNA damage (56). MnSOD expression is less frequently found in tumor cells of invasive breast carcinomas than in non-neoplastic breast epithelial cells (57). Several epidemiological studies have shown that MnSOD polymorphic populations have an increased risk of breast cancer (59-60). The recent findings that 4OH-E2 accumulates in the breast tissue of cancer subjects (61-63) and predominant 4hydroxylation of E2 occurs in the target organs of cancers (64-66) suggest that the target organ of cancer would be particularly sensitive to 4-OH-E2-induced ROS formation. In our studies, overexpression of catalase and antioxidants (N-acetyl cysteine and Ebselen) prevented 4-OH-E2-induced anchorage independent growth of MCF-10A cells. These 
results indicate that 4-OH-E2-induced cell transformation may be mediated, in part, by redox-sensitive signal transduction pathways.

Both AKT and ERK are redox sensitive kinases. Thus, 4-OH-E2-generated ROS may activate ERK or AKT, which could then directly phosphorylate and activate transcription factors controlling cell cycle, cell migration or cell invasion genes. Several investigators have concluded that estrogen-induced AKT activation is promoted by membrane bound $\operatorname{ER} \alpha$ or $\operatorname{ER} \beta(67,68)$. There are no known functional motifs within the structure of the ER that can promote second messenger signaling. There are reports which show no correlation between $\mathrm{ER} \alpha / \beta$ expression patterns and the activation of $\mathrm{AKT}-1 / \mathrm{-} 2$ in estrogen treated breast cancer cell lines. 17 $\alpha$-estradiol, through an ER independent mechanism, activates PI3K-AKT signaling (69). Recently, Lee et.al. (67) reported that up-regulation of PI3K/AKT signaling by E2 is mediated through activation of ER $\alpha$, but not ER $\beta$. In ovarian cancer cells, 4-OH-E2 induces AKT phosphorylation while 2-OH-E2 did not (70). Our study showed that 4-OH-E2 increased AKT poshphorylation in ER $\alpha$ lacking MCF-10 cells, while 2-OH-E2 did not increase AKT phosphorylation. The PI3K inhibitor, LY294002, and ROS modifiers blocked 4-OH-E2-induced AKT phosphorylation. AKT activity depends on its phosphorylation, which is positively regulated by PI3K and negatively regulated by a class of protein phosphatases (PPs) (71). AKT can be activated by both $\mathrm{E} 2$ and $\mathrm{H}_{2} \mathrm{O}_{2}$ (67-73). ROS reversibly regulate cysteinebased phosphatases (reviewed in 47). The ability of E2 and $\mathrm{H}_{2} \mathrm{O}_{2}$ to activate AKT may be attributable to inactivation of cysteine-based phosphatases by ROS (47, 67-73). The 
reversible inactivation of phosphatases, such CDC25A and PTEN, by estrogen-induced ROS may be a key component of AKT activation $(47,72)$.

The PI3K/Akt signaling pathway seems ubiquitous to carcinogenic conversions (74-76). Oxidant mediated hyperactivation of AKT can phosphorylate and inhibit pro-apoptotic proteins such as $\mathrm{BAD}$ and caspase 9 while phosphorylating and activating pro-growth transcription factors such as ASK1 and GSK3. The outcome of this hyperactivation could therefore be cells surviving and proliferating in a high oxidative state. If these cells have been initiated by acquisition of pre-tumorigenic lesions by 4-OHE2 metabolism, oxidant mediated growth of these cells could be the basis for malignant transformation of mammary cells. The loss of PTEN activity, hyperactivation of PI3K/AKT signaling pathway, excess estrogen exposure and oxidative stress have been implicated in breast carcinogenesis (47). In this study, we also observed that PI3K/AKT signaling proteins were hyperactivated in MCF-10A cells treated repeatedly with estradiol and 4-OHE2 though the activations of 4-OHE2 were more than those of E2 and 2-OHE2 respectively. Importantly, chemical and biological antioxidant mitigated PI3K/AKT activations and inhibited estrogen induced mammary tumorigenesis. To rule out the possibility that antioxidant regulation of $\mathrm{PI} 3 \mathrm{~K} / \mathrm{AKT}$ activations are not related to estrogen induced mammary tumorigenesis, we silenced $\mathrm{AKT}_{1}$ expression, the $\mathrm{AKT}$ isoform implicated in survival, growth and tumorigenesis of cells including mammary cells (74-76). We found that silencing of this gene prevented estrogen's ability to transform MCF-10A cells. These data indicates that estrogen induced redox activation of PI3K/AKT signaling pathway is essential for mammary tumorigenesis. 
A substantial number of experimental and epidemiological studies support an important role for AKT in tumorigenesis. PI3-kinase and AKT act as oncogenic determinants in several human cancers. AKT genes are amplified or overexpressed in gastric, ovarian, breast, pancreatic, and prostate cancers $(77,78)$. AKT1 levels are higher in a panel of human breast carcinoma cell lines than in breast epithelial cells, particularly those with higher HER2 expression. AKT1 activity is increased by either E2 or IGF-I in estrogendependent MCF-7 cells, and both factors act synergistically to increase AKT1 activity and promote cell proliferation (79). Transgenic mice expressing AIB1 (ER co-activator) in the mammary gland develop mammary hyperplasia and mammary carcinomas. Increased activation of the PI3K/AKT pathway is implicated in the development of mammary carcinoma in AIBI mice (80). AKT activation amplifies the proliferation induced by cyclin D1 or HPV E7 during morphogenesis and cooperates with these oncoproteins to promote proliferation and morphogenesis in the absence of growth factors (81). H-ras transformation of MCF-10A cells results in upregulation of MAP kinase and PI3-kinase signals (82). Similarly benzo(a)pyrene quinone is reported to induce anchorage-independent growth of MCF-10A cells which depends on the activation of PI3K/AKT activation (83). Chronic activation of AKT2 leads to an increase of the events associated with tumorigenesis (84). Most importantly, AKT activation disrupts mammary acinar architecture and enhances proliferation in an mTOR-dependent manner (80). Our study showed that the exposure of 4-OH-E2 or E2 to normal human breast epithelial MCF-10A cells produced transformed phenotypes. These cells show increased AKT and increased cell number in the absence of EGF or insulin. The 4-OH-E2-induced cell proliferation was attenuated by the antioxidant $\mathrm{N}$-acetylcysteine. Overexpression of 
catalase and MnSOD also reduced the extent of 4-OH-E2-dependent increased cell growth and AKT activation. Taken together, these data indicate that 4-OH-E2-induced ROS activates the AKT pathway in MCF-10A cells to support the growth of cells in growth factor deficient conditions. 


\section{LIST OF REFERENCES}

1. IARC working group. Monographs on the evaluation of hormonal contraception and postmenopausal hormonal therapy. (1999), 72, 399-530

2. National Toxicology Program (NTP). Federal report on carcinogens. Federal Register (2002), 67 (242), 77283-77285.

3. Henderson BE, Ross R, Bernstein L. Estrogens as a cause of human cancer: the Richard and Hinda Rosenthal Foundation award lecture. Cancer Res. (1988), 48,246-253.

4. Holland, M. and Roy, D. Estrone-induced cell proliferation and differentiation in the mammary gland of the female Noble rats. Carcinogenesis (1995), 16, 1955-1961.

5. Xie B, Tsao SW, Wong YC. Induction of high incidence of mammary tumour in female Noble rats with a combination of 17 beta-oestradiol and testosterone. Carcinogenesis (1999), 20,1069-1078

6. Li JJ, Papa D, Davis MF, Weroha SJ, Aldaz CM, El-Bayoumy K, Ballenger J, Tawfik $\mathrm{O}$, Li SA Ploidy differences between hormone- and chemical carcinogen-induced rat mammary neoplasms: comparison to invasive human ductal breast cancer Mol. Carcinog. (2002), 33,56-65.

7. Moon,R.C. (1981) Influence of pregnancy and lactation on experimental mammary carcinogenesis. In Pike,M.C., Siiteri,P.K. and Welsch,C.W. (eds) Banbury Report 8: Hormones and Breast Cancer. Cold Spring Harbor Laboratory, Cold Spring Harbor, pp. 353-364.

8. IARC. Monographs on the evaluation of the carcinogenic risk of chemicals to human: sex hormone. (1979) 21, 173-221.

9. NCI. Uses of hormones after menopause (2003). http://cancer.gov/clinical trials digestpost menopause-hormone-use

10. Roy, D., Palangat, M., Chen, CW, Thomas, RT, Colerangle, JC, Atkinson, A., Yan, ZJ. Biochemical and molecular changes at the cellular levels in response to exposure of environmental estrogen-like chemicals J. Toxicol. Environ. Health, 49, 101-129, 1997.

11. Roy, D, Colerangle, J. and Singh, K.P. Is exposure of environmental or industrial endocrine disrupting estrogen-like chemicals able to cause genomic instability? Front. Biosci., 3, d913-921, 1998. 
12. Roy D and Singh KP. Estrogen-induced genetic alterations and breast, endometrial, testicular and prostate cancers, Current Genomics, 5, 245-257, 2004

13. IARC working group. Monographs on the evaluation of combined estrogenprogestogen contraceptives and menopausal therapy. Vol 91, (2005), http://www.omsoul.com/pdfs/WHO-Pill-Breast-Cancer.pdf.

14.Castagnetta L, Granata OM, L Cocciadiferro, A Saetta, L Polito, G Bronte, S Rizzo, I Campisi, B Agostara, G Carruba: Sex steroids, carcinogenesis, and cancer progression. Ann N Y Acad Sci. 2004 ;1028:233-46

15. Li JJ and Li SA: Estrogen carcinogenesis in Syrian hamster tissues: role of metabolism. Fed Proc 46: 1858-1863, 1987.

16. Russo J, Tahin Q, Lareef MH, Hu YF, Russo IH. Neoplastic transformation of human breast epithelial cells by estrogens and chemical carcinogens. Environ Mol Mutagen 2002; 39: 254-63

17. Russo J, Lareef MH, Tahin Q, Hu YF, Slater C, Ao X, Russo IH. 17 -estradiol is carcinogenic in human breast epithelial cells. J Steroid Biochem Mol Biol 2002; 80: 14962

18. Russo J, Hasan Lareef M, Balogh G, Guo S, Russo IH. Estrogen and its metabolites are carcinogenic agents in human breast epithelial cells. J Steroid Biochem Mol Biol 2003; 87: $1-25$

19. Fernandez SV, Russo IH, Lareef M, Balsara B, Russo J. Comparative genomic hybridization of human breast epithelial cells transformed by estrogen and its metabolites. Int J Oncol 2005; 26: 691-5.

20. Sandra V. Fernandez, Irma H. Russo, Jose Russo Estradiol and its metabolites 4hydroxyestradiol and 2-hydroxyestradiol induce mutations in human breast epithelial cells. Int J Cancer. 2005 Nov 14

21. Cuendet M, Liu X, Pisha E, Li Y, Yao J, Yu L, Bolton JL. Equine estrogen metabolite 4-hydroxyequilenin induces anchorage-independent growth of human mammary epithelial MCF-10A cells: differential gene expression. Mutat Res 2004; 550: $109-21$

22. Liu S, Lin YC. Transformation of MCF-10A human breast epithelial cells by zeranol and estradiol-17 . Breast J 2004; 10: 514-21 
23. Park SA, Na HK, Kim EH, Cha YN, Surh YJ. 2009. 4-hydroxyestradiol induces anchorage-independent growth of human mammary epithelial cells via activation of IkappaB kinase: potential role of reactive oxygen species. Cancer Res 69: 2416-2424.

24. Bocchinfuso WP, Hively WP, Couse JF, Varmus HE, Korach KS: A mouse mammary tumor virus-Wnt-1 transgene induces mammary gland hyperplasia and tumorigenesis in mice lacking estrogen receptor-alpha. Cancer Res. (1999), 59, 18691876

25. Arteaga E, Villaseca P, Bianchi M, Rojas A, Marshall G.Raloxifene is a better antioxidant of low-density lipoprotein than estradiol or tamoxifen in postmenopausal women in vitro. Menopause. 2003,10:142-6

26. Couse JF, Korach KS. Estrogen receptor null mice: what have we learned and where will they lead us? Endocr Rev 1999; 20: 358-417.

27. Felty Q, Xiong WC, Sun D, Sarkar S, Singh KP, Parkash J, et al. 2005. Estrogeninduced mitochondrial reactive oxygen species as signal-transducing messengers. Biochemistry 44: 6900-6909.

28. Felty Q, Singh KP, Roy D. 2005. Estrogen-induced G1/S transition of G0-arrested estrogen-dependent breast cancer cells is regulated by mitochondrial oxidant signaling. Oncogene 24: 4883-4893.

29. Lam E. W. N., Zwacka R., Engelhardt J. F., Davidson B. L., Domann F. E., Oberley L. W. Adenovirus-mediated manganese superoxide dismutase gene transfer to hamster cheek pouch carcinoma cells. Cancer Res., 57: 5550-5556, 1997.

30. Zhou,Q., Liu,L.Z., Fu,B., Hu,X., Shi,X., Fang,J., and Jiang,B.H. (2007) Reactive oxygen species regulate insulin-induced VEGF and HIF-1alpha expression through the activation of p70S6K1 in human prostate cancer cells. Carcinogenesis, 28, 28-37.

31. Roederer,M., Staal,F.J., Raju,P.A., Ela,S.W., Herzenberg,L.A., and Herzenberg,L.A. (1990) Cytokine-stimulated human immunodeficiency virus replication is inhibited by Nacetyl-L-cysteine. Proc.Natl.Acad.Sci.U.S.A, 87, 4884-4888.

32. Steinmetz,K.A. and Potter,J.D. (1996) Vegetables, fruit, and cancer prevention: a review. J.Am.Diet.Assoc., 96, 1027-1039.

33. Tas F, Hansel H, Belce A, Ilvan S, Argon A, Camlica H, et al. 2005. Oxidative stress in breast cancer. Med Oncol 22: 11-15.

34. Wang J, Ito T, Udaka N, Okudela K, Yazawa T, Kitamura H. 2005. PI3K-AKT pathway mediates growth and survival signals during development of fetal mouse lung. Tissue Cell 37: 25-35. 
35. Wang X, McCullough KD, Franke TF, Holbrook NJ. 2000. Epidermal growth factor receptor-dependent Akt activation by oxidative stress enhances cell survival. J Biol Chem 275: 14624-14631.

36. Zhu BT and Liehr JG: Inhibition of the catechol-O-methyltransferase-catalyzed Omethylation of 2- and 4-hydroxyestradiol by catecholamines: implications for the mechanism of estrogeninduced carcinogenesis. Arch Biochem Biophys 304: 248-256, 1993.

37. Emons G, Merriam GR, Pfeiffer D, Loriaux DL, Ball P and Knuppen R: Metbolism of exogenous 4- and 2-hydroxyestradiol in the human male. J Steroid Biochem 28: 499504, 1987.

38. Embrechts J, Lemiere F, Van Dongen W, Esmans EL, Buytaert P, Van Marck E, Kockx M, Makar A.: Detection of estrogen DNA-adducts in human breast tumor tissue and healthy tissue by combined nano LC-nano ES tandem mass spectrometry. J Am Soc Mass Spectrom. (2003), 14, 482-491.

39. Devanesan P, Santen RJ, Bocchinfuso WP, Korach KS, Rogan EG, Cavalieri E. Catechol estrogen metabolites and conjugates in mammary tumors and hyperplastic tissue from estrogen receptor-alpha knock-out (ERKO)/Wnt-1 mice: implications for initiation of mammary tumors. Carcinogenesis. (2001), 22, 1573-1576).

40. Parkash J, Felty Q, and Roy D Estrogen Exerts a Spatial and Temporal Influence on Reactive Oxygen Species Generation that Precedes Calcium Uptake in High-Capacity Mitochondria: Implications for Rapid Nongenomic Signaling of Cell Growth. Biochemistry. 2006, 45(9):2872-81.

41. Dolado I, Nebreda AR. 2008. AKT and oxidative stress team up to kill cancer cells. Cancer Cell 14: 427-429.

42. Ball P and Knuppen R: Catecholestrogens: chemistry, biosynthesis, metabolism, occurance and physiological significance.

Acta Endocrinol 93: 1-127, 1983.

43. Das SK, Tan J, Raja S, Halder J, Paria BC and Dey SK: Estrogen targets genes involved in protein processing, calcium homeostasis, and wnt signaling in the mouse uterus independent of estrogen receptor-alpha and -beta. J Biol Chem 275: 28834-28842, 2000.

44. Barnea,E.R., MacLusky,N.J. and Naftolin,F. (1983) Kinetics of catecholestrogenestrogen receptor dissociation: a possible factor underlying differences in catecholestrogen biological activity. Steroids, 41, 643-656

45. Ronald D. Thomas and Deodutta Roy. Mitochondrial enzyme-catalyzed oxidation and reduction reactions of stilbene estrogen. Carcinogenesis (1995) 16 (4): 891-895. 
46. Galeotti T, Eboli ML, Palombini G, van Rossum GD, Kapoor SC. Inhibition of mitochondrial oxidative metabolism by SKF-525A in intact cells and isolated mitochondria. Biochem Pharmacol. 1983 Nov 15;32(22):3285-95

47. Okoh V, Alok Deoraj, Deodutta Roy. Estrogen-induced reactive oxygen speciesmediated signalings contribute to breast cancer. Biochem Biophys Acta, In Press, 2010.

48. Roy D, Q Cai, Q Felty and S Narayan:Estrogen-induced generation of reactive oxygen and nitrogen species, gene damage and estrogen-dependent cancers. J Toxicol Env Health, 2007, 10(4):235-57.

49. Pervaiz S, Clement MV Superoxide anion: oncogenic reactive oxygen species? Int J Biochem Cell Biol. 2007, 39(7-8):1297-1304.

50. Cejas P, Casado E, Belda-Iniesta C, De Castro J, Espinosa E, Redondo A, Sereno M, García-Cabezas MA, Vara JA, Domínguez-Cáceres A, Perona R, González-Barón M. Implications of oxidative stress and cell membrane lipid peroxidation in human cancer .Cancer Causes Control. 2004, 15(7):707-719

51. Roy D and Liehr JG. Inhibition of estrogen-induced renal carcinogenesis by modulators of estrogen metabolism. Carcinogenesis (1990), 11, 567-570.

52. Liehr, J.G., Roy, D. and Gladek, A. Mechanism of inhibition of estrogen-induced renal carcinogenesis in male Syrian hamsters by vitamin C. Carcinogenesis (1989), 10, 1983-1988.

53. Li JJ, Oberley LW, St Clair DK, Ridnour LA, Oberley TD: Phenotypic changes induced in human breast cancer cells by overexpression of manganese-containing superoxide dismutase.Oncogene 1995, 10:1989-2000

54. Oberley LW, Oberley TD: The role of superoxide dismutase gene amplification in carcinogenesis.J Theor Biol 1984, 106:403-422

55. Oberley LW, Oberley TD: Role of antioxidant enzymes in cell immortalization and transformation.Mol Cell Biochem 1988, 84:147-153

56. Melov S, Coskun P, Patel M, Tuinstra R, Cottrell B, Jun AS, Zastawny TH, Dizdaroglu M, Goodman SI, Huang TT, et al.: Mitochondrial disease in superoxide dismutase 2 mutant mice.Proc Natl Acad Sci USA 1999, 96:846-851

57. Soini Y, Vakkala M, Kahlos K, Paakko P, Kinnula V: MnSOD expression is less frequent in tumour cells of invasive breast carcinomas than in in situ carcinomas or nonneoplastic breast epithelial cells.J Pathol 2001, 195:156-162. 
58. Ambrosone C, Freudenheim J, Thompson P, Bowman E, Vena J, Marshall J, Graham S, Laughlin R, Nemoto T, Shields P: Manganese superoxide dismutase (MnSOD) genetic polymorphisms, dietary antioxidants, and risk of breast cancer.Cancer Res 1999, 59:602606.

59. Mitrunen K, Sillanpaa P, Kataja V, Eskelinen M, Kosma V-M, Benhamou S, Uusitupa M, Hirvonen A: Association between manganese superoxide dismutase (MnSOD) gene polymorphism and breast cancer risk.Carcinogenesis 2001, 22:827-829.

60. Qiuyin Cai, Xiao-Ou Shu, Wanqing Wen, Jia-Rong Cheng, Qi Dai, Yu-Tang Gao and Wei Zheng Genetic polymorphism in the manganese superoxide dismutase gene, antioxidant intake, and breast cancer risk: results from the Shanghai Breast Cancer Study. Breast Cancer Res 2004, 6:R647-R655

61.Castagnetta L, Granata OM, L Cocciadiferro, A Saetta, L Polito, G Bronte, S Rizzo, I Campisi, B Agostara, G Carruba: Sex steroids, carcinogenesis, and cancer progression. Ann N Y Acad Sci. 2004 ;1028:233-46

62. Castagnetta LAM, Granata OM, Traina A, Ravazzolo B, Amoroso M, Miele M, Bellavia V, Agostara B, and Carruba G Tissue content of hydroxyestrogens in relation to survival of breast cancer patients. Clinical Cancer Res 8, 3146-3155, 2002.

63. Rogan EG, Badawi AF, Devanesan PD, Meza JL, Edney JA, West WW, Higginbotham SM, Cavalieri EL. Relative imbalances in estrogen metabolism and conjugation in breast tissue of women with carcinoma: potential biomarkers of susceptibility to cancer. Carcinogenesis 2003; 24: 697-702.

64. Liehr JG, Ricci MJ. 4-Hydroxylation of estrogens as marker of human mammary tumors. Proc Natl Acad Sci 1996; 93: 3294-6.

65. Weisz J, QD Bui, D Roy and JG Liehr. Elevated 4-hydroxylation of estradiol by hamster kidney microsomes: a potential pathway of metabolic activation of estrogens. Endocrinology, Vol 131, 655-661, 1992

66. Wilson AM and Reed GA. Predominant 4-hydroxylation of estradiol by constitutive cytochrome P450s in the female ACI rat liver . Carcinogenesis, Vol. 22, No. 2, 257-263, 2001

67. Lee YR, Park J, Yu HN, Kim JS, Youn HJ, Jung SH. 2005. Up-regulation of PI3K/Akt signaling by 17beta-estradiol through activation of estrogen receptor-alpha, but not estrogen receptor-beta, and stimulates cell growth in breast cancer cells. Biochem Biophys Res Commun 336: 1221-1226. 
68. Sun M, Paciga JE, Feldman RI, Yuan Z, Coppola D, Lu YY, et al. 2001a. Phosphatidylinositol-3-OH Kinase (PI3K)/AKT2, activated in breast cancer, regulates and is induced by estrogen receptor alpha (ERalpha) via interaction between ERalpha and PI3K. Cancer Res 61: 5985-5991.

69. Banerjee S, Saxena N, Sengupta K, Banerjee SK. 2003. 17alpha-estradiol-induced VEGF-A expression in rat pituitary tumor cells is mediated through ER independent but PI3K-Akt dependent signaling pathway. Biochem Biophys Res Commun 300: 209-215.

70.Gao N, Nester RA, Sarkar MA. 2004. 4-Hydroxy estradiol but not 2-hydroxy estradiol induces expression of hypoxia-inducible factor lalpha and vascular endothelial growth factor A through phosphatidylinositol 3-kinase/Akt/FRAP pathway in OVCAR-3 and A2780-CP70 human ovarian carcinoma cells. Toxicol Appl Pharmacol 196: 124-135.

71. Millward TA, Zolnierowicz S, Hemmings BA. 1999. Regulation of protein kinase cascades by protein phosphatase 2A. Trends Biochem Sci 24: 186-191.

72. Niwa K, Inanami O, Yamamori T, Ohta T, Hamasu T, Kuwabara M. 2003. Redox regulation of PI3K/Akt and p53 in bovine aortic endothelial cells exposed to hydrogen peroxide. Antioxid Redox Signal 5: 713-722.

73. Piantadosi CA, Suliman HB. 2006. Mitochondrial transcription factor A induction by redox activation of nuclear respiratory factor 1. J Biol Chem 281: 324-333.

74. Hutchinson J, Jin J, Cardiff RD, Woodgett JR, Muller WJ. 2001. Activation of Akt (protein kinase B) in mammary epithelium provides a critical cell survival signal required for tumor progression. Mol Cell Biol 21: 2203-2212.

75. Hutchinson JN, Jin J, Cardiff RD, Woodgett JR, Muller WJ. 2004. Activation of Akt1 (PKB-alpha) can accelerate ErbB-2-mediated mammary tumorigenesis but suppresses tumor invasion. Cancer Res 64: 3171-3178.

76. Mirza AM, Kohn AD, Roth RA, McMahon M. 2000. Oncogenic transformation of cells by a conditionally active form of the protein kinase Akt/PKB. Cell Growth Differ 11: 279-292.

77. Stauffer F, Holzer P, Garcia-Echeverria C.Blocking the PI3K/PKB pathway in tumor cells.Curr Med Chem Anticancer Agents. 2005 Sep;5(5):449-62. Blocking the PI3K/PKB pathway in tumor cells.Curr Med Chem Anticancer Agents. 2005 Sep;5(5):449-62.

78. Barnett SF, Bilodeau MT, Lindsley CW.The AKT/PKB family of protein kinases: a review of small molecule inhibitors and progress towards target validation.Curr Top Med Chem. 2005;5(2):109-25 
79. Ahmad S, Singh N, Glazer RI. Role of AKT1 in 17beta-estradiol- and insulin-like growth factor I (IGF-I)-dependent proliferation and prevention of apoptosis in MCF-7 breast carcinoma cells. Biochem Pharmacol 1999 Aug 1;58(3):425-30.

80. Maria I. Torres-Arzayus1, Jaime Font de Mora1, 4, Jing Yuan1, Francisca Vazquez1, Roderick Bronson2, Montserrat Rue3, William R. Sellers1 and Myles Brown High tumor incidence and activation of the PI3K/AKT pathway in transgenic mice define AIB1 as an oncogene Cancer Cell 2004 Sep;6(3):263-74.

81. Debnath J, Walker SJ, Brugge JS AKT activation disrupts mammary acinar architecture and enhances proliferation in an mTOR-dependent manner. J Cell Biol. 2003 Oct 27;163(2):315-26.

82. Yang YA, Han WF, Morin PJ, Chrest FJ, Pizer ES.Activation of fatty acid synthesis during neoplastic transformation: role of mitogen-activated protein kinase and phosphatidylinositol 3-kinase.Exp Cell Res. 2002 Sep 10;279(1):80-90.

83.Burdick AD, Davis JW 2nd, Liu KJ, Hudson LG, Shi H, Monske ML, Burchiel SW.Benzo(a)pyrene quinones increase cell proliferation, generate reactive oxygen species, and transactivate the epidermal growth factor receptor in breast epithelial cells.Cancer Res. 2003 Nov 15;63(22):7825-33.

84. Jin J, Woodgett JR. Chronic activation of protein kinase Bbeta/AKT2 leads to multinucleation and cell fusion in human epithelial kidney cells: events associated with tumorigenesis. Oncogene 2005 Aug 18;24(35):5459-70 

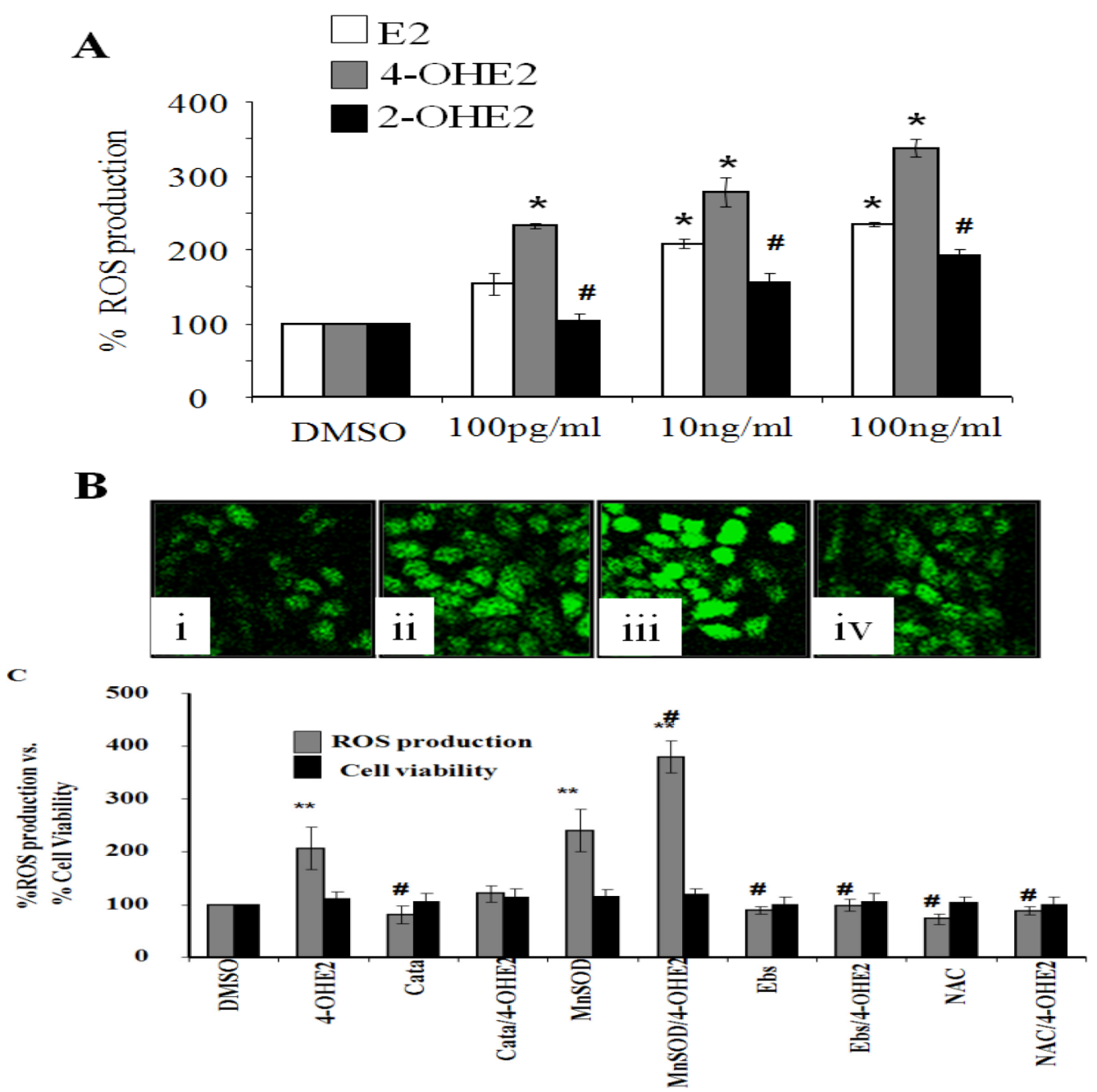

Fig. 1. 17 $\beta$-estradiol and its catechol metabolites induce ROS production in MCF-10A cells in a dose dependent manner. Cells were seeded at $1.0 \times 10^{4}$ cells per well. $24 \mathrm{hrs}$ post seeding, cells were serum starved for $48 \mathrm{hrs}$ in DMEM/F12 (1:1) with 1x penstrep. For the groups that were treated with NAC or ebselen, these cells were pre-treated with $1.0 \mathrm{mM}$ NAC, pH 7.0 or $40 \mu \mathrm{M}$ ebselen for $4 \mathrm{hrs}$ before DCF assay. For the groups that were treated with catalase or manganese super dismutase (MnSOD), these cells were infected with adenovirus over-expressing these ROS modifiers at moi 100 for $48 \mathrm{hrs}$ prior to seeding for DCF assay. At end of starvation and antioxidant treatments, cells were preloaded with $10 \mu \mathrm{M}$ 2',7'-dichlorofluorescin diacetate (DCFH-DA) diluted in Hanks Balance Saline Solution (HBSS), and incubated for 20 mins in $37^{\circ} \mathrm{C}$ incubator. Post DCF treatment, cells were washed with HBSS and treated with various concentrations of estrogens diluted in HBSS and fluorescence emission read on Tecan Genios microplate reader using 485 and $535 \mathrm{~nm}$ as excitation and emission filters respectively. Fluorescence 
images were acquired on confocal microscopy. To determine whether observed ROS modification by estrogens or antioxidant were due to differential cell density or viability, duplicates plates were seeded and treated with ROS modifiers as described above, then challenged with $100 \mathrm{ng} / \mathrm{ml}$ 4-OHE2. Instead of loading DCF, cells were treated with CellTiter-Fluor ${ }^{\mathrm{TM}}$ as described by manufacturer. This reagent measures protease activity as an indication of cell viability. Plates were read on fluorescence plate reader at $400 \mathrm{~nm}$ excitation and $505 \mathrm{~nm}$ emission and data expressed as mean of three-five experiments $+/$ SE. (A) Histogram of fluorescence emitted by the oxidation of DCFH-DA by estrogens and read on Tecan plate reader in $5 \mathrm{~min}$. Data is expressed as mean of $+/$ - SE of five experiments. (*) Indicates significantly different from control (DMSO) groups while (\#) indicates significant different from 4-OHE2, $(\mathrm{P}<0.05)$. (B) Confocal images of cells preloaded with $1.0 \mu \mathrm{M}$ DCF and treated with $100 \mathrm{pg} / \mathrm{ml}$ of various estrogens, and fluorescence image acquired 5 min after treatment. (I) DMSO, (II) E2, (III) 4-OHE2, (IV) 2-OHE2. (C) Histogram of ROS modulation by 4-OHE2 versus viable cells. (**) Indicates significantly different from control (DMSO) groups while (\#) indicates significant different from 4-OHE2, $(\mathrm{P}<0.05)$

A

B
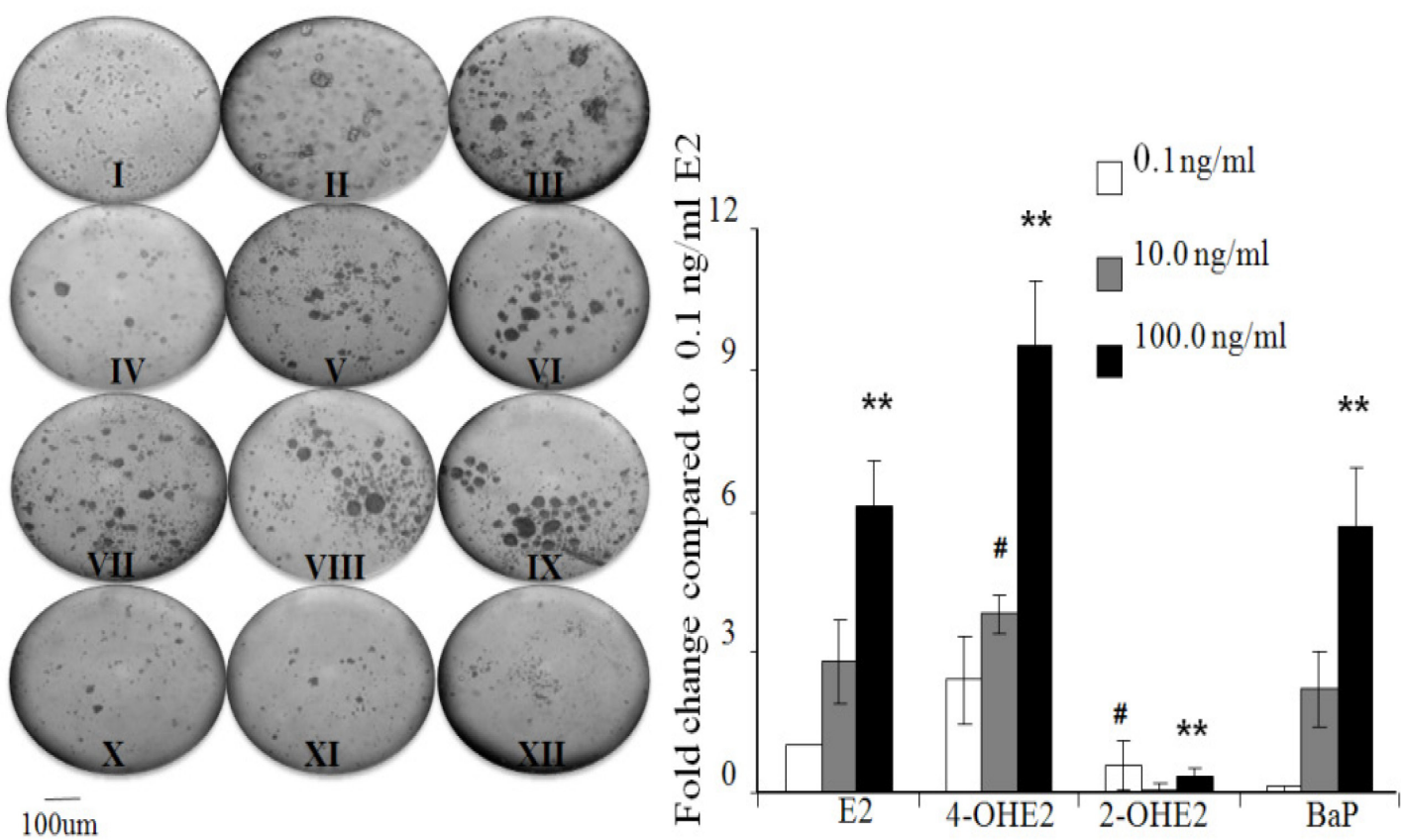

Fig. 2. E2 and 4-OHE2, but not 2-OHE2 transforms MCF-10A cells in a dose dependent manner. MCF-10A cells were seeded at sub-confluence and serum deprived for $48 \mathrm{hrs}$ after which they were exposed to various doses of E2 or its catechol metabolites for two treatment cycles of $48 \mathrm{hrs}$ each, interspersed with $48 \mathrm{hrs}$ recovery period. (I) DMSO, (IIIII) 5.0 and $50.0 \mu \mathrm{g} / \mathrm{ml} \mathrm{BaP}$ as positive controls respectively. We used estrogen concentrations of $0.1,10.0$ and $100.0 \mathrm{ng} / \mathrm{ml}$ respectively for transformation experiments; 
IV-VI) E2; VII-IX) 4-OHE2 and X-XII) 2-OHE2 treatments. Fig 2B) Fold differences in colony formations were compared to colonies from $0.1 \mathrm{ng} / \mathrm{ml}$ estrogen treatments. Data expressed as mean of four wells $+/$ - SD. (**) Indicates significantly different from control $0.1 \mathrm{ng} / \mathrm{ml}$ groups while (\#) indicates significant different from $100.0 \mathrm{ng} / \mathrm{ml} \mathrm{4-OHE2}$ treated group, $(\mathrm{P}<0.05)$

A
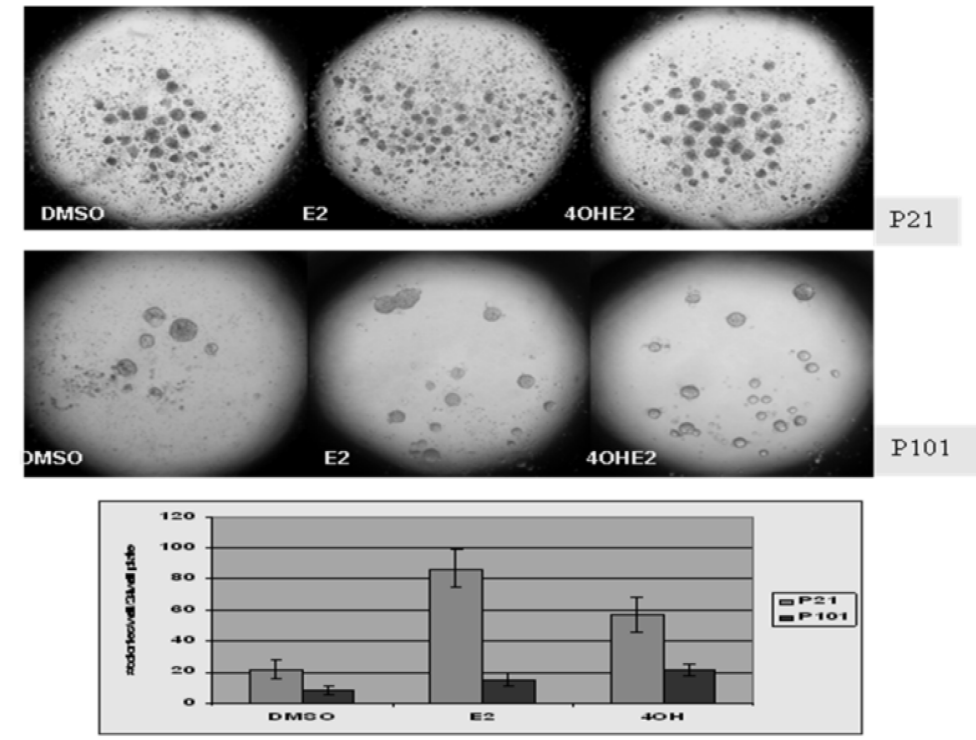

B
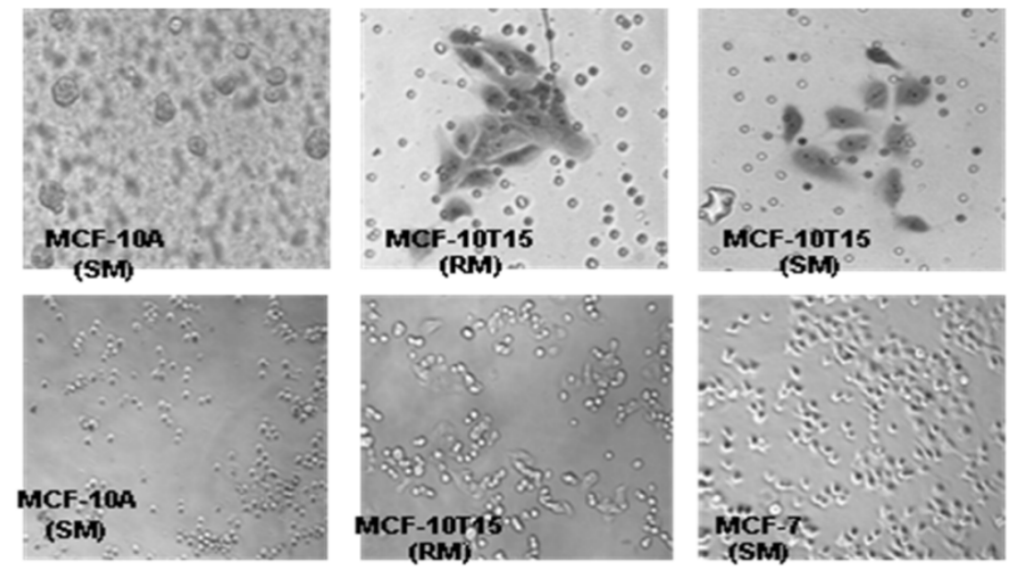

Fig. 3. Clonogenic expansion and invasiveness of 4-OH-E2 transformed MCF-10A cells: A. For colonogenic expansion analysis, we picked several colonies from each soft agar at the end of 21 days and cultured them in media with $10 \% \mathrm{FBS}$, designated regular media (RM). Several of these clones did not passage beyond 10th passage in RM. However, of the 5 that survived up to the $21 \mathrm{st}$ passage, we seeded these cells at $50 \mathrm{k}$ cells $/$ well in soft agar to determine whether these cells have acquired anchorage independent growth properties, a hallmark for transformed cells and whether these clones also respond to $100 \mathrm{pg} / \mathrm{ml}$ estrogens. Cells were fed twice per week and cultured for 21 days. Colonies were counted from quadruplicate wells, $( \pm \mathrm{SD})$. B. To assess invasive properties of the 
clones derived from 4-OH-E2 induced MCF-10A transformed cells, we seeded 10K MCF-10T15 cells, a clone from MCF-10A transformation in BD BioCoat ${ }^{\mathrm{TM}}$ Matrigel ${ }^{\mathrm{TM}}$ Invasion Chambers. We also seeded these cells in glass chamber as we previously found that MCF-10A cells don't attach very well to glass in the first 16-24hrs. For the invasion assay (a), the chemotractant is either growth supplemented media ( SM) or media with only $10 \%$ FBS (RM).

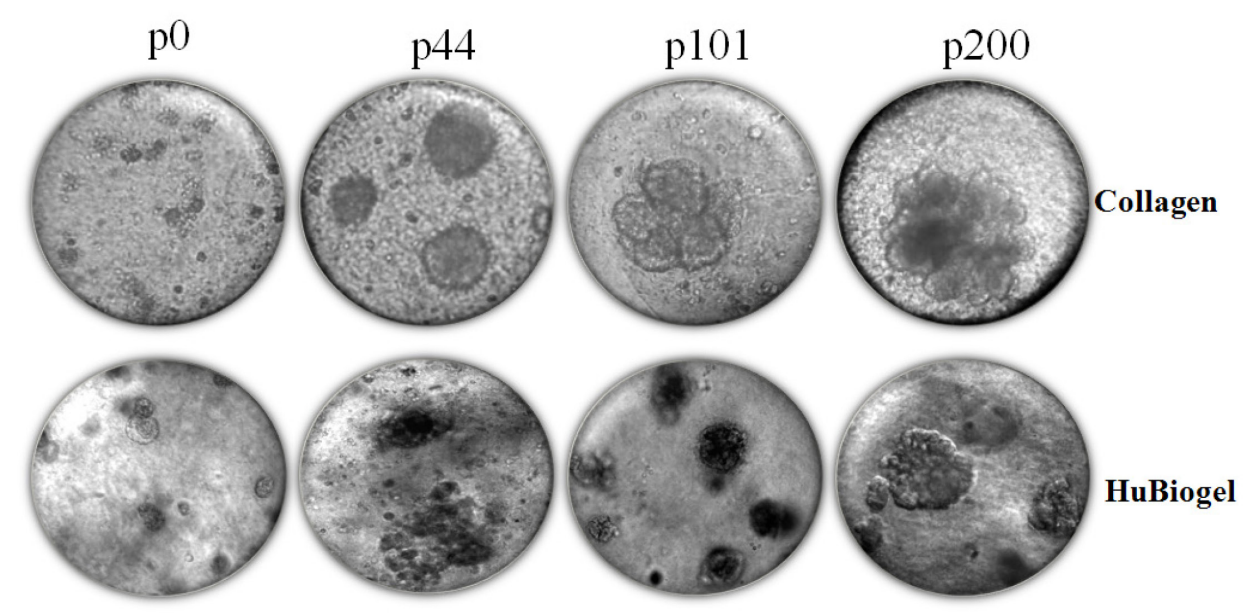

Fig. 4. Spheriod Formation in Collagen and HuBiogel

Single colony from anchorage independent growth were aseptically picked at end of $21^{\text {st }}$ day of culture. Clones were grown in growth factor reduced media (DMEM F12, 5\% FCS, $4 \mathrm{ng} / \mathrm{ml} \mathrm{EGF}, 2.0 \mathrm{ng} / \mathrm{ml}$ insulin, $100 \mathrm{ng} / \mathrm{ml}$ hydrocortisone, 1x penstrep) for 40-60 generations, then in growth factor depleted media (DMEM F12, 5\% FCS, 1x penstrep) onward. Clones were routinely assessed on collagen and HuBiogel for phenotypic evolutions. $\mathrm{p} 0$ indicates transformed cells prior to colony assay, p44-p200 are phenotypes of clone over several passages. Images were acquired with hand held Nikon digital camera over an inverted microscope with 20x objective.

A

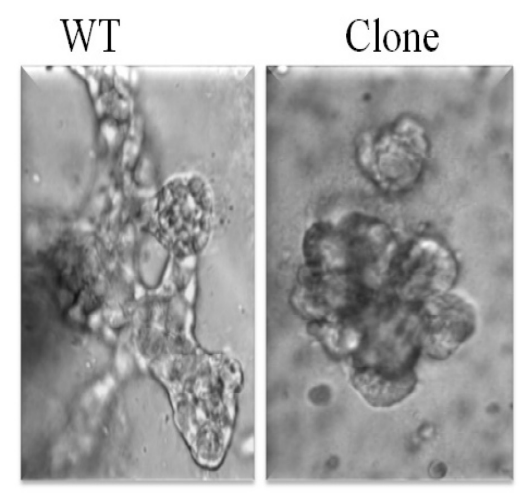

B

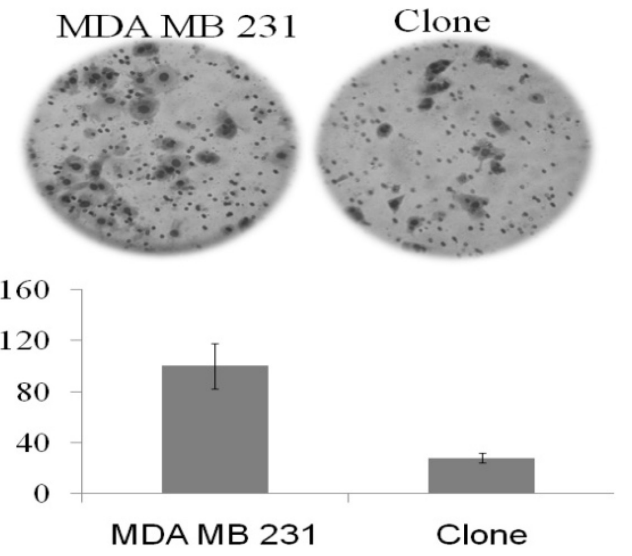




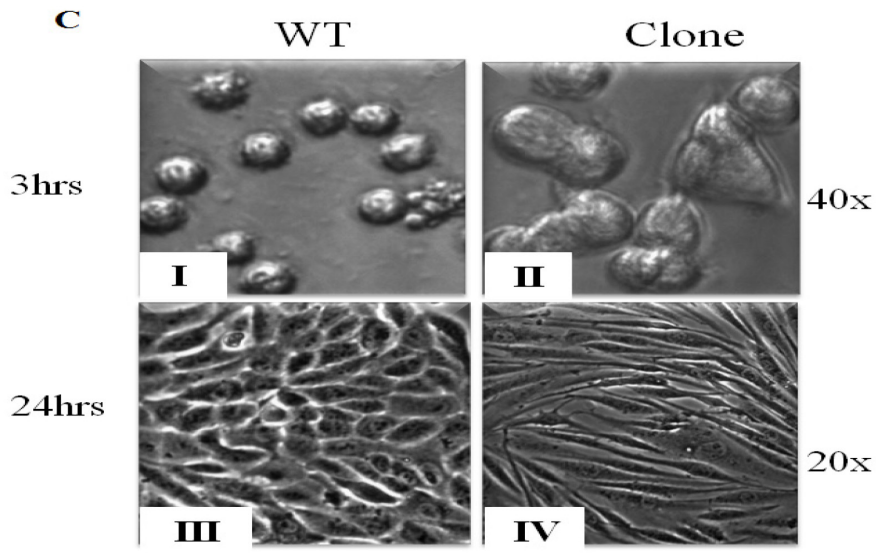

Fig.5. Phenotypic Assessment of Transformed Cells

Clones from p121 cells were assessed for ductulogenesis, seeding phenotype and invasiveness. A) Ductulogenic assay on collagen matrix. B) Invasive characteristics of clone compared to MDA-MB 231 on matrigel $16 \mathrm{hrs}$ post seeding. Data normalized to MDA-MB, +/- SD. Histogram of invaded cells expressed as mean invaded cells per field. C 1-II) Phenotypic assessment of clone versus wild type - 3 hrs post seeding and III-IV) $24 \mathrm{hrs}$ post seeding.

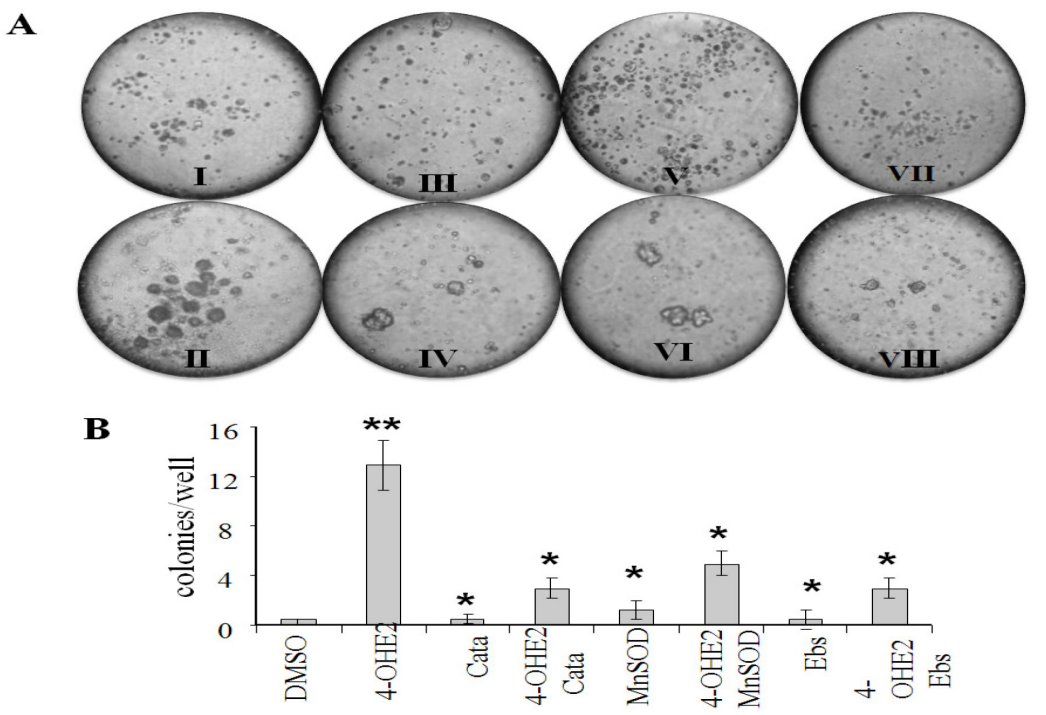

Fig . 6. ROS Scavengers Attenuates Cell Transformation. To determine whether ROS scavenger attenuates in vitro transformations of MCF-10A cells, we infected cells with adenovirus over-expressing catalase or MnSOD at moi 100. Post infections, cells were subjected to transformation regimen. For group that were treated with chemical modifiers, this group were treated continuously with $40.0 \mathrm{uM}$ ebselen throughout transformation period except during recovery times. At end of transformations procedures, cells were seeded for soft agar colony formation at $7.5 \times 10^{4}$ cells/well in 48 well plate. Assays were fed weekly for 3 weeks. Colonies formed in 4 wells were 
enumerated and scored as mean $+/-$ SD. Images were captured with Nikon digital camera over in inverted microscope with 4x objective. Fig 3A: (I) DMSO, (II) 4-OHE2, (III) catalase infected cells, (IV) Catalase+4-OHE2, (V) MnSOD infected cells, (VI) MnSOD infection+4OHE2, (VII) Ebselen treated cells (VIII) Ebselen treated cells + 4-OHE2. Fig 3B: Number of colonies per well. Data are means $+/$ - SD of five plates. (**) Indicates significantly different from control (DMSO) groups while $\left(^{*}\right)$ indicates significant different from 4-OHE2, $(\mathrm{P}<0.05)$

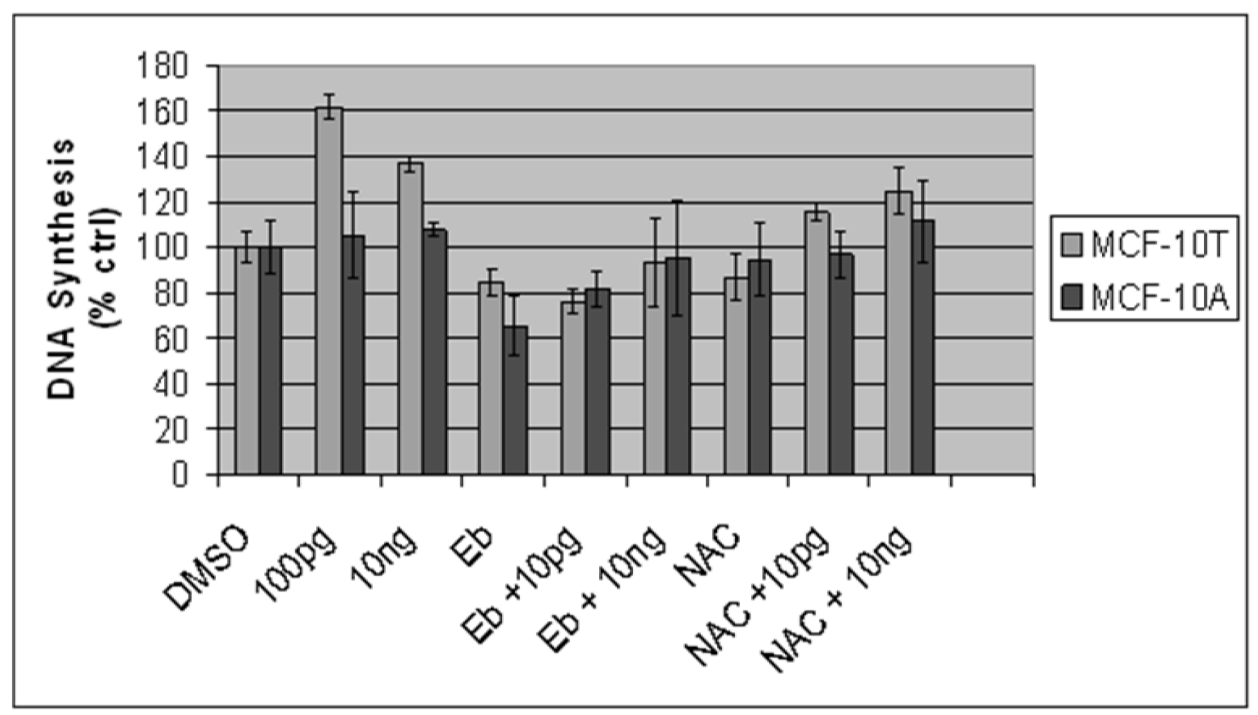

Figure 7. The growth of E2-induced transformed clone was inhibited by both antioxidants, ebselen and $\mathrm{N}$-acetyl cysteine. Cells were grown in 96-well plates for 2 days in 10\% FBS DMEM/F12 and serum starved 2 days prior to addition of E2 for $18 \mathrm{~h}$ $48 \mathrm{~h}$ unless specified otherwise. Bromodeoxy uridine (BrdU) incorporation assay was used to measure DNA synthesis as indicator of apoptosis in transformed cells. Antioxidants ebselen, NAC, and catalase were pretreated for $2 \mathrm{~h}$ prior to the addition of E2. Colorimetric BrdUrd incorporation was measured at $450 \mathrm{~nm}$ with a plate reader. Results are expressed as mean $\mathrm{OD} \pm \mathrm{SD}$ of three separate experiments with control set as $100 \%$ DNA synthesis. $(* *)$ Indicates treatment significantly different from control. $(*)$ Indicates treatment significantly different from E2. $(P<0.05)$ 

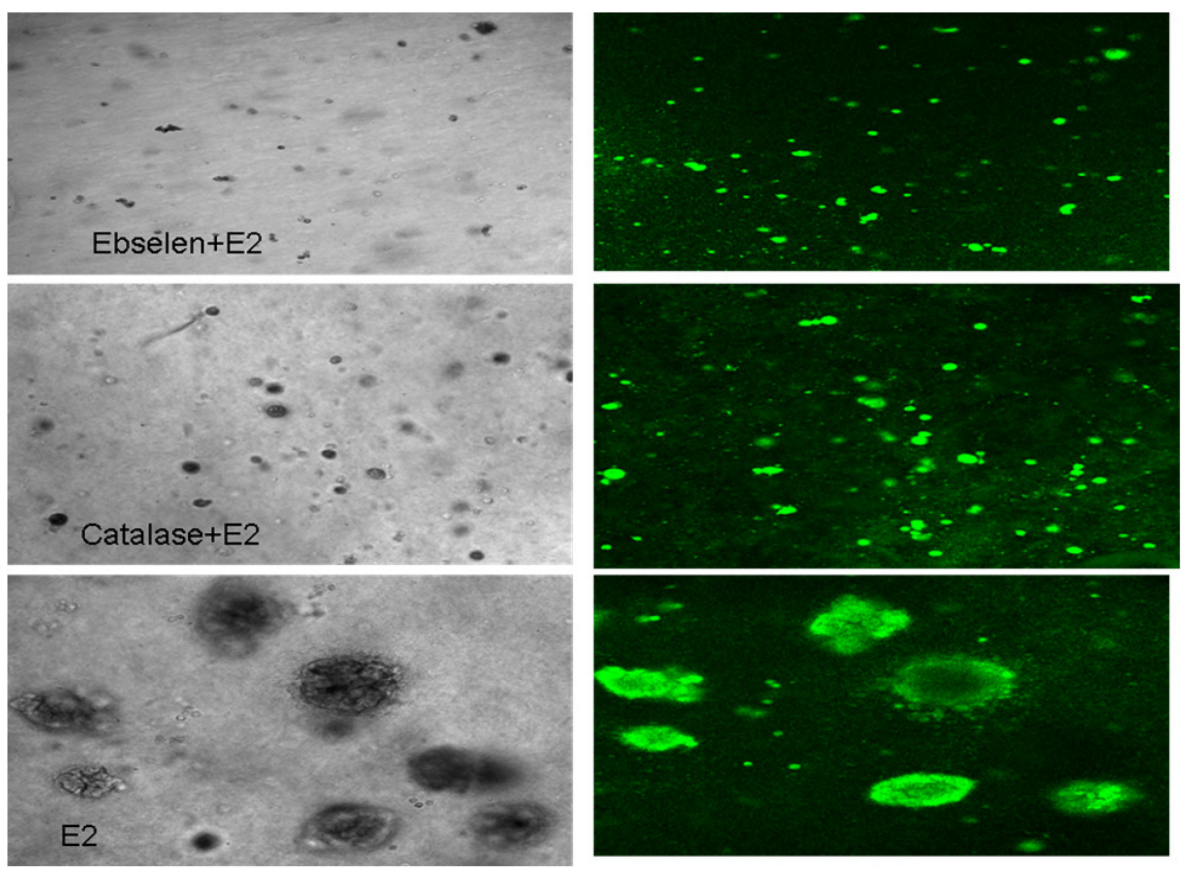

Figure 8. E2-induced 3-D tumor spheroid formation was inhibited by ROS modifiers. Spheroids were grown in a rotary vessel using HuBiogel, a memetic of human stromal matrix in catalase over-expressing cells or ebselen treated cells. Cells were labeled with CFSE using the Vybrant kit for checking viability. All spheroids showing the green fluorophore (Right Upper Panel) indicate that cells in tumor spheroids are alive.

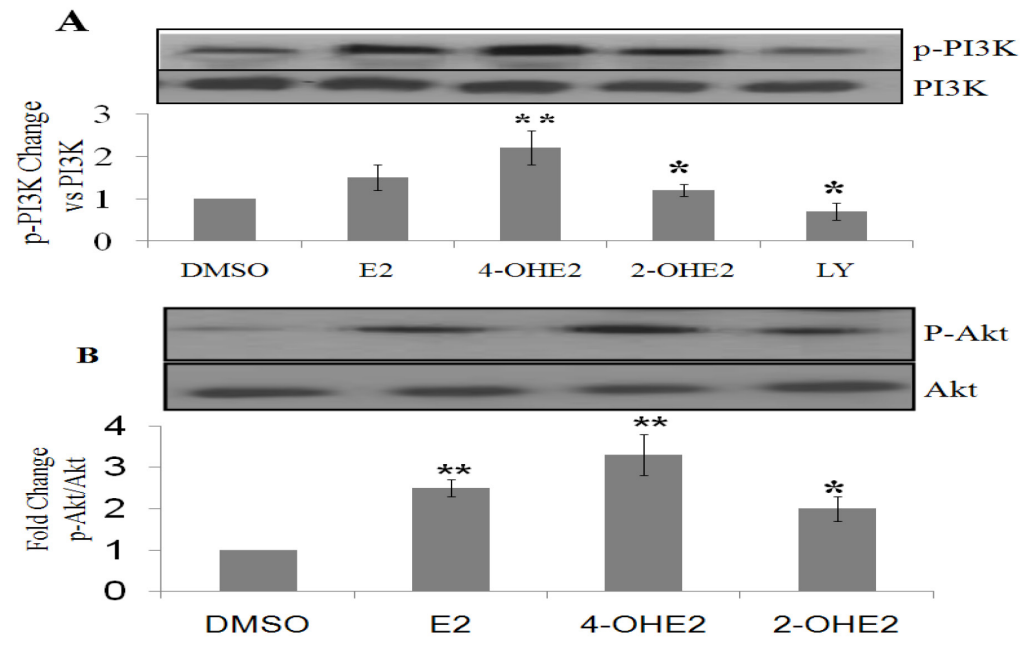

Fig. 9. Estrogen and its metabolites differentially activates PI3K/Akt signaling pathway during mammary transformation. MCF-10A cells were seeded for transformation as described in methods. At the end of transformation process, cells were treated for additional $30 \mathrm{~min}$ with $100.0 \mathrm{ng} / \mathrm{ml}$ estrogens or its catechol metabolites. Cells were harvested and lysed with RIPA buffer and PI3K and Akt proteins were 
immunoprecipitated with respective antibodies and fractionated on 12\% SDS-PAGE electrophoresis gel. Proteins were blotted onto PVDF membrane. Membrane were then probed with (A) p85 (p-PI3K) and p110 subunits of PI3K respectively. (B) Phosphorylated Akt (pAkt) and total Akt. Band intensity were quantified with Biorad GelDoc 2000 and normalized to vehicle. (**) Indicates that E2 and 4-OHE2 treatment group is significantly different from control (DMSO) groups while $(*)$ indicates that other treatments groups are significantly different from 4-OHE2. $(\mathrm{P}<0.05)$. Results are expressed as mean fold change of three separate experiments.

$\mathbf{A}$
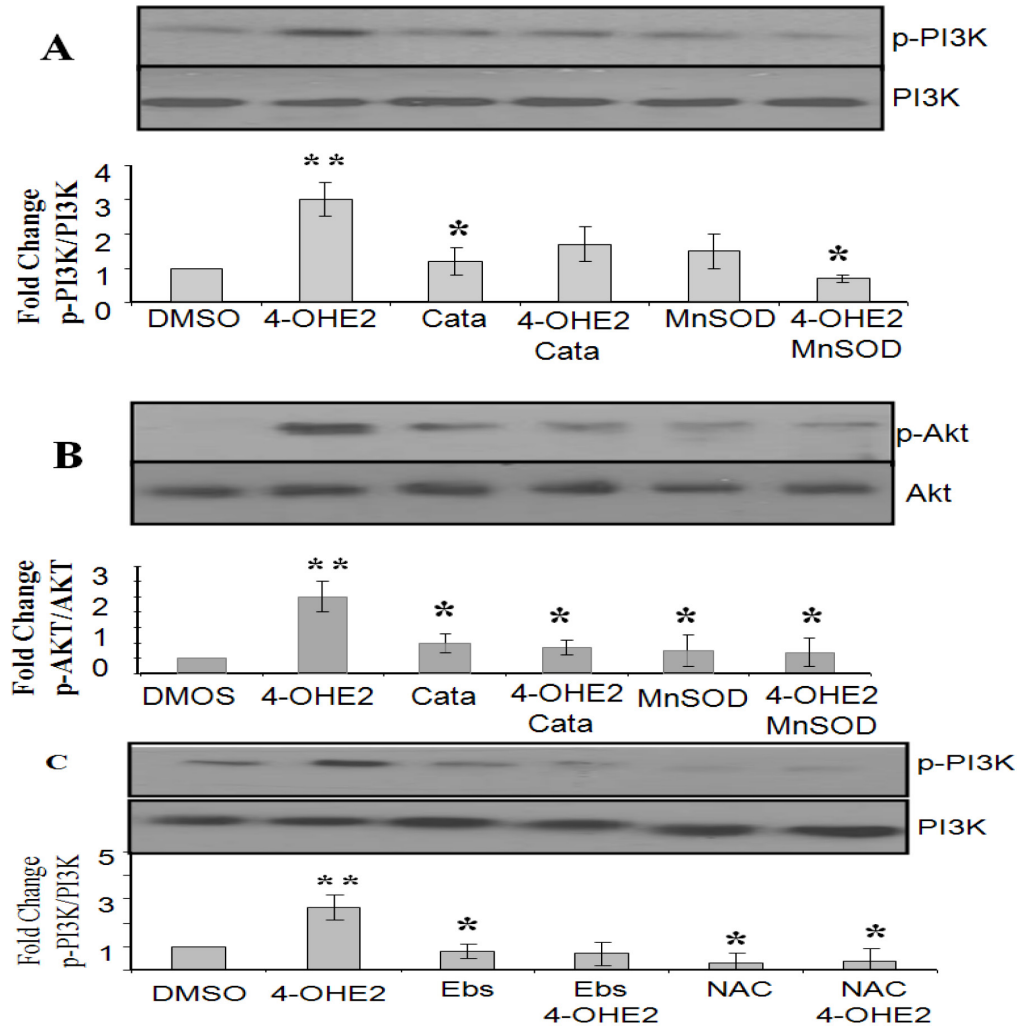

$\mathbf{D}$
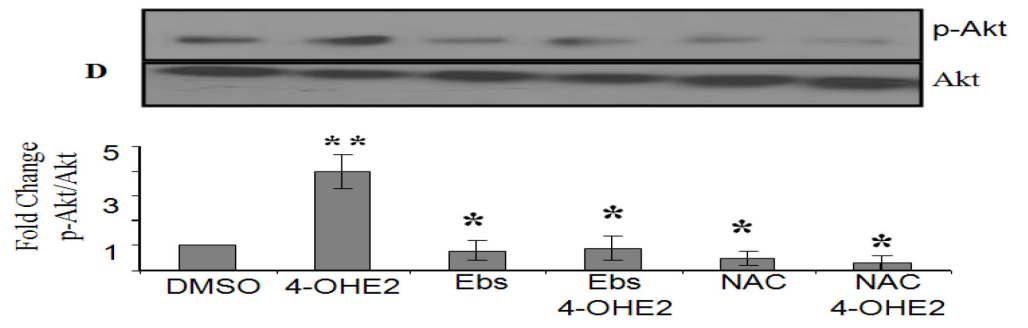

Fig. 10. 4-OHE2 Activation of PI3K/Akt Signaling Pathway is Abrogated by Chemical and Biological ROS Modifiers. MCF-10A were seeded and treated with Ebselen or NAC during transformation regimen, or pre-infected with adenovirus expressing Catalase or MnSOD, then subject to transformation regimen as described in methods. At the end of transformation process, cells were treated for additional 30 minutes with $100 \mathrm{ng} / \mathrm{ml} 4$ - 
OHE2. Cells were lysed with RIPA buffer and immunoprecipitated with PI3K and Akt antibodies respectively. IP products were fractionated on $12 \%$ SDS-PAGE electrophoresis gel. Proteins were blotted onto PVDF membrane. Membranes were then probed with phosphorylated PI3K (p-PI3K) and PI3K, or phosphorylated Akt (pAkt) and total Akt. Band intensity were quantified with Biorad GelDoc 2000 and normalized to vehicle. (A) Immunoblot of activated PI3K and its modulation by biological ROS modifiers at the end of transformation regimen. (B) Immunoblot of activated Akt and its modulation by biological ROS modifiers at the end of transformation regimen. (C) Immunoblot of activated PI3K and its modulation by chemical ROS modifiers at the end of transformation regimen. (D) Immunoblot of activated Akt and its modulation by chemical ROS modifiers at the end of transformation regimen. (**) Indicates that 4OHE2 treatment group is significantly different from control (DMSO) treatments groups while $(*)$ indicates treatment is significantly different from 4-OHE2, $(\mathrm{P}<0.05)$. Results are expressed as mean fold change of three separate experiments.
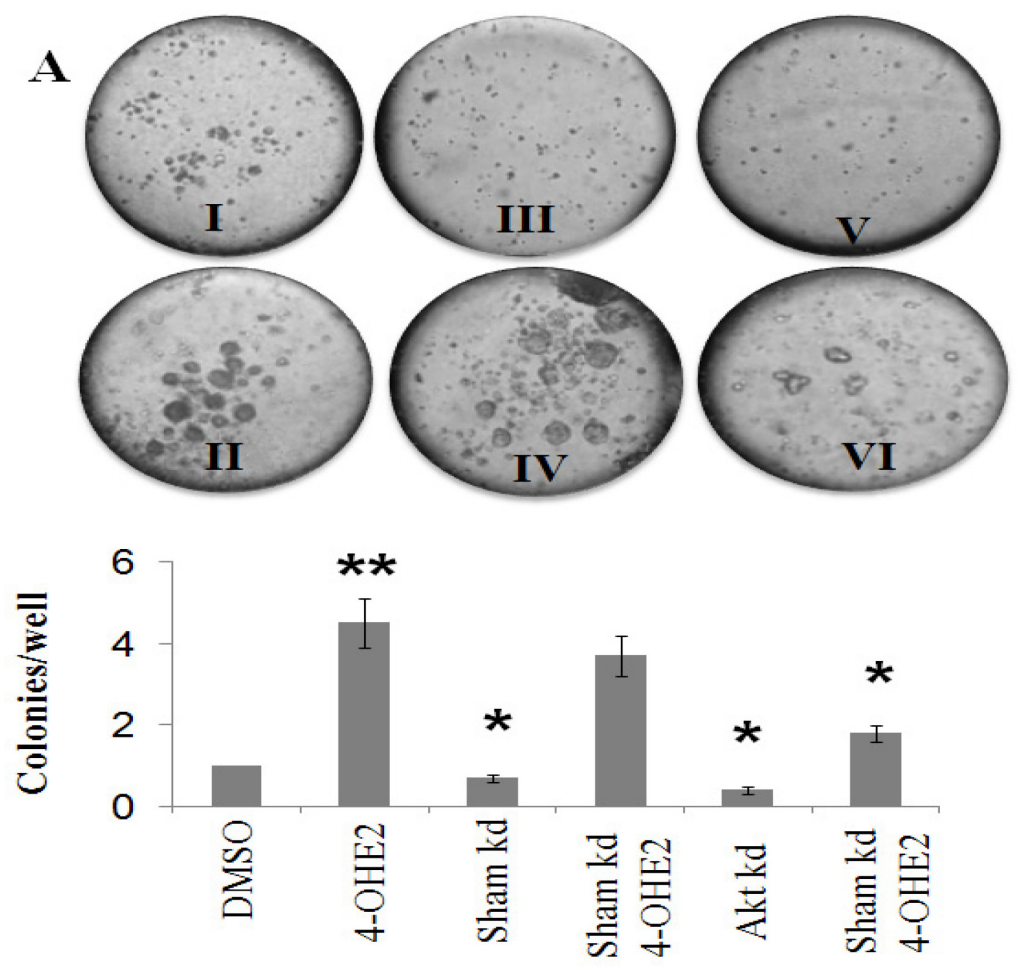
B
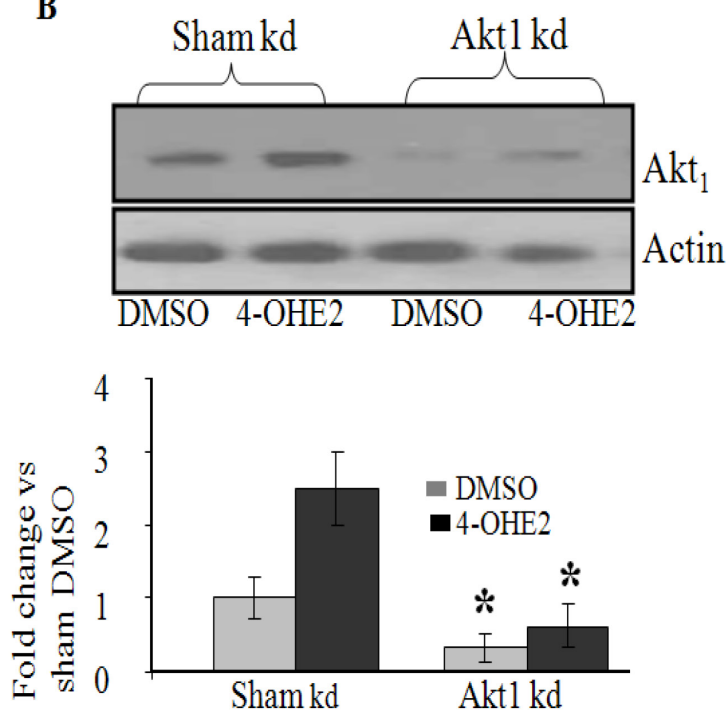

C

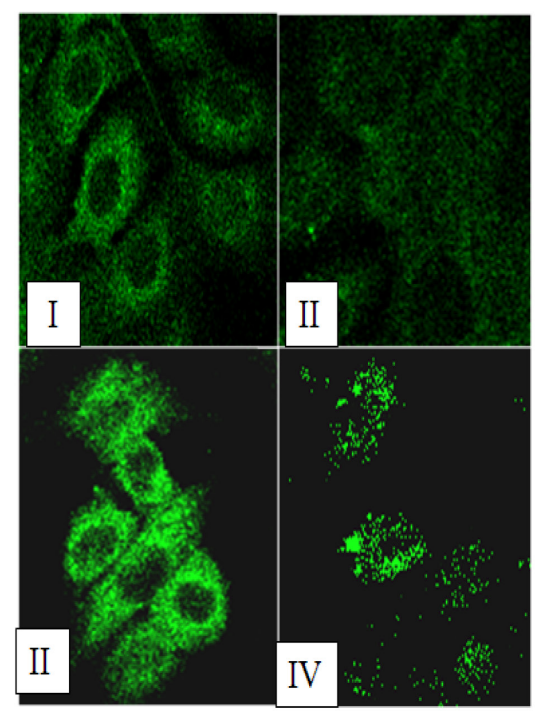

Fig. 11. 4-OHE2 induced Activation of Akt1 Mediates MCF-10A Neoplastic Transformation. To ascertain whether Akt activations are involved during estrogen induced mammary transformation, cells were transfected with shRNA for Akt1 or it corresponding vector, and subsequently subjected to transformation regimen. After transformation process, cells were used for soft agar colony assay, or treated for additional 30 minutes then used for immunoblot. Cells were also seeded for immunofluorescence labeling with anti Akt antibodies for confocal microscopy. Panel A: I) DMSO, II) 4-OHE2, III) Sham Akt1 knockdown, IV) Sham Akt1 knockdown + 4OHE2, V) Akt1 knockdown, VI) Akt1 knockdown + 4-OHE2. (**) Indicates that 4OHE2 treatment group is significantly different from control (DMSO) groups while $\left(^{*}\right)$ indicates that other treatments groups are significantly different from 4-OHE2, $(\mathrm{P}<0.05)$. Panel B: Immunoblot of transformed cells expressing total Akt. Data is expressed as fold difference of 3 experiments, $\mathrm{OD} \pm \mathrm{SD}$. (*) indicates treatment is significantly different from 4-OHE2, $(\mathrm{P}<0.05)$. Panel $\mathrm{C}$ : Immunofluorescence label of transformed cells expressing total Akt, I) sham kd + DMSO, II) Sham kd + 4-OHE2, III) Akt1 kd + DMSO, IV) Akt1 kd + 4-OHE2. 

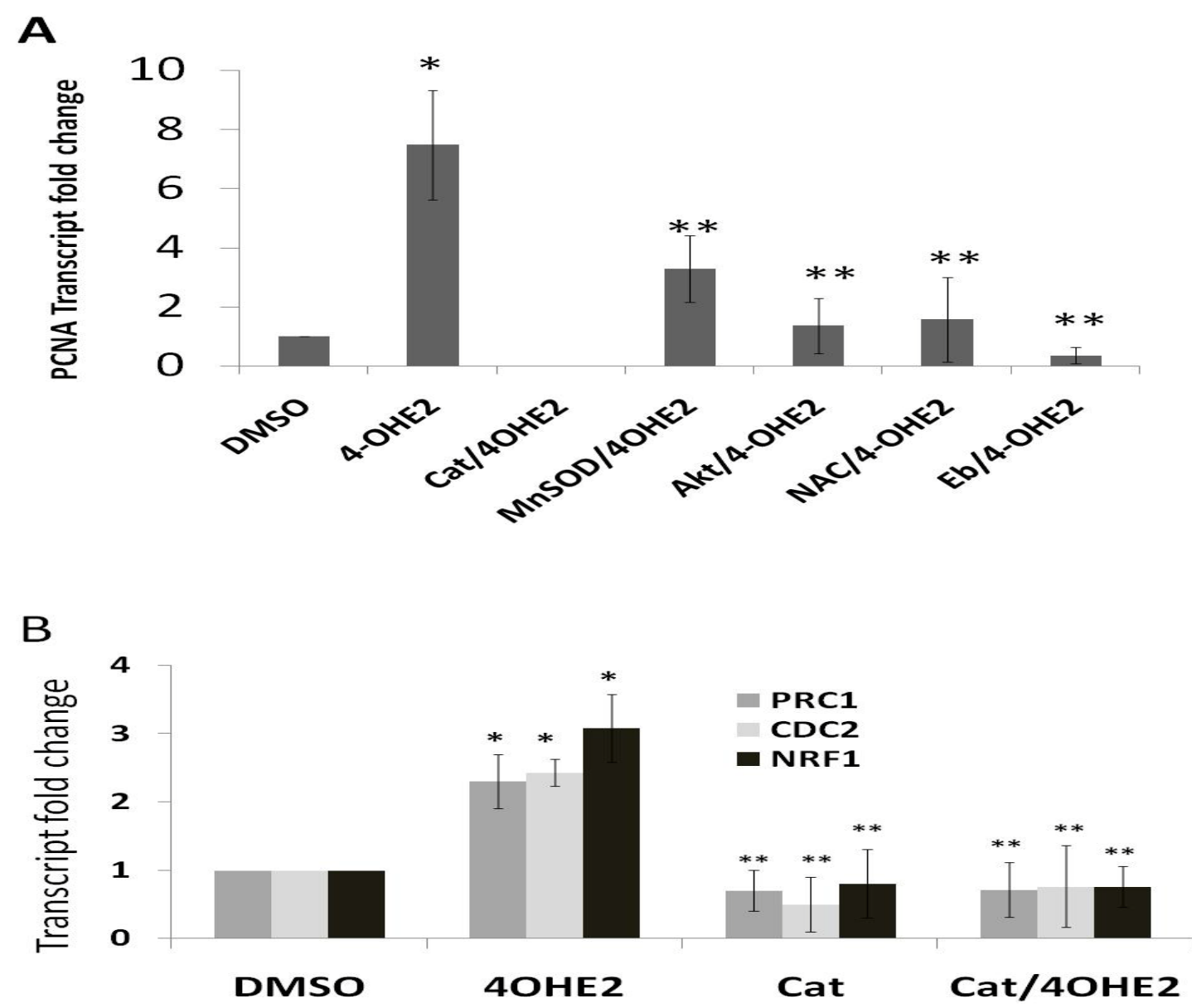

Fig. 12. 4-OHE2 induced up-regulation of cell cycle gene during neoplastic transformation of mammary cells is inhibited by ROS modulators

MCF-10A cells were seeded for transformation as described in methods. At end of transformation period, cells were treated for additional 18 hours with vehicles or estrogens after which they were washed with cold PBS containing protease inhibitors. Cells were detached with trypsin and RNA isolated from 2.0 x106 cells, and 10ng RNA were used for qRT-PCR analysis of cell cycle genes primers on ABI Real time PCR machine. Data represents mean of 3 different experiments $+/-\mathrm{SE},(\mathrm{P}<0.05)$. (*) indicates treatment significantly different from DMSO while $(* *)$ indicates significant difference from 4-OHE2. A) Fold change of PCNA transcript in 4-OHE2 transformed cells treated with ROS modulators, or transformed cells transfected with Akt1 RNAi. B) Fold change of cell cycle genes in 4-OHE2 transformed cells overexpressing catalase. 


\title{
CHAPTER V
}

\section{ESTROGEN-INDUCED REDOX SIGNALING OF NRF1 MEDIATES IN VITRO GROWTH AND METASTASIS OF BREAST CANCER CELLS \\ Victor O. Okoh, Deodutta Roy \\ Department of Environmental and Occupational Health; Stempel College of Public \\ Health and Social Work \\ Florida International University. Miami F1. 33199}

\begin{abstract}
We have shown earlier that chronic exposure to estrogen induces ROS production and promote growth and metastasis of breast cancer cells via ER related pathways. Recently nuclear respiratory factor 1 (NRF1), a transcription factor, known to regulate cell's redox status via mitochondria biogenesis has been implicated to play a role in breast carcinogenesis. In this study we demonstrate that estrogen induced ROS mediated signaling activates AKt activation which phosphorylates NRF1, a transcription factor, known to play a critical role in mitochondrial biogenesis. This is the first report to demonstrate that exposure of MCF-7 cells to estradiol induced phosphorylation of AKt to activate NRF1. Activated NRF1 then modulates estrogen induced growth and invasion of MCF-7 cells in a redox dependent manner. Treatments of cells with ROS modulators or knockdown of NRF1 diminished NRF1 expression as well as estrogen induced growth of MCF-7 cells. These findings suggest that estrogen-induced redox signaling of NRF1 may be required for in vitro growth and metastasis of breast cancer cells.
\end{abstract}




\section{INTRODUCTION}

Excess estrogen (also referred to as $\mathrm{E}_{2}$ or estrogen) exposure is associated with breast, endometrial and testicularovarian cancer [1-3]. Estrogens promote proliferation and growth of cancer cells by activation of estrogen receptors (ER) and non-ER activation pathways $[1 ; 2]$ While ER and regulatory gene altered by estrogen exposure may promote growth of breast cancer cells, recent evidence suggest that reactive oxygen species (ROS) may contribute in regulating survival, proliferation, growth and metastasis of breast cancer $[4-8]$.

The role of ROS in breast cancer is not new. Both in vitro and in vivo studies have suggested that malignant breast cells compared to normal cells are under intrinsic oxidative pressures [9-12], which may correlate positively with excess estrogen exposure [13;14] and inefficient antioxidant systems [15]. These redox imbalances result in accumulations of oxidants, such as, hydrogen peroxide $\left(\mathrm{H}_{2} \mathrm{O}_{2}\right)$ and hydroxyl ions (-OH ) [16;17]. These oxidants can have significant consequences on the fate of cancer cells ranging fromfrom apoptotic cell death, to proliferation, growth, metastasis and therapeutic resistance [18-21]. However, the mechanism (s) involved in oxidative stress and fate of breast cancer is complex and poorly understood. Several studies however suggest that impaired redox mechanism induces dysregulated phosphorylation and dephosphorylation of signaling proteins which activate or deactivate redox sensitive transcription factors [22]. NRF1 (nuclear respiratory factor-1/alpha-palindrome-binding protein) is one of the main transcription factors which are modulated in response to 
oxidative stress., NRF1 is a redox sensitive transcription factor known to regulate mitochondria biogenesis as well as oxidative phosphorylation (OXPHOS) [23;24]. OXPHOS is involved in the production of most of the mitochondria ROS. Dysregulated and increased OXPHOS activity may result in excess ROS production which can have deleterious effects onmtDNA integrity and ETC. [25]. Simultaneously, estrogens have been shown to induce increased NRF1 expressions, OXPHOS activity [26] and ROS production in mammary cancer cells [27]. Therefore, breast cancer tissues with significant oxidative damages $[5 ; 14]$, possibly, are the source of mitochondria derived oxidants via estrogen induced NRF1. This may also explain why $\mathrm{ER}^{+}$breast cancer have high mitochondria copy numbers [28], exhibit significant mtDNA damages [29-31] and positively correlate with NRF1 expressions in higher grades [32;33]. .

In contrast, sublethal levels of ROS induce NRF1 expression which regulates the mitochondria/DNA retrograde communication. If dysregulated, NRF1 can turn on genes involved in carcinogenesis and metastasis of cancer cells [34]. That is why antiestrogenic compounds such as raloxifene and tamoxifen likely fail upon prolong usage because these compounds act as pro-oxidant upon chronic exposures [44-47] as well as inducers of NRF1 [48].

NRF1 is predominantly associated with mitochondria regulation in response to oxidative stress, genome wide in silico analysis however, revealed that this gene also regulates over 400 genes involved in cell cycle progression, metabolism, DNA replication, and 
transcriptional regulation [35], as well as genes involved in cell survival and growth [36], invasion and metastasis [37;38].

In this study, we investigate whether estrogen-induced oxidants mediate in vitro growth and metastasis of malignant breast epithelial cells and the mechanisms involved. Our study revealed that estrogen induced NRF1 expression and its phosphorylation and dephosphorylation activated by redox dependent cellular signaling mediate proliferation, anchorage independent growth and metastasis of MCF-7 cells. Further, over-expression of biological ROS scavengers (MnSOD and Catalase) or treatments of cells with chemical antioxidant, (N-acetylcysteine (NAC) and ebselen), inhibited estrogen induced NRF1 expression and growth of malignant breast epithelial cells.

\section{MATERIALS AND METHODS}

Cell Line and Cell Culture

Human mammary adenocarcinoma cell line (MCF-7) were obtained from American Type Culture Collection (ATCC) and were routinely cultured in phenol red-free DMEM/F12 media with 10\% (vol/vol) FBS, 1x penstrep. DMEM/F12 Media. FBS and antibiotics were purchased from Invitrogen corp. For experiments , cells were seeded at 10-75\% confluency depending on the experimental designs and incubated at $37^{\circ} \mathrm{C}$ in a humidified incubator containing 5\% $\mathrm{CO}_{2}$ and $85 \%$ humidity. Cells were allowed to adhere for $24 \mathrm{hrs}$. after which culture medium were replaced with serum-free media (SFM) containing penicillin-streptomycin $(100 \mu \mathrm{g} / \mathrm{ml}$ each) and cells were allowed to grow for $48 \mathrm{hrs}$. 
Serum deprivation was used to synchronize cells in the $G_{0} / G_{1}$ phase of the cell cycle followed by treatments with estrogens or antioxidants, as described in the figure legends.

Measurement of Reactive Oxygen Species (ROS)

Cellular ROS were measured as previously described [27]. Briefly MCF-7 cells were seeded at a concentration of $1.0 \times 10^{4}$ cells per well in black 96-wells plate with clear flat bottom (ThermoFisher Scientific Inc. USA) and allowed to adhere overnight. Next day, cells were cultured in SFM for $48 \mathrm{hrs}$. They were then pretreated for $4 \mathrm{hrs}$ with chemical antioxidants [ebselen and N-acetyl cysteine (NAC)] diluted in Hank's balanced salt solution (HBSS), followed by incubation with $10 \mu \mathrm{M}$ 2',7'-dichlorofluorescin diacetate (DCFH-DA) (Invitrogen Corp.) for 20 min. Cells were rinsed with HBSS followed by various treatments with $100 \mathrm{pg} / \mathrm{ml}$ estrogens as described in the figure legends. DCFHDA is a non-fluorescent cell-permeable compound, which is acted upon by endogenous esterases that remove the acetate groups generating DCFH. In the presence of intracellular ROS, DCFH is rapidly oxidized to the highly fluorescent 2',7'dichlorofluorescein (DCF). The oxidative products is then measured with a Tecan Genios microplate reader using 485 and $535 \mathrm{~nm}$ as excitation and emission filters, respectively. DCFH-DA stock solutions were diluted at a 1:1 ratio with Pluronic F-127 (20\% w/v).

\section{RNAi transfections}

Pre-designed and tetracycline inducible human shRNA for mitochondria transcription factor A (TFAM) and $\mathrm{Akt}_{1}$ shRNA with corresponding vectorcontrol were purchased from OriGene (OriGene Technologies, Inc. Rockville, MD). Pre-designed NRF1 siRNA 
and corresponding scrambled constructs were purchased from Ambion (Applied Biosystems/Ambion, Austin, TX). Plasmid over-expressing NRF1 were custom made by OriGene (Rockville MD) and FLAG tagged DN-NRF1 is a kind gift from Dr. Liu. All purified plasmids were transfected into 35\% confluent MCF-7 cells using FuGENE 6 (Roche) transfection reagents according to the manufacturer's protocol. Transfection efficiencies for all plasmid were determined by protein expression levels which ranged from $50 \%$ to $80 \%$ reductions in respective gene expressionsThe concentration of plasmids used for transfections in all experiments was as recommended by Roche and were based on surface area of dishes used for each experiment. Post transfection, cells and their lysates were used for western blot analysis, BrdU, soft agar assays and invasion assays as described in subsequent sections.

\section{BrdU cell proliferation assay}

MCF-7 cells were seeded in 96-well plates at a density of 3,500 cells/well and incubated overnight. Cells were plated in quadruplicate for each experimental group. After 24 hrs of incubation cells were cultured in SFM for $48 \mathrm{hrs}$. Cells cells were the treated with E2 $(100 \mathrm{pg} / \mathrm{ml})$ in the presence or absence of antioxidants for $18 \mathrm{hrs}$. Cell proliferations were measured by colorimetric immunoassay of BrdU incorporation into the DNA using Roche BrdU cell labeling kits as recommended by manufactures (Roche Molecular Biochemical, Indianapolis, IN). Briefly, cells were pulsed with BrdU labeling reagent for $3 \mathrm{hrs}$ followed by fixation in FixDenat solution for $30 \mathrm{~min}$ at room temperature. Thereafter, cells were incubated with 1:100 dilution of anti- BrdU-POD for $1 \mathrm{~h}$ at room 
temperature. Finally, the immunoreaction was detected by adding the substrate solution and the color developed was read at $370 \mathrm{~nm}$ with a Tecan Genios microplate reader.

\section{Adenovirus Transduction}

Adenoviruses over-expressing MnSOD (SOD), Catalase (Cata) or control vectors were purchased from ViraQuest, Inc. (North Liberty, IA, USA). MCF-7 cells were seeded into appropriate dishes at $15-70 \%$ confluence depending on the experimental design. Next day, cells were infected with Adenovirus over-expressing SOD, Catalase or vector at either moi 50 to 400 in SFM. Cells were cultured for $48 \mathrm{hrs}$ after which they were used for various experiments.

\section{Chemical antioxidant treatments}

The treatment procedure for Ebselen (a glutathione peroxidase mimetic which also removes both $\mathrm{H}_{2} \mathrm{O}_{2}$ and peroxynitrite) and NAC (a precursor of glutathione and scavenger of ROS [49;50] differs according to the experiments to be performed. For example, in DCFH assays used to measure intracellular ROS in live cells, $40 \mu \mathrm{M}$ and 1.0 $\mathrm{mM}$ ebselen and NAC respectively were pre-loaded onto cells 2-4 hrs before ROS measurement were commenced. For BrdU assays, cells were treated with $40 \mathrm{uM}$ and 1.0 $\mathrm{mM}$ ebselen and NAC respectively throughout the culture periods. For anchorage independent growth assays, antioxidants were mixed with cells and agar matrix before assay commenced, and added to media during bi-weekly feeding of colonies. For immunoprecipitations (IP) and western blot analysis, cells were exposed to a single treatment with these antioxidants during $48 \mathrm{hr}$ culture in SFM before western analysis. . 
Cell viability assay

CellTiter-Fluor ${ }^{\mathrm{TM}}$ Cell Viability kit were purchased from promega corporation and according to manufacturer's instructions assay was conducted. Briefly, cells were seeded in 96 well plate at $1.0 \times 10^{4}$ cells/well, culyuired in SFM for $48 \mathrm{hrs}$ post seeding, and treated accordingly with estrogens and antioxidants. At the end of the treatments , substrate reagent (GF-AFC) were mixed with substrate buffer and dispensed into well. This assay measures cell's protease activities as quiescent and growth arrested cells are still viable even if mitochondria activities or oxidant levels are diminished. Plates were read on fluorescence plate reader at 380-400 nm excitations and $505 \mathrm{~nm}$ emissions.

\section{Western Blot Assays}

Cells for western blot analysis were seeded in T-75 flasks and grown to $70 \%$ confluence and manipulated according to experimental designs. Post treatments, cells were harvested in radioimmune precipitation buffer $(150 \mathrm{mM} \mathrm{NaCl}, 0.5 \%$ deoxycholate, $0.1 \%$ Nonidet P40, $0.1 \%$ SDS, $50 \mathrm{mM}$ Tris) containing protease and phosphatase inhibitors (Roche). Equal amounts of total cellular protein were mixed with loading buffer ( $25 \%$ glycerol, 0.075\% SDS, 1.25\% 2-mercaptoethanol, 10\% bromphenol blue, 3.13\% stacking gel buffer) and fractionated by electrophoresis on $12 \%$ polyacrylamide, $0.1 \%$ SDS resolving gels. Rainbow marker (Biorad USA) was used as the molecular weight standard. Proteins were transferred to PVDF Immobolin-P transfer membranes (Millipore) using transfer buffer [25 mM glycine, $25 \mathrm{mM}$ ethanolamine, and 20\% methanol]. The membranes were blocked one hour at RT with blocking buffer [ $1 \times$ phosphate buffered saline, $0.1 \%$ Tween- 
20 with 5\% (w/v) nonfat dry milk (PBS-T)]. Blots were subsequently incubated for $2 \mathrm{hr}$ at room temperature with various antibodies as indicated in legends.

Immunoprecipitation

For experiments to determine epigenetic modifications of NRF1, cells were seeded in T75 and grown to $70 \%$ confluence. Post treatments, cells were rinsed twice with PBS, harvested with lysis buffer $(150 \mathrm{mM} \mathrm{NaCl}, 0.5 \%$ deoxycholate, $0.1 \%$ Nonidet P- $40,0.1 \%$ SDS, $50 \mathrm{mM}$ Tris) containing protease and phosphatase inhibitors (Roche). Whole cell lysates (WCL) were diluted to $500 \mu \mathrm{g}$ of protein in $1 \mathrm{ml}$ of lysis buffer, and samples were pre-cleared for $1 \mathrm{hr}$ at $4{ }^{\circ} \mathrm{C}$ with $40 \mu \mathrm{l}$ of a 1:1 slurry of protein A-agarose beads (Invitrogen Corp) in lysis buffer and $1 \mu \mathrm{g}$ of rabbit IgG. After a brief centrifugation to remove pre-cleared beads, $0.5 \mu \mathrm{g}$ of anti-NRF1 antibody was added to each sample and incubated on a rocking platform at $4{ }^{\circ} \mathrm{C}$ overnight. Captured proteins were pulled down (precipitated??) by the addition of $10 \mu \mathrm{l}$ of protein A-agarose beads to each sample and the slurries were incubated on the rocking platform at $4{ }^{\circ} \mathrm{C}$ for $2 \mathrm{hrs}$. The beads were then washed five times with lysis buffer and resuspended in $40 \mu \mathrm{L}$ of $1 \times$ SDS electrophoresis sample buffer $[50 \mathrm{mM}$ Tris- $\mathrm{HCl}(\mathrm{pH}$ 6.8), $100 \mathrm{mM}$ dithiothreitol, $2 \%$ SDS, $0.1 \%$ bromophenol blue, and 10\% glycerol], resolved on 12\% SDS-PAGE electrophoresis and transferred onto a PVDF nylon blotting membrane. To determine whether serine residues of NRF1 are phosphorylated due to treatment, blot was probed with 1-5000 mouse monoclonal antibody against phosphoserine residue (Santa Cruz Biotech). To determine whether treatments induced modulations of NRF1 correlates with TFAM, one of its effector, WCL from same group were immunoprecipitated with rabbit anti mtTFA and 
probed with mouse against mtTFA. All primary antibodies were diluted 1:1000 and detected after incubation with horseradish peroxidase(HRPO)-conjugated secondary antibody diluted 1:50,000 PBS-T. Blots were treated with ECL reagents (Amersham Biotech), and all proteins were detected by autoradiography.

Anchorage independent Growth

Anchorage-independent growth assays were performed as previously described [51]. Briefly, base support agar were made fresh by diluting 1.0\% molten agarose mix with 1:1 with $2 \mathrm{x}$ culture media (2x DMEM/F12 media, 20\% HS, 2x Penstrep antibiotics and 200 $\mathrm{pg} / \mathrm{ml}$ estrogens) to a final of $0.5 \%$. molten agar were maintained at $42{ }^{\circ} \mathrm{C}$ water bath until dispensed at $200 \square$ 1/well in 48 well plates, then allowed to solidify for 4 hrs at room temperature. Top agarose overlay were made fresh by mixing $0.7 \%$ molten low melting point (LMP) agarose with $2 \mathrm{x}$ culture media containing appropriate 5000 cells/well, then gently overlaid over preformed base agar. Cells were incubated for a minimum of 21 days in $37^{\circ} \mathrm{C}$ incubator with $5 \% \mathrm{CO}_{2}$. Cultures in 48 well plate were fed once every week with $200 \square 1$ of $0.5 \%$ melted agar in growth media. Colonies of separate cell aggregates at $100 \square \mathrm{M}$ or greater in size, as measured with metamorph software (Nikon Corporation, USA) were counteds. Images were acquired by Olympus C-5060 digital camera under an inverted microscope with 4x objective.

Invasion Assay

The in vitro invasion assay was carried out to examine tumor cell invasiveness as described previously [52] with some modifications. Briefly, 24-well Transwell unit with 
$8 \mu \mathrm{m}$ polycarbonate Nucleopore filters (Corning) were coated with $60 \mu \mathrm{L}$ of 0.8 Matrigel. MCF-7 cells $\left(1 \times 10^{5}\right)$ transfected with plasmid overexpressing NRF1 or null were placed in the upper compartment, and the medium containing $10 \%$ fetal bovine serum was added to the lower compartment. For group treated with NAC, the chemical ROS modifier was added to media in the lower chamber to a concentration of $1.0 \mathrm{mM}$. The Transwell plates were incubated at $37^{\circ} \mathrm{C}$ for 48 and $72 \mathrm{hrs}$ accordingly. Cells invaded to the lower surface of the membrane were stained with Giemsa staining and observed using light microscope. The invading cells were stained and counted per insert and photographed. Experiment were conducted in triplicates and repeated three times.

Statistical analysis

Results are expressed as mean \pm S.D. Differences between means were evaluated by twotailed Student's t-test. ANOVA was used to determine differences between groups.

\section{RESULTS}

Estrogen induced ROS levels mediate proliferation and growth of MCF-7 cells in vitro Estrogens have been reported to modulate mitochondria ROS production in MCF-7 cells and other cell types [27;53]. These ROS are postulated by us and other $[20 ; 47 ; 54 ; 55]$ to mediate proliferation and growth of subsets of breast cancer cells. To test this hypothesis, biological ROS modulators (MnSOD and catalase) were oveerexpressed in MCF-7 cells , or cells were pretreated with chemical ROS modulators, $40 \mu \mathrm{M}$ ebselen or $1.0 \mathrm{mM}$ NAC). These cells were then challenged with $100 \mathrm{pg} / \mathrm{ml}$ estrogens. Data reveals that treatment of cells with estrogen alone increased ROS production and DNA synthesis 
whereas treatment with catalase alone (moi 50) diminished ROS production and DNA synthesis. However, co-treatment of cells with catalase (moi 50) and estrogen significantly increased ROS level and DNA synthesis beyond catalase alone infected groups. Interestingly, similar trends were observed in MnSOD infected cells at moi 50 though the magnitude in ROS production and DNA synthesis is significantly more than that observed in estrogen or catalase treated groups (Fig. 1A). Both chemical ROS modulators used in this experiment also diminished ROS production and DNA synthesis. However, when cells were infected with adenoviruses at moi of 200, catalase diminished estrogen induced ROS production and DNA synthesis while MnSOD significantly increased ROS production and dramatically reduced DNA synthesis compared to cells treated with moi 50 (Fig 1B). To resolve the inverse correlation of MnSOD overexpression at moi 200 and DNA synthesis, we infected cells with various viral loads of MnSOD expressing viruses; and as control, we also infected cells transfected with control adenovirus vectors at moi 50. Infected cells were then used for colony assay and monitored for anchorage independent growth for three weeks. We observed that low viral MnSOD load (moi 5-50) promoted increased number and size of colonies (Fig. 2B, C) whereas viral load higher than moi 50 induced diminished cell growth (Fig 2D-G). Adenovirus containing control vectors at moi 50 did not induce growth advantage over corresponding MnSOD expressing adenoviruses indicating that it's the overexpressed MnSOD that is modulating cell growth. However, to ascertain whether the observed cancer growth retardation of MnSOD infection is higher than moi 50 is due to cell lethality, we stained single cell population from all virus infected groups (control, catalase and MnSOD) with trypan blue solution and found that over $70 \%$ of the cells 
infected with virus up to moi 200 were viable whereas $90 \%$ of moi 400 and above infected cells were not viable after 21 days of cultures in soft agar assay (data not shown). Since moi 200 infected cells were viable up to 21 days, we chose this viral load for subsequent experiments. The effects of ROS modulators on estrogen induced growth of breast cancer were further evaluated byco-treatment of MCF-7 cells with estrogen and biological or chemical ROS modulator. It wasfound that these antioxidants significantly inhibited estrogen induced growth of MCF-7 cells in vitro (Fig 3).

Estrogen induced oxidants activate Akt signaling pathway which contributes to in vitro growth of MCF-7 breast cancer cells

The mechanisms by which estrogen induce cell proliferations and growth of estrogen responsive breast cancer cells are attributable to ER mediated process. It has been shown that upon estrogen stimulations, cells secrete growth factors which activate receptor tyrosine kinases and initiation of complex signaling cascade of phosphorylationdephosphorylation reactions that subsequently leads to cancer cell growth and metastasis [56]. One such signaling pathway activated by estrogen exposure that leads to survival and growth of MCF-7 cells is the PI3K/Akt signaling pathways [57;58]. Oxidants such as superoxides and hydrogen peroxides have likewise been reported to activate this signaling pathway which mediates survival and growth of exposed cells [18-20]. To determine whether E2 induced oxidants can activate PI3K/Akt signaling pathway and whether ROS scavengers or inhibitors of PI3K would mitigateAkt phosphorylation, MCF-7 cells were either infected with biological antioxidants, or pretreated with chemical ROS scavengers (ebselen, NAC) prior to estrogen treatments as described in 
methods. Whole cell lysate were resvolved on 12\% SDS-PAGE gel, and probed with appropriate antibodies. Data reveals that $100 \mathrm{pg} / \mathrm{ml}$ estrogen treatment induced Akt activation which were inhibited by chemical or biological antioxidants as well as by LY294002, an inhibitor of PI3K which regulates Akt activations (Fig 4). These findings support the hypothesis that oxidant (ROS) induced by estrogen exposures can activate Akt signaling proteins and activated Akt has been demonstrated to favor survival, proliferation and growth of cells during periods of oxidative stress [59;60].

Estrogen induced Akt activation phosphorylates NRF1 which promotes growth of responsive cells

Cellular responses to oxidants are mediated in part, by redox activation of NRF1 which regulates mitochondria biogenesis and cellular antioxidant responses [61;62]. NRF1 has been reported to be trans-activated by Akt phosphorylation of its serine/threonine residue in response to growth factors and oxidative stress [62-64]. Trans-activated NRF1 are believed to mediate cellular responses to oxidative stress such as mitochondria biogenesis, restoration of redox homeostasis and induction of survival and proliferation mechanisms of cells [42].

Similarly, treatments of MCF-7 cells with $100 \mathrm{pg} / \mathrm{ml}$ estrogen for 45 minutes induced rapid serine phosphorylation of NRF1 (Fig 5) which were abrogated by both chemical and biological ROS modulators. In addition, silencing of $\mathrm{Akt}_{1}$, the Akt isoform implicated in mediating cell survival and growth [65-67] likewise reduced NRF1 phosphorylation, and anchorage independent growth of MCF-7 cells (Fig 6). These 
findings imply that estrogen induced oxidants modulate NRF1 expressions. It also implies that redox activations of Akt signaling in response to estrogen exposures phosphorylate and tran-sactivates NRF1. The absence of Akt1 expression leads to reduced NRF1 phosphorylation and reduced growth of MCF-7 cells exposed to estrogen.

NRF1 expression promotes in vitro proliferation and growth of estrogen responsive breast cancer cells

In order to show that NRF1 are implicated in the mediation of growth of breast cancer cells in vitro, NRF1 was silenced in MCF-7 cells. Cells were then cultured with or without estrogens for 21 days. Colony formation, growth and viability of cells in soft agar assays were measured. Data reveals that estrogen increased colony formation growth in control knockdown groups (Null kd) comparable to the untransfected cells (Fig 7B i-iv). However, estrogen fails to induce colony formation or colony growth of NRF1 silenced cells implying that NRF1 are essential in the mediation of estrogen induced in vitro growth of MCF-7 cells (Fig 7B v,vi). To test whether reduction in growth is due to cell death because of NRF1 knockdown, cells from soft agar plates were counted for cell viability per 1000 cells using trypan blue exclusion assays. We found that while there were differences in cell death due to NRF1 status, differences were not significant to account for observed lack of colony formations or growth of cells in NRF1 knockdown versus Null kd cells (data not shown). In addition, immunoprecipitation analysis of NRF1 expression and phosphorylation status revealed that Null kd cells expresses increased NRF1 protein and exhibit increased phosphorylation in response to prolonged estrogen exposure (Fig 7A,B). Silencing of NRF1 however, inhibits its expression or phosphorylation in response to chronic exposures to estrogens (Fig 7C). To confirm that 
NRF1 is indeed responsible for this observation, the expression levels of mtTFA, one of the genes targeted by NRF1 expression [68] was assessed. Western blot analysis of cell lysates from Null kd vs NRF1 knock down revealed a positive correlation between NRF1 and mtTFA expressions; i.e. up regulation of NRF1 leads to up regulation of mtTFA and vice versa (Fig 7). To confirm NRF1's role in growth regulation of MCF-7 exposed to estrogens, we overexpressed NRF1 (NRF1ox) or its DN-NRF1 and assessed in vitro proliferation and growth in response to estrogens. We observed that while overexpressing NRF1 enhanced estrogen induced proliferation and growth of MCF-7 cells, over-expressing DN-NRF1 actually reduced estrogen mediated proliferation and growth of MCF-7 cells (Fig. 8). Interestingly however, the effects of NRF1ox alone were significantly greater than E2 treated control cells in both soft agar and BrdU assays.

NRF1 over-expression modulates invasion of MCF-7 cells

NRF1 has been implicated in the modulation of various protease expressions involved in cell migration and spreading. Proteases include the calpains [37] whose over-expression is implicated in tumorigenesis, metastasis and angiogenesis in breast cancer and other cancer types [69;70], GalNAc-T3 genes that function in glycosylation of mucin proteins in epithelial derived tumors [71] which is also plyas a central role in invasive mammary [72] and colorectal [73] carcinoma. In this study, in vitro invasion assay of MCF-7 cells overexpressing NRF1 displayed a threefold increase in invading cells compared to vector or non transfected (NT) group (Fig. 9A). NRF1 ox cells when transfected with DN-NRF1 or treated with ebselen showed significantly higher number of cells compared to the control MCF-7 cells trasnfected with vector/DN-NRF1 alone and also treated with 
ebselen. (Fig. 9B). In addition, groups treated with estrogen also had significantly more invading cells and mucosal environment compared with groups treated with vehicle (Fig 9B). These findings indicate that NRF1 participates in cell invasion in a redox dependent manner.

\section{DISCUSSIONS}

Estrogens are chemicals capable of promoting growth of breast cancer cells via ER and non-ER mediated pathways. Estrogens induce ROS via mitochondria biogenesiss. At sublethal levels, these ROS induce redox signaling that participate in growth of estrogen exposed breast cancer cells $[27 ; 74 ; 75]$. In this study, we provide evidence that estrogen induced ROS are essential for proliferation and malignant growth of estrogen responsive breast cancer cells. We also report that the mechanism involves redox activation and phosphorylation of NRF1 because over-expression of biological ROS scavengers or treatment of cells with chemical antioxidants inhibited NRF1 activation which in turn reduced estrogen mediated growth and metastasis of breast cancer cells.

The role of estrogen induced oxidants in breast carcinogenesis has long been established [76-79]. However, the role of these oxidants in mediation of growth of cancer cell remainscontroversial. In this study, we observed that treatments of MCF-7 cells with a dose comparable to physiological level of estrogen induced intracellular ROS which promoted in vitro growth of breast cancer cells. Conversely pre-treatment of cells with chemical or biological antioxidant prior to estrogen exposure inhibited induced ROS formation and in vitro growth of cells. These observations implies that the growth 
promoting properties of estrogen in breast cancer cells are mediated in part by estrogen induced oxidants as ROS scavengers abolished estrogen induced growth of breast cancer cells. These findings are in line with other reports which indicate that sublethal levels of oxidants induce significant mitogenic effects on a number of gynecological cancers [8082] including breast cancer $[4 ; 54 ; 83]$. It may also explain the aggressive nature of breast cancer attained after therapeutic failures because these therapeutic agents also act as prooxidant upon their prolonged use [44-47]. Nonetheless, the initial antiproliferative responses of these chemotherapeutic agents may be due to their antioxidant properties [84-87].

Our group and others have reported that mitochondria is a major source of estrogen induced ROS [27;75] in breast cancer cells. We investigated whether altering mitochondria MnSOD activity would modulate estrogen induction of intracellular ROS and growth of breast cancer cells. We found that infection of MCF-7 cells with adenovirus overexpressing MnSOD at moi 50 increased intracellular ROS production, as well as increased proliferation and growth of MCF-7 cells. However, when cells were infected with adenovirus at moi 200 , ROS production increased significantly compared to ROS from moi 50 infected cells, but cell proliferation and growth decreased significantly. ROS production from moi 50 infected cells correlated positively with DNA synthesis and growth of MCF-7 cells, however, the effects of estrogen exposure on MnSOD expressing cells were statistically insignificant. This implies that the mitogenicity observed in these cells are due entirely to mitochondria ROS and not by estrogens exposures. Therefore, while we were able to show a direct correlation between intracellular ROS production 
and cell growth in response to estrogen exposure, we were unable to show any significant combinational effects between estrogen exposures, MnSOD overexpression and cell growth even though our data does indicates a correlation between MnSOD expression and cell proliferation.

It has been reported that ROS mediates mitogenic activation of the PI3K/Akt signaling pathway which promotes survival and growth of exposed cells [88;89]. Estrogens has likewise been demonstrated to activate PI3K/Akt signaling pathway in endometrial and breast cancer cells, in an ER dependent and independent manner [90;91]. However, whether oxidants mediate estrogen induced activation of PI3K/Akt signaling in breast cells and whether Akt activation is linked with growth of these cells is not clear. In our study, we observed that estrogen induced Akt activation in breast cancer cells were diminished by catalase over-expression and by chemical ROS scavengers. Whether oxidant activation of Akt in estrogen exposed cells is associated with proliferation and growth regulation is not known. To investigate this possible link, we silenced Akt1, an Akt isoform known to be involved in regulating mammary tumorigenesis and growth of cancer cells [65;92]. Wefound that knocking down this gene diminished estrogen induced proliferation and growth of MCF-7 cells. While Akt is a global activator of a number of transcription factors with diverse physiological functions, our data suggest that estrogen activation of Akt in breast cancer cells are also ROS mediated and activation of Akt signaling cascades are essential in transducing signaling processes that favors survival and growth of breast cancer cells. 
Activated Akt promotes cell survival and growth via a number of mechanisms. For example, Akt phosphorylates and deactivates pro-apoptotic factors such as BAD, Caspase-9, and Forkhead transcription factors (FKHR) as well as other pro-survival transcription factors [93]. Other targets of activated Akt in response to oxidative stress includes NRF1, a redox sensitive gene known to regulate transcription of genes involved in antioxidant responses, apoptosis, as well as regulation of mitochondrial biogenesis [62;94-96]. Oxidant mediated phosphorylation of NRF1 are thought to induce nuclear translocation and transcriptional regulation of various cellular response such as restoration of redox homeostasis, enhancement of cell survival and growth, as well as regulation of mitochondria biogenesis [97]. Prolong estrogen exposure has likewise been reported to up-regulate NRF1 expressions via ER alpha (ER $\alpha)$ mediated mechanisms in MCF-7 cells which leads to increased mitochondria biogenesis in these cells [26]. While this observation is novel, others have reported that sodium butyrate, a non estrogenic but pro-oxidative compound [98] also induces NRF1 expression in MCF-7 cells [71]. Furthermore, SERMs such as TAM, RAL and Fulvestrant which are all pro-oxidant upon chronic exposures [99], also increases NRF1 expression in SERM resistant MCF-7 cells [100]. These studies all suggest that estrogen inductions of NRF1 in estrogen responsive or resistant breast cancer cells are not exclusive to ER status. It implies that perhaps estrogen induced oxidants may also mediate NRF1 expression in breast cancer cells irrespective of ER status.

Here, we report that exposure of MCF-7 cells to estrogen not only up-regulates NRF1 expressions, but it also induces NRF1 phosphorylation by Akt in a redox dependent 
manner. Treatment of cells with ROS modulators or silencing of NRF1 fail to mediate estrogen induced NRF1 expressions and phosphorylation, and inhibited growth of breast cancer cells. While ER $\alpha$ is believed to regulate estrogen induced NRF1 expression in MCF-7 cell line [26], our data indicates that estrogen induced oxidants are essential for NRF1 expressions and phosphorylation. Upon phosphorylation, this transcription factor is believed to translocate into the nucleus where they regulate mitochondria biogenesis, oxidative phosphorylation and mediates oxidant induced survival and growth of breast cancer cells, by unknown mechanism. These observation are in agreement with reports that have shown NRF1 is phosphorylations by oxidants in rat hepatoma cells promoting survival and growth of during periods of oxidative stress [62]. Our data may also explain the observation that despite the high oxidative environment of breast cancer cells in vivo [11], these cells survive, proliferate and grow as opposed to undergoing apoptosis and cell death. Activated NRF1 may also cause cancer cell metastasis, therapeutic failures and poor prognosis of breast cancer patients as oxidative stress are associated with metastasis and drug failures in a number of malignancies including breast cancer $[101 ; 102]$. In addition, it has been reported that estrogen and insulin induce proliferation and growth of MCF-7 cells via NRF1 activation [103], but insulin, with estrogens also, act as pro-oxidants $[104 ; 105]$ and activate Akt signaling pathways $[106 ; 107]$ in a variety of cells types. It is therefore feasible that the pro-oxidative properties of estrogen alone or in combination with insulin promote survival and growth of breast cancer cells through persistent expressions and phosphorylation of NRF1. 
In summary, overexpression of MnSOD and Catalase or treatment with antioxidant ebselen selectively inhibited cell proliferation and invasion of MCF-7 cells that were transfected with NRF1. Also, knocking down Akt isoform in estrogen treated cells that has been shown to phsphorylate NRF1 reduced the rate of cell proliferation. It appears therefore, that the level of NRF1 expression indicates a redox state of breast cancer cells and activation of NRF1 via Akt pathway is a key modulator of estrogen induced breast cancer cell proliferation and metastasis. 


\section{LIST OF REFERENCES}

1. Nilsson,S., Makela,S., Treuter,E., Tujague,M., Thomsen,J., Andersson,G., Enmark,E., Pettersson,K., Warner,M., and Gustafsson,J.A. (2001) Mechanisms of estrogen action. Physiol Rev., 81, 1535-1565.

2.Truss,M. and Beato,M. (1993) Steroid hormone receptors: interaction with deoxyribonucleic acid and transcription factors. Endocr.Rev., 14, 459-479.

3. Cavalieri,E., Chakravarti,D., Guttenplan,J., Hart,E., Ingle,J., Jankowiak,R., Muti,P., Rogan,E., Russo,J., Santen,R., and Sutter,T. (2006) Catechol estrogen quinones as initiators of breast and other human cancers: implications for biomarkers of susceptibility and cancer prevention. Biochim.Biophys.Acta, 1766, 63-78.

4. Brown,N.S. and Bicknell,R. (2001) Hypoxia and oxidative stress in breast cancer. Oxidative stress: its effects on the growth, metastatic potential and response to therapy of breast cancer. Breast Cancer Res., 3, 323-327.

5. Mobley,J.A. and Brueggemeier,R.W. (2004) Estrogen receptor-mediated regulation of oxidative stress and DNA damage in breast cancer. Carcinogenesis, 25, 3-9.

6. Duffy,M.J., Maguire,T.M., Hill,A., McDermott,E., and O'Higgins,N. (2000) Metalloproteinases: role in breast carcinogenesis, invasion and metastasis. Breast Cancer Res., 2, 252-257.

7. Rajagopalan,S., Meng,X.P., Ramasamy,S., Harrison,D.G., and Galis,Z.S. (1996) Reactive oxygen species produced by macrophage-derived foam cells regulate the activity of vascular matrix metalloproteinases in vitro. Implications for atherosclerotic plaque stability. J.Clin.Invest, 98, 2572-2579.

8. Swaim,M.W. and Pizzo,S.V. (1988) Methionine sulfoxide and the oxidative regulation of plasma proteinase inhibitors. J.Leukoc.Biol., 43, 365-379.

9. Kang,D. and Hamasaki,N. (2003) Mitochondrial oxidative stress and mitochondrial DNA. Clin.Chem.Lab Med., 41, 1281-1288.

10. Li,D., Zhang,W., Zhu,J., Chang,P., Sahin,A., Singletary,E., Bondy,M., Hazra,T., Mitra,S., Lau,S.S., Shen,J., and DiGiovanni,J. (2001) Oxidative DNA damage and 8hydroxy-2-deoxyguanosine DNA glycosylase/apurinic lyase in human breast cancer. Mol.Carcinog., 31, 214-223.

11. Musarrat,J., rezina-Wilson,J., and Wani,A.A. (1996) Prognostic and aetiological relevance of 8-hydroxyguanosine in human breast carcinogenesis. Eur.J.Cancer, 32A, 1209-1214.

12. Toyokuni,S., Okamoto,K., Yodoi,J., and Hiai,H. (1995) Persistent oxidative stress in cancer. FEBS Lett., 358, 1-3. 
13. Malins,D.C. and Haimanot,R. (1991) Major alterations in the nucleotide structure of DNA in cancer of the female breast. Cancer Res., 51, 5430-5432.

14. Malins,D.C., Holmes,E.H., Polissar,N.L., and Gunselman,S.J. (1993) The etiology of breast cancer. Characteristic alteration in hydroxyl radical-induced DNA base lesions during oncogenesis with potential for evaluating incidence risk. Cancer, 71, 3036-3043.

15. Hazra,T.K., Das,A., Das,S., Choudhury,S., Kow,Y.W., and Roy,R. (2007) Oxidative DNA damage repair in mammalian cells: a new perspective. DNA Repair (Amst), 6, 470480 .

16. Klein,C.B., Frenkel,K., and Costa,M. (1991) The role of oxidative processes in metal carcinogenesis. Chem.Res.Toxicol., 4, 592-604.

17. Lloyd,R.V., Hanna,P.M., and Mason,R.P. (1997) The origin of the hydroxyl radical oxygen in the Fenton reaction. Free Radic.Biol.Med., 22, 885-888.

18. Goldkorn,T., Balaban,N., Matsukuma,K., Chea,V., Gould,R., Last,J., Chan,C., and Chavez,C. (1998) EGF-Receptor phosphorylation and signaling are targeted by H2O2 redox stress. Am.J.Respir.Cell Mol.Biol., 19, 786-798.

19. Huang,R.P., Peng,A., Golard,A., Hossain,M.Z., Huang,R., Liu,Y.G., and Boynton,A.L. (2001) Hydrogen peroxide promotes transformation of rat liver nonneoplastic epithelial cells through activation of epidermal growth factor receptor. Mol.Carcinog., 30, 209-217.

20. Irani,K., Xia,Y., Zweier,J.L., Sollott,S.J., Der,C.J., Fearon,E.R., Sundaresan,M., Finkel,T., and Goldschmidt-Clermont,P.J. (1997) Mitogenic signaling mediated by oxidants in Ras-transformed fibroblasts. Science, 275, 1649-1652.

21. Pelicano,H., Carney,D., and Huang,P. (2004) ROS stress in cancer cells and therapeutic implications. Drug Resist.Updat., 7, 97-110.

22. Martindale,J.L. and Holbrook,N.J. (2002) Cellular response to oxidative stress: signaling for suicide and survival. J.Cell Physiol, 192, 1-15.

23. Li,B., Holloszy,J.O., and Semenkovich,C.F. (1999) Respiratory uncoupling induces delta-aminolevulinate synthase expression through a nuclear respiratory factor-1dependent mechanism in HeLa cells. J.Biol.Chem., 274, 17534-17540.

24. Herzig,R.P., Scacco,S., and Scarpulla,R.C. (2000) Sequential serum-dependent activation of CREB and NRF1 leads to enhanced mitochondrial respiration through the induction of cytochrome c. J.Biol.Chem., 275, 13134-13141.

25. Rustin,P. (2002) Mitochondria, from cell death to proliferation. Nat.Genet., 30, 352353. 
26. Mattingly,K.A., Ivanova,M.M., Riggs,K.A., Wickramasinghe,N.S., Barch,M.J., and Klinge,C.M. (2008) Estradiol stimulates transcription of nuclear respiratory factor-1 and increases mitochondrial biogenesis. Mol.Endocrinol., 22, 609-622.

27. Felty,Q., Xiong,W.C., Sun,D., Sarkar,S., Singh,K.P., Parkash,J., and Roy,D. (2005) Estrogen-induced mitochondrial reactive oxygen species as signal-transducing messengers. Biochemistry, 44, 6900-6909.

28. Shen,J., Platek,M., Mahasneh,A., Ambrosone,C.B., and Zhao,H. (2010) Mitochondrial copy number and risk of breast cancer: a pilot study. Mitochondrion., 10, 62-68.

29. Tseng,L.M., Yin,P.H., Chi,C.W., Hsu,C.Y., Wu,C.W., Lee,L.M., Wei,Y.H., and Lee,H.C. (2006) Mitochondrial DNA mutations and mitochondrial DNA depletion in breast cancer. Genes Chromosomes.Cancer, 45, 629-638.

30. Chen,J.Q., Delannoy,M., Cooke,C., and Yager,J.D. (2004) Mitochondrial localization of ERalpha and ERbeta in human MCF7 cells. Am.J.Physiol Endocrinol.Metab, 286, E1011-E1022.

31. Richard,S.M., Bailliet,G., Paez,G.L., Bianchi,M.S., Peltomaki,P., and Bianchi,N.O. (2000) Nuclear and mitochondrial genome instability in human breast cancer. Cancer Res., 60, 4231-4237.

32. Niida,A., Smith,A.D., Imoto,S., Tsutsumi,S., Aburatani,H., Zhang,M.Q., and Akiyama,T. (2008) Integrative bioinformatics analysis of transcriptional regulatory programs in breast cancer cells. BMC.Bioinformatics., 9, 404.

33. Landis,M.D., Seachrist,D.D., Montanez-Wiscovich,M.E., Danielpour,D., and Keri,R.A. (2005) Gene expression profiling of cancer progression reveals intrinsic regulation of transforming growth factor-beta signaling in ErbB2/Neu-induced tumors from transgenic mice. Oncogene, 24, 5173-5190.

34. Erol,A. (2005) Retrograde regulation due to mitochondrial dysfunction may be an important mechanism for carcinogenesis. Med.Hypotheses, 65, 525-529.

35. Cam,H., Balciunaite,E., Blais,A., Spektor,A., Scarpulla,R.C., Young,R., Kluger,Y., and Dynlacht,B.D. (2004) A common set of gene regulatory networks links metabolism and growth inhibition. Mol.Cell, 16, 399-411.

36. Gugneja,S. and Scarpulla,R.C. (1997) Serine phosphorylation within a concise amino-terminal domain in nuclear respiratory factor 1 enhances DNA binding. J.Biol.Chem., 272, 18732-18739.

37. Asangani,I.A., Rasheed,S.A., Leupold,J.H., Post,S., and Allgayer,H. (2008) NRF1, and AP-1 regulate the promoter of the human calpain small subunit 1 (CAPNS1) gene. Gene, 410, 197-206. 
38. Chang,W.T. and Huang,A.M. (2004) Alpha-Pal/NRF1 regulates the promoter of the human integrin-associated protein/CD47 gene. J.Biol.Chem., 279, 14542-14550.

39. Huo,L. and Scarpulla,R.C. (2001) Mitochondrial DNA instability and periimplantation lethality associated with targeted disruption of nuclear respiratory factor 1 in mice. Mol.Cell Biol., 21, 644-654.

40. Kelly,D.P. and Scarpulla,R.C. (2004) Transcriptional regulatory circuits controlling mitochondrial biogenesis and function. Genes Dev., 18, 357-368.

41. Hickson-Bick,D.L., Jones,C., and Buja,L.M. (2008) Stimulation of mitochondrial biogenesis and autophagy by lipopolysaccharide in the neonatal rat cardiomyocyte protects against programmed cell death. J.Mol.Cell Cardiol., 44, 411-418.

42. Suliman,H.B., Carraway,M.S., Welty-Wolf,K.E., Whorton,A.R., and Piantadosi,C.A. (2003) Lipopolysaccharide stimulates mitochondrial biogenesis via activation of nuclear respiratory factor-1. J.Biol.Chem., 278, 41510-41518.

43. Suliman,H.B., Welty-Wolf,K.E., Carraway,M., Tatro,L., and Piantadosi,C.A. (2004) Lipopolysaccharide induces oxidative cardiac mitochondrial damage and biogenesis. Cardiovasc.Res., 64, 279-288.

44. Oge,A., Sezer,E.D., Ozgonul,M., Bayraktar,F., and Sozmen,E.Y. (2003) The effects of estrogen and raloxifene treatment on the antioxidant enzymes and nitrite-nitrate levels in brain cortex of ovariectomized rats. Neurosci.Lett., 338, 217-220.

45. Konyalioglu,S., Durmaz,G., and Yalcin,A. (2007) The potential antioxidant effect of raloxifene treatment: a study on heart, liver and brain cortex of ovariectomized female rats. Cell Biochem.Funct., 25, 259-266.

46. Arteaga,E., Villaseca,P., Bianchi,M., Rojas,A., and Marshall,G. (2003) Raloxifene is a better antioxidant of low-density lipoprotein than estradiol or tamoxifen in postmenopausal women in vitro. Menopause., 10, 142-146.

47. Schiff,R., Reddy,P., Ahotupa,M., Coronado-Heinsohn,E., Grim,M., Hilsenbeck,S.G., Lawrence,R., Deneke,S., Herrera,R., Chamness,G.C., Fuqua,S.A., Brown,P.H., and Osborne,C.K. (2000) Oxidative stress and AP-1 activity in tamoxifen-resistant breast tumors in vivo. J.Natl.Cancer Inst., 92, 1926-1934.

48. Klinge,C.M., Riggs,K.A., Wickramasinghe,N.S., Emberts,C.G., McConda,D.B., Barry,P.N., and Magnusen,J.E. (2010) Estrogen receptor alpha 46 is reduced in tamoxifen resistant breast cancer cells and re-expression inhibits cell proliferation and estrogen receptor alpha 66-regulated target gene transcription. Mol.Cell Endocrinol., 323, 268276. 
49. Roederer,M., Staal,F.J., Raju,P.A., Ela,S.W., Herzenberg,L.A., and Herzenberg,L.A. (1990) Cytokine-stimulated human immunodeficiency virus replication is inhibited by Nacetyl-L-cysteine. Proc.Natl.Acad.Sci.U.S.A, 87, 4884-4888.

50. Staal,F.J., Roederer,M., Herzenberg,L.A., and Herzenberg,L.A. (1990) Intracellular thiols regulate activation of nuclear factor kappa B and transcription of human immunodeficiency virus. Proc.Natl.Acad.Sci.U.S.A, 87, 9943-9947.

51. Zhang,X., Zhu,T., Chen,Y., Mertani,H.C., Lee,K.O., and Lobie,P.E. (2003) Human growth hormone-regulated HOXAl is a human mammary epithelial oncogene. J.Biol.Chem., 278, 7580-7590.

52. Ko,C.H., Shen,S.C., Lee,T.J., and Chen,Y.C. (2005) Myricetin inhibits matrix metalloproteinase 2 protein expression and enzyme activity in colorectal carcinoma cells. Mol.Cancer Ther., 4, 281-290.

53. Stirone,C., Duckles,S.P., Krause,D.N., and Procaccio,V. (2005) Estrogen increases mitochondrial efficiency and reduces oxidative stress in cerebral blood vessels. Mol.Pharmacol., 68, 959-965.

54. Burdon,R.H. (1995) Superoxide and hydrogen peroxide in relation to mammalian cell proliferation. Free Radic.Biol.Med., 18, 775-794.

55. Burdon,R.H., Gill,V., and Alliangana,D. (1996) Hydrogen peroxide in relation to proliferation and apoptosis in BHK-21 hamster fibroblasts. Free Radic.Res., 24, 81-93.

56. Davis,R.J. (1993) The mitogen-activated protein kinase signal transduction pathway. J.Biol.Chem., 268, 14553-14556.

57. Stoica,G.E., Franke,T.F., Wellstein,A., Czubayko,F., List,H.J., Reiter,R., Morgan,E., Martin,M.B., and Stoica,A. (2003) Estradiol rapidly activates Akt via the ErbB2 signaling pathway. Mol.Endocrinol., 17, 818-830.

58. Ikeyama,S., Kokkonen,G., Shack,S., Wang,X.T., and Holbrook,N.J. (2002) Loss in oxidative stress tolerance with aging linked to reduced extracellular signal-regulated kinase and Akt kinase activities 4. FASEB J., 16, 114-116.

59. Kirkegaard,T., Witton,C.J., McGlynn,L.M., Tovey,S.M., Dunne,B., Lyon,A., and Bartlett,J.M. (2005) AKT activation predicts outcome in breast cancer patients treated with tamoxifen. J.Pathol., 207, 139-146.

60. Hutchinson,J., Jin,J., Cardiff,R.D., Woodgett,J.R., and Muller,W.J. (2001) Activation of Akt (protein kinase B) in mammary epithelium provides a critical cell survival signal required for tumor progression. Mol.Cell Biol., 21, 2203-2212. 
61. Piantadosi,C.A., Carraway,M.S., Babiker,A., and Suliman,H.B. (2008) Heme oxygenase-1 regulates cardiac mitochondrial biogenesis via Nrf2-mediated transcriptional control of nuclear respiratory factor-1. Circ.Res., 103, 1232-1240.

62. Piantadosi,C.A. and Suliman,H.B. (2006) Mitochondrial transcription factor A induction by redox activation of nuclear respiratory factor 1. J.Biol.Chem., 281, 324-333.

63. Novotny,V., Prieschl,E.E., Csonga,R., Fabjani,G., and Baumruker,T. (1998) Nrf1 in a complex with fosB, c-jun, junD and ATF2 forms the AP1 component at the TNF alpha promoter in stimulated mast cells. Nucleic Acids Res., 26, 5480-5485.

64. Suliman,H.B., Carraway,M.S., Tatro,L.G., and Piantadosi,C.A. (2007) A new activating role for $\mathrm{CO}$ in cardiac mitochondrial biogenesis. J.Cell Sci., 120, 299-308.

65. Heron-Milhavet,L., Franckhauser,C., Rana,V., Berthenet,C., Fisher,D., Hemmings,B.A., Fernandez,A., and Lamb,N.J. (2006) Only Akt1 is required for proliferation, while Akt2 promotes cell cycle exit through p21 binding. Mol.Cell Biol., $26,8267-8280$.

66. Brazil,D.P., Yang,Z.Z., and Hemmings,B.A. (2004) Advances in protein kinase B signalling: AKTion on multiple fronts. Trends Biochem.Sci., 29, 233-242.

67. Blank,P.S., Silverman,H.S., Chung,O.Y., Hogue,B.A., Stern,M.D., Hansford,R.G., Lakatta,E.G., and Capogrossi,M.C. (1992) Cytosolic pH measurements in single cardiac myocytes using carboxy-seminaphthorhodafluor-1. Am.J.Physiol, 263, H276-H284.

68. Virbasius,J.V. and Scarpulla,R.C. (1994) Activation of the human mitochondrial transcription factor A gene by nuclear respiratory factors: a potential regulatory link between nuclear and mitochondrial gene expression in organelle biogenesis. Proc.Natl.Acad.Sci.U.S.A, 91, 1309-1313.

69. Carragher,N.O., Fonseca,B.D., and Frame,M.C. (2004) Calpain activity is generally elevated during transformation but has oncogene-specific biological functions. Neoplasia., 6, 53-73.

70. Demarchi,F. and Schneider,C. (2007) The calpain system as a modulator of stress/damage response. Cell Cycle, 6, 136-138.

71. Izumi,H., Ohta,R., Nagatani,G., Ise,T., Nakayama,Y., Nomoto,M., and Kohno,K. (2003) $\mathrm{p} 300 / \mathrm{CBP}$-associated factor (P/CAF) interacts with nuclear respiratory factor-1 to regulate the UDP-N-acetyl-alpha-d-galactosamine: polypeptide Nacetylgalactosaminyltransferase-3 gene. Biochem.J., 373, 713-722.

72. Chu,J.S. and Chang,K.J. (1999) Mucin expression in mucinous carcinoma and other invasive carcinomas of the breast. Cancer Lett., 142, 121-127. 
73. Matsuda,K., Masaki,T., Watanabe,T., Kitayama,J., Nagawa,H., Muto,T., and Ajioka,Y. (2000) Clinical significance of MUC1 and MUC2 mucin and p53 protein expression in colorectal carcinoma. Jpn.J.Clin.Oncol., 30, 89-94.

74. Felty,Q. and Roy,D. (2005) Mitochondrial signals to nucleus regulate estrogeninduced cell growth. Med.Hypotheses, 64, 133-141.

75. Felty,Q., Singh,K.P., and Roy,D. (2005) Estrogen-induced G1/S transition of G0arrested estrogen-dependent breast cancer cells is regulated by mitochondrial oxidant signaling. Oncogene, 24, 4883-4893.

76. Cavalieri,E., Frenkel,K., Liehr,J.G., Rogan,E., and Roy,D. (2000) Estrogens as endogenous genotoxic agents--DNA adducts and mutations. J.Natl.Cancer Inst.Monogr,75-93.

77. Clemons,M. and Goss,P. (2001) Estrogen and the risk of breast cancer. N.Engl.J.Med., 344, 276-285.

78. Yager,J.D. and Leihr,J.G. (1996) Molecular Mechanisms of Estrogen Carcinogenesis. Annual Review of Pharmacology and Toxicology, 36, 203-232.

79. Bhat,H.K., Calaf,G., Hei,T.K., Loya,T., and Vadgama,J.V. (2003) Critical role of oxidative stress in estrogen-induced carcinogenesis. Proc.Natl.Acad.Sci.U.S.A, 100, 3913-3918.

80. Szatrowski,T.P. and Nathan,C.F. (1991) Production of large amounts of hydrogen peroxide by human tumor cells. Cancer Res., 51, 794-798.

81. Chan,D.W., Liu,V.W., Tsao,G.S., Yao,K.M., Furukawa,T., Chan,K.K., and Ngan,H.Y. (2008) Loss of MKP3 mediated by oxidative stress enhances tumorigenicity and chemoresistance of ovarian cancer cells. Carcinogenesis, 29, 1742-1750.

82. Toki,N., Kagami,S., Kurita,T., Kawagoe,T., Matsuura,Y., Hachisuga,T., Matsuyama,A., Hashimoto,H., Izumi,H., and Kohno,K. (2010) Expression of mitochondrial transcription factor $\mathrm{A}$ in endometrial carcinomas: clinicopathologic correlations and prognostic significance. Virchows Arch., 456, 387-393.

83. Roberts,R.A., Laskin,D.L., Smith,C.V., Robertson,F.M., Allen,E.M., Doorn,J.A., and Slikker,W. (2009) Nitrative and oxidative stress in toxicology and disease. Toxicol.Sci., 112, 4-16.

84. Burns,J., Yokota,T., Ashihara,H., Lean,M.E., and Crozier,A. (2002) Plant foods and herbal sources of resveratrol. J.Agric.Food Chem., 50, 3337-3340.

85. Jang,M., Cai,L., Udeani,G.O., Slowing,K.V., Thomas,C.F., Beecher,C.W., Fong,H.H., Farnsworth,N.R., Kinghorn,A.D., Mehta,R.G., Moon,R.C., and Pezzuto,J.M. 
(1997) Cancer chemopreventive activity of resveratrol, a natural product derived from grapes. Science, 275, 218-220.

86. Perumal,S.S., Shanthi,P., and Sachdanandam,P. (2005) Combined efficacy of tamoxifen and coenzyme Q10 on the status of lipid peroxidation and antioxidants in DMBA induced breast cancer. Mol.Cell Biochem., 273, 151-160.

87. Yano,T., Yajima,S., Hagiwara,K., Kumadaki,I., Yano,Y., Otani,S., Uchida,M., and Ichikawa,T. (2000) Vitamin E inhibits cell proliferation and the activation of extracellular signal-regulated kinase during the promotion phase of lung tumorigenesis irrespective of antioxidative effect. Carcinogenesis, 21, 2129-2133.

88. Crowder,R.J. and Freeman,R.S. (1998) Phosphatidylinositol 3-kinase and Akt protein kinase are necessary and sufficient for the survival of nerve growth factor-dependent sympathetic neurons. J.Neurosci., 18, 2933-2943.

89. Wang,X., McCullough,K.D., Franke,T.F., and Holbrook,N.J. (2000) Epidermal growth factor receptor-dependent Akt activation by oxidative stress enhances cell survival. J.Biol.Chem., 275, 14624-14631.

90. Ahmad,S., Singh,N., and Glazer,R.I. (1999) Role of AKT1 in 17beta-estradiol- and insulin-like growth factor I (IGF-I)-dependent proliferation and prevention of apoptosis in MCF-7 breast carcinoma cells. Biochem.Pharmacol., 58, 425-430.

91. Guo,R.X., Wei,L.H., Tu,Z., Sun,P.M., Wang,J.L., Zhao,D., Li,X.P., and Tang,J.M. (2006) 17 beta-estradiol activates PI3K/Akt signaling pathway by estrogen receptor (ER)dependent and ER-independent mechanisms in endometrial cancer cells. J.Steroid Biochem.Mol.Biol., 99, 9-18.

92. Maroulakou,I.G., Oemler,W., Naber,S.P., and Tsichlis,P.N. (2007) Akt1 ablation inhibits, whereas Akt2 ablation accelerates, the development of mammary adenocarcinomas in mouse mammary tumor virus (MMTV)-ErbB2/neu and MMTVpolyoma middle T transgenic mice. Cancer Res., 67, 167-177.

93. Morris,J.B., Kenney,B., Huynh,H., and Woodcock,E.A. (2005) Regulation of the proapoptotic factor FOXO1 (FKHR) in cardiomyocytes by growth factors and alpha1adrenergic agonists. Endocrinology, 146, 4370-4376.

94. Evans,M.J. and Scarpulla,R.C. (1989) Interaction of nuclear factors with multiple sites in the somatic cytochrome c promoter. Characterization of upstream NRF1, ATF, and intron Sp1 recognition sequences. J.Biol.Chem., 264, 14361-14368.

95. Evans,M.J. and Scarpulla,R.C. (1990) NRF1: a trans-activator of nuclear-encoded respiratory genes in animal cells. Genes Dev., 4, 1023-1034.

96. Morrish,F., Giedt,C., and Hockenbery,D. (2003) c-MYC apoptotic function is mediated by NRF1 target genes. Genes Dev., 17, 240-255. 
97. Kwong,M., Kan,Y.W., and Chan,J.Y. (1999) The CNC basic leucine zipper factor, Nrfl, is essential for cell survival in response to oxidative stress-inducing agents. Role for Nrf1 in gamma-gcs(1) and gss expression in mouse fibroblasts. J.Biol.Chem., 274, 37491-37498.

98. Jeng,J.H., Kuo,M.Y., Lee,P.H., Wang,Y.J., Lee,M.Y., Lee,J.J., Lin,B.R., Tai,T.F., and Chang,M.C. (2006) Toxic and metabolic effect of sodium butyrate on SAS tongue cancer cells: role of cell cycle deregulation and redox changes. Toxicology, 223, 235247.

99. Fernando,R.I. and Wimalasena,J. (2004) Estradiol abrogates apoptosis in breast cancer cells through inactivation of BAD: Ras-dependent nongenomic pathways requiring signaling through ERK and Akt. Mol.Biol.Cell, 15, 3266-3284.

100. Fan,M., Yan,P.S., Hartman-Frey,C., Chen,L., Paik,H., Oyer,S.L., Salisbury,J.D., Cheng,A.S., Li,L., Abbosh,P.H., Huang,T.H., and Nephew,K.P. (2006) Diverse gene expression and DNA methylation profiles correlate with differential adaptation of breast cancer cells to the antiestrogens tamoxifen and fulvestrant. Cancer Res., 66, 1195411966.

101. Conklin,K.A. (2004) Chemotherapy-associated oxidative stress: impact on chemotherapeutic effectiveness. Integr.Cancer Ther., 3, 294-300.

102. Wolf,D.M., Langan-Fahey,S.M., Parker,C.J., McCague,R., and Jordan,V.C. (1993) Investigation of the mechanism of tamoxifen-stimulated breast tumor growth with nonisomerizable analogues of tamoxifen and metabolites. J.Natl.Cancer Inst., 85, 806812.

103. Watanabe,A. (2003) Cloning and characterization of the promoter region of the bovine membrane tethering protein $\mathrm{p} 115$ gene and its regulation in mammary epithelial cells. Biochim.Biophys.Acta, 1629, 60-72.

104. Thibodeau,P.A., Kachadourian,R., Lemay,R., Bisson,M., Day,B.J., and Paquette,B. (2002) In vitro pro- and antioxidant properties of estrogens. J.Steroid Biochem.Mol.Biol., $81,227-236$.

105. Carnesecchi,S., Carpentier,J.L., Foti,M., and Szanto,I. (2006) Insulin-induced vascular endothelial growth factor expression is mediated by the NADPH oxidase NOX3. Exp.Cell Res., 312, 3413-3424.

106. Brozinick,J.T., Jr. and Birnbaum,M.J. (1998) Insulin, but not contraction, activates Akt/PKB in isolated rat skeletal muscle. J.Biol.Chem., 273, 14679-14682.

107. Tsai,E.M., Wang,S.C., Lee,J.N., and Hung,M.C. (2001) Akt activation by estrogen in estrogen receptor-negative breast cancer cells. Cancer Res., 61, 8390-8392 


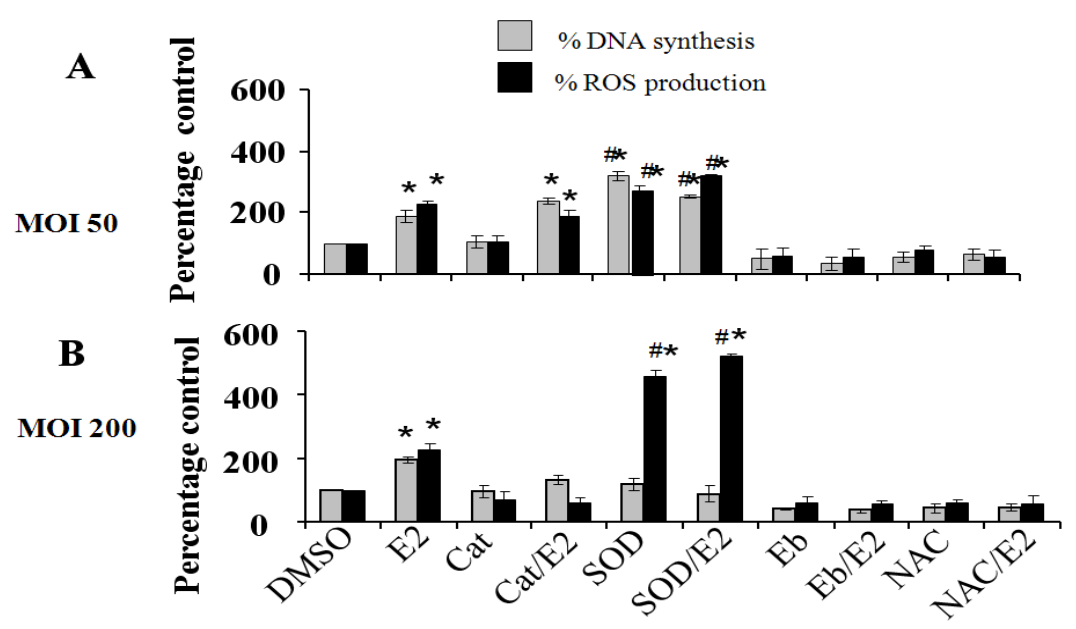

Fig. 1. Estrogen induced ROS mediates in vitro proliferation of MCF-7 breast cancer Cells. 3500 cells/well were seeded in 96well plate for BrdU cell proliferation assays and $1.0 \times 10^{\wedge} 4$ cells/well for ROS production assays. Next day, cells were infected with Adenovirus over-expressing MnSOD or Catalase at either moi 50 or 200 in serum free media. Other group of cells was treated with $40 \mu \mathrm{m}$ ebselen and $1 \mathrm{mM}$ NAC diluted also in serum free media. Cells were cultured for $48 \mathrm{hrs}$ and assayed for ROS production or BrdU assays. For ROS assays, cells were pretreated for 4hrs before assay with ebselen and NAC after which $10 \mu \mathrm{M}$ DCF were loaded onto the cells for $20 \mathrm{mins}$, then cells were challenged with $100 \mathrm{pg} / \mathrm{ml}$ estrogen, and ROS readings were taken every 5 mins on Tecan plate reader. For cell proliferation assays, $48 \mathrm{hrs}$ post infections, wells were challenged with $100 \mathrm{pg} / \mathrm{ml}$ estrogen and allowed to incubate for additional $18 \mathrm{hrs}$ after which BrdU assay were carried out with Roche BrdU assay kit. (A) MCF-7 cells infected with catalase or MnSOD at moi 50, or treated chemical antioxidant, then challenged with estrogen. (B) MCF-7 cells infected with catalase or MnSOD at moi 200, or treated chemical antioxidant, then challenged with estrogen. ROS production upon E2 challenge was compared with DNA synthesis. Data is expressed as standard error of mean of three experiments, (+/- SE). $(*)$ indicates significant different from control group. (*\#) indicates treatment significantly different from E2 treated group. $(\mathrm{P}<0.05)$ 

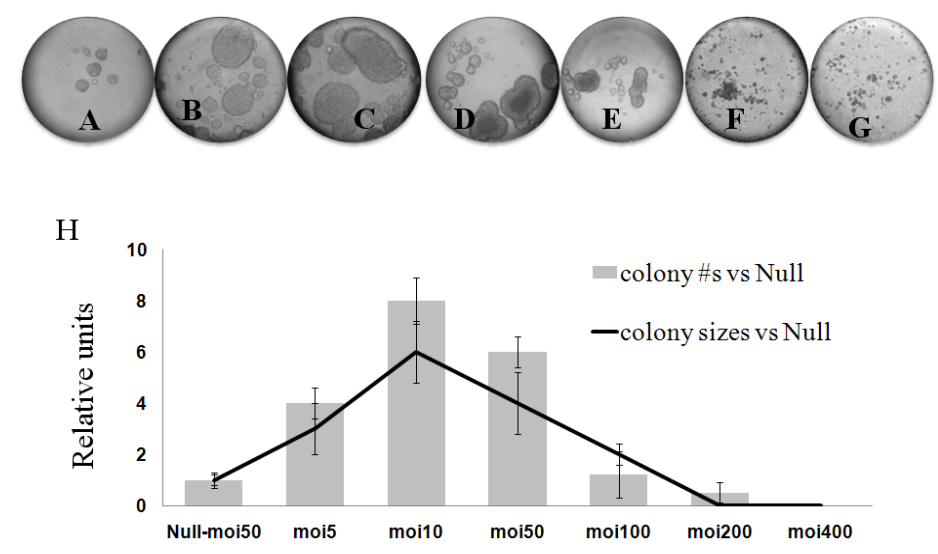

Fig. 2. Differential effects of ROS production on in vitro growth of MCF-7. MCF-7 cells were infected with various concentrations of MnSOD over-expressing viruses for 24hrs after which cells were detached and seeded for soft agar assays such that each well in 48 well plate had 5000cells/well. Cells were incubated for 5 weeks with weekly feeding. Colony numbers and sizes were scored using Nikon metamorph software and expressed as mean of five wells, + - SD. $(*)$ indicates significant difference from control group (null moi 50), $(\mathrm{P}<0.05)$. Representative Images were acquired with hand held Nikon camera over an inverted microscope with $4 \mathrm{x}$ objective. A) AdEmpty (Null) moi50, B) AdMnSOD Moi 5, C) AdMnSOD moi 10, D) AdMnSOD moi 50, E) AdMnSOD moi 100, F) AdMnSOD moi 200, G) AdMnSOD moi 400, H) Mean colony and size numbers compared to null vector.
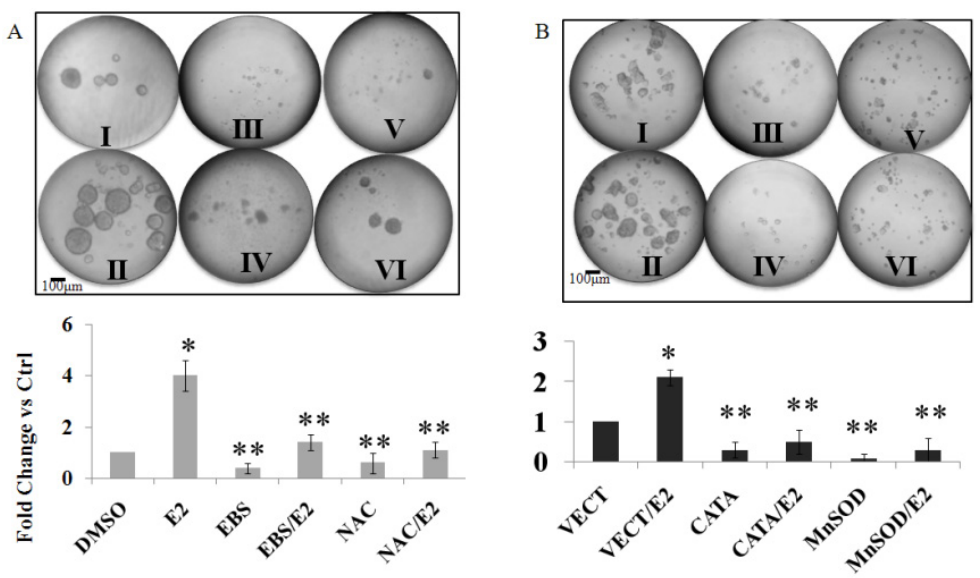

Fig 3. ROS Scavengers inhibits E2 induced growth of MCF-7 cells. Cells were infected with biological antioxidants for $24 \mathrm{hrs}$ in serum free media and allowed to recover afterwards. $1.0 \times 10^{\wedge} 4$ cell pellet was resuspended with 500ul $2 \times$ culture media containing $100 \mathrm{pg} / \mathrm{ml} \mathrm{E} 2$ or $40 \mu \mathrm{M}$ ebselen. Cell suspensions were then mixed 1:1 with $0.5 \%$ molten agarose and over layered on precast bottom agarose in 48 well plate. Cultures were allowed to incubate for $3-5$ wks with weekly feeding and images were acquired with a hand-held Nikon digital camera over $4 \mathrm{x}$ inverted microscope. Qudruplicate wells were 
counted and expressed as mean three experiments $+/$ - SE. (Panel A: Chemical antioxidant treatment group) (I) DMSO, (II) $100 \mathrm{pg} / \mathrm{ml} \mathrm{E2}$, (III) Ebs, (IV) Ebs/E2, (V) NAC, (VI) $\mathrm{NAC} / \mathrm{E} 2$. (Panel B: Biological antioxidant treatment group) (I) DMSO, (II) $100 \mathrm{pg} / \mathrm{ml}$ E2, (III) Cata, (IV) Cata/E2, (V) MnSOD, (VI) MnSOD/E2. (*) indicates significant difference from control group. $(* *)$ indicates significant difference from $\mathrm{E} 2$ treated group, $(\mathrm{P}<0.05)$.

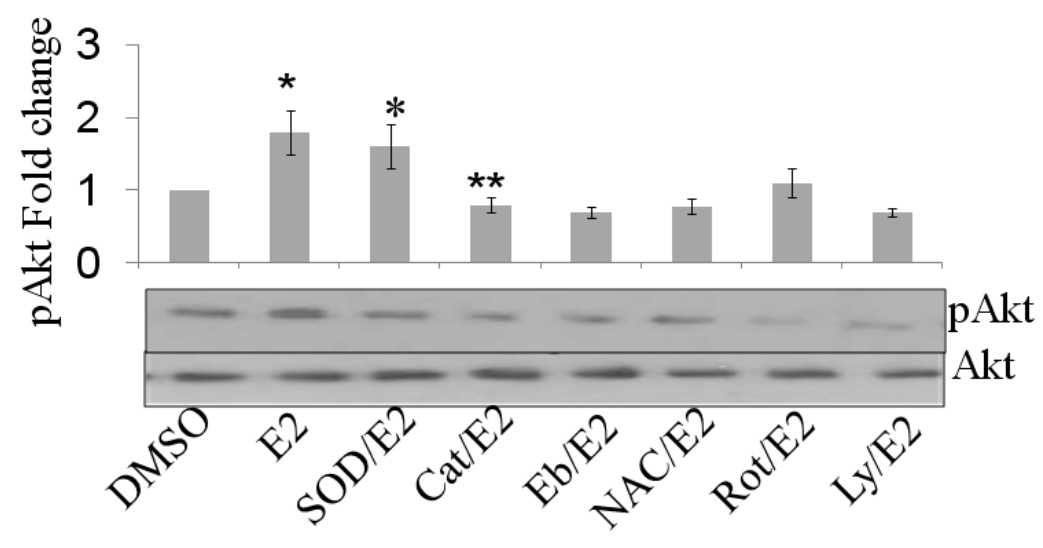

Fig. 4. Estrogen induced activation of Akt is abrogated by ROS scavengers. MCF-7 cells were either pre-infected with MnSOD or catalase at moi 50 and cells seeded for experiment, or cells were seeded and treated with $40 \mu \mathrm{M}$ ebselen, $10 \mu \mathrm{mol} / \mathrm{L}$ LY294002 (LY) and 1.0 $\mu \mathrm{M}$ Rotenone for $48 \mathrm{hrs}$ in starvation media. At end of starvation periods, cells were harvested and lysed with RIPA buffer, and 100 ug total proteins were fractionated in SDS PAGE electrophoresis gel. Blots were probed for phosphorylated Akt (pAkt) and total Akt and band intensity were quantified with Biorad GelDoc 2000 and normalized to vehicle. (A) Representative Immunoblot probed for pAkt and total Akt. (B) Densitometry of pAkt normalized with total Akt and expressed as fold change vs. DMSO. (**) indicates significant difference from control group. $\left(^{*}\right)$ indicates significant difference from E2 treated group, $(\mathrm{P}<0.05)$. 

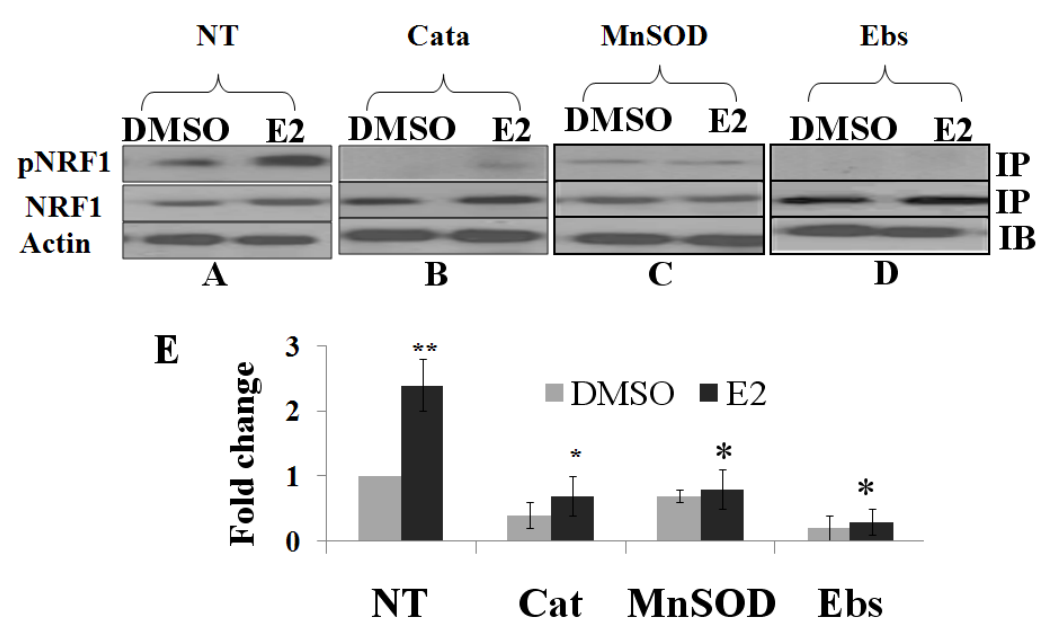

Fig. 5. Estrogen induced NRF1 activation is abrogated by ROS scavengers. To determine whether ROS scavengers mitigates estrogen induced activations of NRF1 in breast cancer, MCF-7 cells were seeded, infected with catalase or MnSOD, or with 40uM ebselen and estrogen as previously described. Lysate were immunoprecipitated with NRF1 and immunoblot probed with anti serine antibody (pNRF1) or NRF1 antibody. For loading control, 50 ug whole cell lysate (WCL) were fractionated and blot probed with beta actin (actin). Band intensity of pNRF1 was compared with NRF1, and then normalizes with DMSO from NT group. Representative data of 3 experiments is presented above. (Panel A) Non transfected group (NT) treated DMSO or E2, (Panel B, C) Catalase or MnSOD infected groups respectively, and then treated with DMSO or E2. (Panel D) Ebselen and E2 co-treated group. (E) Densitometry of pNRF1 normalized with total NRF1 and expressed as fold change vs. DMSO in NT group. (**) Indicates that E2 treatment group is significantly different from control (DMSO) groups while $(*)$ indicates that other treatments groups are significantly different from E2 treatment groups. Data is expressed as mean of 3 experiments, $\mathrm{OD} \pm \mathrm{SE},(\mathrm{P}<0.05)$.

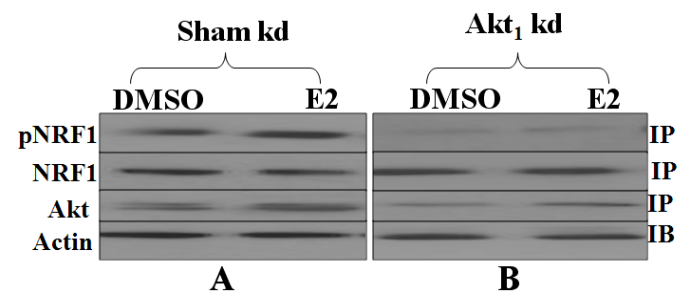

C

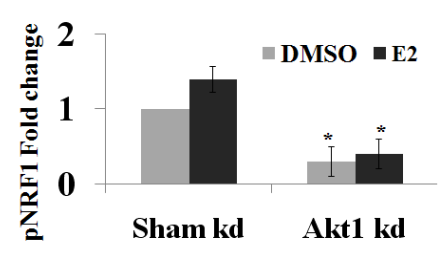

D

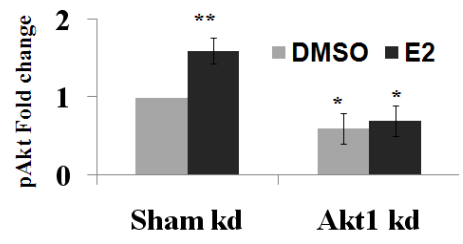



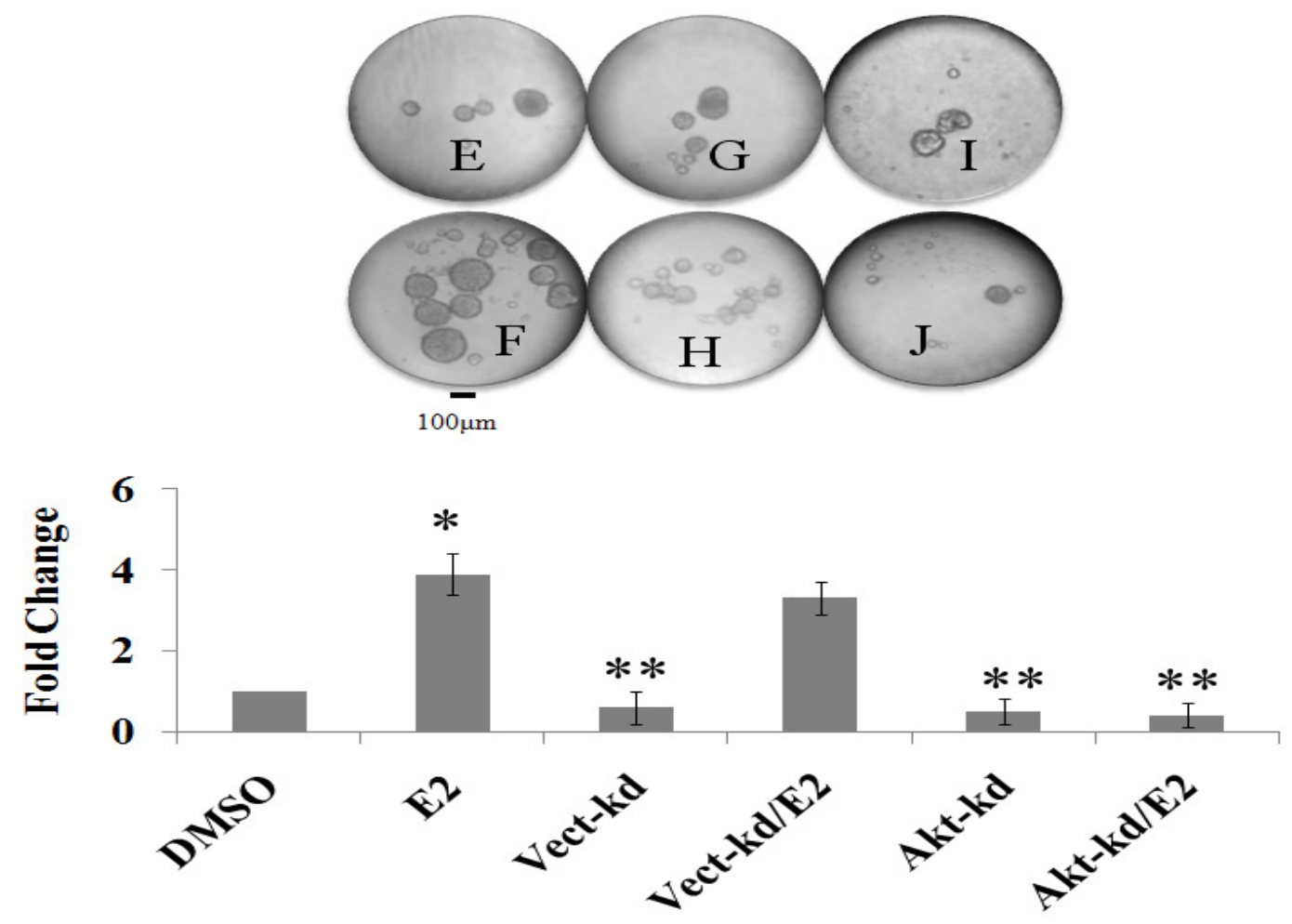

Fig. 6. Akt phosphorylate and activate NRF1 which mediate in vitro growth of MCF-7 cells. To determine role of Akt and NRF1 phosphorylation in estrogen induced growth of breast cancer cells, MCF-7 cells were transfected with pre-designed and verified Akt1 shRNA plasmid or its vector for $72 \mathrm{hrs}$ with FuGENE 6 transfection reagent without change of media. Post transfection, cells were seeded for colony assay, or challenged with $100 \mathrm{pg} / \mathrm{ml}$ estrogen or DMSO for 30 mins. Cells were then harvested with RIPA buffer and 500 ug total protein was IP with NRF1, fractionated on SDS-PAGE and blots probed with serine antibody. 50 ug of WCL was also fractionated on SDS-PAGE gel and probed for total Akt, and $\beta$ actin as experimental loading control. Band intensity were measured with Biorad versadoc 2000 software and expressed as fold change from DMSO. (Panels A and B) Western blot analysis of vector and Akt ${ }_{1}$ shRNA plasmid transfected into MCF-7 cells then treated with DMSO or E2. (C D) Band intensity of NRF1 phosphoserine (pNRF1) normalized to total NRF1, and Akt normalized to actin respectively. (E-J) Representative pictures colonies from soft agar assay after 3 weeks incubation, and expressed as mean +/- SE of three experiments. (E) DMSO, (F) E2, (G) vector- $\mathrm{kd} / \mathrm{DMSO},(\mathrm{H})$ vector- $\mathrm{kd} / \mathrm{E} 2$, (I) $\mathrm{Akt}_{1} \mathrm{kd} / \mathrm{DMSO}$, (J) Akt $\mathrm{kd} / \mathrm{E} 2$, (K) Fold increase of colony formation versus DMSO. (**) Indicates that E2 treatment group is significantly different from control (DMSO) groups while $\left(^{*}\right)$ indicates that other treatments groups are significantly different from E2 treatment groups. Data is expressed as mean of 3 experiments, $\mathrm{OD} \pm \mathrm{SE},(\mathrm{P}<0.05)$. 

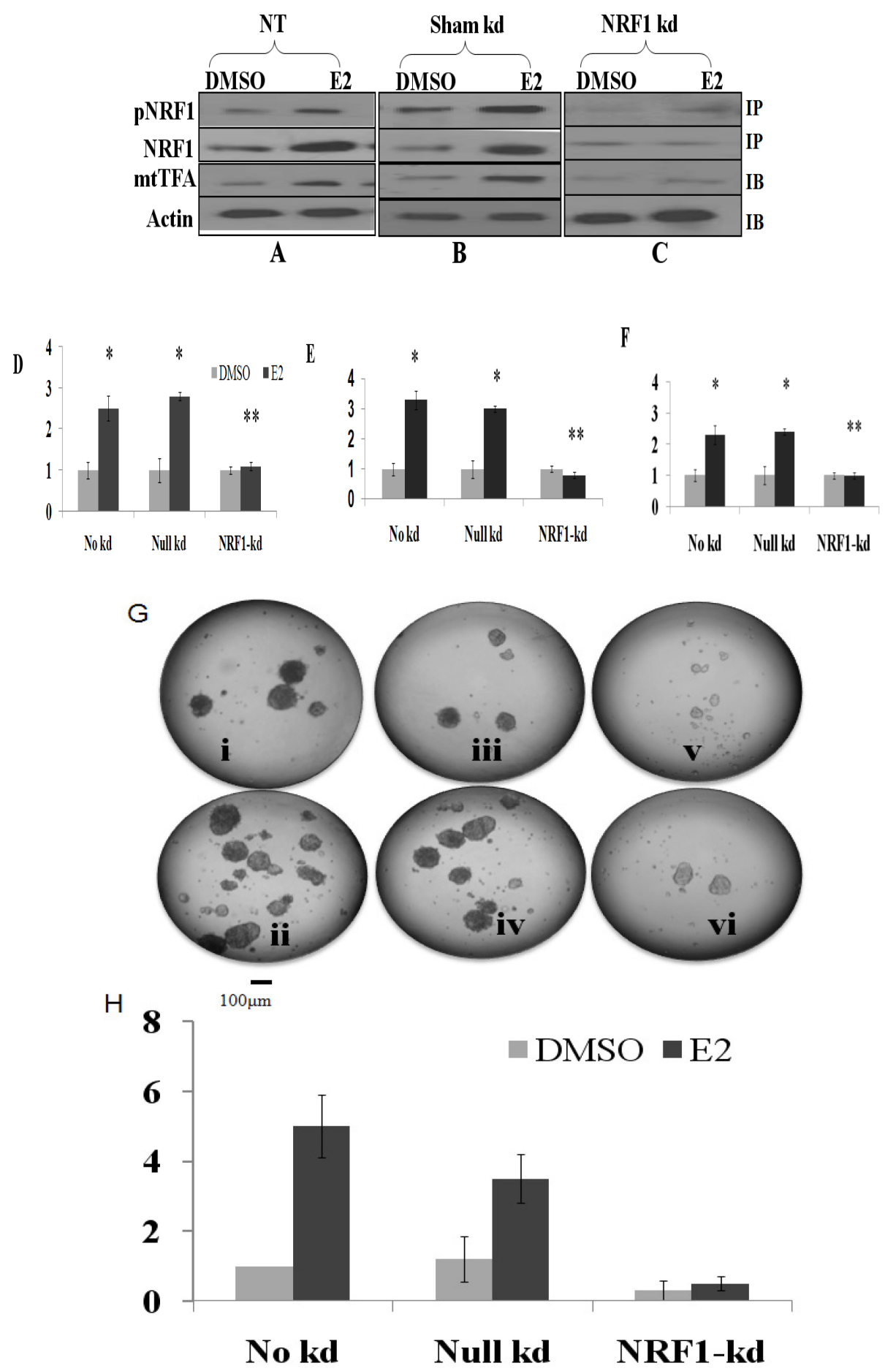

Fig. 7. Silencing of NRF1 attenuates estrogen induced in vitro growth of MCF-7.

MCF-7 cells were transfected with shRNA vector or NRF1 shRNA plasmid for $96 \mathrm{hrs}$. Post transfection, cells were seeded for colony assays or treated with DMSO or $100 \mathrm{pg}$ E2 for 30mins, then harvested and lysed with RIPA buffer. 500 ug total proteins were coimmunoprecipitated with anti NRF1 antibody, and blots probed with either anti NRF1, 
anti phosphoserine and anti mtTFA antibodies. (Panel A) Non transfected cells (NT) probed with anti serine, anti NRF1, anti mtTFA and anti actin respectively. (Panel B) Vector transfected cells probed with anti serine, anti NRF1, anti mtTFA and anti actin respectively. (Panel C) NRF1 kd cells probed with anti serine, anti NRF1, anti mtTFA and anti actin. (D-F) Densitometry of NRF1 knocked on (D) phosphorylated NRF1 compared to total NRF1, (E) total NRF1 compared to actin. (F) mtTFA expression compared to actin. (G) Representative pictures of colony assay of MCF-7 cells with NRF1 knockdown + estrogens treatment; (i) NT-DMSO, (ii) NT-E2, (iii) vector-DMSO, (iv)vector-E2, (v) NRF1-kd-DMSO, (vi) NRF1-kd-E2. (H) Fold change of colonies compared to NT-DMSO. (*) Indicates that E2 treatment group is significantly different from control (DMSO) groups while $(* *)$ indicates that other treatments groups are significantly different from E2 treatment groups. Data is expressed as mean of 3 experiments, $\mathrm{OD} \pm \mathrm{SE},(\mathrm{P}<0.05)$
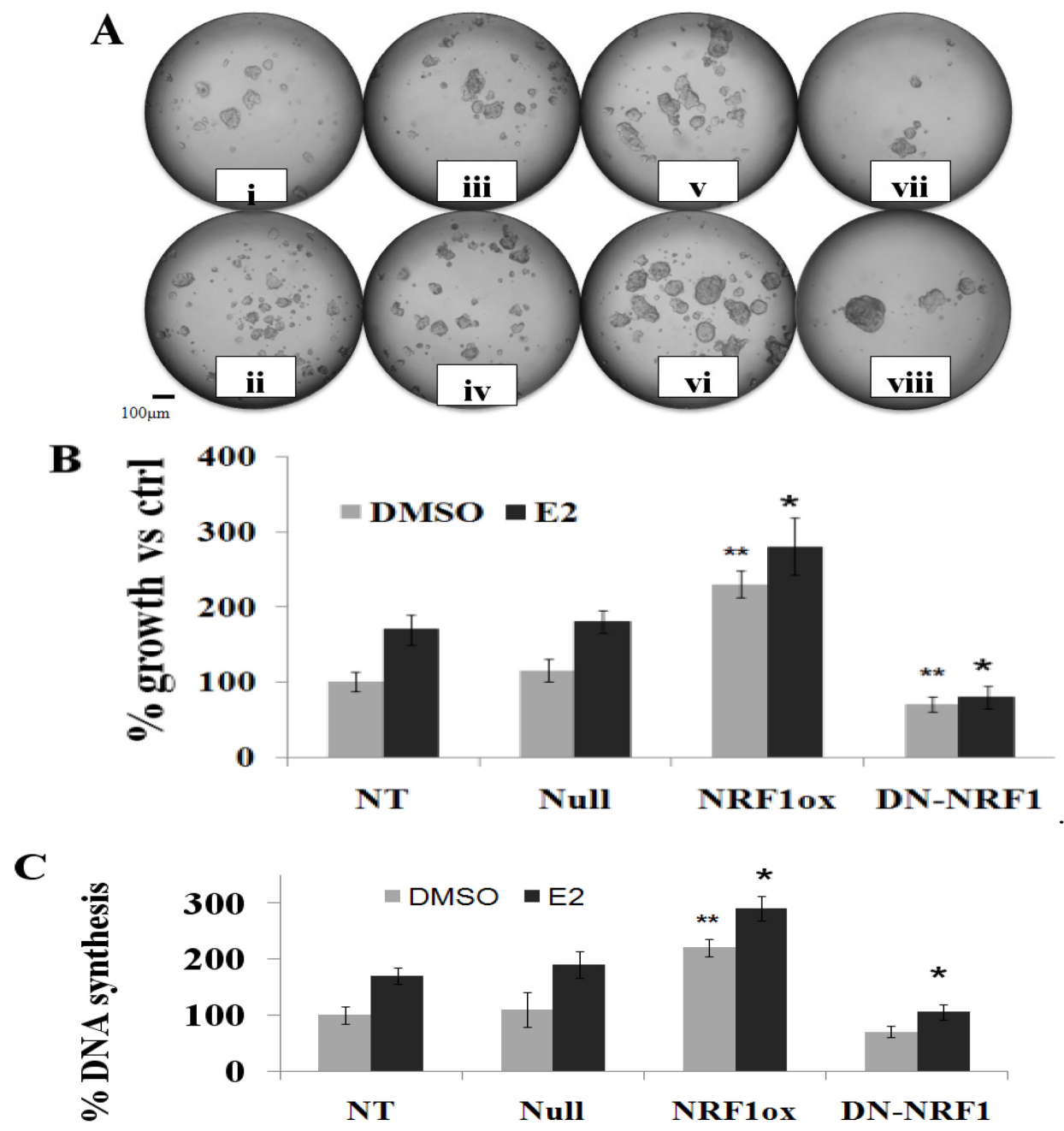
Fig. 8. NRF1 expressions modulates estrogen induced proliferation and growth of MCF-7 cells. MCF-7 cells were transfected with plasmid either over-expressing or underexpressing NRF1 (NRF1-ox and NRF1-kd for 48hrs. Transfected cells were subsequently used for colony assay, with or without $100 \mathrm{pg} / \mathrm{ml} \mathrm{E} 2$ treatments for 21 days. (A) Colonies formed by MCF-7 cells transfected with NRF1 modulating plasmid with vector control. (i) NT-DMSO, (ii) NT-E2, (iii) Vector-DMSO, (iv) vector-E2, (v) NRF1-ox-DMSO, (vi) NRF1-ox-E2, (vii) NRF1-kd-DMSO, (viii) NRF1-kd-E2. (B). Enumerated colony count were expressed as percentage change from NT treatment group +/- SD of three experiments. $(*)$ indicates treatment significantly different from E2. $(* *)$ indicates treatment significantly different from control. $(\mathrm{P}<0.05)$

A
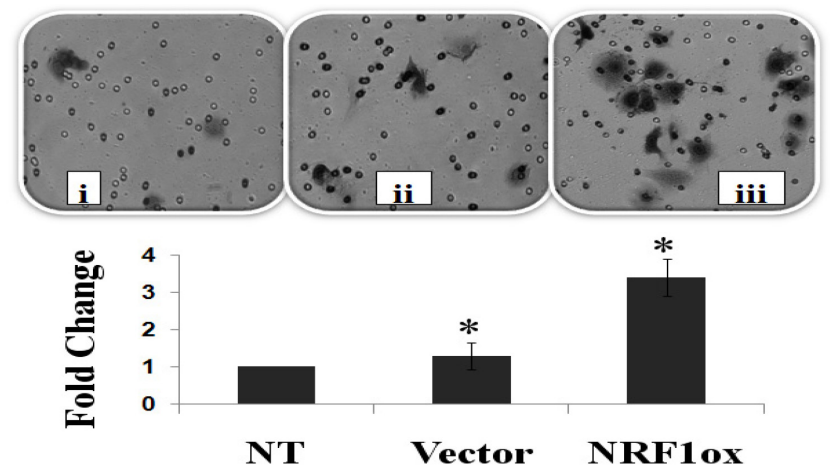

B.

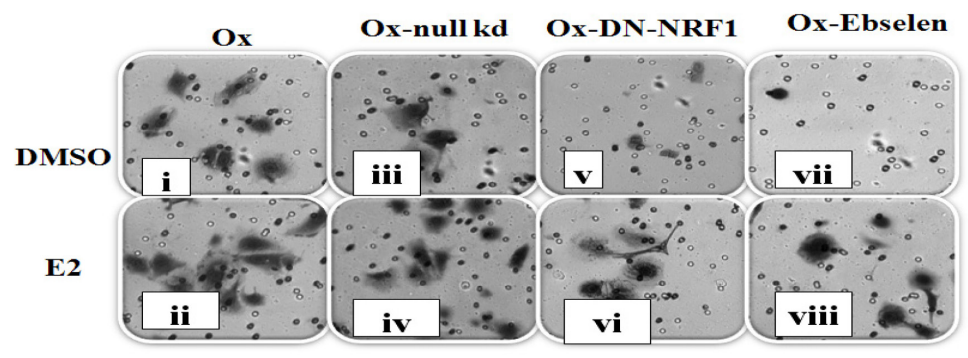

$\square \mathrm{DMSO} \quad \mathrm{E} 2$
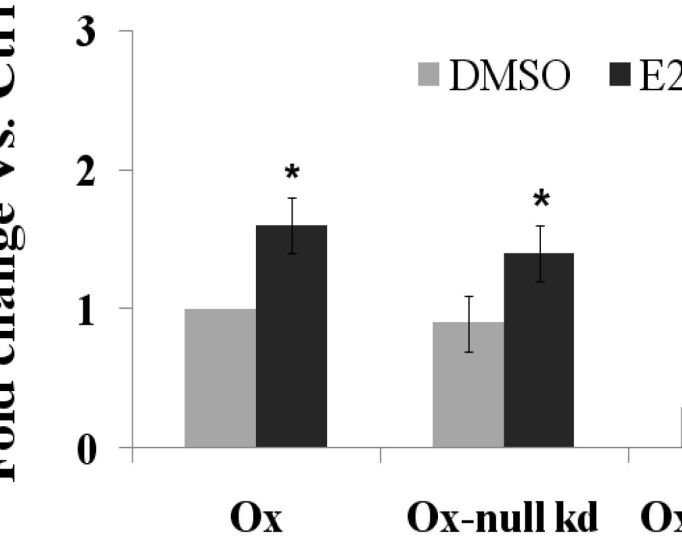
Fig. 9. NRF1 over-expression modulates invasion of MCF-7 cells. MCF-7 cells were transfected with either Null vector (Vector) or NRF1 over-expressing vector (Ox). In a separate experiment, cells were also co-transfected with $\mathrm{Ox}, \mathrm{Ox}+$ vector, $\mathrm{Ox}+\mathrm{NRF} 1$ knockdown plasmids $(\mathrm{Ox}+\mathrm{Kd}) .1 .0 \times 10^{4}$ cells were seeded on matrigel invasion chamber with $8.0 \mu \mathrm{M}$ pore size and $10 \%$ FBS media with or without $100 \mathrm{pg} / \mathrm{ml}$ estrogen were added to the bottom of wells as chemoattractant. Cells were cultured for $72 \mathrm{hrs}$ in CO2 incubator. Invaded cells at bottom of wells were stained and images were acquires with Nikon microscope over 20x objective, and metamorph software. Data represents invaded cells over 5 fields, +/- SD. (A)Invasion of NRF1ox expressing cells; i) DMSO, ii) vector, iii) NRF1ox. (B) Invasion of Co-transfected NRF1ox plasmid with or without estrogen as chemoattractant; i) $\mathrm{Ox}+\mathrm{DMSO}$, ii) $\mathrm{Ox}+\mathrm{E} 2$, iii) $\mathrm{Ox}+$ vector+DMSO, iv) $\mathrm{Ox}+$ vector+E2, v) $\mathrm{Ox}+\mathrm{NRF} 1 \mathrm{kd}+\mathrm{DMSO}$, vi) $\mathrm{Ox}+\mathrm{NRF} 1+\mathrm{E} 2$. (*) indicates treatment significantly different from Ox/DMSO. (**) indicates treatment significantly different from Ox/Null/E2. (*\#) indicates treatment significantly different from Ox/Null/DMSO. $(\mathrm{P}<0.05)$ 


\title{
CHAPTER VI
}

\section{THE ACTIVATION OF NRF1 BY ESTROGEN IS NECESSARY FOR BREAST CELL SUSCEPTIBILITY TO DEVELOP A MALIGNANT PHENOTYPE AND FOR INVASIVE GROWTH OF BREAST TUMORS \\ Victor O. Okoh, Alok Deoraj, Jai Parkash and Deodutta Roy \\ Department of Environmental and Occupational Health; Stempel College of Public \\ Health and Social Work}

Florida International University. Miami F1. 33199

\begin{abstract}
Understanding the contribution of NRF1 activation to the susceptibility for the development of malignant phenotype cells by estrogen is the focus of this study. Consistent with the redox-sensitivity of NRF1, 4-OH-E2-induced NRF1 expression and its phosphorylation and acetylation were inhibited by the glutathione peroxidase mimic, ebselen and by overexpression of ROS modifying genes, catalase and MnSOD. NRF1 was bound to the promoters of the cell cycle genes pcna, cyclin b1, and cdc $25 \mathrm{c}$, and prc 1 , confirming the prediction that these promoters contain NRF1 elements. The exposure of MCF10 A cells to a carcinogenic dose of 4-OHE2 increased the binding of NRF1 to the promoters of these genes and that 4-OHE2-induced binding could be inhibited by cotreatment with ebselen (antioxidant), or over expression of catalase ( $\mathrm{H} 2 \mathrm{O} 2$ scavenger). These results suggest that 4-OH-E2-generated oxidants, particularly $\mathrm{H} 2 \mathrm{O} 2$, may mediate NRF1 binding to these gene promoters. Decreasing NRF1 protein levels via specific siRNA Knock down of NRF1, PCAF and AKT inhibited 4-OH-E2 induced generation of malignant phenotype. Together, these data suggest that ROS accelerate cell-cycle progression and anchorage-independent growth in 4-OH-E2-transformed cells by
\end{abstract}


controlling the expression of cell cycle genes in an NRF1-dependent manner. In summary, estrogen-mediated activation of a redox sensitive signaling pathway regulates NRF1 phosphorylation and acetylation events. These two events enhance its activating function by increasing its localization close to nuclear targets and its affinity for promoters of target genes. This, in turn, contributes to the susceptibility of normal breast epithelial cells to develop malignant phenotype.

\section{INTRODUCTION}

NRF1/ $\alpha$-PAL (nuclear respiratory factor-1/ $\alpha$-palindrome-binding protein) is a transcription factor (1-3). Initially, this transcription factor was mostly famous for controlling nuclear-mitochondrial interactions that coordinate regulation of nuclear and mitochondrial genes during organelle biogensis. A genome-wide analysis has revealed that NRF1 binding elements are present in genes involved in DNA replication, mitosis, and cytokinesis, suggesting that NRF1 plays an important role in cell cycle regulation $(4,5)$. Interestingly, the NRF1 recognition site is one of the seven transcription factor binding sites which are most frequently found in the proximal promoters of ubiquitous genes, indicating a broader spectrum of target genes for NRF1. NRF1 overexpression has been observed in hepatoma, neuroblastoma and thyroid oncocytoma (6-8). In B cell chronic lymphocytic leukemia (CLL) patients, the mRNA expression of the mitochondrial biogenesis factors NRF1 and TFAM in the majority of leukemic cells is higher than normal lymphocytes (9). While there are more than 20 Oncomine studies with NRF1 over expression, the (actual) role NRF1 plays in breast cancer remains the least studied of all transcription factors. We have recently meta-analyzed 18 published 
breast cancer microarray data (10). From our study, we found that: 1) NRF1 was significantly overexpressed in ER+ tumors compared to ER- tumors; and 2) NRF1 was significantly overexpressed as breast tumor's grade increased. Investigation of the role of NRF1 in breast carcinogenesis is the central focus of this study.

Elevated lifetime estrogen exposure is a well-known major risk factor for breast cancer, however the underlying mechanisms of breast susceptibility to estrogen's carcinogenic effect remain elusive. In human breast cancer cells, the expression of almost $15 \%$ of the genes significantly affected by E2 contains the NRF1 binding element, and the NRF1 binding signature is significantly enriched in the promoters of genes induced by estrogen treatment (11). Recently, Klinge's group reported that the NRF1 promoter contains a half imperfect ERE, and E2 stimulates NRF1 expression (12) through the ER pathway. Motifs bound by ELK1, E2F, NRF1 and NFY positively correlate with malignant progression of breast cancer (13). From these studies, it appears that NRF1 may contribute to estrogeninduced malignant transformation of breast epithelial cells. Therefore, we first investigated in this study whether NRF1 influences the susceptibility of the breast epithelial cells to develop tumors in response to exposure to a well known major breast cancer risk factor, estrogen. 4-OH-E2 is the most prevalent E2 metabolite in human breast tumor tissues, with tumor tissue concentrations exceeding normal tissue concentrations by several folds (14-16). Moreover, 4-OH-E2 is strongly carcinogenic, while E2 is weakly carcinogenic and the other E2 metabolite, 2-OH-E2, is noncarcinogenic. Based on these data, 4-OH-E2 was used as the main model compound in 
this study to produce malignant phenotype in breast epithelial cells differentially expressing NRF1.

NRF1 is highly redox sensitive protein $(17,18-22)$. Similar to the other transcription factors, the activation of NRF1 is essential for its optimal binding to the promoters of target genes. NRF1 can bind to DNA in the absence of its phosphorylation. However, both phosphorylation and acetylation increase NRF1 DNA binding to the promoters and transcriptional activation $(23,24)$. We and others have shown that estrogen exposure to breast cells produce reactive oxygen species (ROS) $(18,25,26,27)$. We have shown that NRF1 binding to its promoter is inhibited by mitochondrial inhibitors as well as by antioxidants (18). Thus, estrogen-generated ROS may also regulate NRF1 expression. Therefore, we also examined whether a carcinogenic dose of 4-OH-E2 increases NRF1 phosphorylation and acetylation in MCF-10A cells and that these changes are inhibited by antioxidants or overexpression of catalase. Our findings revealed that activation of NRF1 by phosphorylation and acetylation depended on estrogen-induced ROS formation. This is essential for NRF1 to contribute to the susceptibility of breast epithelial cells to estrogen's carcinogenic effect. We further determined whether NRF1 over-expression converts non-aggressive breast tumors to aggressive and invasive tumors, and a dominant negative suppressor of NRF1 is sufficient to prevent aggressive and invasive tumor formation in vivo. We confirmed our in vitro findings of the role of NRF1 in breast cancer invasion by in vivo. 


\section{MATERIALS AND METHODS}

\section{Reagents}

17ß-Estradiol (E2), 2-hydroxyestradiol (2-OH-E2), 4-hydroxyestradiol (4-OH-E2), Ebselen, N-acetyl-cysteine (NAC), Dimethylsulfoxide (DMSO) were all purchased from Sigma (St Louis, MO, USA). All antibodies; PI3K (p110), phospho PI3K (p85), phospho-Akt (ser 473) and total Akt antibodies were purchased from Cell Signaling Technology Inc. (Boston, MA). All tissue cultures reagents were purchased from Invitrogen Corporation (CA) unless otherwise specified.

Culture of cells and MCcells and Adenovirus Gene Transfer Human mammary epithelial cells (MCF-10A) and breast cancer MCF-7 and MDA-MB 231 cells were obtained from American Type Culture Collection (ATCC). MCF-10A cells were routinely cultured in phenol red-free DMEM-F12 media (1:1) supplemented with $5 \%$ horse serum, hydrocortisone $(0.5 \mu \mathrm{g} / \mathrm{ml})$, insulin $(10 \mu \mathrm{g} / \mathrm{ml})$, epidermal growth factor $(20 \mathrm{ng} / \mathrm{ml}), 100 \mathrm{ng} / \mathrm{ml}$ cholera toxin and penicillin-streptomycin $(100 \mu \mathrm{g} / \mathrm{ml}$ each $)$ and incubated at $37^{\circ} \mathrm{C}$ in a humidified atmosphere containing $5 \% \mathrm{CO}$. Breast cancer cells were cultured in DMEM-F12 Media with $10 \%$ fetal calf serum. The cell culture media, serum, antibiotics, and growth supplements except cholera toxin (Calbiochem, La Jolla, CA) were purchased from Invitrogen Corp CA). For experimental purposes, culture media were changed to starvation media (serum free media + antibiotics) and allowed to incubate for $48 \mathrm{hrs}$ prior to commencement of most experiments, unless otherwise indicated. Serum deprivation synchronizes cells in the G0/G1 phase of the cell cycle. 
The Adenovirus-CMV (empty vector), Adenovirus-MnSOD (AdCMVMnSOD), and Adenovirus-Catalase (AdCMVCat) constructs were purchased from ViraQuest, Inc. (North Liberty, IA, USA). The adenovirus constructs used were replication-defective, E1- and E3-deleted recombinant adenovirus. Inserted into the E1 region of the adenovirus genome was either the human MnSOD or catalase gene, both of which are driven by a cytomegalovirus promoter. Cells were seeded in plates at $15 \%-70 \%$ confluence. The following day, cells were infected with Adenoviruses over-expressing MnSOD or catalase or vector at $100 \mathrm{MOI}$ in serum free media. Control cells were treated with 100 MOI of the adenovirus-CMV construct. This viral load were determined to achieve greater than $50 \%$ growth arrests of MCF-10A cells without significant cell death for duration of experiment. Infected cells were cultured for $48 \mathrm{hrs}$ after which cells were used for experiments.

\section{Akt1 and NRF1 RNAi transfections}

Pre-designed and verified human shRNA for Akt1 or NRF1 and corresponding null vector controls were purchased from OriGene (OriGene Technologies, Inc. Rockville, MD). Transfections of cells were carried out in sub-confluent cell population using FuGENE 6 (Roche) transfection reagents according to the manufacturer's protocol. Briefly, MCF10A cells were seeded in 6 well plates with growth factor supplemented media (SM) overnight. Post seeding, cells were transfected with $2 \mu$ l of Fugene-6 (Roche) preincubated for $20 \mathrm{~min}$ at room temperature with $0.5 \mu \mathrm{g}$ plasmid RNAi or its null controls (sham). Forty eight hrs post transfection, media were changed to serum-free (starvation media) media and incubated for additional $48 \mathrm{hrs,} \mathrm{after} \mathrm{which} \mathrm{cells} \mathrm{were} \mathrm{used}$ 
for various experiments. Transfection efficiencies ranged between $60-80 \%$ as quantified by decreased protein expressions levels.

\section{Cell viability assay}

CellTiter-Fluor ${ }^{\mathrm{TM}}$ Cell Viability kit was purchased from promega corporation and used according to manufacturer's instructions. Briefly, cells were seeded in 96 well plate at a density of 1.0x104 cells/well, serum starved for $48 \mathrm{hrs}$ and treated with estrogens or ROS modifiers. At the end of treatments procedure, substrate reagent (GF-AFC) were mixed with substrate buffer and dispensed into well. This assay measures protease activities in live cells as opposed to MTT or MTS assay kits that measure formations of formazon crystals by mitochondrial enzymes. Plates were read on a fluorescence plate reader at $380-400 \mathrm{~nm}$ excitation and $505 \mathrm{~nm}$ emission and data is expressed as mean of three experiments $+/-\mathrm{SD}$.

\section{Cell transformation}

The cell transformation was carried out by a modified protocol of Russo's group (18). Briefly, MCF-10A cells were seeded at $30 \%$ density in a $10 \mathrm{~cm}$ dish. After $24 \mathrm{hrs}$ of seeding, media were replaced with stavations media and allowed to culture for $48 \mathrm{hrs,}$ and then cells were subjected to two treatment cycles with E2 or its catechol metabolites. A treatment cycle includes $48 \mathrm{hrs}$ starvation period, $48 \mathrm{hrs}$ treatment period $(100 \mathrm{ng} / \mathrm{ml}$ of either E2, 2-OHE2, and 4-OHE2), and 48 hrs recovery period in growth media containing $10 \%$ horse serum (HS) and no growth suppliments. At the end of two treatments cycles, cells that would be used for immunoprecipitation and Western blot analysis were treated 
for additional 30 mins with estrogens, lysed with RIPA buffer, immunoprecipitated and processed for western analysis. For anchorage independent growth assay 5000 cells/well were used for colony formation assays in soft agar.

Anchorage independent Growth

Anchorage-independent growth, an indicator of neoplastic transformations of cells, was assessed soft agar assay. Briefly, base support agar were made fresh by diluting 1.0\% molten agarose mixed with 1:1 2x culture media (2x DMEM/F12 media, 20\% HS, 2x penstrep antibiotics and $200 \mathrm{pg} / \mathrm{ml}$ estrogens) to a final $0.5 \%$. Molten agar was left at 42 oC in a water bath until dispensed at $200 \mathrm{ul} /$ well in 48 well plates, then allowed to solidify for $4 \mathrm{hrs}$ at room temperature. Top agarose overlay were made fresh by mixing $0.7 \%$ molten agarose with $2 \mathrm{x}$ culture media containing appropriate 5000 cells/well, then gently overlaid over base agar. Cells were incubated for a minimum of 21 days in $37^{\circ} \mathrm{C}$ incubator with 5\% CO2. Cultures were fed every week with top agar layer and colony formation was assumed when cell masses are 100 micron or greater as measured on a Nikon TE2000U inverted microscope (Nikon Corp., USA) with Metamorph software (Universal Imaging, USA), Images were acquired by using an Olympus C-5060 digital camera attached to the Nikon TE2000U inverted microscope with 4x objective. Four wells were enumerated for each groups and data expressed as mean of five wells +/- SD.

\section{Invasion Assay}

In order to determine invasiveness of cells NRF1 overexpressing, cells $(5.0 \times 103$ cells $/ \mathrm{ml}$ ) were seeded over $8 \mu \mathrm{m}$ pore transwell filter insert (Transwell, Coastar Cambridge, MA) precoated with Matrigel (Collaborative Research, Bedford, MA). 
Chemoattractants used were reduced growth factor supplemented media or media with 10\% FBS media positive control cells MDA MB 231. Matrix invasion were allowed for $16 \mathrm{hrs}$ at $37{ }^{\circ} \mathrm{C}$ in a $\mathrm{CO} 2$ incubator. The non-invaded cells inside chambers were wiped off with a cotton swab, and the filters were fixed, stained by Diff Quick (Sigma, St. Louis, MO), cut out and mounted onto glass slides. The total number of cells that crossed the membrane were counted under a light microscope, enumerated and expressed as fold increase compared to parent cell line. The experiments were repeated five times and results are expressed as the mean \pm S.E.

\section{Chemical antioxidant treatments}

The treatment procedure for Ebselen (a glutathione peroxidase mimetic which also removes both $\mathrm{H} 2 \mathrm{O} 2$ and peroxynitrite) or NAC (a precursor of glutathione and scavenger of ROS) $(31,32)$ varies according to the experiments design. For all experiments, $40 \mu \mathrm{M}$ ebselen and 1.0 mM NAC were used for cell treatments. For example, in DCF assays, antioxidants were pre-loaded onto cells for 2-4 hrs before ROS measurement commences. For BrdU assays, cells were cultured with the chemical antioxidants throughout the experimental procedure. For transformation regimen, antioxidants were applied to cells each time cells were treated with estrogens. For anchorage independent growth assays, antioxidants were added to soft agar matrix media and during weekly feeding of colonies.

Immunoprecipitation and Western Blot Analysis

After the respective treatments, cells were rinsed twice with ice cold phosphate buffered saline (PBS), harvested with lysis buffer $(150 \mathrm{mM} \mathrm{NaCl}, 0.5 \%$ deoxycholate, $0.1 \%$ 
Nonidet P-40, $0.1 \%$ SDS, $50 \mathrm{mM}$ Tris) containing protease and phosphatase inhibitors (Roche). Samples were diluted to $500 \mu \mathrm{g}$ of protein in $1 \mathrm{ml}$ of lysis buffer, and precleared for $1 \mathrm{hr}$ at $4{ }^{\circ} \mathrm{C}$ with $10 \mu \mathrm{l}$ of 1:1 slurry of protein A-agarose beads (Invitrogen Corp) in lysis buffer. After a brief centrifugation to remove pre-cleared beads, $2 \mu \mathrm{g}$ of desired capture antibodies were added to each supernatant and incubated on a rocking platform at $4{ }^{\circ} \mathrm{C}$ overnight and captured proteins were precipitated with $40 \mu 1$ of protein A-agarose beads for $2 \mathrm{hr}$. The beads were washed five times with lysis buffer and resuspended in $40 \mu \mathrm{L}$ sample loading buffer, subjected to electrophoresis and electroblotted onto a PVDF nylon membrane. Primary antibodies used for Western blots were diluted 1:1000 in phosphate buffered saline Tween-20, PBST and horseradish peroxidase-conjugated secondary antibodies were diluted 1:50,000 in PBST. Blots were treated with ECL reagents (Amersham Biotech), and proteins were detected by autoradiography. Band intensity was quantified with Bio-Rad Gel Doc Imaging System.

Immunofluorescence Labeling

MCF-10A cells were seeded and treated in chamber slides as indicated in legends to the figures. Post treatments, cells were fixed with ice cold methanol for 15mins, and permeabilized with $0.5 \%$ Triton X-100 for 30 . Cells were blocked with $1 \%$ normal goat sera for $1 \mathrm{hr}$ after which they were probed with antibodies diluted 1:500 for Akt and 1:500 for phospho Akt. Alexa Fluor labeled secondary antibody directed against Akt antibody was diluted 1:1000. The confocal fluorescence images were scanned on a Nikon TE2000U inverted fluorescence microscope equipped with a Nikon D-Eclipse C1 laser scanning confocal microscope system (Nikon Corp., USA). The z-series scanning were 
done at every $1 \mu \mathrm{m}$ up to a z-depth of $10 \mu \mathrm{m}$ by using a Nikon $40 \times 1.30 \mathrm{NA}$ DIC H/N2 Plan Fluor oil immersion objective. The built-in Nikon EZ-C1 software was used for confocal image acquisition and analyses.

\section{RESULTS}

Estrogen-induced ROS regulate NRF1 expression: Recently, Klinge's group reported that the NRF1 promoter contains a half imperfect ERE, and E2 stimulates NRF1 expression (12) through the ER pathway. ROS is an important mediator of mitochondrial biogenesis by controlling the expression of the nuclear respiratory factor- 1 and mitochondrial transcription factor A. NRF1 expression is increased by menadione, lipopolysaccharide (LPS), tertiary butyl hydroperoxide (t-BH), and H2O2 $(19,20)$. Using physiologically achievable E2 concentration of $1 \mathrm{nM}$, which corresponds to the estrogenic menstrual peak, we have shown that E2 induces rapid formation of ROS in MCF-7 cells $(21,22)$. Therefore, we tested the effect of carcinogenic regimen of 4-OH-E2 on the NRF1 expression in presence of ROS modifiers. The expression of NRF1 was increased by several folds by 4-OH-E2 and this increase in the expression of NRF1 was inhibited by over-expression of catalse and MnSOD and co-treatment with Ebselen (Figures 1 and 2). This indicated that 4-OH-E2-induced NRF1 expression is redox sensitive.

The exposure of MCF-10A cells to carcinogenic dose regimen of 4-OH-E2 increased the phosphorylation and acetylation of NRF1 (Figures 3-5). Both phosphorylation and acetylation of NRF1 by two independent signaling molecules may control NRF1 activation. We assessed phosphorylation and acetylation of NRF1 by Western blotting 
and confocal microscopy after treating MCF-10A cells with 4-OH-E2 in serum-free medium in the same condition that produces malignant phenotype. Cell lysates were immunoprecipitated with NRF1 antibody, resolved on an gel, transferred to a membrane, and probed individually with anti-serine, anti-lysine, anti-AKT, anti-NRF1 and antiPCAF antibodies. In addition to increased phosphorylation and acetylation of NRF1 by 4OH-E2 treatment, we also detected AKT and PCAF in the NRF1 immunoprecipitates (Fig. 3 and 4). 4-OH-E2 exposure to MCF-10A cells induced serine phosphorylation of NRF1 and overexpression of catalase and MnSOD blocked 4-OH-E2-induced phosphorylation of serine residues on NRF1. NRF1 phosphorylation preceded P/CAF recruitment for acetylation, because silencing of AKT prevented acetylation of NRF1.

The exposure of MCF-10A cells to a carcinogenic dose of 4-OH-E2 increased NRF1 binding to the gene promoters for the cell cycle regulators cyclin B1, Cdc25c, and Pcna: MCF-10 A (5x105 cells /dish) were seeded, grown for $24 \mathrm{hrs,} \mathrm{serum} \mathrm{starved} \mathrm{for} \mathrm{another}$ $24 \mathrm{hrs}$, and transfected with NRF1, PCAF, and AKT RNAi, as well as with AdMnSOD (MnSOD) and Adcatalase (Cat). They were then treated with ebselen using the cell transformation condition as described above, and then treated with 4-OH-E2. In a preliminary ChIP analysis, we found that NRF1 is bound to the promoters of the cell cycle genes Pcna, Cyclin B1, and Cdc25c, confirming the prediction that these promoters contain NRF1 elements (Fig. 6). We also found that the exposure of MCF-10A cells to a carcinogenic dose of 4-OH-E2 increased the binding of NRF1 to the promoters of these genes, and that 4-OH-E2-induced binding could be inhibited by cotreatment with ebselen (antioxidant), by an over expression of catalase (H2O2 scavenger) and MnSOD, and by 
RNAi of NRF1, PCAF and AKT. These results suggest that 4-OH-E2-generated oxidants, particularly $\mathrm{H} 2 \mathrm{O} 2$, may mediate NRF1 binding to these gene promoters.

Silencing of NRF1 and its interacting partners (PCAF or AKT) prevented 4-OH-E2induced anchorage-independent growth of MCF-10A cells: 4-OH-E2 treatment was able to induce AIG positive colony formation (Figures 2-4 and 7); and in NRF1, AKT, or PCAF RNAi silenced cells, 4-OH-E2 was not able to produce any colony. The effects of 4-OH-E2 on colony formation in cells transfected with scrambled RNAi of NRF1, PCAF, and AKT were similar to WT cells. This indicates that 4-OH-E2-dependent anchorageindependent growth of MCF-10A cells is dependent on NRF1 signaling.

\section{DISCUSSIONS}

The novel finding emerged from this study are that the increased expression of NRF1 renders support to the growth of MCF-7 cells to form tumors in vivo. Alternatively, the knockdown of NRF1 blocks the ability of invasive ER-MD-MBA-231 breast cancer cells to form aggressive tumors or prevents these cells to metastasize to other organs. Phosphorylation and acetylation of NRF1, which are redox sensitive, enhanced its binding to promoter consensus sequences of cell cycle genes and subsequently, transcriptional activation. Therefore, it is plausible that phosphorylation and acetylation of NRF1 could contribute to the growth as well as invasiveness of the breast tumor.

Recent studies show several genes with the ability to transform normal cells to malignant cells that are direct downstream targets of NRF1 (HP1 $\alpha$, SMYD3, CAPNS1) $(28,29,30)$. 
The overexpression of a NRF1 regulatable gene, heterochromatin protein 1 alpha (HP1 $\alpha$ ), involved in gene silencing produces genomic instability in cells (31-33), which is essential for cell transformation. Similarly, overexpression of another NRF1 transcription target gene, SMYD3, produces transformed phenotypes (34). Since these genes are overexpressed in human breast cancer tissues, we postulate that these NRF1 regulatable genes alone or in concert with others may contribute to the estrogen-induced malignant phenotype. Recently, Klinge's group reported that the NRF1 promoter contains a half imperfect ERE, and E2 stimulates NRF1 expression (12) through the ER pathway in MCF-7 cells. Even if a small amount of ER $\beta$ present in ER $\alpha$ negative MCF-10A cells is involved in an increased synthesis of NRF1, it would not explain how increased localization close to nuclear targets or enhanced ability to bind to the promoters of target genes will be achieved upon estrogen exposure. Furthermore, ER signaling may be under the influence of NRF1 through its target gene, SMYD3. SMYD3 functions as a coactivator of $\mathrm{ER} \alpha$ and potentiates ER $\alpha$ activity in response to its ligand (35).

We have shown that NRF1 binding to its promoter is inhibited by mitochondrial inhibitors as well as by antioxidants (18). We and others have shown that estrogen exposure to breast cells produce reactive oxygen species (ROS) $(18,25-27)$.Thus, estrogen-generated ROS may also regulate NRF1 expression. Both phosphorylation and acetylation of NRF1 protein control its activation $(23,24)$. NRF1 has been shown to be phosphorylated by redox sensitive kinases p38MAPK, ERK, and AKT $(19,20)$ and acetylated by P/CAF. The protein tyrosine phosphatases (PTPs) which control ERK and AKT phosphorylation and histone deacetylases which control histone acetyl transferase 
(HAT) activity of P/CAF are highly sensitive to ROS (35-41). The oxidation of PTEN's active site by ROS makes them inactive, which, in turn, stop dephosphorylation of PI3K to occur and thus result in an active AKT (PKB) (42-46). In fact, a higher activation of stress-activated protein kinases has been reported in E2-treated MCF-7 cells, which is considered to contribute to the E2-proliferative effect (47). Thus, estrogen-generated ROS may inactivate PTEN leading to an active phosphorylated PI3K. Subsequently, the active PI3K may activate AKT which will directly phosphorylate NRF1. By a similar mechanism histone decetylases, such as, HDAC3 and hSirT1, are inactivated by ROS (42-46), which in turn can allow P/CAF to acetylate NRF1. Our studies showed that a carcinogenic dose of 4-OH-E2 increased NRF1 phosphorylation and acetylation in MCF$10 \mathrm{~A}$ cells and that these changes were inhibited by antioxidants or overexpression of catalase. This suggests that phosphorylation and acetylation of NRF1, which are redox sensitive, enhance its binding to promoter consensus sequences and subsequently, transcriptional activation. Findings of this study further showed that NRF1 binding to the promoters of cell cycle genes, PCNA, cyclin B1 and Cdc25C was inhibited by knockdown of NRF1, PCAF and AKT by their shRNA. Therefore, it is plausible that phosphorylation and acetylation of NRF1 could contribute to the aggressiveness and invasiveness of the breast tumor. 


\section{LIST OF REFERENCES}

1. Evans, M. J. and Scarpulla, R. C. NRF1: a trans-activator of nuclear-encoded respiratory genes in animal cells. Genes Dev. 4, 1023-1034, 1990.

2. Huo L, Scarpulla RC.Mitochondrial DNA instability and peri-implantation lethality associated with targeted disruption of nuclear respiratory factor 1 in mice. Mol Cell Biol. 21, 644-54, 2001.

3. Roy D, Tamuli R . NRF1 (nuclear respiratory factor 1). Atlas Genet Cytogenet Oncol Haematol.2008,URL http://AtlasGeneticsOncology.org/Genes/NRF1ID44233ch7q32.html

4. Elkon R, Linhart C, Sharan R, Shamir R, Shiloh Y. Genome-wide In Silco identification of transcription regulators controlling the cell cycle in human cells. Genome research, 13, 773-780, 2003

5. Cam H, Balciunaite E, Blais A, Spektor A, Scarpulla RC, Young C, Kluger Y, Dynlacht BD. A common set of gene regulatory networks links metabolism and growth inhibition. Mol Cell, 16, 399-411, 2004.

6. Dong X , Ghoshal K, Majumder S, Satya P. Yadav, and Samson T. Jacob. Mitochondrial transcription factor $\mathrm{A}$ and its downstream targets are upregulated in a rat hepatoma J. Biol. Chem., 277, 43309-43318, 2002

7. Savagner F et al.. PGC-1-related coactivator and targets are upregulated in thyroid oncocytoma. Biochem Biophys Res Commun, 310, 779-784, 2003.

8. Kunkle, B., Q. Felty, G. Narasimhan, F. Trevino, D. Roy. Meta-analysis of brain tumor microarray data using Oncomine identifies NRF1, Tfam and Myc co-expressedgenes: its implications in the development of childhood brain tumors. Proceeding chapter, 18th World IMACS / MODSIM Congress, 2009, http://www.mssanz.org.au/modsim09/B6/kunkle_B6b.pdf

9. Carew JS, S T Nawrocki, R H Xu, K Dunner Jr, D J McConkey, W G Wierda, M J Keating and $\mathrm{P}$ Huang. Increased mitochondrial biogenesis in primary leukemia cells: the role of endogenous nitric oxide and impact on sensitivity to fludarabine. Leukemia 18, 1934-1940, 2004.

10. Kunkle, B., Q. Felty, F. Trevino, D. Roy, Meta-analysis of breast cancer microarray data identifies upregulation of NRF1 expression in human breast carcinoma. Proceeding chapter, 18th World IMACS / MODSIM Congress, 2009, http://www.mssanz.org.au/modsim09/B6/kunkle_B6a.pdf 
11. Scafoglio $\mathrm{C}$ et al.,. Comparative gene expression profiling reveals partially overlapping but distinct genomic actions of different antiestrogens in human breast cancer cells. J Cell Biochem 98,1163-84, 2006.

12. Mattingly KA, Margarita M. Ivanova, Krista A. Riggs, Nalinie S. Wickramasinghe, Margaret J. Barch and Carolyn M. Klinge. Estradiol stimulates transcription of nuclear respiratory factor-1 and increases mitochondrial biogenesis. Molecular Endocrinology 22, 609-622, 2008.

13. Niida A, Smith AD, Imoto S, Tsutsumi S, Aburatani H, Zhang MQ, Akiyama T. Integrative bioinformatics analysis of transcriptional regulatory programs in breast cancer cells. BMC Bioinformatics 9, 404-410, 2008

14.Castagnetta L, Granata OM, L Cocciadiferro, A Saetta, L Polito, G Bronte, S Rizzo, I Campisi, B Agostara, G Carruba: Sex steroids, carcinogenesis, and cancer progression. Ann N Y Acad Sci. 1028:233-46, 2004.

15. Castagnetta LAM, Granata OM, Traina A, Ravazzolo B, Amoroso M, Miele M, Bellavia V, Agostara B, and Carruba G Tissue content of hydroxyestrogens in relation to survival of breast cancer patients. Clinical Cancer Res 8, 3146-3155, 2002.

16. Rogan EG, Badawi AF, Devanesan PD, Meza JL, Edney JA, West WW, Higginbotham SM, Cavalieri EL. Relative imbalances in estrogen metabolism and conjugation in breast tissue of women with carcinoma: potential biomarkers of susceptibility to cancer. Carcinogenesis 24: 697-702, 2003.

17. Felty Q, Roy D. Estrogen, mitochondria, and growth of cancer and non-cancer cells. J Carcinog. 15, 4, 1, 2005.

18. Felty Q, Xiong WC, Sun D, Sarkar S, Singh KP, Parkash J, Roy D. Estrogen-Induced mitochondrial reactive oxygen species as signal-transducing messengers. Biochemistry 44, 6900-6909, 2005.

19. Piantadosi CA, Suliman HB. Mitochondrial transcription factor A induction by redox activation of nuclear respiratory factor 1.J Biol Chem. 281, 324-33, 2006.

20. Hagir B. Suliman, Martha S. Carraway, Karen E. Welty-Wolf, A. Richard Whorton and Claude Piantadosi Lipopolysaccharide Stimulates Mitochondrial Biogenesis via Activation of Nuclear respiratory Factor-1 J. Biol. Chem., 278, 41510-41518, 2003

21. Felty Q, Singh KP, Roy D. Estrogen-induced G(1)/S transition of $G(0)$-arrested estrogen-dependent breast cancer cells is regulated by mitochondrial oxidant signaling. Oncogene 24, 4883-93, 2005. 
22. Parkash J, Felty Q, and Roy D Estrogen Exerts a Spatial and Temporal Influence on Reactive Oxygen Species Generation that Precedes Calcium Uptake in High-Capacity Mitochondria: Implications for Rapid Nongenomic Signaling of Cell Growth. Biochemistry 45, 2872-81, 2006.

23. Gugneja, S. and Scarpulla, R. C. Serine phosphorylation within a concise aminoterminal domain in nuclear respiratory factor 1 enhances DNA binding. J. Biol. Chem. $272,18732-18739,1997$

24. Izumi H, Ryo Ohta, Gunji Nagatani, Tomoko Ise, Yoshifumi Nakayama, Minoru Nomoto, and Kimitoshi Kohno. p300/CBP-associated factor (P/CAF) interacts with nuclear respiratory factor-1 to regulate the UDP-N-acetyl-alpha-d-galactosamine: polypeptide N-acetylgalactosaminyltransferase-3 gene. Biochem J, 373, 713-722, 2003.

25. Mobley, J. A. and Brueggemeier, R. W. Estrogen receptor-mediated regulation of oxidative stress and DNA damage in breast cancer. Carcinogenesis 25, 3-9, 2004.

26. Sastre-Serra JJ, Adamo A Valle, Maria Margarita, Isabel I Garau, Jordi J Oliver and Pilar P Roca. Estrogen down-regulates uncoupling proteins and increases oxidative stress in breast cancer. Free Rad Biol Med, Ahead of Print , 2009

27. Perillo B, Ombra MN, Alessandra Bertoni, Concetta Cuozzo, Silvana Sacchetti. Annarita Sasso, Lorenzo Chiariotti, Antonio Malorni, Ciro Abbondanza, Enrico V. Avvedimento. DNA Oxidation as triggered by $\mathrm{H} 3 \mathrm{~K} 9 \mathrm{me} 2$ demethylation drives estrogeninduced gene expression. Science 319, 202-206, 2008

28. Lieberthal, JG., Marissa Kaminsky, Christopher N Parkhurst and Naoko Tanese. The role of YY1 in reduced HP1 $\alpha$ gene expression in invasive human breast cancer cells. Breast Cancer Res, 11, R42, 2009

29. Irfan A. Asangani, Suhail A.K. Rasheed, Jörg H. Leupold, Stefan Post and Heike Allgayer. NRF1, and AP-1 regulate the promoter of the human calpain small subunit 1 (CAPNS1) gene. Gene, 410, 197-206, 2008

30. Furukawa Y, Nakamura Y. International Patent WO/ 2006/121208. Polymorphisms of the E2F-1 binding element and methods of determining cancer susceptibility. http://www.wipo.int/pctdb/en/wo.jsp

31. De Koning $\mathrm{L}$ et al. Heterochromatin protein 1 : a hallmark of cell proliferation relevant to clinical oncology. EMBO Mol Med, 1 (3), 178 - 191, 2009 32. Sharma, GS et al. Human Heterochromatin Protein 1 Isoforms HP1Hs and HP1Hs Interfere with hTERT-Telomere Interactions and Correlate with Changes in Cell Growth and Response to Ionizing Radiation. Mol Cellular Biol, 22-23, 8363-8376, 2003

33. Luo X-G, Tao Xi, Shu Guo, Zhi-Peng Liu, Nan Wang, Yong Jiang, Tong-Cun Zhang. Effects of SMYD3 overexpression on transformation, serum dependence, and apoptosis sensitivity in NIH3T3 cells. IUMBMB Life, 61, 679 - 684, 2009. 
34. Kim H, Kyu Heo, Jeong Hoon Kim, Kyunghwan Kim, Jongkyu Choi and Woojin An. Requirement of Histone Methyltransferase SMYD3 for Estrogen Receptor-mediated Transcription. J Biol Chem, 284, 19867-19877, 2009.

35. Preishl EE, Novotny V, Csonga R, Jaksche D et al. A novel splice variant of the transcriptional factor Nrfl interacts with the TNF alpha promoter and stimulates transcription. Nucleic Acid Res 26,2291-2297,1998.

36. Wang C, Zhiping Li, Yinan Lu, Runlei Du, Sanjay Katiyar, Jianguo Yang, Maofu Fu, Jennifer E. Leader, Andrew Quong, Phyllis M. Novikoff and Richard G. Pestell. Cyclin D1 repression of nuclear respiratory factor 1 integrates nuclear DNA synthesis and mitochondrial function. PNAS, 103, 11567-11572, 2006

37. Koichi Niwa et al Redox Regulation of PI3K/AKT and p53 in Bovine Aortic Endothelial Cells Exposed to Hydrogen Peroxide Antioxidants \& Redox Signaling 5, 713-722, 2003

38. Annette Salmeen, David Barford, Functions and Mechanisms of Redox Regulation of Cysteine-Based Phosphatases Antioxid Redox Signal 7, 560-577, 2005.

39. Lee, S.R., et al. Reversible inactivation of the tumor suppressor PTEN by H2O2. J. Biol. Chem. 277, 2 0336-20342, 2002.

40. Leslie, N.R., et al. Redox regulation of PI 3-kinase signalling via inactivation of PTEN. EMBO J. 22:5501-5510, 2003.

41. Connor, K.M., et al. 2005. Mitochondrial $\mathrm{H} 2 \mathrm{O} 2$ regulates the angiogenic phenotype via PTEN oxidation. J. Biol. Chem. 280:16916-16924.

42. Moodie FM, John A. Marwick, Charlotte S. Anderson, Patryk Szulakowski, Saibal K. Biswas, Mark R. Bauter, Iain Kilty, Irfan Rahman. Oxidative stress and cigarette smoke alter chromatin remodeling but differentially regulate NF-KappaB activation and proinflammatory cytokine release in alveolar epithelial cells, The FASEB J, 18, 18972001, 2004

43. Adcock IM, Borja Cosio, Loukia Tsaprouni, Peter J. Barnes, Kazuhiro Ito. Redox regulation of histone deacetylases and glucocorticoid-mediated inhibition of the inflammatory response. Anti Redox Signaling 7: 144-152, 2005.

44. Natalia Pediconi, et al. SirT1-Dependent regulation of the PCAF-E2F1-p73 apoptotic pathway in response to DNA damage. Mol Cell Biol 29, 1989-1998, 2009.

45. Brunet, A et al. Stress-Dependent Regulation of FOXO Transcription Factors by the SIRT1 Deacetylase. Science 303, $2011-$ 2015, 2004. 
46. Chang K, Nobuyuki Shimizu, Yuji Fukushima, Jeevendra Martyn, Masao Kaneki. iNOS Inactivates Sirt1, a Key Regulator of Stress Resistance and Metabolism, by SNitrosylation, Anesthesiology 105, A1067, 2006.

47. Nishina, H. et al. Physiological roles of SAPK/JNK signaling pathway. J Biochem 136,123-6, 2004. 


\section{FIGURES AND LEGENDS}
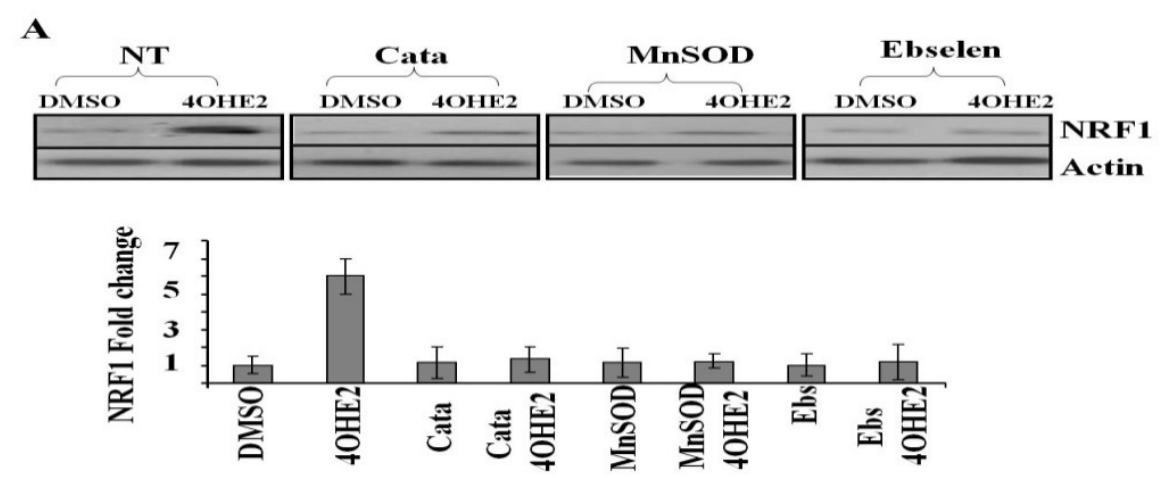

$\mathbf{B}$
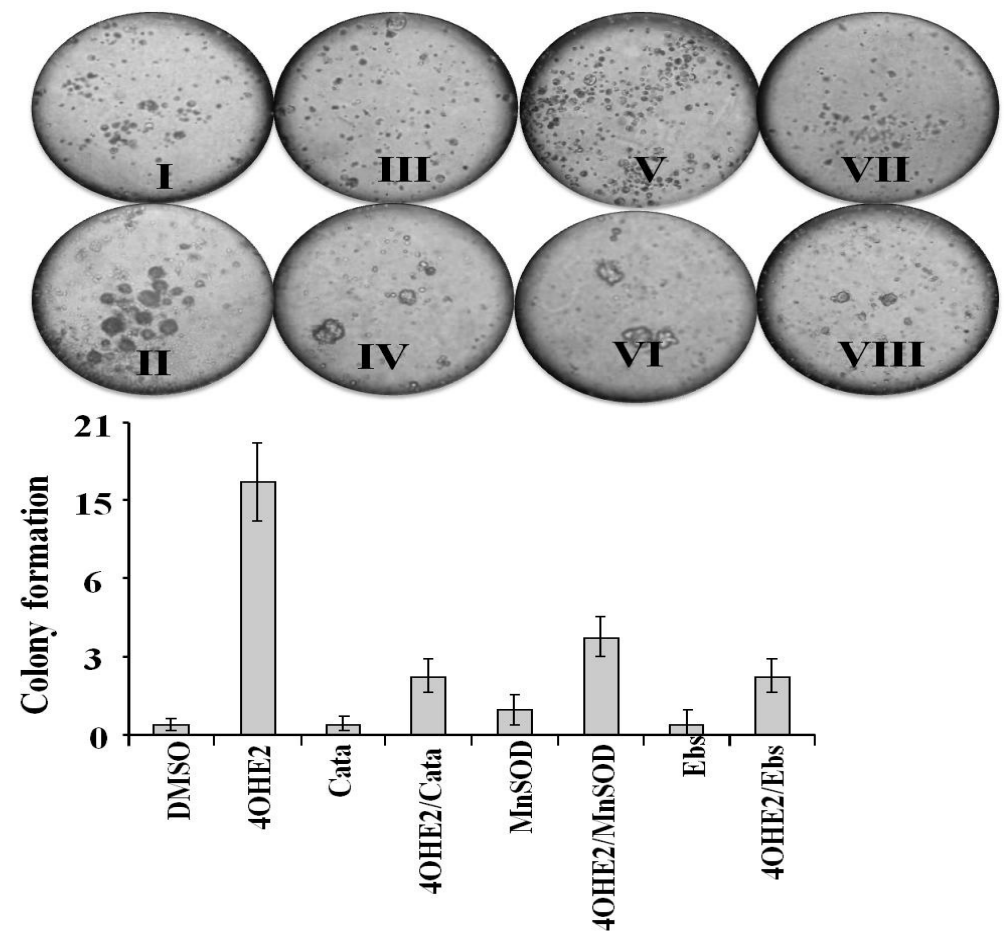

Fig. 1. Redox expression of NRF1 modulates 4OHE2 induced mammary transformation. MCF-10A cells were seeded for $24 \mathrm{hrs}$ and infected with Adenovirus overexpressing catalase, MnSOD, or null construct at moi 100. $24 \mathrm{hrs}$ post infection, cells were subjected to transformation regimen with or without $100 \mathrm{ng} / \mathrm{ml}$ estrogens. For groups treated with chemical antioxidant, these cells were co-treated with $40 \mu \mathrm{M}$ ebselen and estrogen for the duration of transformation protocol except during recovery period. Post transformation, cells were either lysed with RIPA buffer, fractionated on $12 \%$ SDS-PAGE gel, then blot probed for NRF1 and beta actin expression, or seeded for anchorage independent growth on soft agar. A) Immunoblot of transformed cells normalized to Null/DMSO and band intensity quantified with Biorad geldoc 2000. B) Representative picture of colony count 
per area in 24 well plate, normalized to Null/DMSO. Data expressed as mean of 3 experiments +/- $\mathrm{SE}, \quad(\mathrm{P}<0.05)$. (I) AdNull/DMSO, (II) AdNull/4OHE2, (III) AdCata/DMSO, (IV) AdCata + 4-OHE2, (V) AdMnSOD/DMSO, (VI) Ad/MnSOD+ 4OHE2, (VII) Ebselen, (VIII) Ebselen + 4-OHE2.

$\mathbf{A}$

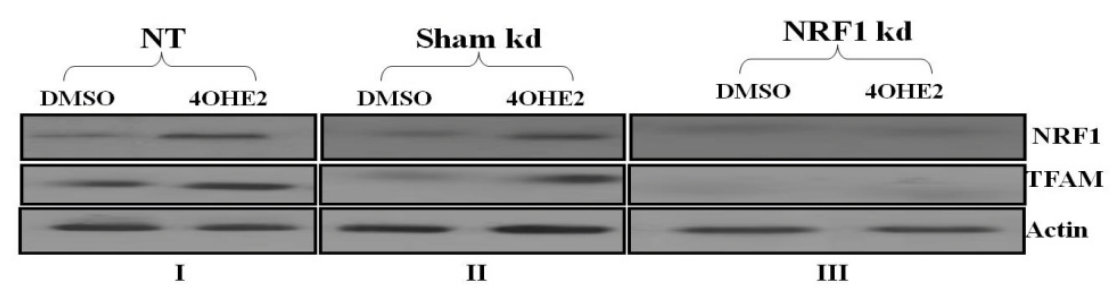

IV
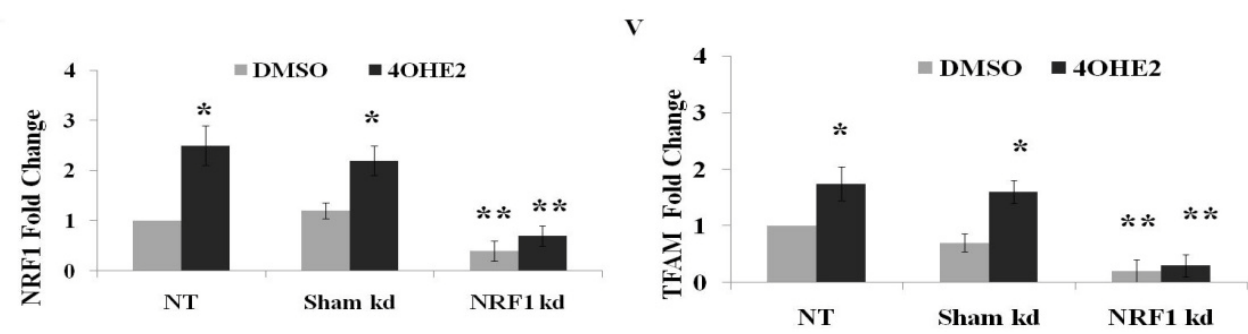

B
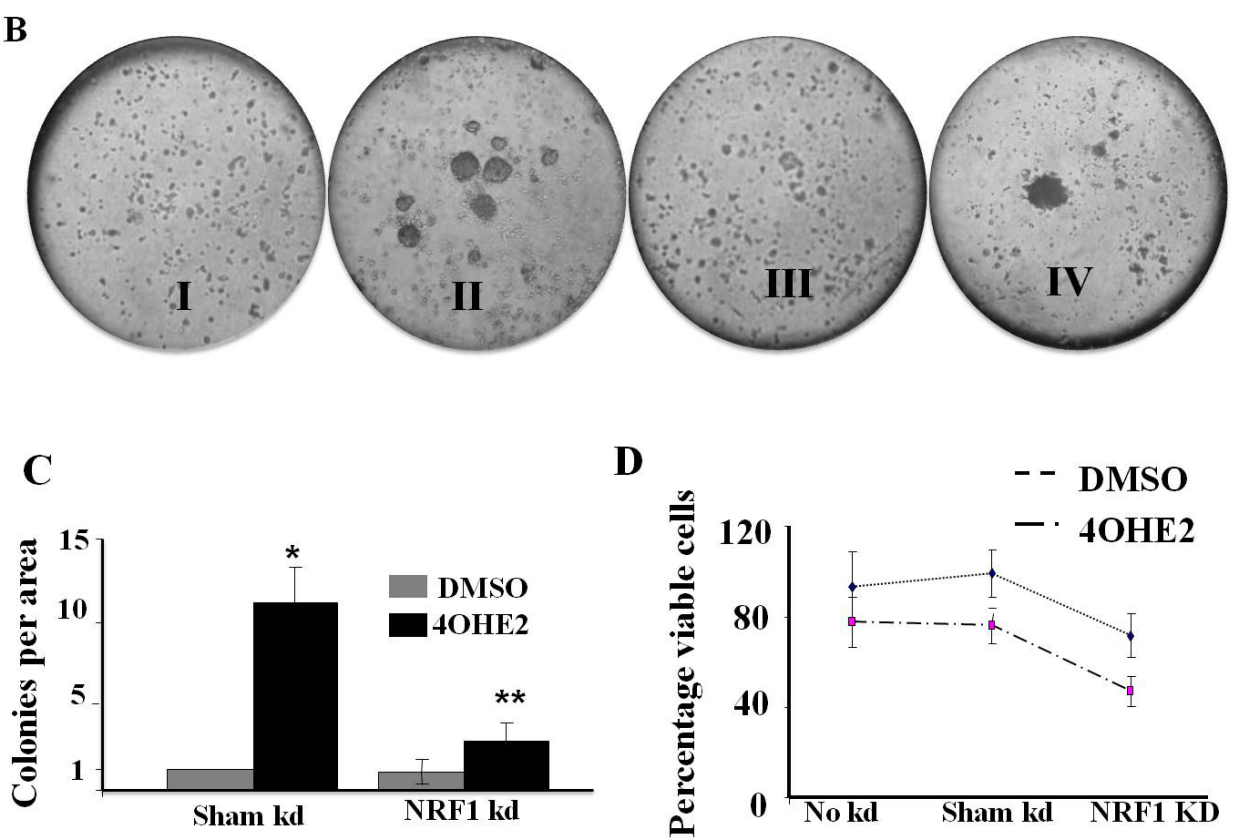

D

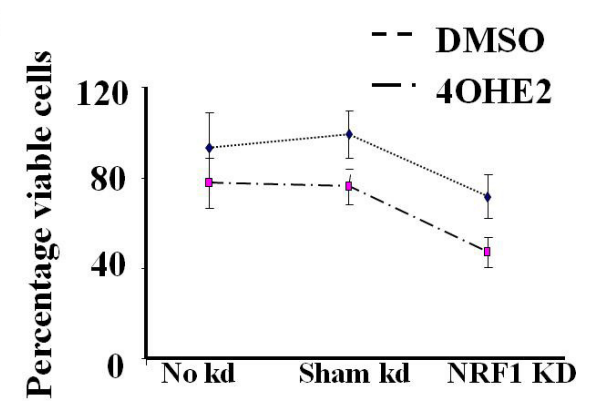

Fig. 2 NRF1 expression mediates 4OHE2 induced mammary tumorigenesis. MCF-10A cells were seeded at $20-30 \%$ confluency overnight and transfected with NRF1 shRNA or it corresponding null vector. Post transfection, cells were subjected to transformation regimen as previously described. Post transfection, cells were used for western blot analysis probed for NRF1, TFAM and actin expressions, or anchorage independent growth assay. A) Immunoblot of transformed cells normalized to non transfrected cells 
(NT)/DMSO and band intensity quantified with Biorad geldoc 2000. (I) immunoblot of non transfected (NT) cells; (II) immunoblot of null transfected cells (III), immunoblot of NRF1 shRNA transfected cells; (IV) Fold change of NRF1 expression normalized to NT/DMSO; (V) Fold change of TFAM expression normalized to NT/DMSO. (B,C) Colonies formed after 21 days in soft agar assay were enumerated and expressed as numbers colonies per area. Five areas from each well was averaged over 3 plates and expressed as mean, +/- SE. $(\mathrm{P}<0.05)$. $\quad(*)$ indicate significant difference from non transfected (NT/DMSO) group. (**) indicate significant difference from 4OHE2 treatment group. (D) Trypan blue cell viability assessment of single cell suspension from colony assay at the end of 21 days culture per 1000 cells.

A

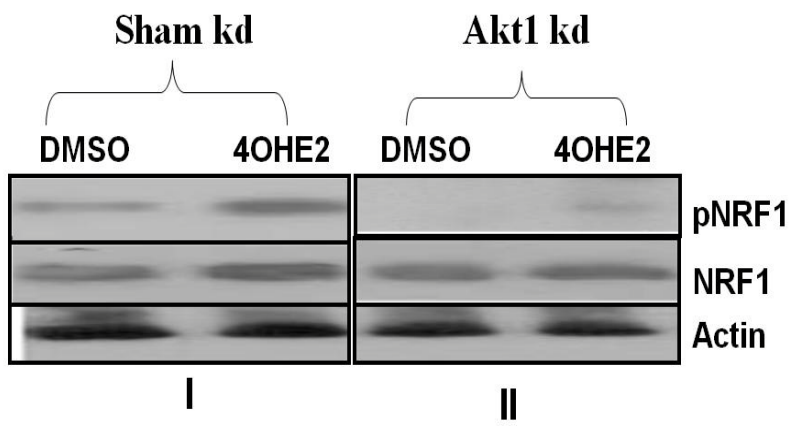

III
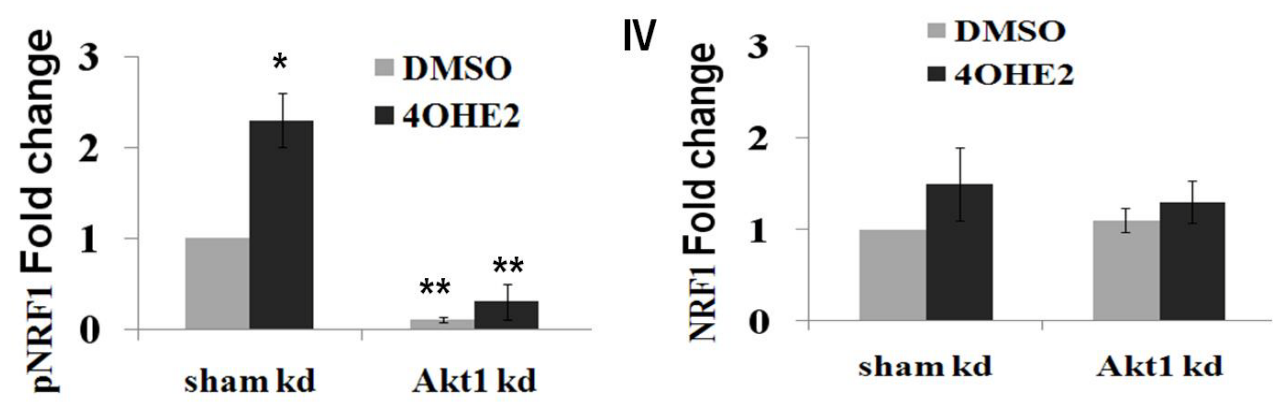


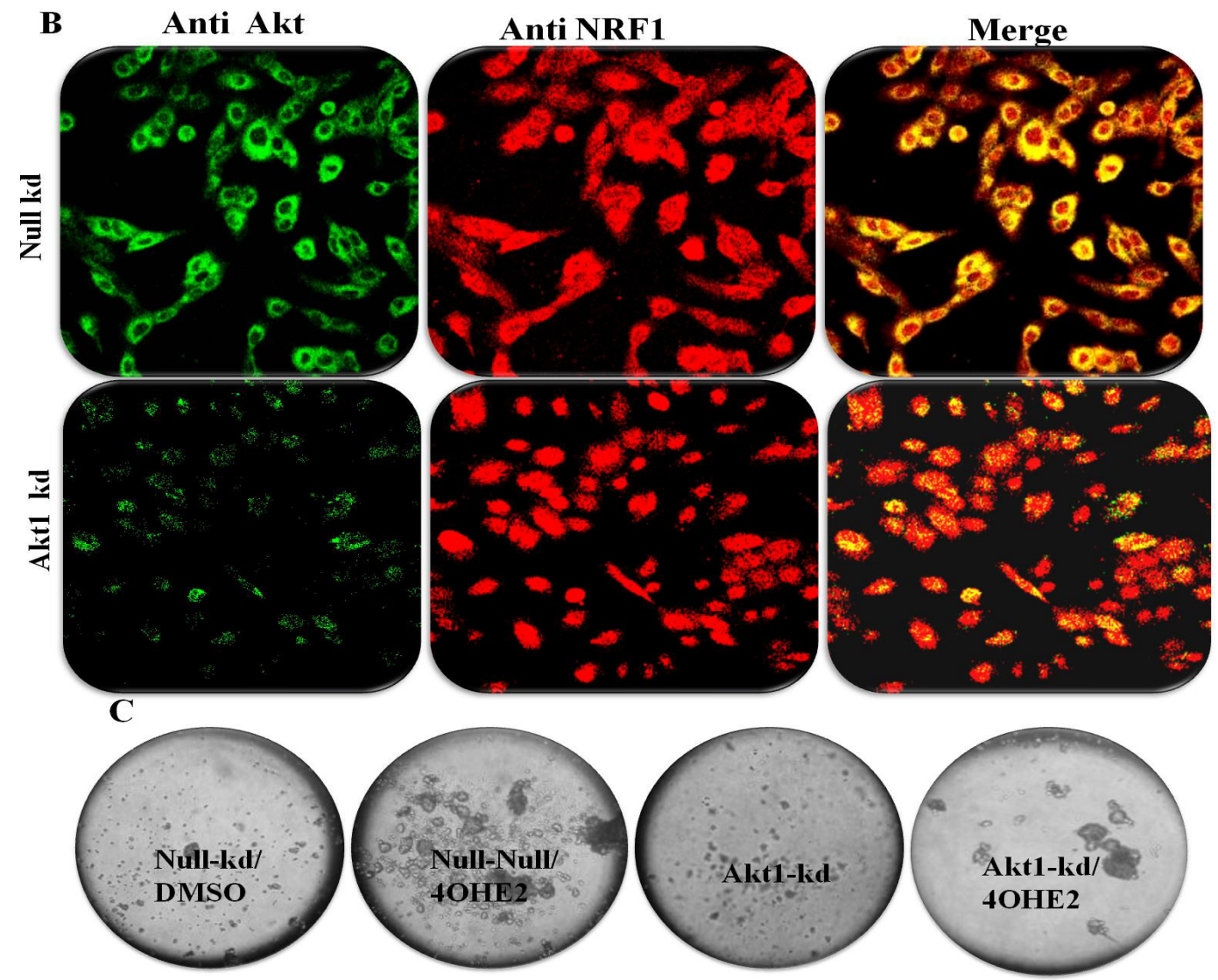

Fig. 3. Activation of Akt phosphorylate NRF1 during mammary tumorigenesis. Cells were transfected with Akt shRNA or null constructs, and then subjected to transformation regimen as previously described. Post transformation, cells were either treated with estrogen for additional $30 \mathrm{mins}$ and used for co-immunoprecipitation western blot analysis, or for used for colony assay. A) Western blot analysis of NRF1 immunoprecipitated proteins probed with anti phosphoserine (pNRF1) or anti NRF1 antibodies respectively. (I) Immunoblot of null transfected cells (sham); (II) immunoblot of Akt1 knockdown cells (Akt1-kd); (III) phosphorylated NRF1 fold change compared to sham/DMSO treated group; (IV) NRF1 expression fold change compared to NRF1 expression from sham/DMSO. Data expressed as mean of three experiments, +/- SE. $(\mathrm{P}<0.05)$. (*) indicate significant difference from null (sham/DMSO) group. $(* *)$ indicate significant difference from 4OHE2 treatment group. B) Immunoflorescence label of sham or Akt1-kd transformed cells probed for Akt (green) or NRF1 (red) expression. Yellow is co-localization of Akt and NRF1 expression. C) Anchorage independent growth assay of transformed cells transfected with sham or Akt shRNA. 
A
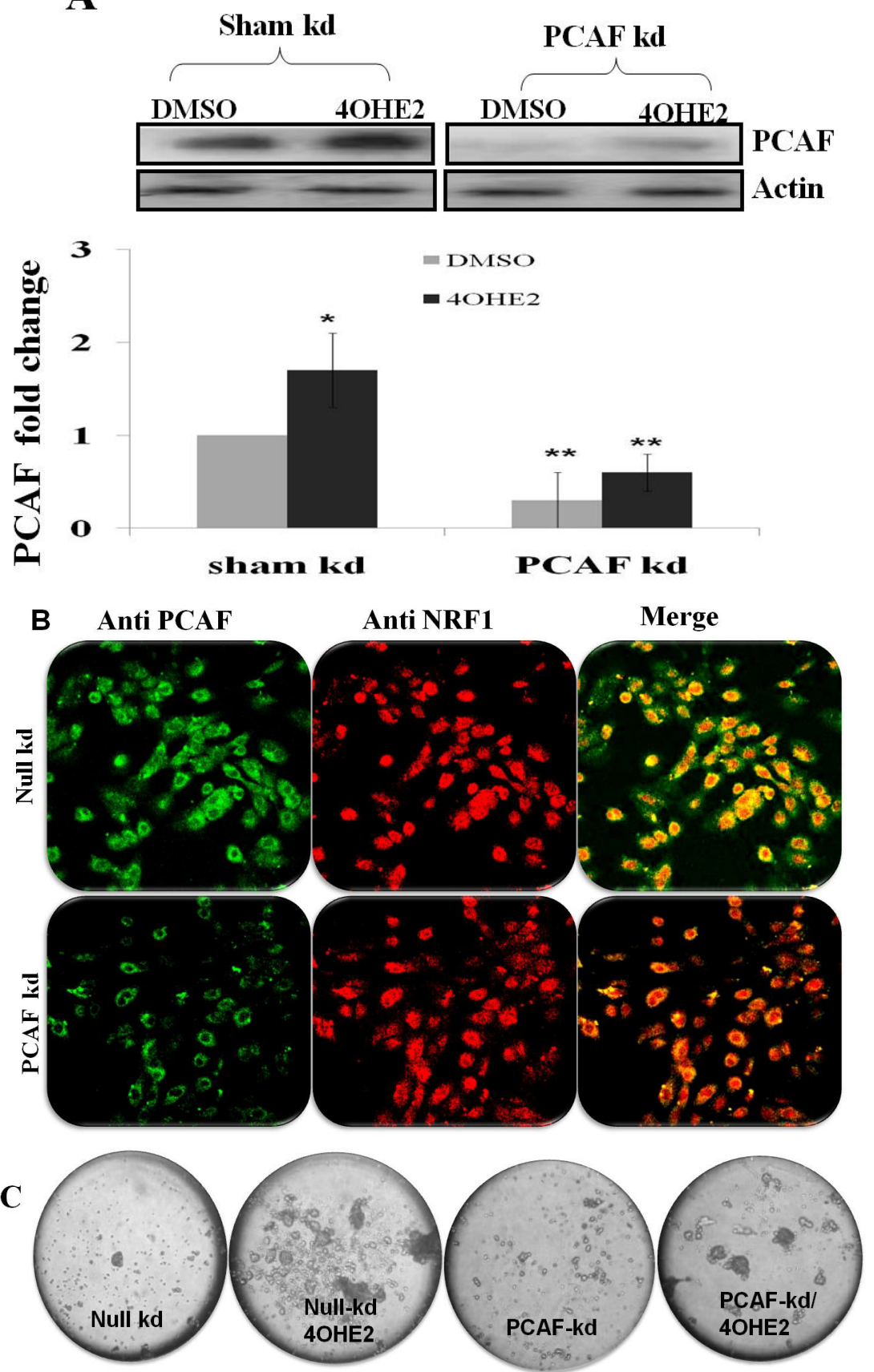

Fig. 4. PCAF expression participates in 4OHE2 induced mammary transformation. Cells were transfected with PCAF shRNA plasmid and cells were subjected to transformation regimen. Post transformation, cells were either treated with estrogen for additional 30 mins and used for western blot analysis, or seeded for colony assay formation and confocal immunoflorescence analysis. A) Immunoblot of sham or PCAF RNAi transfected cells and the fold change of PCAF expression compared to sham/DMSO treated group. Data expressed as mean of three experiments, +/- SE, $(\mathrm{P}<0.05) . \quad(*)$ indicate significant difference from null (sham/DMSO) group while $(* *)$ indicate 
significant difference from 4OHE2 treatment group. B) Immunoflorescence label of sham or PCAF-kd transformed cells probed for PCAF (green) or NRF1 (red) expression. Yellow is co-localization of PCAF and NRF1 expression. C) Anchorage independent growth assay of transformed cells transfected with sham or PCAF shRNA.
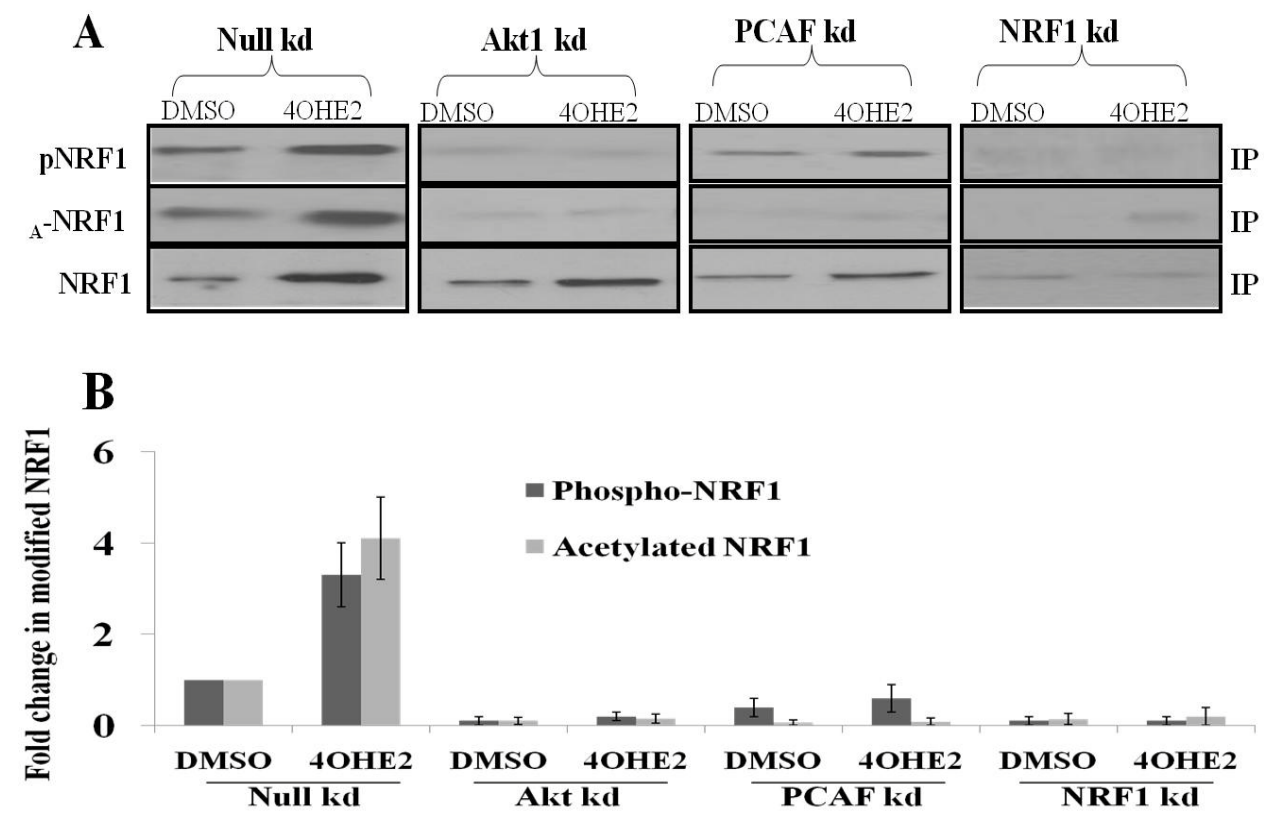

Fig. 5. Akt Phosphorylation of NRF1 induces its Acetylation during mammary transformation. MCF-10A cells were transfected with NRF1, Akt1, PCAF or null shRNA plasmids and the cells were subjected to transformation regimen as previously described. Post transformation, cells were treated with estrogen for additional 30 mins and lysed with RIPA buffer. $750 \mu \mathrm{g}$ of whole cell lysate (WCL) were immunoprecipitated with NRF1 antibody and eluent fractionated on $12 \%$ SDS-PAGE gel. Blots were probed with anti serine (pNRF1), anti acetyl lysine ( $\left.{ }_{A} \mathrm{NRF} 1\right)$, anti NRF1(NRF1) antibodies respectively. A) Immoblot depicting the effects various RNAi on NRF1's phosphorylation and acetylation during MCF-10A transformation with 4OHE2. B) Densitometry of phosphorylated and acetylated NRF1 upon Akt1, PCAF and NRF1 knockdown. Data expressed as mean of three experiments, $+/-\mathrm{SE},(\mathrm{P}<0.05)$. 

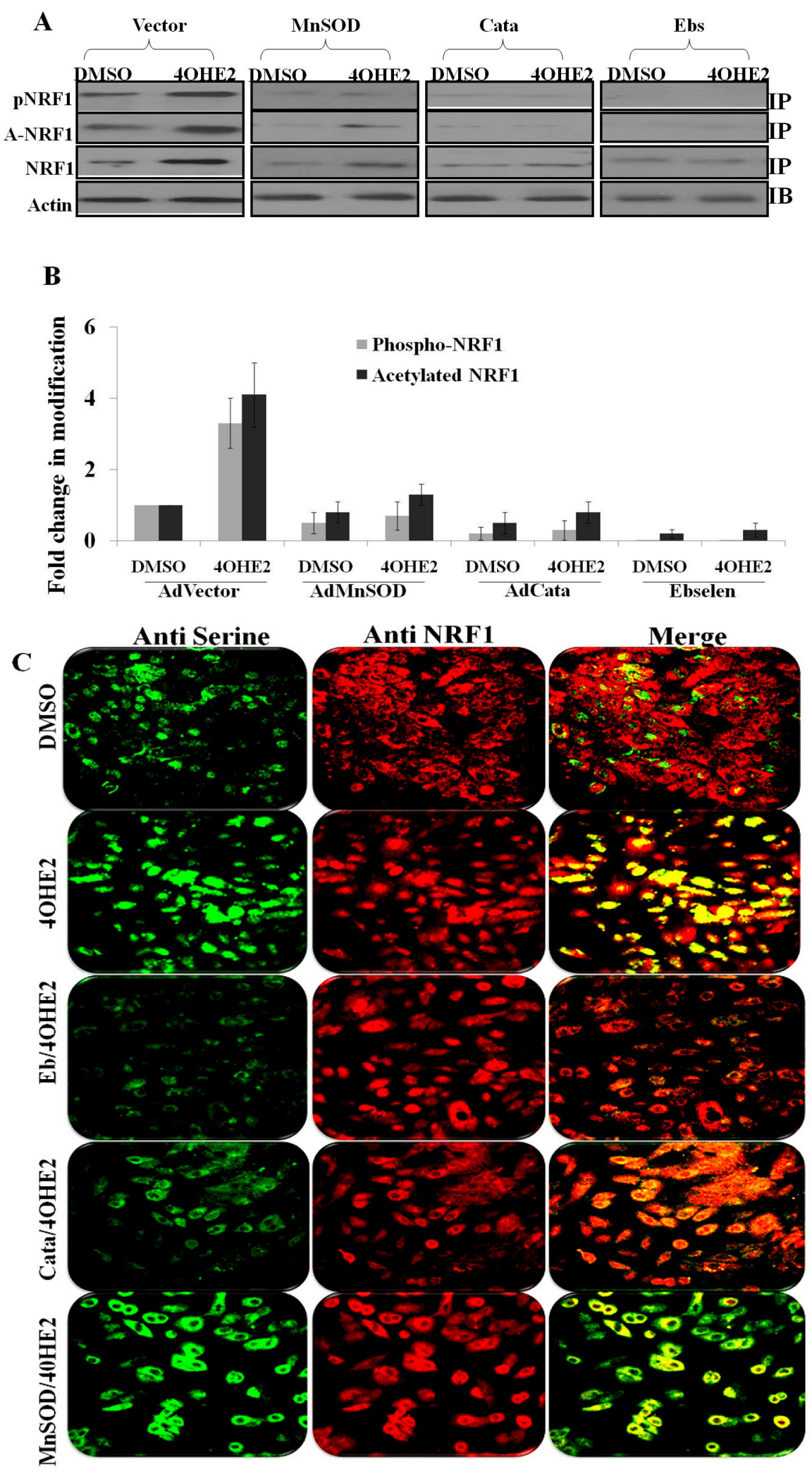
Fig. 6. Transactivation of NRF1 during mammary tranformation is redox dependent. MCF-10A cells were co-treated with estrogens and ROS modulators as previously described. Post transfection, cells were either seeded on chamber slide for confocal microscopy analysis, or treated for additional $30 \mathrm{mims}$, then harvested with RIPA buffer. $750 \mu \mathrm{g}$ of WCL were immunoprecipitated with NRF1 antibody and eluent were fractionated on $12 \%$ SDS-PAGE gel. Blots were then probed with anti serine (pNRF1), anti acetyl lysine ( ${ }_{A} \mathrm{NRF} 1$ ), anti NRF1(NRF1) antibodies respectively. $50 \mu \mathrm{g}$ of WCL was also fractionated on SDS-PAGE gel and blot probed with beta actin anti body. A) Immoblot depicting the effects various RNAi on NRF1's phosphorylation and acetylation during MCF-10A transformation with 4OHE2. B) Normalized band intensity of phosphorylated and acetylated NRF1 upon Akt1, PCAF and NRF1 knockdown respectively. Data normalized to vector/DMSO and expressed as mean fold change of three experiments, $+/-\mathrm{SE},(\mathrm{P}<0.05)$. C) Immunoflorescence label of cells co-treated with biological and chemical ROS modifiers, then probed for serine (green) or NRF1 (red) colocalization (yellow).

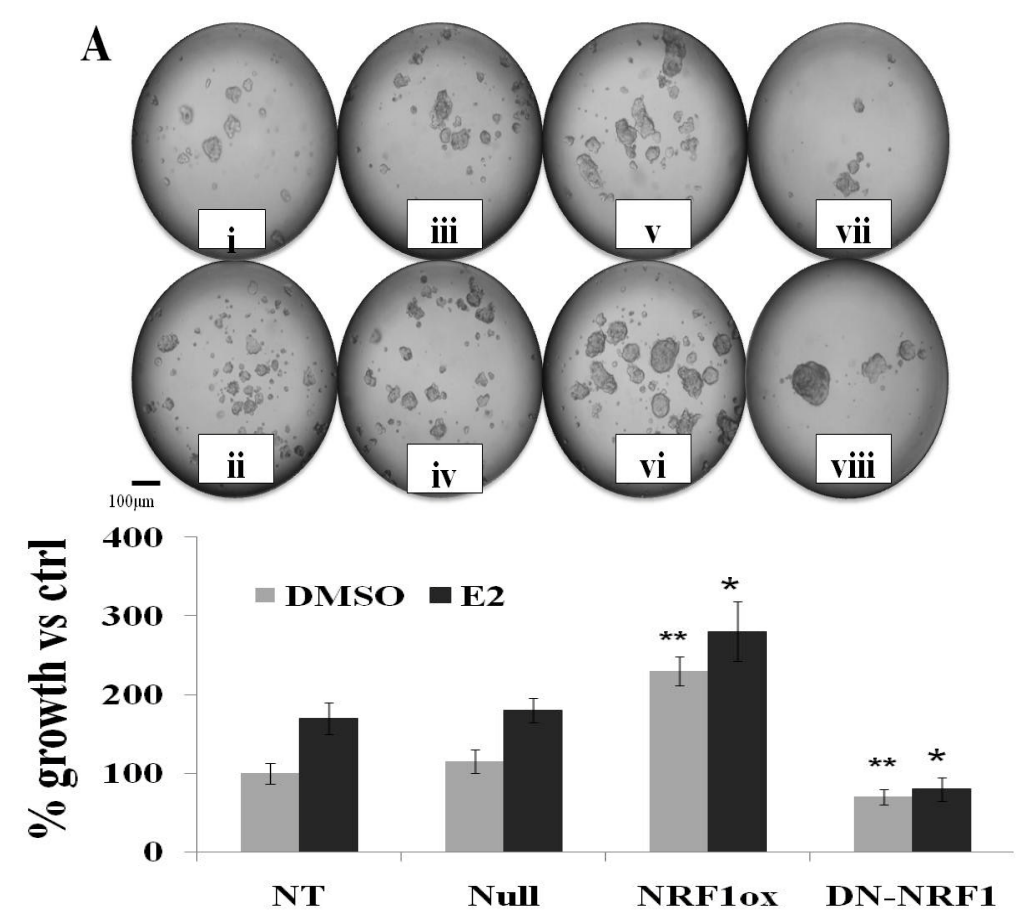

$\mathrm{B}$

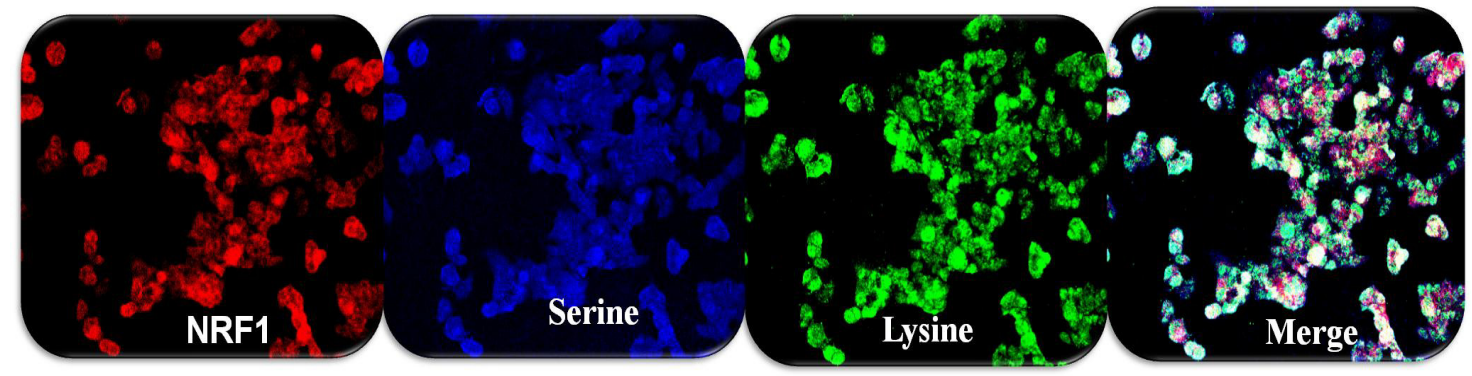


$\mathrm{C}$
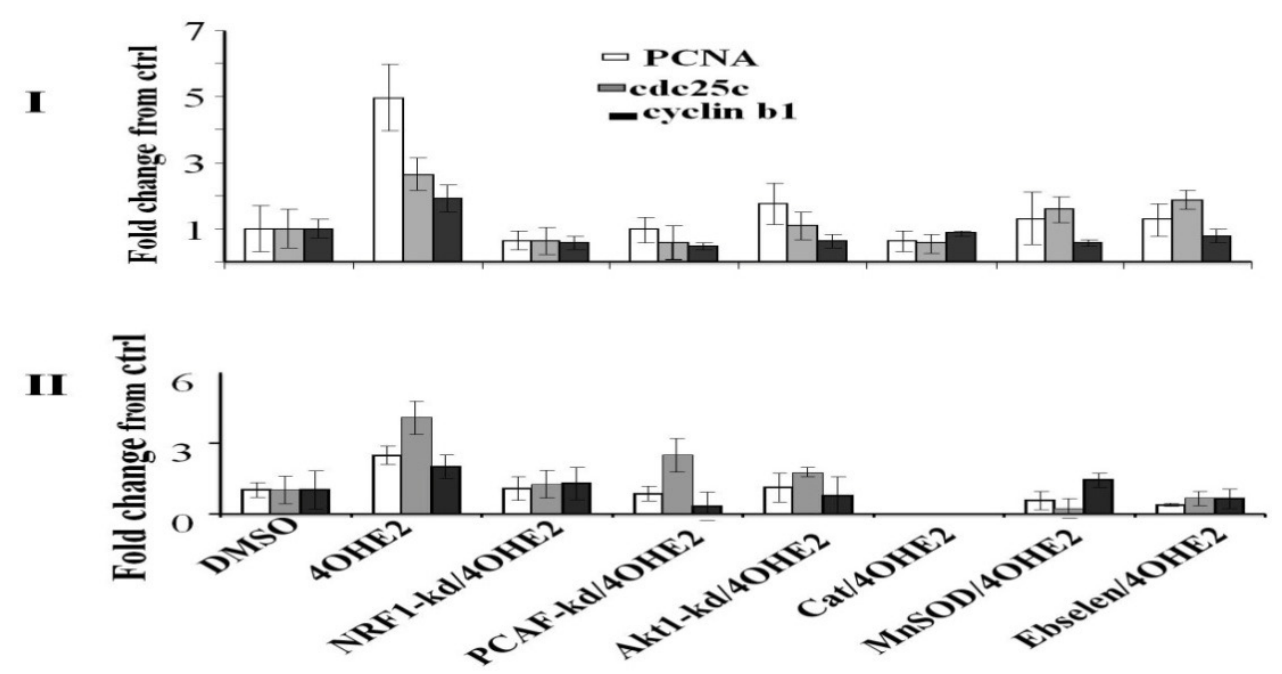

Fig. 7. NRF1 expression is involved in invitro growth of breast cancer cells. A) Colonies formed by MCF-7 cells transfected with NRF1 modulating plasmids, with null vector control. (i) NT-DMSO, (ii) NT-E2, (iii) Vector-DMSO, (iv) vector-E2, (v) NRF1-oxDMSO, (vi) NRF1-ox-E2, (vii) NRF1-kd-DMSO, (viii) NRF1-kd-E2. (B). Enumerated colony count were expressed as percentage change from NT treatment group +/- SD of three experiments. $(*)$ indicates treatment significantly different from E2. (**) indicates treatment significantly different from control.

$(\mathrm{P}<0.05)$. B) Immunoflorescence labeling of MCF7 cells treated for 45 mins with $10 \mathrm{nM}$ estrogens, then probed for NRF1, serine, acetyl lysine antibodies respectively. NRF1 (red), serine (blue), acetyl lysine (green), merge of NRF1/serine/acelty lysine (white). C) MCF-10A cells were seeded for transformation as described in methods. At end of transformation period, cells were treated for additional 18 hours with vehicles or estrogens after which they were washed with cold PBS with protease inhibitors. Cells were detached with trypsin and $2.0 \times 10^{6}$ cells were counted and used for either ChIP assay or qRT-PCR analysis. PCR reactions with DNA or cDNA primers for cell cycle regulatory genes were assembled in $25 \mathrm{ul}$ final volume and PCR reactions on ABI Real time PCR machine. Data represents mean of 3 different experiments $+/-\mathrm{SE},(\mathrm{P}<0.05)$. (I) CHiP analysis for NRF1 promoter occupancy of selected cell cycle regulatory gene. (II) Quantitative RT-PCR (qRT-PCR) for transcriptional expression of selected cell cycle regulatory gene. 
VITA

\section{VICTOR O. OKOH}

\section{EDUCATION}

2010 Ph.D Student. Public Health, Environmental and Occupational Health Dept., Florida International University

1998 MSPH. Toxicology, Environmental Toxicology Dept., University of Alabama, Birmingham

1993 B.S. Biology, Natural Science and Math, University of Alabama, Birmingham DISSERTATION TITLE

4-Hydroxy $\beta$ Estradiol-Induced Oxidants-Mediated Signaling is Involved in the Development of Breast Cancer. Mentor: Dr. Deodutta Roy

PROFESSIONAL EXPERIENCE

2008-Present Adjunct Instructor, Environmental and Occupational Health, Florida International University

2004-2008 Research Associate, Dept. of Environmental and Occupational Health, Florida International University

2003-2004 Research Associate, Dept. of Pediatrics, University of Alabama, Birmingham

1998-2004 Research Scientist, Pulmonary and Critical Care Medicine, University of Alabama, Birmingham

1996-1998 Sr. Clinical Research Scientist, Haynes Immunogenetics. Baptist Medical Center Princeton. Birmingham Alabama

1994-1998 Research Assistant, Dept. of Pathology, University of Alabama Birmingham

TEACHING

2008-Present Biological Basis of Environmental Pollution and Public Health, Florida International University

1992-1993 Teacher's Assistant, Human Anatomy and Physiology, University of Alabama 
1991-1992 Teacher's Assistant, Dept of Chemistry, University of Alabama Birmingham

PUBLICATIONS

2005 Lawrence S. Prince, Heather I. Dieperink, Victor O. Okoh, German A. FierroPerez. Toll-like receptor signaling inhibits structural development of the distal fetal mouse lung. Developmental Dynamics 233:553-561, 2005.

2004 Prince LS, Okoh VO, Moninger TO, Matalon S. Lipopolysaccharide increases alveolar type II cell number in fetal mouse lungs through Toll-like receptor 4 and NFkappaB. Am J Physiol Lung Cell Mol Physiol. 2004 Nov;287(5):L999-1006.

2004 Okoh V.; Young G.D.; Winokur T.S.; Garver Jr R.I.

A Novel Assay for the Quantification of Invasion from Raft Cultures of Lung Carcinoma. Clinical and Experimental Metastasis, 2004, vol. 21, iss. 1, pp. 1-6(6).

2002 Young GD, Winokur TS, Cerfolio RJ, Van Tine BA, Chow LT, Okoh V, Garver RI Jr. Differential expression and biodistribution of cytokeratin 18 and desmoplakins in non-small cell lung carcinoma subtypes. Lung Cancer. 2002 May;36(2):133-41.

1999 X Wu, K Goldsmith, V Okoh and RI Garver, Jr. Antineoplastic 'Multimodality Adenovirus' containing E1A and a Therapeutic Transgene. Tumor Targeting (1999) 4, 170-178.

\section{ABSTRACTS AND MEETINGS}

Deodutta Roy, Quentin Felty, Victor Okoh, and Nana-Aisha Garba.

Inhibition of Estrogen-Induced Growth of Breast Cancer Cells by Modulating In Situ Oxidant Levels. Poster Presentation at DoD Era of Hope Breast Cancer Research Program, 2008.

Deodutta Roy, Quentin Felty, Joyce Slingerland, Nana-Aisha Garba, Rosalind Penny, and Victor Okoh. Reversible Inactivation of CDC25A by Estrogen and Antiestrogen-Induced Reactive Oxygen Species may be Involved in the Phosphorylation of P27. Poster Presentation at DoD Era of Hope Breast Cancer Research Program, 2008.

\section{HONORS}

Phi Kappa Phi Honor society.

Golden Key International Honour Society

Several Dean's List 